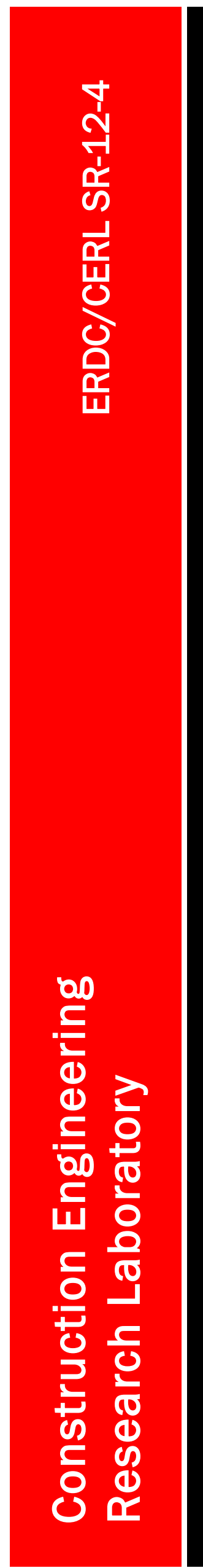

Center for the Advancement of Sustainability Innovations (CASI)

\title{
Installation Strategic Planning Guidebook
}

Kathleen S. Vann, David R. Della-Rovere,

May 2012

Paul M. Loechl, and Harold E. Balbach

US Army Corps

of Engineers $S_{\circledast}$

Engineer Research and Development Center

PaulM. Loechl, and Harold E. Babach

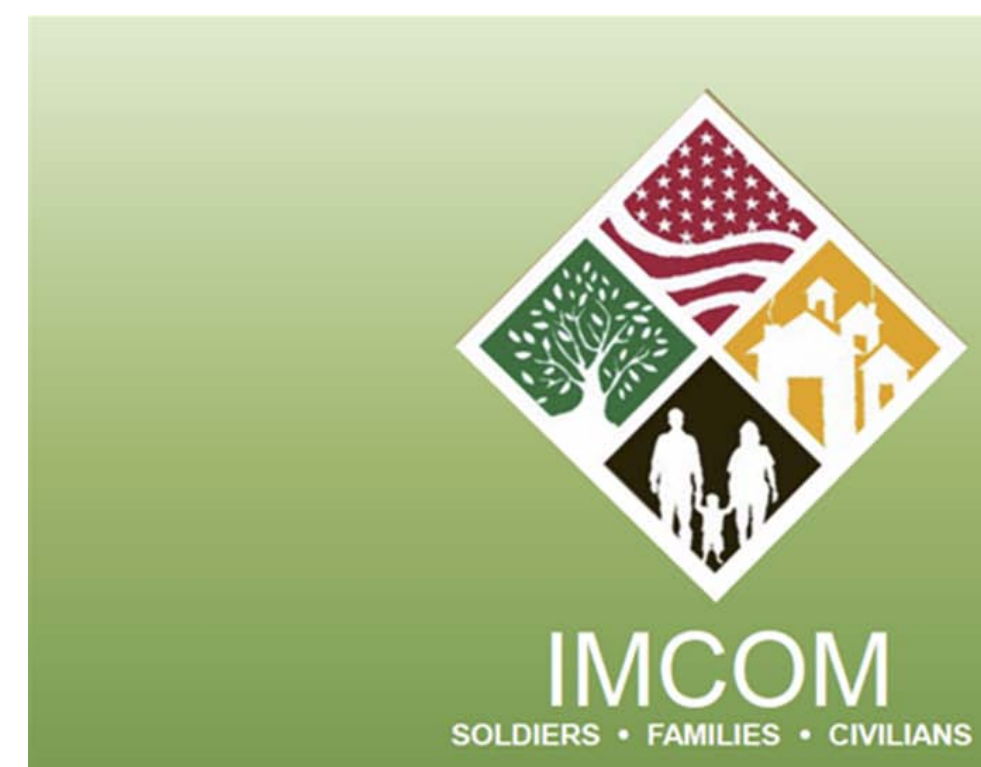

\section{We are \\ THE ARMY'S HOME}

Approved for public release; distribution is unlimited. 



\section{Installation Strategic Planning Guidebook}

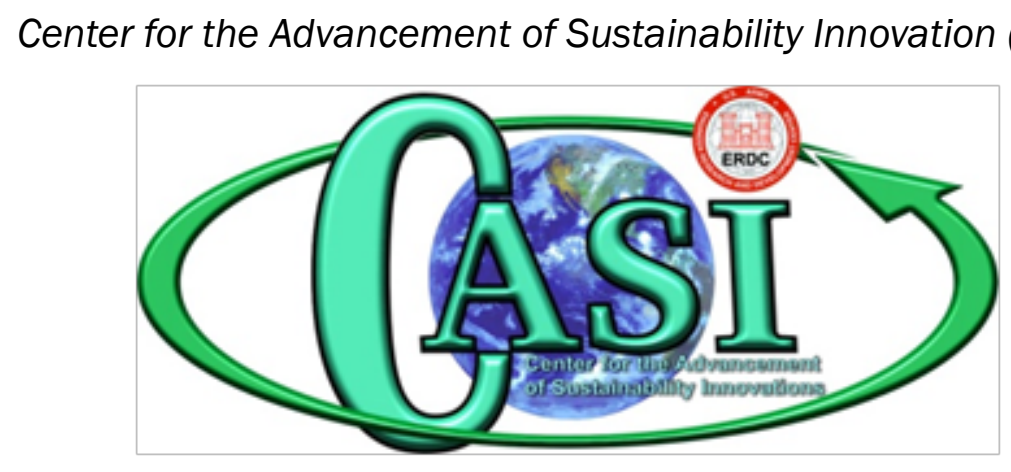

Paul M. Loechl and Harold E. Balbach

Construction Engineering Research Laboratory (CERL)

U.S. Army Engineer Research and Development Center 2902 Newmark Dr.

Champaign, IL 61822-1076

Kathleen S. Vann and David R. Della-Rovere

Headquarters, Installation Management Command (HQ IMCOM) 2405 Gun Shed Road

Fort Sam Houston, TX 78234-1223

Final Report

Approved for public release; distribution is unlimited. 


\section{Abstract}

The Installation Strategic Planning Guidebook is designed as a textbook for use in conjunction with the Installation Management Academy Plans, Analysis, and Integration Office (PAIO) Signature Course. The book is designed to leverage internet based multimedia content with embedded hyperlinks along with a capability for content to be searchable and copyable.

DISCLAIMER: The contents of this report are not to be used for advertising, publication, or promotional purposes. Citation of trade names does not constitute an official endorsement or approval of the use of such commercial products. All product names and trademarks cited are the property of their respective owners. The findings of this report are not to be construed as an official Department of the Army position unless so designated by other authorized documents. 
INSTALLATION MANAGEMENT COMMAND

\section{INSTALLATION STRATEGIC PLANNING GUIDEBOOK}

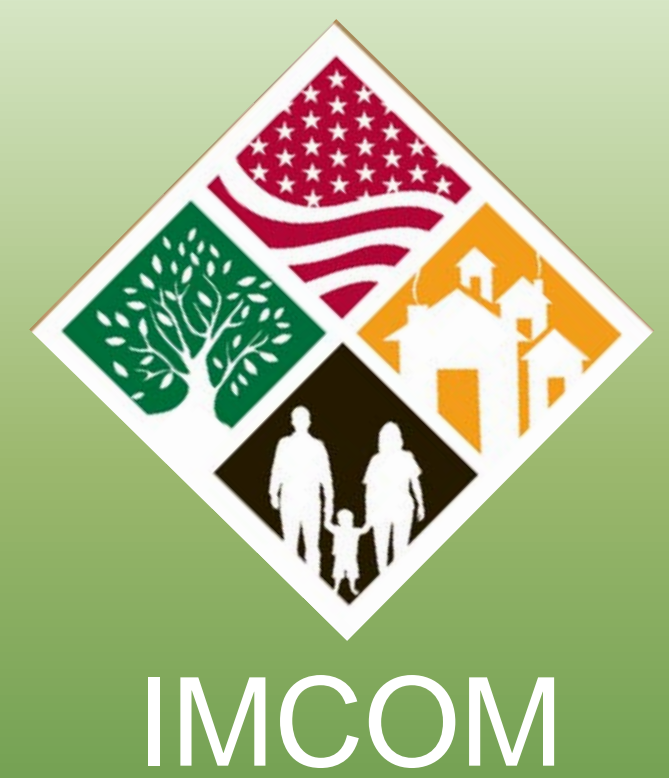

SOLDIERS • FAMILIES • CIVILIANS

we are
THE ARMY'S HOME

APRIL 2012 
Installation Strategic Planning Guidebook 


\section{Installation Strategic Planning Guidebook}

\section{Installation Strategic Planning Guidebook}

Summary. The Installation Strategic Planning Guidebook is designed as a text book for usage in conjunction with the Installation Management Academy Plans, Analysis, and Integration Office (PAIO) Signature Course. The book is designed to leverage internet based multimedia content with embedded hyperlinks along with a capability for content to be searchable and copyable.

Applicability. The information provided applies to all of Installation Management Command.

Suggested Improvements. The proponent for the ISSP Guidebook is the Headquarters Installation Management Command, G5, ATTN: IMPL-S (Strategic Planning and Assessment Division), 2405 Gun Shed Road, Fort Sam Houston, TX 78234-1223. Users may send comments and suggested improvements on DA Form 2028 (Recommended Changes to Publications and Blank Forms) directly to Headquarters, Installation Management Command, ATTN: IMPL-S, 2405 Gun Shed Road, Fort Sam Houston, TX 78234-1223.

Online Discussion Forum. IMCOM supports the principles of Knowledge Management and encourages collaboration and innovations in an environment where there is freedom to contribute, communicate, and provide unimpeded feedback. The HQ IMCOM G5 Plans Directorate has an established discussion forum provided in GarrisonCommander.com where you can download the most current update to this Guidebook and provide comments and suggested improvements at the following web link:

https://forums.army.mil/CommunityBrowser.aspx?id=1732454\&lang=en-US 


\section{Table of Contents}

List of Figures and Tables..................................................................................... vii

Foreword

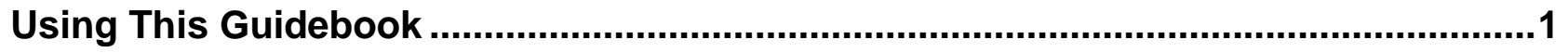

Chapter 1: “A-to-G" Strategic Planning Model Overview ..............................................2

Chapter 2: Where We Are - Creating Awareness ......................................................

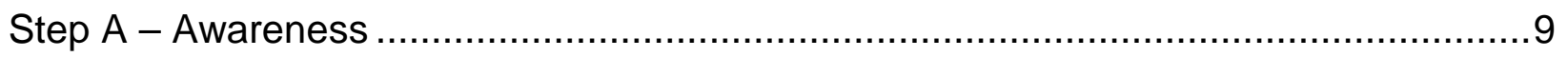

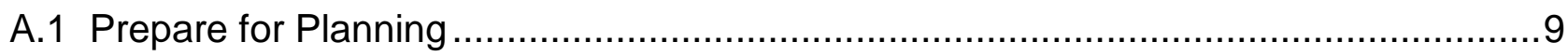

A.2 Senior Leadership Commitment $=$ Commanders' Intent …..............................10

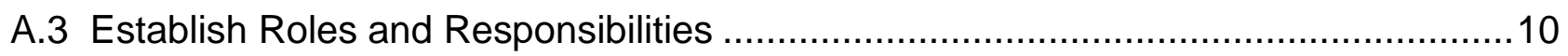

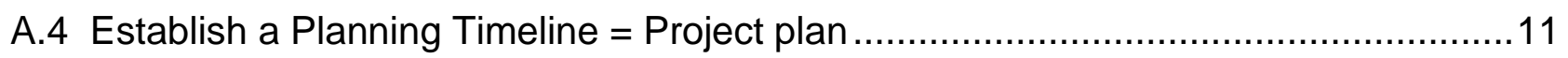

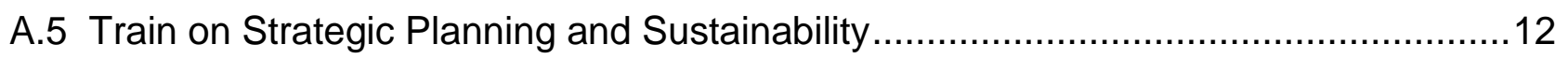

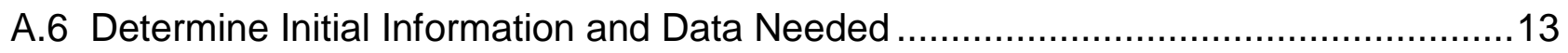

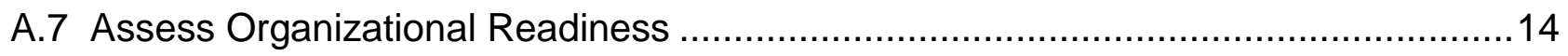

A.8 Develop and Execute a Strategic Communication Plan ........................................19

Chapter 3: Where We Are - Establishing the Baseline ..............................................21

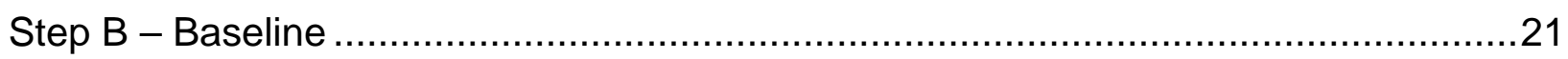

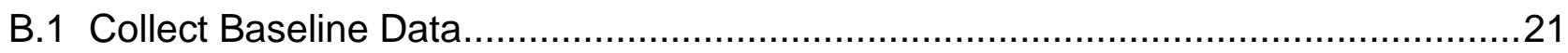

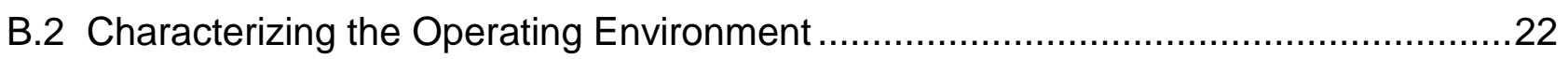

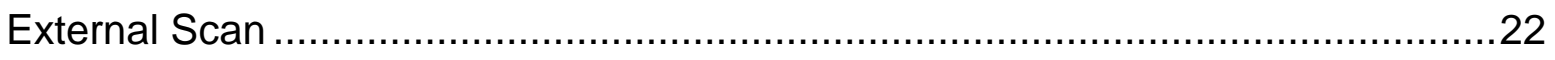

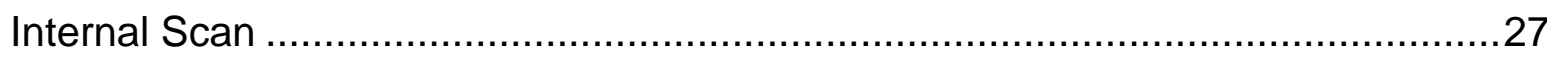

B.3 Working Session 1 - Critical Issues and Challenges Development Session ..............38

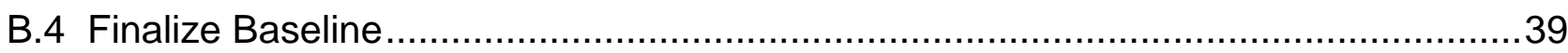

Chapter 4: Where We Want To Be - Clear Mission, Vision, and Goals ......................40

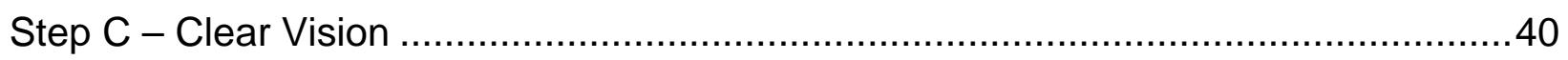

C.1 Establish the Installation Vision, Mission and Community Values Statements ...........41

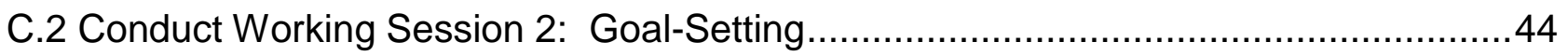

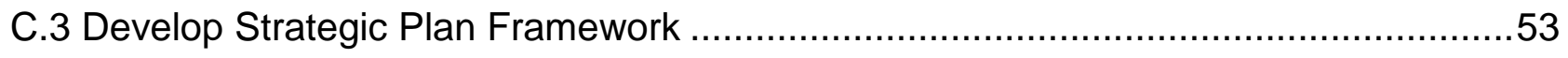

Chapter 5: How We Get There - Down to Action .......................................................54

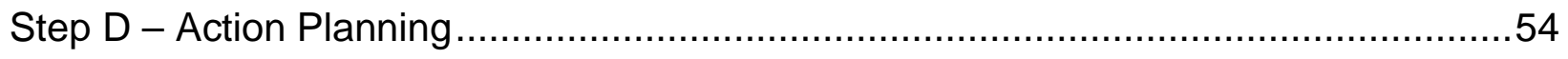

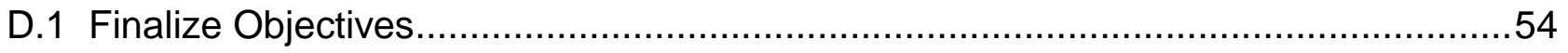




\section{Installation Strategic Planning Guidebook}

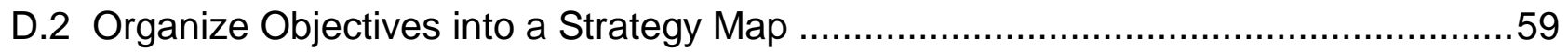

D.3 Developing Performance Measures for Objectives - Getting Organized...................59

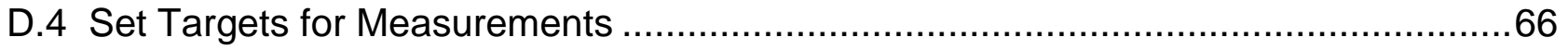

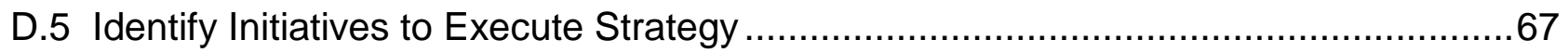

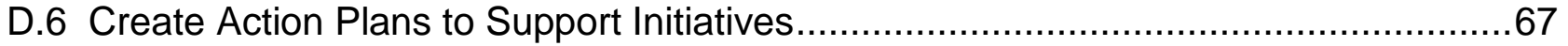

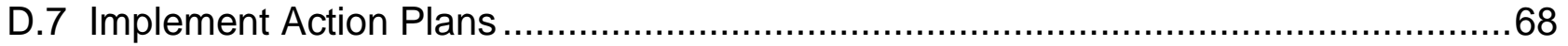

D.8 Link Resources to Initiatives and Action Plans …..............................................69

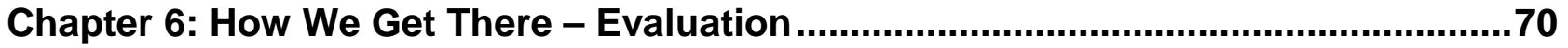

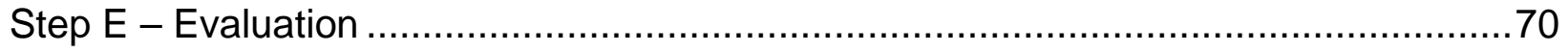

Chapter 7: How We Are Doing - Feedback and Continual Improvement.....................71

Step F - Feedback and Continual Improvement …….............................................

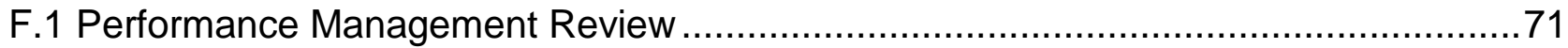

F.2 Army Communities of Excellence (ACOE) …….............................................

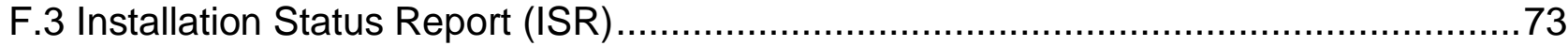

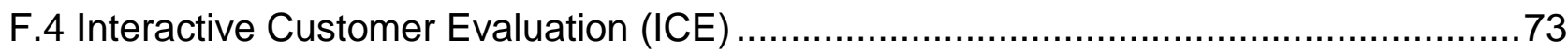

Chapter 8: How We Are Doing - Get Better .............................................................74

Step G - Get Better - Monitoring and Evaluating Your Strategy ................................74

G.1 Maintenance Check \#1: ISP System Components .............................................

G.2 Maintenance Check \#2: The Performance Measurement Team .............................77

G.3 Maintenance Check \#3: New Legal Requirements/ Issues ....................................77

G.4 Maintenance Check \#4: New Developments/Technology ......................................77

Chapter 9: Installation Planning Board (IPB) ...........................................................

Appendix A: Sample Commander's Letter of Intent to Begin Integrated Strategic

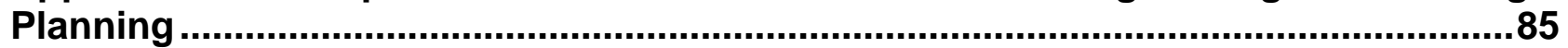

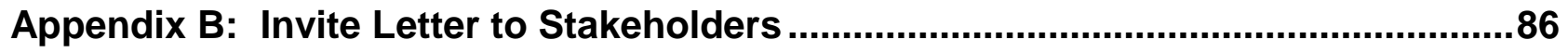

Appendix C: Invite Letter Internal to Installation......................................................

Appendix D: Sample Strategic Planning Training Course Agenda.............................88

Appendix E: Recommended Strategic Planning Professional Reading List ............89

Appendix F: Sample ISSP Leadership Interview Questions.....................................92

Appendix G: ISSP Leadership Interview Data Analysis Process ..............................93

Appendix H: Environmental Scanning Matrix/Worksheets .....................................94 


\section{Installation Strategic Planning Guidebook}

Appendix I: Probability I Impact Matrix - Issues Priorities......................................106

Appendix J: Vision, Mission and Values..........................................................107

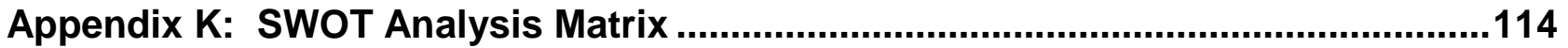

Appendix L: Sample List of Prospective Strategic Planning Workshop Participants 115

Appendix M: Workshop Sign-In Roster/Sheet .........................................................118

Appendix N: Sample Workshop Floor Plan ........................................................119

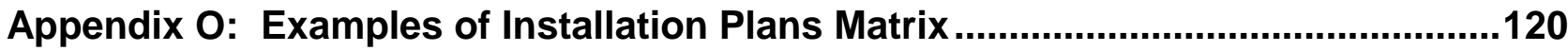

Appendix P: Strategic Planning Workshop Evaluation Form...................................124

Appendix Q: Climate Change Effects Adaptation Framework and Methodology....126

Appendix R: Using the Army's Strategic Management System (SMS) to Evaluate ISP

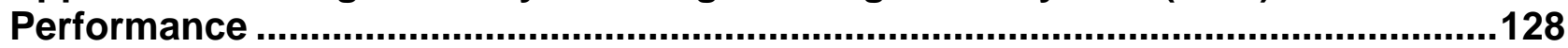

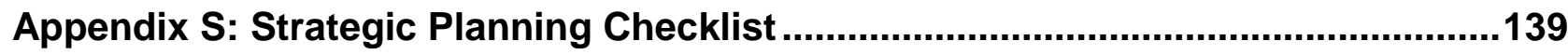

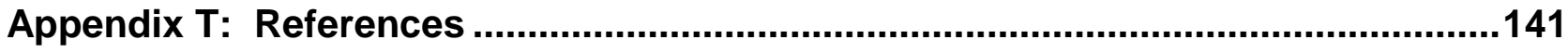

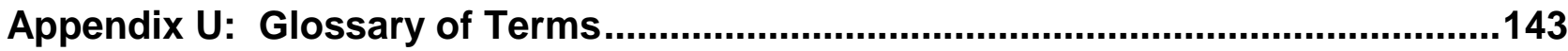

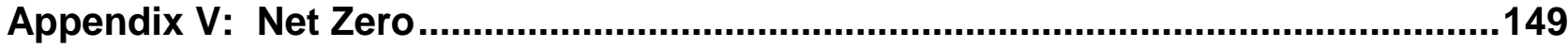




\section{List of Figures and Tables}

\section{Figures}

Figure 1. IMCOM Principles of Sustainability .............................................................

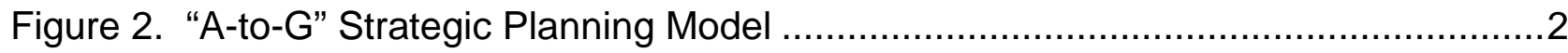

Figure 3. Expanded "A-to-G" Strategic Planning Model ...............................................

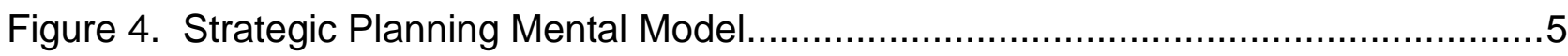

Figure 5. Installation Management Campaign Plan v4, November 2011.........................

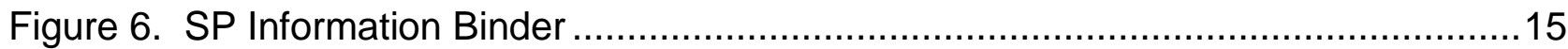

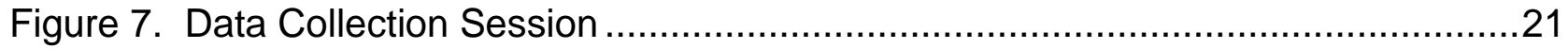

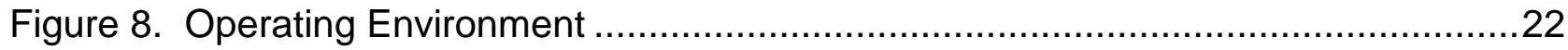

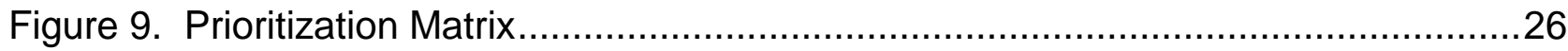

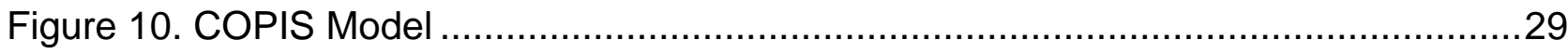

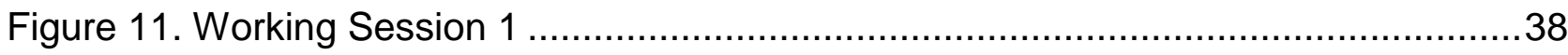

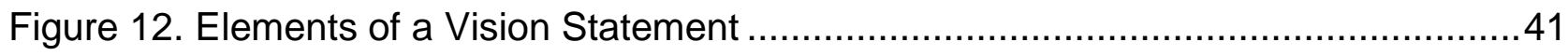

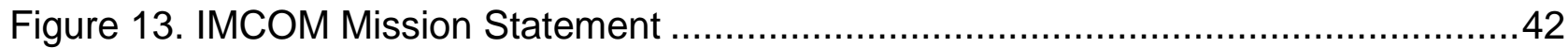

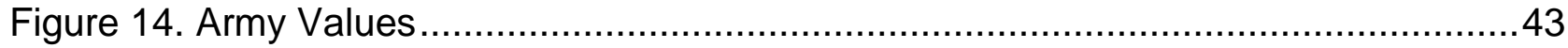

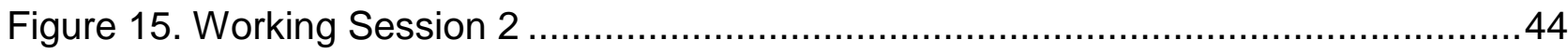

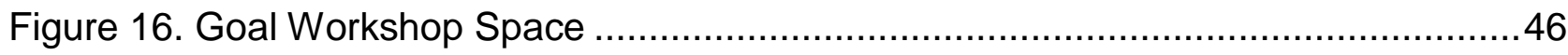

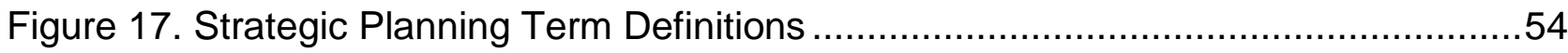

Figure 18. Example of How Different Levels of Performance Measures are Deployed at

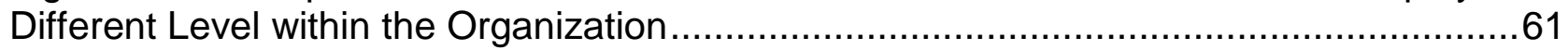

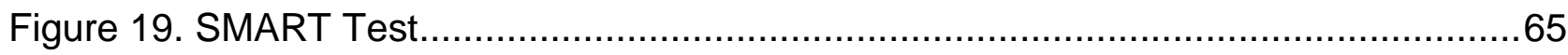

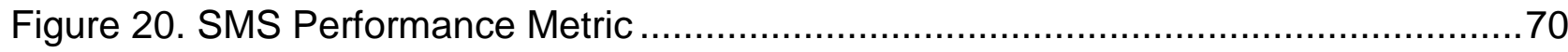

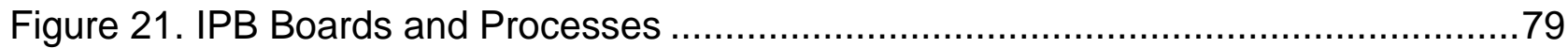

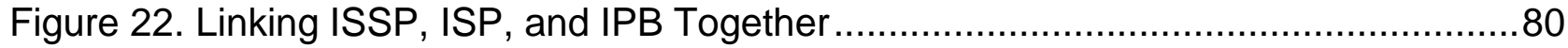

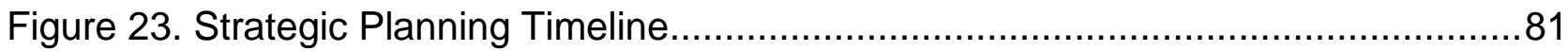

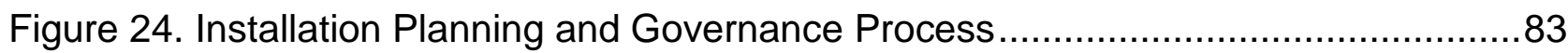

Figure 25. SMS Organizational Node and Scorecard Tree …...................................130

Figure 26. DPW Organizational Node and Bowling Scorecard Tree ............................131

Figure 27. SMS Scorecard Tree Naming Convention Example ….............................132

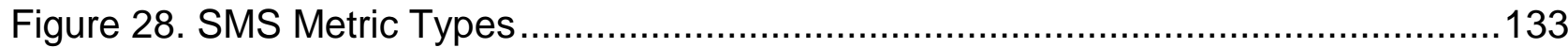

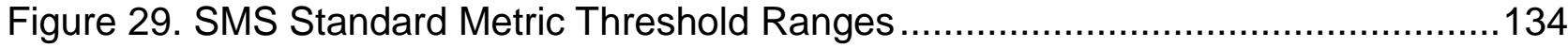

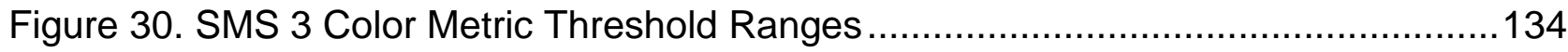

Figure 31. SMS 3 Color Metric Stabilize Threshold Ranges .....................................135

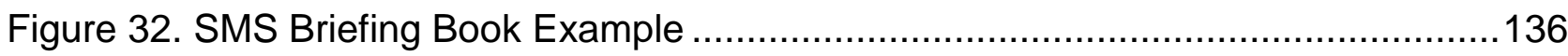

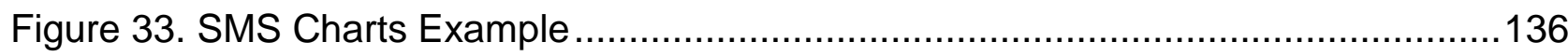

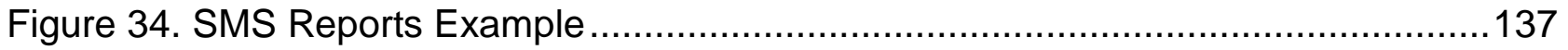


Figure 35. SMS Strategy Maps for Army, IMCOM and Garrison Levels........................137

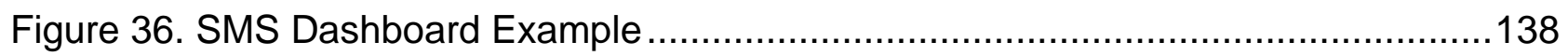

\section{Tables}

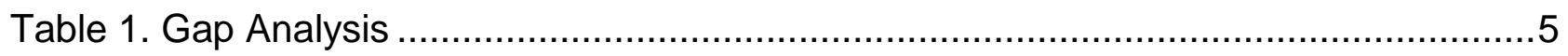

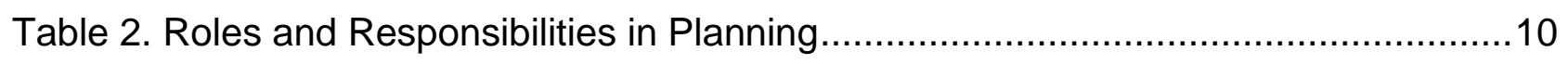

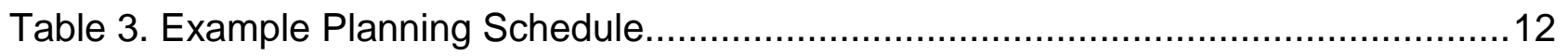

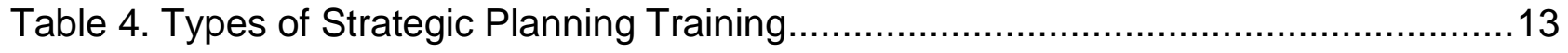

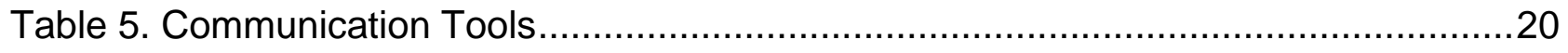

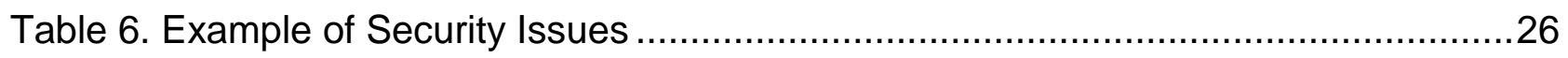

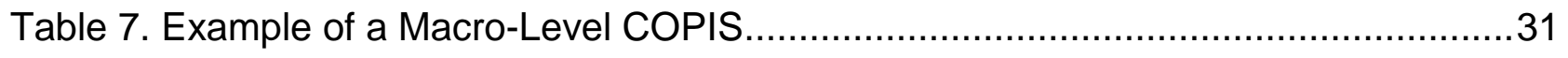

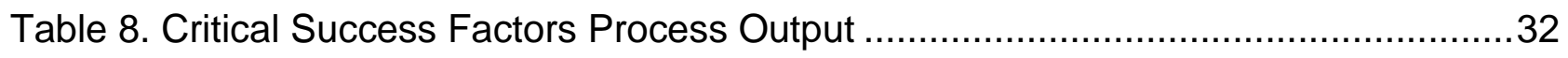

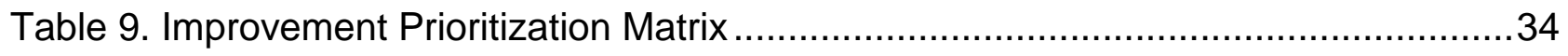

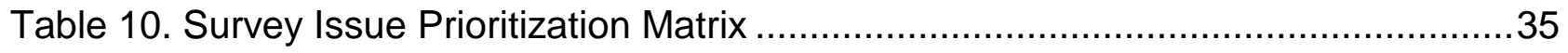

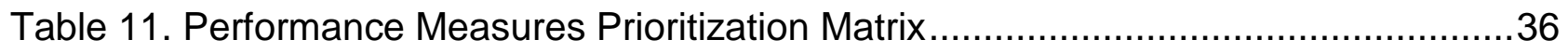

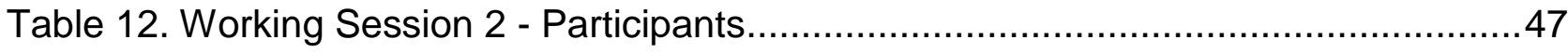

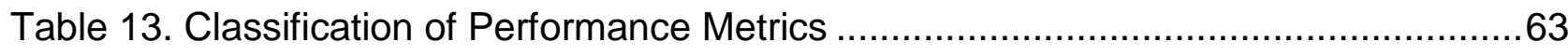

Table 14. SMS Scorecard Tree: Organization/Service Structure ….............................129

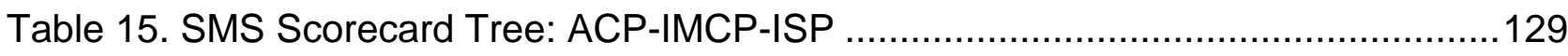

Table 16. SMS Metric Scorecard Tree Thresholds ................................................... 132

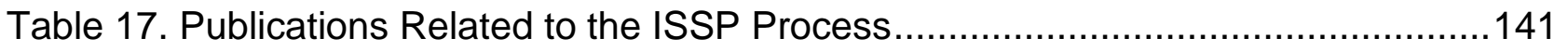




\section{Foreword}

The Installation Management Command has matured as an organization since it's activation as the Installation Management Agency in October, 2002, largely through the evolution of its business processes. As Army missions become increasingly complex and the pace of change continues to accelerate, our approach to strategic planning must include a broader group of stakeholders, as well as ensure that our operations are sustainable over time. Thus we have adopted the Integrated Strategic and Sustainability Planning (ISSP) process described in this guidebook to improve how we conduct installation strategic planning. The desired end state of the ISSP process is an Installation Strategic Plan (ISP) that integrates all stakeholder requirements and challenges in a manner that is sustainable over time.

The Department of the Army (DA) defines sustainability as meeting current and future mission requirements worldwide while safeguarding human health, improving quality of life, and enhancing the natural environment. Sustainability means developing and optimizing the use of all resources - workforce, infrastructure, financial, information, natural materials, energy, etc. - to best support current and future mission requirements.

The Army is a leader in sustainability within the Federal Government. Its journey started in 2000 when Senior Leaders voiced concerns over factors that were increasingly impacting their ability to train units. Senior Leaders realized our installations faced longterm issues in accomplishing changing missions in an environment of increasing costs and declining resources.

Today's operational environment is characterized by a rapid pace of change, uncertainty and complexity. Effective decision making must be based on a greater awareness of the interrelationships of the myriad processes and systems in play on our installations in both the near term and in the future. Integrated planning, systems thinking and sustainability assessments are critical to effective planning and decision making in the coming era.

$\mathrm{HQ}$, IMCOM has the responsibility to assist Garrisons in this process by providing guidance and direction, supporting installation planning, identifying sustainable approaches and technologies, leading appropriate enterprise-wide sustainability solutions, supporting development of public/private partnerships, being an advocate for resourcing installations, and leading the transition to integrated problem solving. 


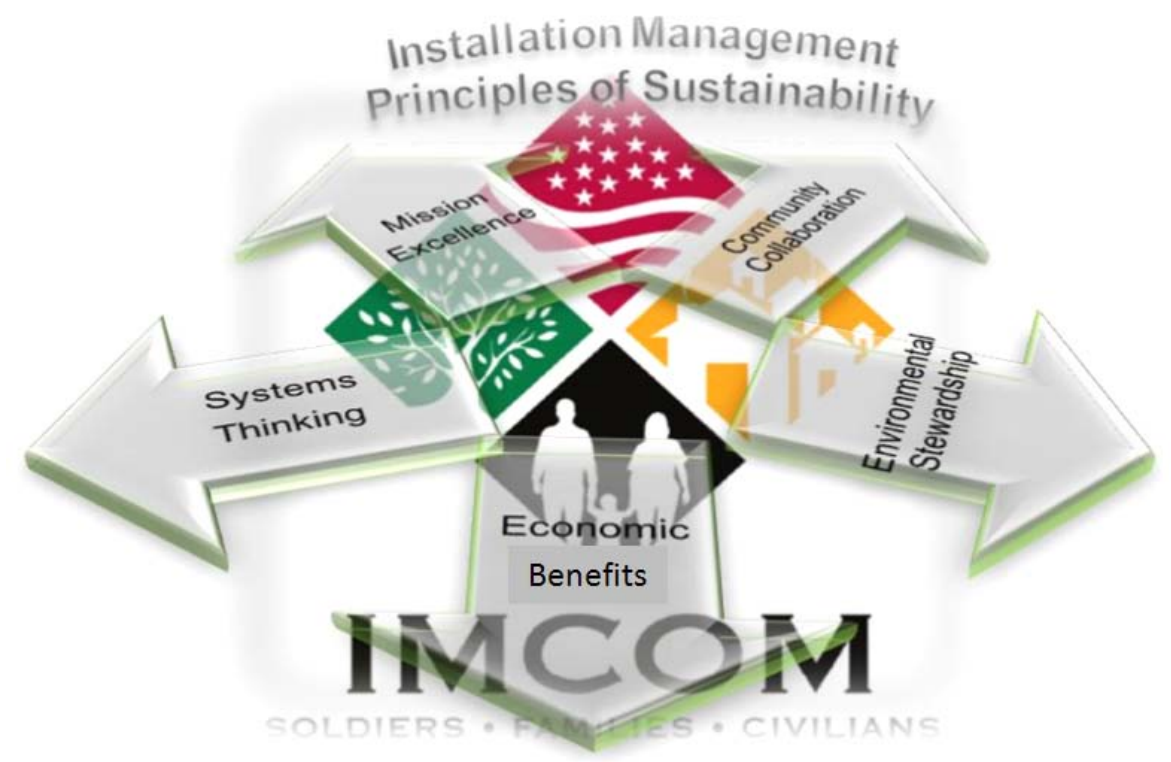

Figure 1. IMCOM Principles of Sustainability

The Installation Strategic Planning (ISP) Guidebook is written for the Garrison PAIO who will be the champion for leading the installation through the planning process with the goal of developing a strategic plan that describes the path that will lead to a sustainable installation in the future. The Guidebook will support the PAIO in applying the IMCOM Principles of Sustainability (Figure 1).

The Guidebook will describe how to apply systems thinking to goals that will enhance Mission Excellence, Community Collaboration, Environmental Stewardship, and Economic Benefit. The ISSP process supports installations in meeting a variety of requirements including the strategic planning components of AR 5-1, the Army Campaign Plan, the Army Sustainability Campaign Plan, and AR 11-32, Army LongRange Planning System. This process is applicable to the development of integrated, sustainable strategic plans that support the Army in meeting the requirements of Executive Order (EO) 13514, Federal Leadership in Environmental, Energy, and Economic Performance including requirements to plan for and report progress on sustainability.

The ISSP process illustrated in this Guidebook accomplishes several important functions. First, it enables the development of long range goals, objectives and actions that support sustainable installation development and operations. Second, by engaging a broad group of stakeholders, it fosters installation-wide ownership of the strategic plan's, goals, objectives and actions. It engages local community stakeholders to better understand mutual needs; strengthen existing relationships; and encourage support from community partners. The ISSP process builds a roadmap for long-term change that enables and enhances installation readiness. It promotes development of a sustainable community, both inside and outside the fence line, and protects resources to ensure their availability for current and future missions. The ISSP process outlined in this Guidebook can be used to: 


\section{Installation Strategic Planning Guidebook}

- Create a new strategic plan or update an existing plan to include long-term sustainability considerations

- Develop indicators to monitor the installation's progress toward becoming more sustainable

- Establish goals and objectives that will be assigned to the installation governance process

Installations who apply the sustainability principles to management operations operationalize sustainability through collaborative, integrated, and cross-functional team-based execution that results in efficient resource management and ensures resources are available when needed. For the installation system of systems, this will involve the commitment, communication and coordination of leaders at all levels to a long-range installation management vision and a mission-oriented approach based on a continuing return on the installation's investment by more effectively applying resources to meet the installation's mission. Mission-critical resources include, but are not limited to:

(1) Human capital (personnel quality and quantity, institutional knowledge, knowledge management, technical expertise, employee morale and effective team work)

(2) Natural capital (land, drinking water, air quality, airspace, navigable waters)

(3) Infrastructure (fixed [vertical and horizontal] and mobile)

(4) Information technology

(5) Financial capital (appropriated and non-appropriated funding, integrated sourcing).

(6) Energy

This Guidebook provides a proven method to ensure the efficient and effective development of Installation Strategic Plans at Department of the Army (DA) Commands and Installations. The Guidebook also shows how to implement the ISSP process IAW IMCOM Policy Memorandum 11-32-1, Operationalizing Sustainability. The Garrison Plans, Analysis, and Integration Office (PAIO) may update or add to the Guidebook as needed via attachments or change documents applicable to their installation.

Finally, this Guidebook incorporates processes and techniques used successfully by IMCOM personnel on IMCOM installations. We captured lessons learned and best practices so that we might shorten the learning curve for those who are seeking to improve their strategic planning success. We ask that you help us further improve the Guidebook by providing your comments, recommendations and lessons learned. 


\section{Using This Guidebook}

This Guidebook is intended for the installation strategic planner who is tasked to lead the development of an installation-wide, cross-functional strategic plan. It is based upon lessons learned at 40 installations that have completed the ISSP process. The most critical lesson has been that every installation tailors the ISSP process to fit their needs. While specific steps are recommended, options and alternatives are offered that allow tailoring the strategy to unique local conditions.

Planning is the process of deciding what to do, how to do it, and when to complete it. An installation's strategic plan is a tool for assisting Commanders with setting priorities for competing demands on human, natural, technical, financial and other resources.

What sets the ISSP planning methodology apart from many others is that it stresses the need for integrated, inclusive planning by customers, stakeholders and operators that employs sustainability principals to ensure that the resulting plan is executable.

The ISSP process uses a cyclic planning model for developing, implementing, and maintaining installation strategic plans. This model, referred to as the "A-G" model (See Figure 2), is a multi-phased process that provides a structured engagement of customers, stakeholders and operators to ensure participation and ownership in the resulting plan. The process delivers an Installation Strategic Plan (ISP) that defines long-term goals, leads to an adaptable and sustainable installation, and provides optimal support to current and future missions. 


\section{Chapter 1: "A-to-G" Strategic Planning Model Overview}

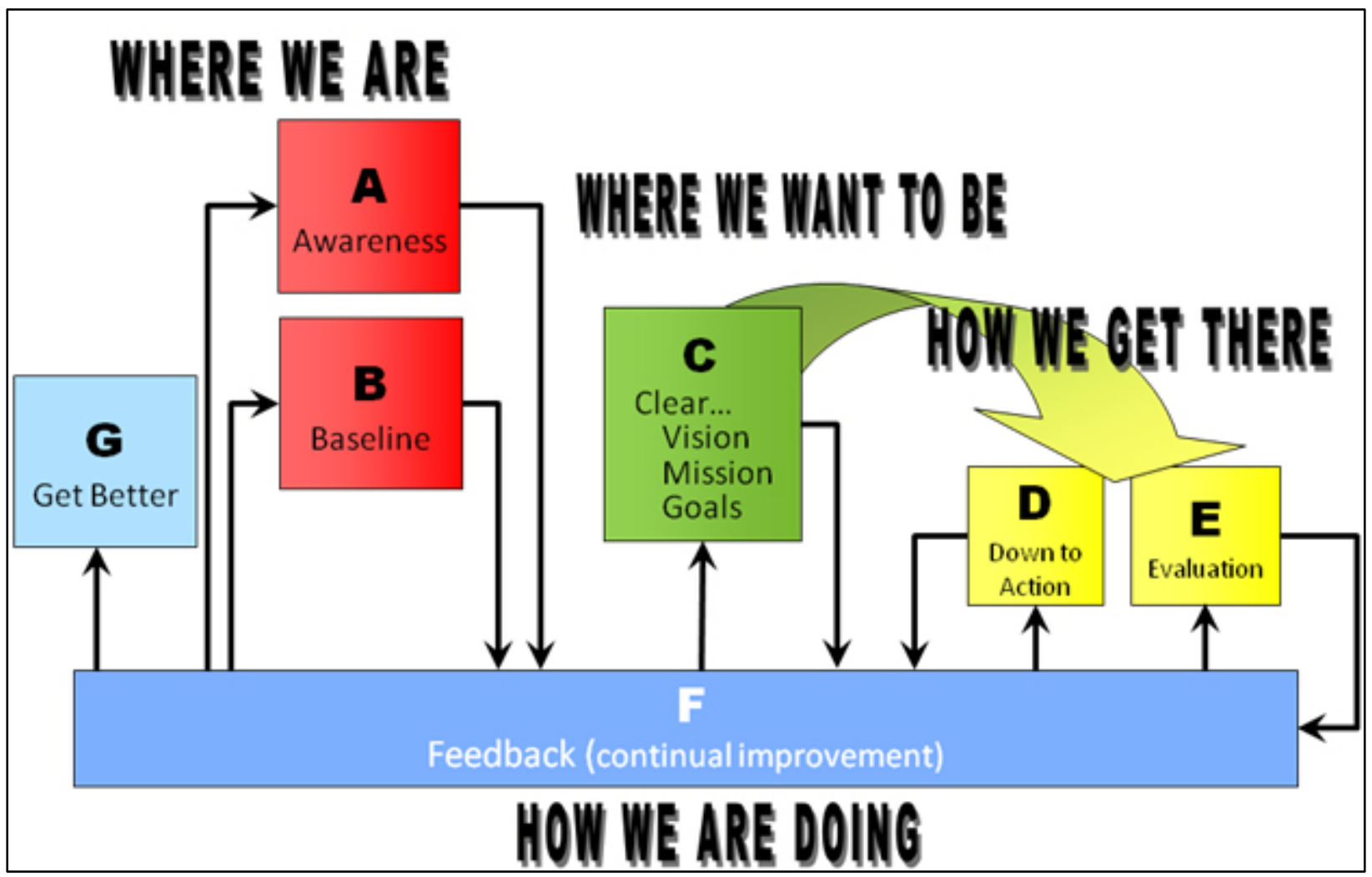

Figure 2. "A-to-G" Strategic Planning Model

The "A-to-G" Model supports a simple and commonly used strategic planning process to identify "Where We Are"; "Where We Want to Be"; "How We Get There" and "How We Are Doing". Each phase of the model consists of activities designed to gather information, teach installation stakeholders about planning and sustainability, and compile the consensus vision for the installation as represented in long-term goals, objectives, and actions. Appendices to the Guidebook contain sample materials that can be used to conduct each working session described in the remainder of this section. A summary definition for each step of the model is provided as follows:

Step A: Creating Awareness. Step A creates an understanding of the need to plan; gets the key players and leaders engaged; assesses the organization's readiness to plan; generates the planning strategy; creates a solid project plan for strategic planning, and identifies required pre-work. Other items in this initial planning step include time line and decision points, and how to engage the Senior Commander (SC) to obtain his/her support. During this step, planning team members receive an introduction to sustainability, gain an understanding of the Army's sustainability strategy, the value of integrated planning, and how to prepare for the challenging process of organizational change. 
Step B: Develop a Baseline. Step B develops a clearer understanding of current and future operating environments at both the Army and the installation levels. During this step, planners assess the organization's current capabilities and identify current and planned SC and tenant organizations' future requirements.

Step C: Developing a Clear Vision, Mission and Goals. Armed with the information derived in Step B, participants will develop a vision, goals and strategies to close the gaps between where the installation is today and where it needs to be in the future to support the Senior Commander in a sustainable manner.

Step D: Down to Action. During this step, participants complete detailed action plan(s) that will outline how the strategy identified in the previous step will be executed. This includes setting objectives, initiatives the organization will undertake in order to meet and achieve the objectives, and measures and critical milestones to track and manage performance. The installation should update the action plans on an annual basis. Long-term goals and intermediate objectives can be revised as needed; however, a formal revision using Steps A-C usually occurs no sooner than 5 years after completion.

Steps E and F: Evaluation and Feedback. At this point participants will document how progress toward achieving the strategic goals will be tracked and reported, including how often and by whom. Participants will also document how often the ISP will be re-evaluated to ensure it remains relevant and consistent with customer requirements and sustainability factors.

Step G: Get Better. This step closes the loop from the previous purpose to Step A. It ensures that the information collected in Steps $E$ and $F$ are used effectively to adjust the strategy; realign resources; apply lessons learned about the strategic planning process or implementation; support continuous process improvement; and improve customer feedback tools and processes.

The expanded model on the next page (Figure 3) shows each of the seven steps broken into specific processes and activities. 


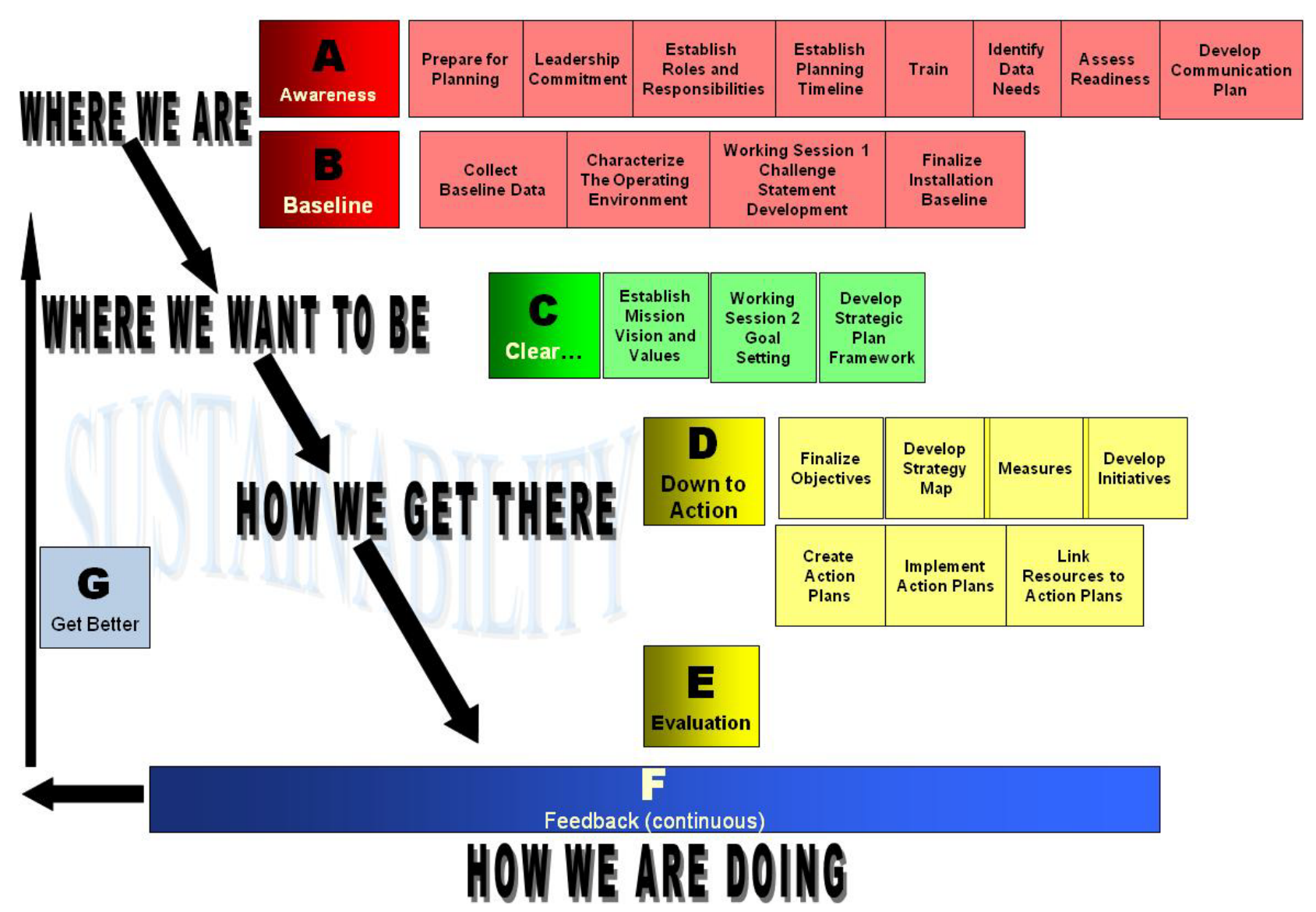

Figure 3. Expanded "A-to-G" Strategic Planning Model

To facilitate understanding of the strategic planning process, it can be helpful to think through a mental model as to how the planning will proceed. For virtually any strategic planning process or model, there are four basic phases that are considered: (1) Where We Are (2) Where We Want To Be (3) How We Get There, and (4) How We Are Doing. Table 1 below depicts a gap analysis that compares a current state to a future state and the gaps that will need to be addressed in order to successfully achieve a desired endstate. Figure 4 describes the mental model used throughout this Guidebook. You may find this helpful in explaining what is happening throughout the planning event. 
Table 1. Gap Analysis

\begin{tabular}{|c|c|c|}
\hline $\begin{array}{c}\text { Where We Are } \\
\text { (Current State) }\end{array}$ & Gaps & $\begin{array}{c}\text { Where We Want To Be } \\
\text { (Future State) }\end{array}$ \\
\hline $\begin{array}{c}\text { External Environmental Scan } \\
- \text { Identified Opportunities } \\
- \text { Identified Threats }\end{array}$ & $\leftrightarrow$ & $\begin{array}{c}\text { External Environmental Scan } \\
\text {-Exploited Opportunities } \\
\text {-Addressed Threats }\end{array}$ \\
\hline $\begin{array}{c}\text { Internal Environmental Scan } \\
- \text { Identified Weaknesses } \\
- \text { Identified Strengths }\end{array}$ & $\leftrightarrow$ & $\begin{array}{c}\text { Internal Environmental Scan } \\
\text {-Addressed Weaknesses } \\
\text {-Exploited Strengths }\end{array}$ \\
\hline $\begin{array}{c}\text { Mission Analysis (COPIS) } \\
- \text { Current Mission } \\
\text { (Systems Perspective) }\end{array}$ & $\leftrightarrow$ & $\begin{array}{c}\text { Mission Analysis } \\
\text {-Needed Mission }\end{array}$ \\
\hline $\begin{array}{c}\text { Survey Data } \\
- \text { Current Performance }\end{array}$ & $\leftrightarrow$ & $\begin{array}{c}\text { Survey Data } \\
\text {-Needed Performance }\end{array}$ \\
\hline $\begin{array}{c}\text { Critical Issues } \\
\text { - Current Performance } \\
\text { (What the installation must do right) }\end{array}$ & $\leftrightarrow$ & $\begin{array}{c}\text { Critical Issues } \\
\text {-Needed Performance }\end{array}$ \\
\hline $\begin{array}{c}\text { Performance Measures } \\
- \text { Current Performance }\end{array}$ & $\leftrightarrow$ & $\begin{array}{c}\text { Performance Measures } \\
\text {-Needed Performance }\end{array}$ \\
\hline
\end{tabular}

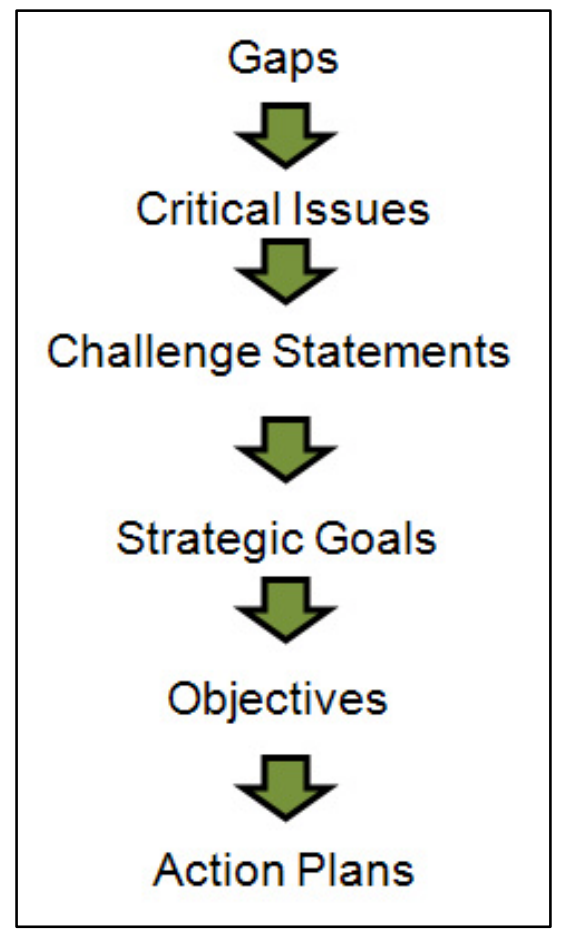

Figure 4. Strategic Planning Mental Model 


\section{Installation Strategic Planning Guidebook}

In the strategy development part of the strategic planning process, planning models typically refer to a "gap analysis." This is where the installation compares its current state ("Where We Are") with its desired future state, or vision ("Where We Want To Be"), and identifies the performance gaps between current and future states. This is done to highlight critical issues which the installation must address to attain its vision. To do gap analysis, an installation must operationally define current and future states so as to identify performance gaps. In other words, the installation must state the yardsticks on which it will compare states. The Strategic Planning Mental Model (Fig. 4) shows six operational definitions of current and future state. They are External and Internal Environmental Scan, Mission Analysis, Survey Data, Critical Success Issues, and Organizational Performance Measures.

The manner in which the methodology in this Guidebook is described is that the strategic planning team and other members of the organization will first create a desired future state and then gather or create current and desired future state data relative to each of these six operational definitions. Then the planning team will study the gaps with respect to each of these and from these identify the truly critical issues that the installation must address to move toward the desired future state. 


\section{Chapter 2: Where We Are - Creating Awareness}

The strategic sustainability planning process is conducted by the Garrison Commander (GC) in support of and in concurrence with the Senior Commander (SC). The first step is to create a planning team which usually consists of the Garrison Plans, Analysis, and Integration Office (PAIO) and various installation subject matter experts. The PAIO will typically coordinate and document the planning effort. Once the plan is completed, the PAIO will assist with tracking progress of the implementation of the plan.

The ISP is different than a traditional Garrison strategic plan. First, an ISP addresses issues that could impact any or all activities of the installation. Traditional Garrison strategic plans address the performance of Garrison functions and facilities in support of the mission. Second, an ISP includes a long-term planning component to address issues that may take years to address. For example, developing a walkable, net zero installation will require long term changes to infrastructure, facility placement and land use, transportation systems, and workforce behavior. Traditional Garrison strategic plans usually address change to be accomplished during the GC's tenure. Third, an ISP provides an investment strategy for the long-term. It defines change that will create an adaptable installation to best support current and future missions. Fourth, an ISP provides a bridge across multiple Commanders and mission changes to document longterm (and short-term) modifications that will improve the performance of the installation. Finally, an ISP allows an installation the opportunity to bring sustainability into all facets of business and operations across the installation and outside the installation.

The Installation Management Campaign Plan (IMCP) provides the scope of an installation strategic plan by identifying the key attributes which must be reflected at each installation (Figure 5). The IMCP Lines of Effort (LOEs) and Keys to Success (KTS) were developed to essentially define the characteristics of an installation that will best meet SC, Soldier, Civilian, and Family needs. However, the IMCP addresses the near future with a timeframe of seven years. As such, each installation prepares its strategic plan to identify the changes that will result in a sustainable installation to meet the current and future IMCPs. The installation strategic plan should also address local factors, operating conditions or customer requirements at your installation. The IMCP currently contains six LOEs and 34 KTS that are broken down into the various actions and initiatives that ultimately lead to accomplishing the IMCOM strategic priorities. Remember, these are the IMCOM overall LOE and KTS and do not replace the development of local action plans tailored specifically to your installation's conditions. In addition to the IMCP, you should also refer to the "Joint Vision 2020" and other strategy documents found at the following website: http://www.acsim.army.mil. 


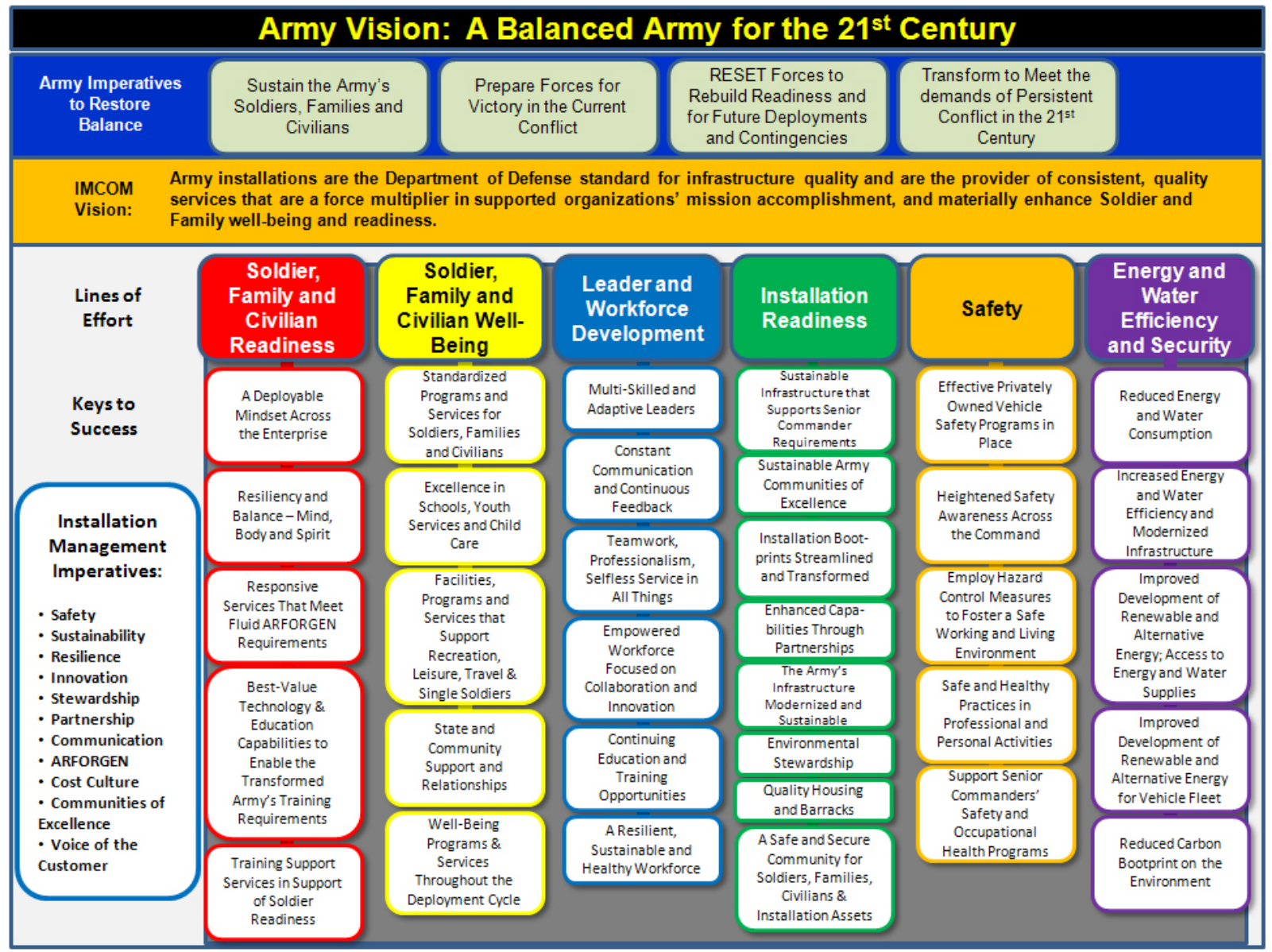

Figure 5. Installation Management Campaign Plan v4, November 2011 


\section{Step A - Awareness}

The first step in the "A-to-G Strategic Planning Model" is to get organized and begin the planning to plan process. This includes all of the preliminary work to prepare the planning team for the strategic planning endeavor. The planning team will start the process by building an understanding of how the installation community and its leadership view and use strategic planning. This step can consist of the following activities:

A.1 Prepare for Planning

A.2 Obtain Senior Leadership Commitment

A.3 Establish Roles and Responsibilities

A.4 Establish a Planning Timeline

A.5 Train on Strategic Planning and Sustainability

A.6 Determine Initial Information and Data Needed

A.7 Assess Organizational Readiness

A.8 Develop and Execute a Communication Plan

\section{A.1 Prepare for Planning}

The GC is responsible for developing the installation strategic plan (ISP) and his/her PAIO will lead the planning process. An ISP will address all facilities and activities needed to support and sustain current and future missions within the context of the local community. As such, the plan will require input from all installation and community stakeholders, including the senior commander. The GC planning team, however, will have responsibility for coordinating all activities and compiling the resulting information to develop the plan. So the ISP development starts with the Garrison team. The PAIO, as the lead in the process, should become familiar with the ISSP as laid out in this Guidebook.

To begin, schedule an initial planning session with the GC to discuss the ISSP process and the roles and responsibilities of the SC, GC, PAIO and Garrison staff. It is very important to do this up front to prevent misunderstandings about the process, timing, action officers, and the desired products. The PAIO and the GC should discuss what they want and need from each other to ensure ISSP success. You must be clear about the level of staff commitment required, and the extent of the pre-work that must be accomplished

Note: It is critical that the SC be involved to ensure participation by unit and tenant commanders. It is important for the SC and GC to understand the PAIO role is to facilitate and document the plan envisioned by all stakeholders. The PAIO should not write a plan without stakeholder input. All parties must come to agreement on roles, and it is helpful to capture it in writing. (pre-work is identified in each section of this Guidebook). Once the GC concurs with the ISSP requirements, you may be asked to help articulate his/her expectations.

When engaging the GC, the planner may begin by providing an overview of the ISSP process including the expected deliverables and timelines. The ISSP Process Desk-side 
Brief is part of the ISSP Companion slide-deck and is located at https://www.us.army.mil/suite/page/608884. It provides a PowerPoint presentation template that can be modified to reflect installation-specific considerations. After reviewing the briefing materials, you might ask the GC to articulate his/her initial expectations of the planning process in general and the PAIO role to support the process. Capture these on a flip chart or white board where they are clearly visible to you and the GC. Review the list and identify expectations you feel you can't or shouldn't meet. Discuss each item until there is clear, common understanding. Next, suggest items the GC may have overlooked, but which you feel he/she should reasonably expect and discuss each item until agreement is reached. You should now have a good list of GC expectations. During this discussion, you should also identify the support needed from the GC and Garrison staff to ensure success. Other items in this initial discussion include validating the initial time line (presented in the slides), decision points, next steps, and how to engage the Senior Commander and obtain his/her support. Once the GC gives approval to continue with the Awareness phase of the process, move on to the next steps outlined below.

\section{A.2 Senior Leadership Commitment = Commanders' Intent}

The SC and the GC establish priorities for subordinates and supporting organizations and individuals. One of the ways they do this is through StratComm messages that describe their desired end state and that they want to commit resources to the ISSP process. The PAIO should draft proposed strategic messages for the SC and GC to sign and send out that describe the desired end state, the process to be used (ISSP), and a timeline that includes In Progress Reviews (IPRs) with the SC. Doing so demonstrates that this effort is a priority with the installation's Senior Leader, and will be checked for progress and results accordingly. Appendix A provides a letter of intent for the Garrison Commander to begin strategic planning.

\section{A.3 Establish Roles and Responsibilities}

Once you meet with the GC, it is critical to establish and ensure ISSP participants understand their roles in the ISSP process, and what their "deliverables" are. These should be put into the initial meeting announcement, and repeated at the first group meeting to ensure there is a common understanding of expectations. Table 2 below provides common roles and responsibilities assigned to installation leaders and the planning team.

Table 2. Roles and Responsibilities in Planning

\begin{tabular}{|l|l|}
\hline \multicolumn{2}{|c|}{ Roles and Responsibilities } \\
\hline Senior & $\bullet$ Approves ISSP process and timeline \\
& - Signs invitations and provides Command emphasis to insure participation \\
& $\begin{array}{l}\text { - Signs final ISP } \\
\text { - Provides ultimate decision on implementation priorities that best support } \\
\text { current and future missions }\end{array}$ \\
\hline $\begin{array}{l}\text { Garrison } \\
\text { Commander }\end{array}$ & - Approves Action Plans and responsibilities \\
\hline
\end{tabular}




\begin{tabular}{|c|c|}
\hline \multicolumn{2}{|r|}{ Roles and Responsibilities } \\
\hline & $\begin{array}{l}\text { - Generate meeting announcements } \\
\text { - Execute supporting StratComm } \\
\text { - Ensures Garrison and tenant participation } \\
\text { - Provides IPRs to Senior Commander } \\
\text { - Work with the SC to establish priorities among competing demands within } \\
\text { action plans and budgets }\end{array}$ \\
\hline $\begin{array}{l}\text { Directorate and } \\
\text { Special Staff } \\
\text { Chiefs; tenant } \\
\text { participants }\end{array}$ & $\begin{array}{l}\text { - Prepare for and participate in planning events } \\
\text { - Identify recurring planning requirements in their functional areas } \\
\text { - Integrate relevant strategic goals and objectives into operational plans } \\
\text { (e.g., a goal for high-performance buildings should be reflected in the } \\
\text { Master Plan and Installation Design Guidebook) } \\
\text { - Integrate requirements identified by Team leaders into budgeting cycles } \\
\text { - Track and document progress in meeting goals/objectives. Add } \\
\text { information to SMS } \\
\text { - Document successes and failures }\end{array}$ \\
\hline PAIO & $\begin{array}{l}\text { - Serve as Action Officer to execute Garrison Commander strategic } \\
\text { planning responsibilities as appropriate; } \\
\text { - Coordinate planning activities } \\
\text { - Document baseline } \\
\text { - Facilitate all strategic planning sessions if she/he has the requisite } \\
\text { - } \text { experience } \\
\text { - Support Directors and team leaders in integrating strategic goals into } \\
\text { relevant operational plans and budgets } \\
\text { - Provide status reports to GC } \\
\text { - Identify and coordinate engagement with subject matter experts to } \\
\text { support implementation of new approaches (i.e., Net-Zero, climate } \\
\text { change, sustainability, high-performance buildings, human capital } \\
\text { - planning, etc.) (See Appendices Q and U) } \\
\text { - Provide information and data to GC for use in the Installation Planning } \\
\text { - Integrate ACOE and strategic planning functions }\end{array}$ \\
\hline Team Leads & $\begin{array}{l}\text { - Serve as the ISSP Team Leads for designated functional areas once the } \\
\text { team is formed; facilitate team activities to provide input to the larger } \\
\text { ISSP planning team } \\
\text { - Lead implementation of specific-actions to insure success } \\
\text { - Provide information and data to the PAIO for use in baselining and } \\
\text { tracking } \\
\text { - Document successes and failures } \\
\text { - Identify technical needs } \\
\text { - Identify requirements (people and funds) to support planning }\end{array}$ \\
\hline
\end{tabular}

\section{A.4 Establish a Planning Timeline $=$ Project plan}

Table 3 below provides a typical planning timeline for the ISSP process, according to the A-G Model. Adjustments will be required to account for mission requirements (readiness exercises, training events, deployment schedules, etc.) and change of GC. Check with the SC G3 Operations team and the Garrison DPTMS to establish the 
planning schedule to best fit with training and major activity schedules. Once the overall schedule is determined, your organization will need to determine more specific timelines for each event of the process and ensure you have identified your start and stop times.

The availability of suitable facilities and space for each working session of the ISSP process may also impact your timeline. For example, the goal setting session (Phase 2 - Step C) will require a separate room for each goal-team (established during the baselining process) to be used over a three-day period. These break-out rooms should be located in the same building since goal-setting has large and small group sessions throughout the process.

Table 3. Example Planning Schedule

\begin{tabular}{|c|c|c|c|c|c|c|c|c|c|}
\hline $\begin{array}{l}\text { VAction } \\
\text { Month }\end{array}$ & 1 & 2 & 3 & 4 & 5 & 6 & 7 & 8 & 9 \\
\hline Phase 1 - Awareness & & & & & & & & & \\
\hline Phase 1 - Baseline & & & & & & & & & \\
\hline $\begin{array}{l}\text { Phase } 2 \text { - Clear, Visic } \\
\text { Mission and Goal-sett }\end{array}$ & & & & & & & & & \\
\hline Phase 3 - Down to $A c$ & & & & & & & & & \\
\hline $\begin{array}{l}\text { 1. Objectives } \\
\text { Development } \\
\text { 2. Action Planning }\end{array}$ & & & & & & & & & \\
\hline $\begin{array}{l}\text { Phase } 4 \text { - Evaluate, } \\
\text { Feedback, Get Better }\end{array}$ & & & & & & & & & \\
\hline
\end{tabular}

Finally, make the most of the available time by announcing meetings well in advance, publishing (and adhering to) an agenda, and performing as much work as possible outside the meetings. Doing so will improve the chances of adhering to the original timeline. Appendix B: Invite Letter to Stakeholders and Appendix C: Invite Letter Internal to Installation show templates for announcing the beginning meetings and inviting the appropriate stakeholders and staff to the process.

\section{A.5 Train on Strategic Planning and Sustainability}

The ISSP is a complex strategic planning process that results in a long-term installationwide strategic plan. Additional training on strategic planning and sustainability concepts will be needed. It is recommended that you segment your training events based on roles and responsibilities of participants and the topics to be presented. The more senior leaders need only an overview of the process you plan to employ and general sustainability concepts. Team members who will be developing action plans may need more extensive, subject-specific training. For example, CPAC and DHR staff may want training on human capital planning as a means to developing a sustainable workforce. Consider "just in time" training when appropriate so there is a minimal time gap between learning and applying skills. For example, training in building action plans is best delivered just prior to or in conjunction with entering Step D: Down to Action. Table 4 provides a list of recommendations for the types and duration of training on strategic 
planning concepts. In addition, Appendix D provides an agenda for a strategic planning course that may be available for all. Appendix $E$ provides sources for additional strategic planning reading.

Table 4. Types of Strategic Planning Training

\begin{tabular}{|l|l|}
\hline Audience & Training \\
\hline $\begin{array}{l}\text { Senior Leadership } \\
\text { (SC, CSM' GC, } \\
\text { CSM) and Tenant } \\
\text { Leaders }\end{array}$ & $\begin{array}{l}\text { 1 hour high-level overview, focus on Army strategy, overall planning } \\
\text { process and end state; and the Senior Commander and Garrison } \\
\text { Commander decision-making opportunities/events }\end{array}$ \\
\hline $\begin{array}{l}\text { Mid-level Leadership } \\
\text { Garrison Directors }\end{array}$ & $\begin{array}{l}4 \text { hours training with an emphasis on strategy, objectives and action } \\
\text { plans }\end{array}$ \\
\hline $\begin{array}{l}\text { Division/Branch } \\
\text { Chiefs }\end{array}$ & $\begin{array}{l}\text { One day training with emphasis on action plans or two day training with } \\
\text { emphasis on creation of actual work center action plans }\end{array}$ \\
\hline $\begin{array}{l}\text { Workforce and } \\
\text { tenants }\end{array}$ & $\begin{array}{l}\text { One hour overview with emphasis on Senior Leadership desired end } \\
\text { state (for example at a town hall) followed up by articles in the post } \\
\text { newspaper or other media }\end{array}$ \\
\hline PAIOs & Two-day class with hands-on exercise application opportunities \\
\hline
\end{tabular}

\section{A.6 Determine Initial Information and Data Needed}

Data is essential to establishing a baseline, setting targets and measuring change. Data also helps the planning team to understand the current operating environment of the installation and where there are opportunities for improvement. For example, data that defines an upward trend in energy consumption and overall cost may represent an issue that threatens the long-term sustainability of the installation. Development patterns that illustrate growth near installation range boundaries may represent impacts on training that threaten the current and future use of the installation for certain types of training. Work with your directorates to identify any changing climatic patterns that influence the severity and duration of weather events and the effects they may have on air and ground conditions and operations which may cause impacts to training, critical assets, and safety. There is always a danger of "paralysis by analysis" so be very selective and minimalist in the data to be collected and introduced in the planning sessions. As you prepare for the ISSP, realize that data collection is a critical component of this process.

It helps to have some initial data and information even before baselining. One effective approach is to review the Garrison mission, vision and organizational profile. Then ask yourself; what are the desired outcomes the Garrison must achieve to enable your Senior Commander's mission success? These outcomes might suggest the types of information that will be useful in understanding the mission. Other critical statistics will be compiled during Step B.1 for use in the baseline. As you start the initial data collection process you may want to include such data as:

- Organizational chart

- A description of each tenant unit's mission and activities 
- An installation map that identifies current locations of all Garrison and tenant organizations, boundaries of the cantonment area, transportation networks, training areas, and other mission-important facilities

- An aerial view of the installation and surrounding communities. A series of such photos over the past 20-40 years is helpful in illustrating growth and development patterns. Google Earth ${ }^{\circledR}$ maps, which now include the capability to display older coverage may provide a simple, if less rigidly accurate, source for these materials;

- A summary of Army, IMCOM, and Mission Campaign Plan topics critical to the installation

- Installation statistics on number of buildings, size and layout (including maps)

- Installation resource consumption and cost data - energy, water, transportation fuel, etc.; Installation material consumption (if available) and waste generation and cost data; historical data from ISR-NI

- Proposed construction plans, including upcoming efforts, Military Construction Army (MCA) budget, repurposing efforts, draft and completed 1391s, etc.

- Installation natural resource concerns (for example, wetlands, number of endangered species, water use restrictions, encroachment on training lands/habitats, net zero initiatives, climate change affects)

- Workforce demographics and employment statistics (for example time to fill vacant jobs for specialty positions, average age of workforce, etc.)

- Regional and State economic impact

- Community and regional information on issues of concern like employment, housing, crime, education, development plans, etc.

All of the information that supports an understanding of the entire installation system will be useful in the ISSP. These data will help the stakeholders to make decisions based upon the IMCOM Sustainability Principles: Mission, Community Engagement, Environmental Stewardship, Economic Benefit, and Systems Thinking.

Initially, begin with collecting summary information that will be useful in describing the issues the strategic planning process will address. As the baseline is developed, additional considerations will arise and others may be identified as lower priority. The purpose of data collection at this point is to begin the gathering process. The amount of information compiled during the ISSP process can be substantial. Figure 6, Senior Leader Information Binder provides an example outline to assist the Senior Leadership in compiling the documentation gathered.

\section{A.7 Assess Organizational Readiness}

Throughout Step A, the planning team is trying to help the SC and GC determine if the organization is ready for strategic planning. There are a number of factors which can impede progress including: 
- Training events

- Deployments

- Changes in Garrison or Senior Command

- Inspections by parent organizations or regulators which require personnel support

- Real-world emergencies

- Resistance to planning

- Other situations

Prior to engaging in strategic planning, organizational senior leaders may assess the organization's readiness to plan and determine what to do if the organization is not ready. An effective way to assess readiness is through individual or group interviews conducted by the PAIO.
Senior Leader SP Information Binder

Tab 1 - Map to event location

Tab 2 - Agenda

Tab 3 - Vision and Mission - including Army, SC, Tenants and IMCOM

Tab 4 - Internal Scan Results

Tab 5 - External Scan results

Tab 6 - Validated SWOT Analysis

Tab 7 - Garrison Organizational Profile (ACOE)

Tab 8 - Values Scan

Tab 9 - Survey Data Results (if any)

Tab 10 - Pertinent Measure Data

Tab 11 - Interview Results (if any)

Tab 12 - Background / Educational materials

Figure 6. SP Information Binder

Interviews and subsequent data feedback allow the strategic planner to present perceptions of current and future state, performance gaps and planning barriers as perceived by senior leaders. Although the primary purpose of the interviews is to collect data that will allow the group to assess readiness to plan, other benefits can also be gained. The interviews can identify major obstacles to effective planning, and reinforce the need for planning by allowing senior leaders to compare their perceptions with each others. The next two pages provide an example of the interview process and Appendix $F$ refers to a list of questions the planning team might use to determine organizational readiness.

It is critical at this time to allow the leadership an opportunity to thoroughly analyze and discuss the data being presented. Appendix G ISSP Leadership Interview Data Analysis Process will walk you through this step. The intended outcome of this session is for the planning team to ensure the organization is prepared for strategic planning.

Note: Complete the assessment of readiness step even if the organization already has a strategic plan in place or has been through several iterations of strategic planning. This step should be emphasized if there have been changes within the strategic planning team. This will help to "level" the group. 


\section{Example Interview Process}

\section{Interviews:}

The readiness assessment process begins with the PAIO interviewing key installation stakeholders (Garrison leadership team, program leaders, etc.) (see Appendix F). During the interview process, it is recommended that there be two people to administer the interviews; one to ask the questions and another to record the response(s). The strategic planner may need to recruit someone to assist and to serve as recorder. It is helpful to give the questions to the interviewees beforehand so they have time to think about their responses. It is also helpful to have the recorder use a notebook computer to record responses during the interview session. Capturing the data in electronic format makes it easier to combine data across interviews for analysis. The information must be non-attributable and used with the interviewee's permission!).

These interviews last approximately one hour each and should be scheduled as such. If an individual who is part of the planning team is not available for interview, but would be available for the data feedback session, allow him or her to provide written responses due to you by the end of the interview sessions. These data can still be incorporated for the feedback session. Theoretically, all the interviews could be done via written response, but interviews tend to provide much richer data; interviewees tend to say more than they would write, and they can't delegate responsibility for answering the questions.

\section{Interview Information Reviews:}

Once all the interviews are completed, the strategic planner reviews the information and analyzes the data in preparation for feedback to the planning team.

1. The first step in data analysis is to sort the information by question. If you had the recorder capture the responses via computer, you can combine all the interviewees' responses into a single word processor file (see Appendix G). A good data analysis tool that will allow you to organize the responses into common themes is the affinity diagram; use one grouping for each interview question. To analyze the data this way, it is helpful to print off the responses to individual questions in a large font, on hardcopy. Then with scissors, you can cut out each individual response for the question onto strips. Each individual may have given more than one response per question, so you may have multiple strips for each person, for each question. Put all the responses for individual interview questions in separate envelopes and mark the envelope with that question number. For example, the first question asks for a list of the organization's customers. Assume the respondent gives you a list of five customer groups. You record this information as a list of five responses. Be sure to double space between each response. Do this for all the questions. Then off the printed sheet(s), cut each response into its own strip. Put all the responses for question one into an envelope. Do the same for the remaining questions and repeat for each interviewee. Compile responses for all interviewees on a given question into the same envelope. 
2. The second step is to relate the data to each question. When you have grouped responses for a given question, write down descriptive, consistent titles for each group and how many responses were in each group. Some responses for a given question will be "orphans" (i.e., responses that did not logically group with other responses). The number of orphan responses for a given question is very important. If many individuals are giving responses that are not repeated by other interviewees, this may be a sign that interviewees tend to interpret the question differently, thus bringing the validity of the question to bear. The actual orphan responses should be recorded and included in the analysis report, but in the data outbrief, the strategic planner will just state the number of orphans for that specific question to save time.

3. The third step is to list the data on flipchart paper. On the top of a piece of flipchart paper, put a short title for the question. Do this for each question. Under the title, list each data-related group name with the number of responses in that group in parentheses next to it. List these related groups from the highest number of responses to the lowest, down the page. You may want to leave extra space between naturally occurring breaks in the number of responses. In the bottom right hand corner, record the number of orphans.

4. The PAIO will need to prepare a handout for the feedback session. The Senior Leader Information Binder, Figure 6 will be given at the conclusion of the feedback session to all the participants. This handout will include the same information as the flip chart papers, but with the orphans listed out.

\section{Interview Information Feedback:}

The strategic planner will need to arrange a minimum of two hours for this feedback session. The room for the presentation will need to have a blank wall to accommodate 10 - 12 sheets of flipchart paper, one for each interview question and a couple extras for recording data created during the feedback session. It is very important to be able to display the results of the interview questions simultaneously and allow ample time for leadership to discuss the information.

When displaying the data, divide the wall into three sections. Put the organization's name across the top of all three sections to reinforce an organizational "systems" perspective. The first section can be titled "Present State." The flipchart sheets that you hang in this section are: Mission, Key Customers, Key Products/Services, and Current Performance. The second section can be titled "Change Factors" and should include sheets: What to Do, Ready to Plan?, Obstacles, Overcoming Obstacles, and Pre-work Barriers. The third section can be titled "Future State." The sheets for this section are: Vision, What's Different, and Planning Horizon: 25 years. Fold each sheet of flip chart paper up from the bottom so that only the header shows. Secure lightly with a piece of tape. During the briefing, you will reveal the entire sheet as you brief, by removing the tape and allowing the entire flip chart paper to become visible. The strategic planner will set the agenda for the data feedback session. The Garrison commander should open the session with welcoming comments and state the purpose of this feedback session. 
The strategic planner should meet with the commander prior to the data feedback session and provide him or her opportunity to preview the interview results to eliminate the surprise factor. This meeting should also be used to prepare the commander for making opening remarks.

Note: You may want to have the team develop a list of Rules of Engagement (ROEs) as guidelines or norms for group behavior during the session.

The purpose of the feedback session is for the strategic planner to present the findings from the interviews and to lead the group through a guided discussion in order to determine readiness to plan and to highlight differences in perceptions regarding the organization. The strategic planner should explain to the group the process used to collect and present the data (i.e., conducted interview, grouped related data, definition and meaning of orphans, etc.). Inform the group that they will receive a handout shortly after the data is presented. Allow the group to draw their own conclusions because it is their data. Begin with the first section titled "Present State," and then proceed to the second section titled "Change Factors," then to third section titled "Future State." During the presentation of data, allow no questions. There will be plenty of time for discussion later. It is very important to ask the group to look for patterns, trends, interrelationships and attention grabbers in the data. Focus the group's attention on what is happening across questions, not just within questions.

After presenting results for each question, take a short break to allow everyone an opportunity to come forward to look at and discuss the response sheets. After the break, direct the group through a guided discussion of the data. This is when you encourage individuals to ask questions about the data or seek clarification. Try to allow other group members to answer the questions as much as possible. The strategic planner should say as little as possible. Remember, this is leadership's information.

Continue facilitation with the group through the point of reaching a consensus on understanding the organization's perceived current state, future state, performance gaps and major obstacles to effective planning.

\section{STOP! - You need a clear decision by leadership to proceed or postpone the} ISSP for now.

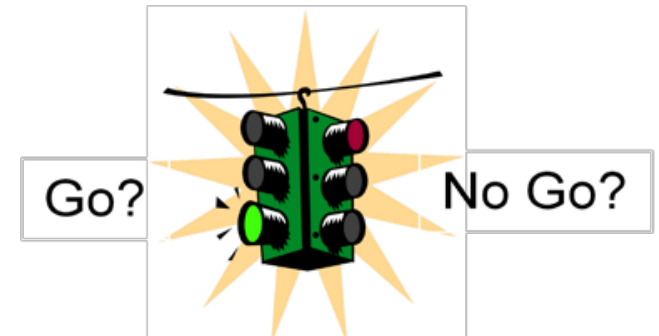

After the group reaches the decision to proceed or not, take a short break. If the group feels that the organization is not ready to proceed with strategic planning, then determine what next steps need to be taken in order to be ready for the strategic 
planning session, and plan to make them happen. If the group decides the organization is ready, then the organization can proceed with step A.8.

\section{A.8 Develop and Execute a Strategic Communication Plan}

The purpose of the Strategic Communication Plan is three fold: First, to create dialog and discussion that is multi-directional, running top-down and bottom-up, and horizontal across and outside the organization. Second, seek input from everyone who touches the products and services. With communication the more methods you use the better. Third, your organization will want to ensure there's an opportunity to provide feedback and build acceptance; people need to know you heard them and the communications process is not all about one way information flow. A list of communication tools is shown in Table 5.

Why is communication critical to implementing strategy? Successful implementation and achievement of results can only be achieved if they are acknowledged, understood and accepted by constituents. The organization's Vision, Mission, strategic direction and goals are a driving force for all management and employee decisions and effort in the work place. While communication and deployment of the installation's strategic message should begin as soon as the Vision, Mission, Values, and Guiding Principles drafted during the leadership workshop are formalized, feedback is a vital part of this communication process and a way to gather input from key stakeholders. Once finalized, results should be communicated to all stakeholders as quickly as possible to guarantee both reception and comprehension.

A letter to stakeholders is one way to begin the process of communicating your installation's intent to involve all of the people and organizations that have a vested interest in the success and sustainability of your installation. Appendix B provides a sample invite letter to stakeholders. Externally communicating the installation strategic plan will achieve several key outcomes:

- Customers will recognize a focus on their needs; opportunity to improve relationships with customers

- Suppliers will play a much more visible role in doing business with the organization

- Other organizations may partner with the organization to maximize resource efficiencies and to achieve common regional (sustainability) goals

- Parent organization might redirect resources or justify additional resources in support of the plan

- Stakeholders will be able to align with the vision

- Surrounding community leaders will accept the plan and may participate actively in future planning efforts 
Table 5. Communication Tools

\begin{tabular}{|c|c|c|}
\hline \multicolumn{3}{|c|}{ Example - External Communication Tools } \\
\hline Tool & Purpose & How to Use \\
\hline $\begin{array}{l}\text { Brochure/ } \\
\text { Handouts }\end{array}$ & $\begin{array}{l}\text { - Introduces the strategic plan } \\
\text { without too much detail } \\
\text { - Easily disseminated at } \\
\text { professional meetings } \\
\text { - Creates networking opportunity }\end{array}$ & $\begin{array}{l}\text { - Distribute with an introductory letter } \\
\text { - Personally distribute } \\
\text { - Have available when you meet with } \\
\text { stakeholders }\end{array}$ \\
\hline $\begin{array}{l}\text { Letter and } \\
\text { Copy of Plan }\end{array}$ & $\begin{array}{l}\text { - Convey the plan } \\
\text { - Convey leadership and } \\
\text { organizational commitment } \\
\text { - Vehicle for requesting feedback, } \\
\text { supplemental plans, and } \\
\text { resources }\end{array}$ & $\begin{array}{l}\text { - Mail or hand deliver to customers } \\
\text { and stakeholders } \\
\text { - Use as a tool to explain how the } \\
\text { Strategic Plan affects organizational } \\
\text { members } \\
\text { - Distribution method is critical }\end{array}$ \\
\hline $\begin{array}{l}\text { Personal } \\
\text { Meeting }\end{array}$ & $\begin{array}{l}\text { - Personal sharing of the plan by } \\
\text { the senior leader } \\
\text { - Make time for immediate } \\
\text { feedback and questions }\end{array}$ & $\begin{array}{l}\text { - Senior leader conducts initial and } \\
\text { periodic meetings with external } \\
\text { customers and stakeholders }\end{array}$ \\
\hline $\begin{array}{l}\text { Meetings with } \\
\text { local community } \\
\text { (partners / } \\
\text { suppliers }\end{array}$ & $\begin{array}{l}\text { - Solicit input from outside } \\
\text { stakeholders } \\
\text { - Provide installation direction }\end{array}$ & $\begin{array}{l}\text { - Participate in local boards, forums, } \\
\text { and meetings }\end{array}$ \\
\hline
\end{tabular}

\begin{tabular}{|c|c|c|}
\hline \multicolumn{3}{|c|}{ Example - Internal Communication Tools } \\
\hline Tool & Purpose & How to Use \\
\hline Brochure & $\begin{array}{l}\text { - Conveys the plan without a lot } \\
\text { of detail }\end{array}$ & $\begin{array}{l}\text { - Distribute to all employees at } \\
\text { meetings and orientations }\end{array}$ \\
\hline Letter/ memo & $\begin{array}{l}\text { - Explains plan in words of senior } \\
\text { leader }\end{array}$ & $\begin{array}{l}\text { - Distribute to all employees, formal } \\
\text { means of distribution }\end{array}$ \\
\hline Posters & - Serves as reminders of plan & - Display in high traffic areas \\
\hline $\begin{array}{l}\text { ISSP } \\
\text { Strategic Plan/ } \\
\text { Newsletter }\end{array}$ & $\begin{array}{l}\text { - Educates employees in detail } \\
\text { - Keeps work force informed } \\
\text { - Provides progress reports } \\
\text { - Emphasizes commitment } \\
\text { - Links the plan with everyday } \\
\text { work }\end{array}$ & $\begin{array}{l}\text { - Use first issue to roll out the plan } \\
\text { - Use subsequent issues to } \\
\text { communicate progress, results, } \\
\text { lessons learned and new initiatives } \\
\text { - Can be easily distributed to all } \\
\text { employees hard copy or email }\end{array}$ \\
\hline $\begin{array}{l}\text { All-hands } \\
\text { Meetings }\end{array}$ & $\begin{array}{l}\text { - Reinforces senior leader } \\
\text { commitment } \\
\text { - Encourages Q \& A for } \\
\text { employees }\end{array}$ & $\begin{array}{l}\text { - Senior leader invite to stakeholders } \\
\text { - Discuss strategic plan, model and } \\
\text { process }\end{array}$ \\
\hline $\begin{array}{l}\text { Briefing } \\
\text { Material with } \\
\text { notes }\end{array}$ & $\begin{array}{l}\text { - Emphasizes senior leader } \\
\text { commitment } \\
\text { - Ensures constancy of message }\end{array}$ & $\begin{array}{l}\text { - Distribute to department heads and } \\
\text { mid-level managers to explain to } \\
\text { their employees } \\
\text { - Must be updated regularly }\end{array}$ \\
\hline Email & $\begin{array}{l}\text { - To communicate the plan and } \\
\text { any updates to the plan } \\
\text { - Accessible to all }\end{array}$ & $\begin{array}{l}\text { - Should come from senior leader } \\
\text { - Not a substitute for personal } \\
\text { interface with leader }\end{array}$ \\
\hline
\end{tabular}




\section{Chapter 3: Where We Are - Establishing the Baseline}

\section{Step B - Baseline}

At this point, the strategic planning team has established a foundation for the strategic planning process. The planning team has engaged stakeholders, identified data needs, conducted some training, and most importantly has established Command emphasis and support for the planning effort. The next step in the process is developing a baseline for the installation (Figure 7). The baseline will characterize the long-term issues that threaten the sustainability of the installation. This step consists of the following activities:
B.1 Collect Baseline Data and Draft Baseline
B.2 Characterizing the Operating Environment:
- Conduct an External Scan
- Conduct an Internal Scan
B.3 Working Session 1 - Challenge Statement Development
B.4 Finalize Installation Baseline

\section{B.1 Collect Baseline Data}

It's time to start compiling an installation baseline that stakeholders will use to define critical issues that the strategic plan will address. Remember that the strategic plan should be used to define the change needed to best support current and future missions. PAIO will compile the information identified previously and develop a draft baseline document for review and comment by installation stakeholders. The baseline should serve as a quick reference guide to key statistics concerning the installation operation in support of the Mission, Soldiers and their Families, the civilian workforce and in consideration of the surrounding community.

\section{Data Collection Session - Baseline}

Duration: 30 days to collect

Format: Interviews, surveys, assessments

Host: Planning Lead (PAIO)

Participants:

- Garrison Commander

- Deputy Garrison Commander

- Major tenant representatives

Products:

- Internal scan

- External scan

Figure 7. Data Collection Session

The goal of an installation baseline is to provide an overview of current and future issues that the installation will face. If possible, the baseline should document trends like increasing energy cost over time, development patterns around the installation, climatic changes expected to affect operations (Appendix Q), safety, or security, or expected mission changes/growth. To the greatest extent possible, the data should be tied back to the functions/activities related to them as defined through the Customer, 
Output, Input, Supplier (COPIS) analysis which you will create or update during the Internal Scan. For example, data on water and energy use should be tied back to organizations (if metering is functional). The strategic plan developed using the ISSP process should position the installation to address short, intermediate, and long-term issues. Further, the data compiled for the initial baseline will become the basis for measuring accomplishment of and improvement tied to goals, objectives, and action plans as developed in Session C and D of the A-G Model. It is critical to the ISSP process to develop a draft baseline that provides all of the data collected by your planning team. As your team completes activities under Step B, the baseline should be refined and expanded to present a more complete picture of the installation.

\section{B.2 Characterizing the Operating Environment}

The operating environment (Figure 8) will help to explain the Who, What, Where, and Why the installation functions as it does. Characterizing the operational environment will help to not only define the critical issues and challenges, but also may illustrate potential solutions and paths forward. To characterize the operating environment, your team will conduct external and internal scans. Appendix $\mathrm{H}$ provides several worksheets to facilitate that process. The information developed by the planning team to characterize the operating environment will then be used to refine the installation baseline. The data and information compiled in the baseline will be validated by Garrison leadership and then summarized via challenge statements during Working Session 1.

\section{External Scan}

\section{What Happens During This Step?}

The external scan forms the context in which the strategic planning process will be accomplished. This is where the organization must take a serious look at its surroundings, in terms of events, norms, patterns and trends that will manifest themselves within the planning horizon. Later, this information will be used to derive planning assumptions and to identify future opportunities and threats. Note: This means that it is extremely important that this section be as accurate and factual as possible.

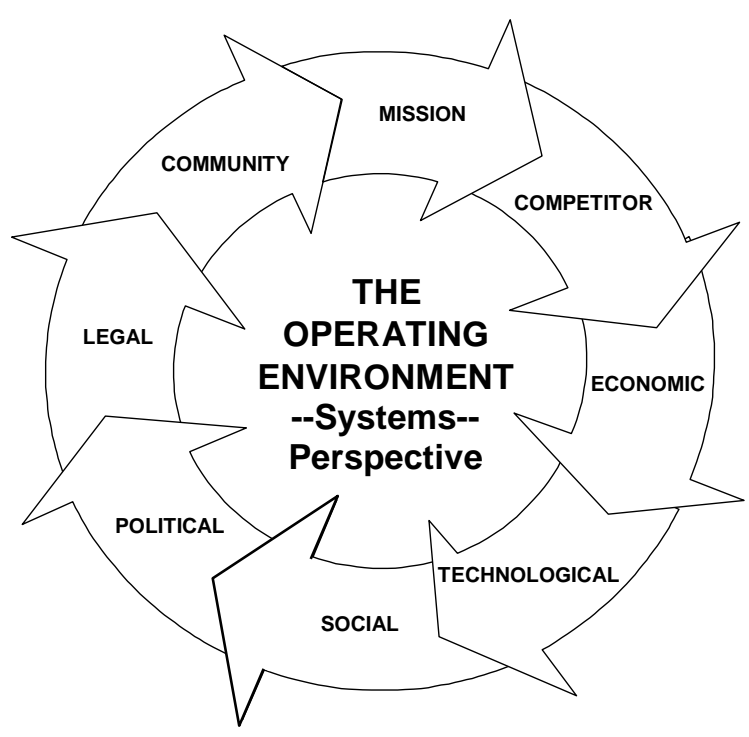

Figure 8. Operating Environment

You need to understand and anticipate these factors early in the planning process so that you can have a realistic perspective. Let's face it, at times you can operate in crisis mode and just try to make it from one day to the next focusing on what needs to get done today or tomorrow. If you focus too much on the day-to-day tasks, then you could miss out on some great opportunities. Some opportunities may be easy to ignore in favor of the day to day urgent tasks that pile up in your inbox. 
At this point, senior leaders take "time-out" and explore a variety of issues which even though they are outside their realm of control they could either enhance or inhibit the well-being and mission accomplishment of their organization in the future.

Look at the leading edge concepts in each of the operating environments; community, economic, technology, etc., and decide how they could influence your future or how you could use them to your advantage. In addition, consider potential future trends that are not so apparent in our operating environment today, such as climate change (Appendix Q), transportation, logistics, well-being etc. that could affect mission operations. This task is no longer simply your "best guess" at what the future may hold, but becomes your decisions about what you see going on around you and how you want to use it to form a future of your choosing (as opposed to chance). This Guidebook capitalizes on a concept taken from Plan or Die - 10 Keys to Organizational Success (Nolan, Goodstein, and Pfeiffer, Pfeiffer \& Company, 1993, pg. 129) which illustrates distinct categories for an environmental scan; internal customer, competitive, industry-specific and macro. Then, to ensure you address the entire installation, the Guidebook includes the additional sustainability principles of mission excellence, community collaboration and the systems perspective. By looking at the most recent developments in each field, this step becomes one of information gathering and not one of futile attempts to predict an unknown future.

\section{Opportunities and Threats}

The gathering of external data for the purpose of strategic planning is generally known as environmental scanning (i.e., the 360-degree gathering and analysis of information from a variety of sources on such matters as customers' needs and expectations, technology developments, demographics, politics, and societal trends). Many strategic planners see this information as the key to the planning process.

The types of information you will need to investigate in the external scan process are identified more clearly in Appendix $\mathrm{H}$, Environmental Scanning Matrix Worksheets. The questions under each aspect are not intended to give full coverage for the particular aspect, but are offered simply to serve as thought provokers and points of departure.

During the external scan the three categories you want to consider are:

Category 1 - Policy, Regulation, Laws, and New Missions

Category 2 - Community/Region Profile

Category 3 and 4 - Business and Industry Standards and Trends

In addition to the matrix worksheets, be sure you include information that describes the installation's surroundings, in terms of:

- Land development around the installation border;

- Economic development in the surrounding communities;

- Regional quality of life for Soldiers, Families, and Civilians; 
- Regional issues that impact or support mission performance;

- Resource consumption and the potential for future competition for those resources (water, airspace, bandwidth, etc.);

- Regional approaches toward waste management; and

- Regional energy assets and options

Later this information will be used to identify future opportunities and threats.

The need for organizations to change has never been greater than we are seeing today. The challenges most organizations are facing do not lend themselves to success by adaptation. That's because the very rules by which the Army does business are being shifted rapidly, and with the rapid shifts come additional challenges the organization faces from internal demands. So why bother with this separate conscious effort to look outside the organization to see what is going on? Timothy Nolan in his book Plan or Die $(1993$, p. 2) provided an interesting example of what happens if we do not take a good look at our environment and examine why adapting may not be a sufficient response.

\section{The Boiled Frog Story}

In a laboratory, frogs were placed in shallow pans of room temperature water. They were free to jump out of the pans at any time. Under each pan was a Bunsen burner, which heated the water very gradually. As the temperature rose, degree by degree, the frogs adapted to the new temperature. Unfortunately, regardless of how hot the water became the frogs never became uncomfortable enough to jump out of the pan. In fact, they stayed right there until the heat was so intense that the frogs died. Now that's adaptability! The frog's survival requires the ability to realize at some point that it is getting into "hot water" and needs to stop adapting. The frog needs to jump out of the pan and into the unknown to get to a new and safer environment.

The Army is great at adapting to changes! So good in fact, that we need to be careful that we do not adapt too well, like the frogs, and end up getting burned. The external scanning step gives you an opportunity to look outside your plan and see if you need to jump.

\section{Where Do You Get the Information?}

Garrison staff assigned to complete this portion of the pre-work should do some significant research in trade journals, professional publications, news and business publications, etc. You may want to consider helping the team identify sources of data prior to assigning POCs and assign each section to a different individual. Allow them a maximum of one page per section to consolidate their thoughts in bullet format. The format is very important because it will facilitate analysis of the data during the strategic planning event. Assigning each section to a different person ensures no one person gets overburdened with too much pre-work, and using the one-page limitation and bullet format for each section ensures the strategic planning team will not be provided with too much data. In the past one organization conducted a focus group to look at the future 


\section{Installation Strategic Planning Guidebook}

on a variety of topics. One focus group was composed of military spouses to look at issues that could impact family life in the future. Another way to gather this information is to assign personnel such as the JAG, OPS, etc., to prepare short briefings to senior leadership on the future threats and opportunities of the organization. You could also seek volunteers to research and brief the future of different topics which may affect your organization. No matter how you collect the information, remember that the quality of the information received from these sources will be crucial to the success of the External Scan. Just remember, it's important that you do not overwhelm your audience with data at this point or give them too much information to process. You want to give each leader enough information to understand their operating environment in some depth and be prepared to use that knowledge as they develop strategy in their day-today decisions.

\section{How to Get Through This Step?}

At this point, you may notice that you have a plethora of data that needs to be sorted through. A simple way to sort through all this data is to gather all of the issues (threats and opportunities) and put them onto post-it notes. Post all of these notes and create an affinity layout. After you have a wall or board full of post-it notes, have everyone (in silence) get up and arrange the post-it notes in columns that make sense to them-the items on the post-it notes should connect in some logical way. When each person is "happy" with the columns, ask them to return to their seats.

Next, use a prioritization matrix, such as in Figure 9 to sort out which issues are the important ones. This should be done by senior leaders in a planning session. The benefit of having senior leaders complete this process is they will become more familiar with the issues that have been collected and have a better understanding of what has been identified as important. Just make sure when you have senior leaders do this that the post-it notes are already filled out and they have had plenty of time to read over the list of threats and opportunities before the session so they are familiar with them and able to sort through them quickly. 


\section{THREAT AND OPPOR TUNITY PRIOR ITIZA TIO N}

\begin{tabular}{|c|c|}
\hline $\begin{array}{c}\text { URGENT } \\
\underline{\text { IMPORTANT }}\end{array}$ & $\frac{\text { NOT URGENT }}{\text { BUT }}$ \\
\hline$\underline{\text { UR GEN T }}$ & $\underline{\text { IMPORTANT }}$ \\
$\underline{\text { B U T }}$ & $\underline{\text { NOT URGENT }}$ \\
$\underline{\text { UN IMPORTANT }}$ & $\underline{\text { UN IMPORTANT }}$ \\
\hline 1989 stephen R.covey & \\
\hline
\end{tabular}

Figure 9. Prioritization Matrix

Senior Leaders will then need to focus on those issues which are urgent and important without ignoring the "not urgent but important issues." By consciously putting things in the bottom half (unimportant areas) it will be easier to identify them as things that shouldn't be wasting the organization's time or worries because they are not important at this time. Use Appendix I as an aide to determine a prioritization of issues that likely will have an impact on the installation. This matrix allows you to plot the probability of impact on the organization against the probability of occurrence.

However you choose to do this step, do not get bogged down in the details. This should be like dipping your big toe into the waters outside your organization just to see what the temperature is. Don't get pulled into a long and drawn out swim here, but insure leadership is aware of any policy, regulations or laws that the organization may not have fully addressed. In a nutshell: take a quick look outside and decide what things are most important. Then you will be ready to look inward (internal scan) at your own organization and plan your future. To illustrate the concept, Table 6 shows a sample external scan for security.

Table 6. Example of Security Issues

\begin{tabular}{|l|l|}
\hline \multicolumn{2}{|c|}{ The Security Environment is Changing } \\
\hline \multicolumn{1}{|c|}{ Yesterday } & \multicolumn{1}{c|}{ Tomorrow } \\
\hline Known adversaries and understood threats & $\begin{array}{l}\text { Unpredictable opponents, unknown } \\
\text { challenges }\end{array}$ \\
\hline National survival at stake & Vital interests at risk \\
\hline $\begin{array}{l}\text { Humanitarian and "lesser" operations a } \\
\text { sideline }\end{array}$ & $\begin{array}{l}\text { Multiple humanitarian and "lesser" } \\
\text { operations the norm }\end{array}$ \\
\hline $\begin{array}{l}\text { Slow spread of nuclear, biological and } \\
\text { chemical (NBC) weapons }\end{array}$ & Rapid spread of NBC weapons \\
\hline
\end{tabular}




\begin{tabular}{|l|l|}
\hline Combat oriented to open plains, deserts & $\begin{array}{l}\text { Conflict also likely in cities, jungles and } \\
\text { mountains }\end{array}$ \\
\hline Extensive forward-basing structure & Project power increasingly from the U.S. \\
\hline Information an adjunct to weapons & Information as a weapon/target \\
\hline
\end{tabular}

Note:

1) Throughout the internal scan you will have the planning team conducting numerous small group activities. You may want to ensure that individuals from similar functions are dispersed across groups to help maintain the organizational systems perspective in the small groups.

2) Brainstorming, affinity diagrams and multi-voting are used a great deal in sequence throughout the planning process. This sequence really helps to ensure that the interim products throughout the planning process reflect a true systems perspective.

\section{Internal Scan}

"We can keep busy rearranging the deck chairs on the sinking Titanic, but this ignores the obvious problem."

- Dr. Eric Allenbaugh, Wake-Up Calls

Taking time to conduct a thorough internal scan helps your organization to look not just at the data that is easiest to collect, but to focus any and all improvement efforts that really matter to the organization. In addition, the internal scan provides the opportunity for team members to become familiar with the current internal performance of the organization in preparation for gap analysis under the goal/strategy development. A well thought out internal scan will provide a systematic process of collecting and analyzing data to determine the current, historical or projected status of an organization.

\section{Internal Scan - Assess Organizational Results}

\section{How Do You Get Through This Step?}

This portion of the planning event will consist of studying organizational assessment results, organizational survey data (if available), performance against critical success factors (what the organization must excel at/do right), and organizational performance measures such as readiness reports, nuclear surety inspections, performance reports and metrics, fitness reports, quality of life and job satisfaction surveys, ACOE results, last year's strategic plan, organizational history, other inspection reports etc. The 
strategic planning team will review the current states for each of these areas, and also describe the organization's required performance in these areas.

First identify points of contact (POCs) for each of the sections identified in the Senior Leader Information Binder (SLIB). The POCs must come from the strategic planning team. It is critical that you help the strategic planning team understand that building, maintaining and updating the SLIB is their responsibility.

Break the strategic planning team into two equally sized groups. Assign one group responsibility for the organizational assessment results and performance against critical success factors. Assign the other group responsibility for organizational survey data and organizational performance measures.

As the POC for a given section, an individual will be responsible for ensuring the necessary data are collected. The actual collection of the data can be delegated. It is very important for the POCs and the entire strategic planning team to know that the quality and effectiveness of the strategic planning process is largely dependent on the quality of the pre-work - garbage in, garbage out. A good deal of time and effort must go into the pre-work to make the planning effective and efficient.

Below are the Internal Scan items to be completed and a description of how they can be completed, if the data does not exist. As you move into this step ensure there is a common understanding of the requirements and the time it will take the planning team to complete them. Some of the information sought will require the planning team to meet with stakeholders as well as require stakeholders to take time to document their organization mission and functions. Several tools have been identified that can be used to refine or explore in depth the information described in Figure 8:

- Tool 1 - Process Characterization - Customer, Output, Process, Input, Supplier (COPIS)

- Tool 2 - Current Vision, Mission and Values

- Tool 3 - Army Community of Excellence (ACOE) / Organizational Profile

- Tool 4 - Surveys

- Tool 5 - Organizational Performance Measures

- Tool 6 - Review of current Strategic Plan, Higher HQ Plans, and senior leader Interview Results

\section{Strengths and Weaknesses}

The external environmental scan consists of an assessment of the outside world in which the organization will operate over the planning horizon. The internal environmental scan consists of an organization looking inward, assessing its own strengths and weaknesses. 
Tool 1 - Process Characterization (Customer, Output, Process, Input, Supplier COPIS)

A critical sustainability concept is "systems thinking." So a critical part of the internal scan should be an effort to describe the installation system. One way to document an installation's system function is using the Customer, Output, Process, Input, Supplier (COPIS) model. An installation staff certified or familiar with Lean Six Sigma (LSS) analyses will recognize the COPIS tool since it is used in SIPOC format for LSS process assessments. Further, your installation's Organizational Profile, or Six Sigma evaluations may have COPIS information already documented for use during this step. For this effort, the planning team will seek to document the organizations, activities and functions that make up the installation system to support the mission. The level of detail of the COPIS is up to the planning team - that is, once you have the overall description, your team can spend additional time on developing detailed analyses of each system. To start, however, installations should develop a broad, high-level description using the COPIS model, Figure 10.

This step of the internal assessment process will require cross-functional representation from the organization in order to complete it. It is best to engage individuals as close to the top of the functional hierarchy as possible. Functional directors are preferred. What is needed is a big picture perspective. Also, a strategic planner will be required for this part of the pre-work along with the input gathered during the senior leader interview sessions. COPIS analysis consists of identification of key customers and stakeholders, key outputs, key processes, key inputs and key suppliers.

\begin{tabular}{|c|c|c|c|c|}
\hline CUSTOMER & OUTPUT & PROCESS & INPUT & SUPPLIER \\
\hline $\begin{array}{l}\text { Who is the } \\
\text { primary } \\
\text { customer that } \\
\text { consumes the } \\
\text { output? }\end{array}$ & $\begin{array}{l}\text { What is the } \\
\text { deliverable to } \\
\text { the customer } \\
\text { and what is the } \\
\text { standard? }\end{array}$ & $\begin{array}{l}\text { What are the } \\
\text { key processes } \\
\text { that deliver the } \\
\text { output? }\end{array}$ & $\begin{array}{l}\text { What are the } \\
\text { inputs that } \\
\text { enable the key } \\
\text { processes? }\end{array}$ & $\begin{array}{l}\text { Who are the } \\
\text { input suppliers } \\
\text { and what is the } \\
\text { standard? }\end{array}$ \\
\hline
\end{tabular}

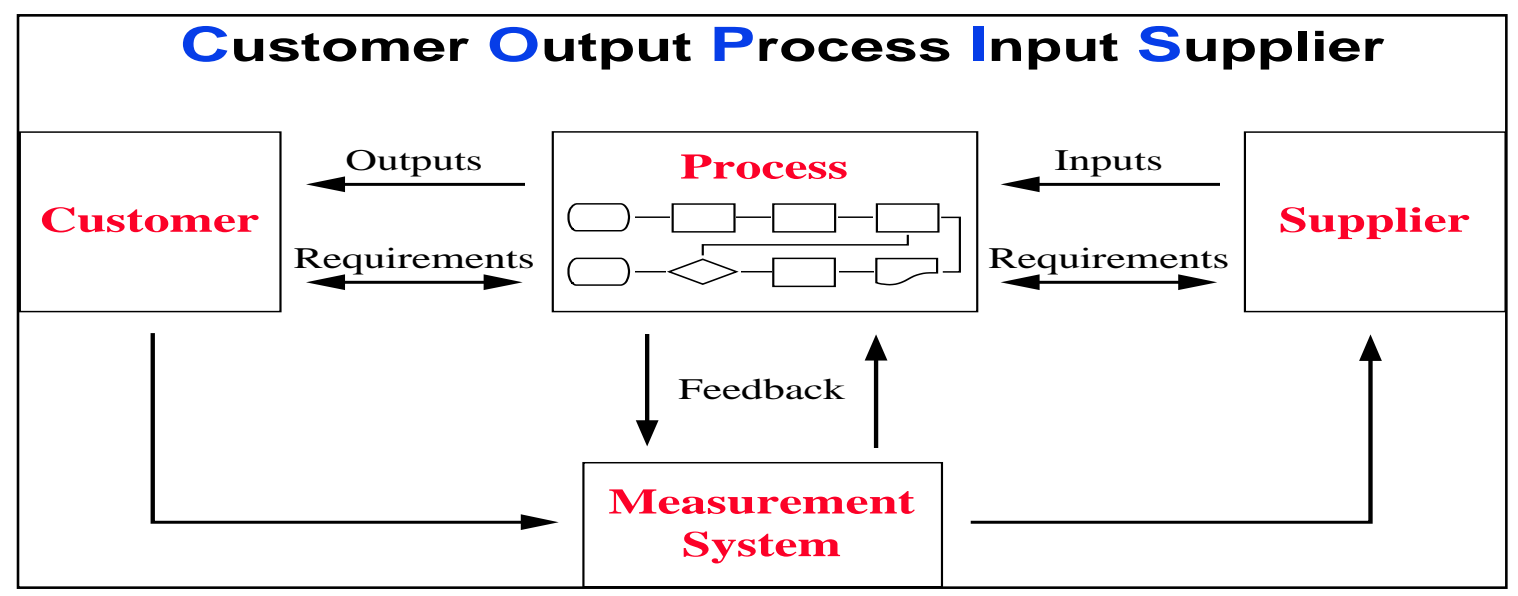

Figure 10. COPIS Model 
The level of detail of the COPIS is up to the planning team - that is, once you have the overall description, your team can spend additional time on developing detailed analyses of each system. If you choose to complete a COPIS assessment at each level of the organization, be careful when you roll up lower level COPIS assessments that you do more than just cut and paste them together. You could end up with a very long and detailed COPIS assessment for your organization that has too much information for it to use. There will be a shifting mission and customer focus as the COPIS is built at the Garrison and installation level. External customers at unit or division level may be internal customers at the Garrison or installation level (e.g., the interaction between a Brigade Combat Team S2/3 Operations Officer and the Director of Plans, Training, Mobilization and Security (DPTMS) at an installation).

When you work through the COPIS process, you should be using it to capture not only what you do now, but also what you should be doing. The COPIS is also a good tool to use as you work though the process of adding a new output or service to what you already do. The COPIS process can also help you to identify whether you have everything you need; from the right suppliers to

Note: This can be very difficult and requires some very high-level thinking. It requires a system perspective that may not have previously existed among the group members. all the measurements in place before you ever start cranking out a product or service. While past performance has shown many organizations focused solely on EXTERNAL outputs and customers for the Customer/Supplier Model, it is suggested that you draw a dividing line and prioritize your COPIS for BOTH EXTERNAL AND INTERNAL outputs. The easiest way to differentiate between the two is to decide if the output goes to people outside the organization (External) or to people inside the organization (Internal). For the purpose of this exercise, differentiate between your key and support processes as your key support process will almost always be the internal ones. Just one final tip here; you may find outputs, processes or inputs which apply to both external and internal customers. The bottom line is COPIS is your tool; adapt it to your needs. An example of a macro-level COPIS is shown in Table 7.

"It is a very hard undertaking to seek to please everybody."

- Maxim 675, Publilius Syrus 
Table 7. Example of a Macro-Level COPIS

\begin{tabular}{|c|c|c|c|c|}
\hline CUSTOMERS & OUTPUTS & PROCESSES & INPUTS & SUPPLIERS \\
\hline $\begin{array}{l}\text { Soldiers } \\
\text { Families } \\
\text { Civilians } \\
\text { Reserve } \\
\text { Nat'l Guard } \\
\text { Retirees } \\
\text { Veterans } \\
\text { Contractors } \\
\text { Other Stake- } \\
\text { holders }\end{array}$ & $\begin{array}{l}\text { - } \text { Command } \\
\text { - Support } \\
\text { - Housing } \\
\text { - Soldier \& Family } \\
\text { Support } \\
\text { - Logistics } \\
\text { - Infrastructure } \\
\text { - Support } \\
\text { - Natural } \\
\text { Infrastructure } \\
\text { Support } \\
\text { - Security } \\
\text { - Services } \\
\text { - Information } \\
\text { Technology } \\
\text { - HR } \\
\text { - Management } \\
\text { - Mission } \\
\text { - Support* } \\
\text { - Health Services } \\
\text { - Non-BASOPS }\end{array}$ & 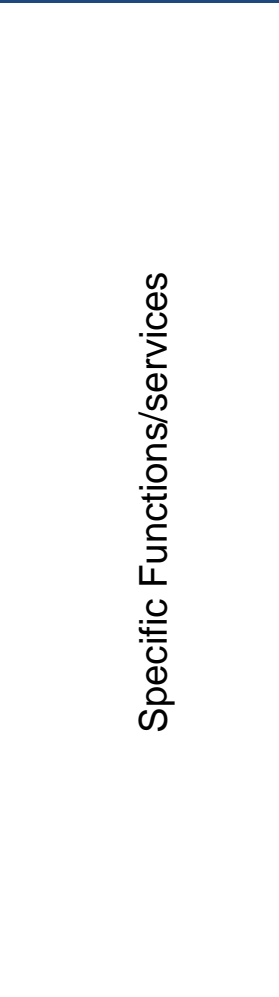 & $\begin{array}{l}\text { Infrastructure } \\
\text { Civ Pay/ } \\
\text { Manpower } \\
\text { Supplies/ } \\
\text { Equipment } \\
\text { Contracts } \\
\text { Other Funds }\end{array}$ & $\begin{array}{l}\text { Standard } \\
\text { Garrison Org } \\
\text { Contractors } \\
\text { DA/IMCOM } \\
\text { Other } \\
\text { External Orgs }\end{array}$ \\
\hline
\end{tabular}

$\underline{\text { Tool } 2 \text { - Current Vision, Mission, Values }}$

Current Values Information: Consolidate the values the organization has previously identified, as well as values from the organization's higher headquarter systems such as IMCOM and Army. Do not generate organizational values at this time if they do not already exist. Also include any recent culture or climate survey data, or data from any other source which you feel may shed light on what the organization's values are.

Current Vision/Mission Information: For this section the organization should gather any information regarding its future state. This should include current organizational vision statements, any data indicating future customers, future customer requirements, future key processes, etc.

Internal Environmental Scan: Here you are asked to follow the same process previously accomplished during the external scan in section B.2 Characterizing the Operating Environment. This time you will utilize the Internal Environment as your foundation for the assessment. Don't forget to take a serious look at the installation's surroundings, in terms of events, norms, patterns and trends that will manifest themselves within the planning horizon. The types of information to look at under the internal environment piece of the scan are more clearly articulated below. The questions under each aspect are not intended to give full coverage for the particular aspect, but are offered simply to 
serve as thought provokers and points of departure. You continue the internal scanning process by utilizing the remaining Environmental Scanning Matrix/Worksheets located in Appendix $\mathrm{H}$.

Category 5 and 6 - Leadership and Management

Category 7 and 8 - Operating Environment

Category 9 and 10 - Program and Market Analysis

\section{Critical Success Factor Analysis}

Critical success factors (CSFs) are those areas in which things must go right for the organization to excel. The CSF concept was first introduced by John F. Rockhart in the Harvard Business Review ("Chief Executives Define Their Own Data Needs," Harvard Business Review, March-April 1979, pgs. 81-93). CSFs tend to include both internal and external factors and may not be easily identifiable. CSFs pertain to any areas, customer-oriented or not, where the organization must perform well. CSFs can include other things such as the need to procure funding for continued operation, upgrading computer technology to state of the art, changing the culture of the organization from an internal focus to customer focus, etc. Identification of CSFs can be one of the trickiest yet most vital portions of the pre-work.

CSF analysis involves first identifying what the potential critical success factors for the organization are, and then evaluating the organization's performance against them. At this point, the person assigned this part of the pre-work must create a list of CSFs for the organization by answering the question, "What are the really important things that must happen for this organization to be successful?" CSFs are often industry-specific, so you may want to steer the members who are working this part toward trade journals, professional publications, and the organization's senior leaders as potential sources of information. When evaluating the organization's performance against the CSFs, the evaluation should be as factual as possible. Here, the strategic planning team will want to identify experienced organizational members with a systems perspective to accomplish the critical success factor analysis. Table 8 shows the process output.

Table 8. Critical Success Factors Process Output

\begin{tabular}{|l|l|l|}
\hline \multicolumn{3}{|c|}{ Critical Success Factors } \\
\hline $\begin{array}{l}\text { Potential Critical } \\
\text { Success Factor }\end{array}$ & $\begin{array}{l}\text { Must Address for } \\
\text { Mission } \\
\text { Excellence }\end{array}$ & $\begin{array}{l}\text { Must Address } \\
\text { for } \\
\text { Vision } \\
\text { Attainment }\end{array}$ \\
\hline Potential Critical & 10 - Definitely & $\begin{array}{l}10-\text { Definitely } \\
5-\text { Somewhat } \\
\text { Success Factor }\end{array}$ \\
& $5-$ Somewhat at all \\
& $0-$ Not at all & \\
\hline List Critical Factor \#1 & & \\
\hline
\end{tabular}




\begin{tabular}{|l|l|l|}
\hline \multicolumn{2}{|c|}{ Internal Assessment - CSF } \\
\hline Current State & Performance Gap & Future State \\
\hline $\begin{array}{l}\text { Current Performance } \\
\text { on CSF }\end{array}$ & $\begin{array}{l}\text { Required Future } \\
\text { Performance }\end{array}$ \\
\hline $\begin{array}{l}\text { List Performance } \\
\text { on CSF \#1 }\end{array}$ & \\
\hline
\end{tabular}

If the above table format is used, the pre-work team should fill out only the first two columns in the CSF Prioritization Matrix, and only the first column in the Internal Assessment table. The rest will be filled out later by the planning team.

Tool 3 - Army Community of Excellence (ACOE) Organizational Profile and Documentation

Organizational Profile:

Your Organizational Profile sets the context for the way your organization operates. A completed organizational profile documents the organization's environment, key working relationships and strategic situation - including competitive environment, strategic challenges and advantages, and performance improvement system which serve as an overarching compass for your organizational performance management system:

- Most appropriate starting point for self assessment (in preparation for strategic planning)

- Organizational environment including main products, services, culture, vision, mission, values, etc.

- Organizational relationships including structure and governance systems, customer and stakeholder groups, suppliers, etc.

- Competitive environment such as size and growth of your industry, markets served

- Strategic context includes key business, operational, and human resource challenges and advantages

- Performance improvement system

- Helps to identify potential gaps in key information and focus on key performance requirements and mission results

- Information becomes the key factor for comparison in any organization

- Provides an excellent place to begin discussions within your organization

- A non-threatening way to start because you are merely defining and describing what you do. 


\section{$\underline{\text { ACOE or other organizational assessment analysis }}$}

ACOE results provide organizations with a view of internal and external strengths and opportunities for improvement, relative to a set of established criteria, generally Malcolm Baldrige National Quality Award (MBNQA)-based criteria. Assessments tend to provide an evaluation of the organization in terms of some set of criteria which serve as a template for an "ideal" organization. In many cases, strengths and opportunities for improvement identified during the assessment are more or less important when measured against an organization's desired end-state. This part of the pre-work involves identifying major themes from the assessment so that the organization's senior leaders can begin to identify which gaps are strategically important. Don't forget to include other assessment results here: Readiness Inspections, Nuclear Surety Inspections, employee surveys, etc.

This analysis will involve creation of an affinity diagram for both organizational strengths and opportunities for improvement. The staff team will need printed in large font, the strengths and opportunities for improvement. Have the team cut out the individual strengths for all assessment categories and lay them out randomly on a table. A strategic planner should guide the individuals through creation of an affinity diagram of the organization's strengths to include naming of the grouped items. Have the team record the names of these groups, the number in each group, and also have them list the individual responses that did not group with any others. Then repeat this process for the opportunities for improvement.

When this is done for both the strengths and opportunities for improvement, place the affinity strengths and opportunities for improvement groups and the individual responses in tables like Table 9, and fill out the middle column using the 1 to 10 scale indicated. Do not fill out the last column. The strategic planning team will fill out the last column during the strategic planning event.

Table 9. Improvement Prioritization Matrix

\begin{tabular}{|l|l|l|}
\hline \multicolumn{3}{|c|}{$\begin{array}{c}\text { Opportunity for Improvement } \\
\text { Prioritization Matrix }\end{array}$} \\
\hline Criteria & $\begin{array}{l}\text { Must Address for } \\
\text { Mission Excellence }\end{array}$ & $\begin{array}{l}\text { Must Address for } \\
\text { Vision Attainment }\end{array}$ \\
\hline $\begin{array}{l}\text { Opportunity for } \\
\text { Improvement }\end{array}$ & $\begin{array}{l}10-\text { Definitely } \\
5-\text { Somewhat } \\
0-\text { Not at all }\end{array}$ & $\begin{array}{l}10-\text { Definitely } \\
5-\text { Somewhat } \\
0-\text { Not at all }\end{array}$ \\
\hline $\begin{array}{l}\text { Opportunity for } \\
\text { Improvement \# 1 }\end{array}$ & & \\
\hline $\begin{array}{l}\text { Opportunity for } \\
\text { Improvement \# 2 }\end{array}$ & & \\
\hline
\end{tabular}




\begin{tabular}{|l|l|l|}
\hline \multicolumn{3}{|c|}{ Strength Prioritization Matrix } \\
\hline Criteria & $\begin{array}{l}\text { Must Exploit for } \\
\text { Mission Excellence }\end{array}$ & $\begin{array}{l}\text { Must Exploit for } \\
\text { Vision Attainment }\end{array}$ \\
\hline Strengths & $\begin{array}{l}10-\text { Definitely } \\
5-\text { Somewhat } \\
0-\text { Not at all }\end{array}$ & $\begin{array}{l}10-\text { Definitely } \\
5-\text { Somewhat } \\
0-\text { Not at all }\end{array}$ \\
\hline Strengths \# 1 & & \\
\hline
\end{tabular}

\section{Tool 4 - Surveys}

\section{Survey data}

If the organization has completed a culture, climate or other type of survey ensure the information is incorporated during the planning process. Be sure to use only organization-wide versus functional area data. Have the members assigned this portion gather data from the recent survey(s) and create a report outlining any statistically significant findings, major themes, patterns or trends. Include the findings in prioritization matrix tables like the following Table 10.

Table 10. Survey Issue Prioritization Matrix

\begin{tabular}{|l|l|l|}
\hline \multicolumn{3}{|c|}{ Survey Issue Prioritization Matrix } \\
\hline Survey Issues & $\begin{array}{l}\text { Must Address for } \\
\text { Mission Excellence }\end{array}$ & $\begin{array}{l}\text { Must Address for } \\
\text { Vision Attainment }\end{array}$ \\
\hline Survey Issue & $\begin{array}{l}10-\text { Definitely } \\
5-\text { Somewhat } \\
0-\text { Not at all }\end{array}$ & $\begin{array}{l}10-\text { Definitely } \\
5-\text { Somewhat } \\
0-\text { Not at all }\end{array}$ \\
\hline Issue \# 1 & & \\
\hline \multicolumn{2}{|c|}{ Internal Assessment - Organizational Survey } \\
\hline Current State & Performance Gap & Future State \\
\hline $\begin{array}{l}\text { Current Performance } \\
\text { on Survey Issue }\end{array}$ & & Required Future \\
\hline $\begin{array}{l}\text { Performance on } \\
\text { Survey Issue \# 1 }\end{array}$ & & \\
\hline
\end{tabular}

If the above table format is used, the pre-work team should fill out only the first two columns in the Survey Issue Prioritization Matrix, and only the first column in the Internal Assessment table. 


\section{Tool 5 - Organizational Performance Measures}

\section{Organizational Performance Measures}

Gather and consolidate any relevant organizational performance data relating to overall organizational performance, or performance relating to key processes (organizational processes which are used to produce or deliver your key outputs) identified in the COPIS or the result from prior strategic planning activities. These data should include such things as effectiveness and efficiency measures and measures of customer satisfaction, such as ISR-S, ISR-I, CLS, and all other DoD, DA, or IMCOM mandated metrics. These data will supplement the data included in organizational assessments or external assessment reports. It is very important that this data be kept at the organizational or key process level. If the organization attempts to gather all the data available in the organization, they will create a significant amount of unnecessary work for themselves, and inundate the planning team with unnecessary data. Focus only on key measures. Use Table 11 as a format guide.

Table 11. Performance Measures Prioritization Matrix

\begin{tabular}{|l|l|l|}
\hline \multicolumn{3}{|c|}{ Performance Measures Prioritization Matrix } \\
\hline $\begin{array}{l}\text { Performance } \\
\text { Measures }\end{array}$ & $\begin{array}{l}\text { Must Address for } \\
\text { Mission Excellence }\end{array}$ & $\begin{array}{l}\text { Must Address for } \\
\text { Vision Attainment }\end{array}$ \\
\hline Performance Measure & $\begin{array}{l}\text { 10- Definitely } \\
5-\text { Somewhat } \\
0-\text { Not at all }\end{array}$ & $\begin{array}{l}10-\text { Definitely } \\
5-\text { Somewhat } \\
0-\text { Not at all }\end{array}$ \\
\hline $\begin{array}{l}\text { Performance Measure } \\
\text { \# }\end{array}$ & & \\
\hline \multicolumn{2}{|c|}{ Internal Assessment - Performance Measures } \\
\hline Current State & Performance Gap & Future State \\
\hline $\begin{array}{l}\text { Current Performance } \\
\text { on the Measure }\end{array}$ & & $\begin{array}{l}\text { Required Future } \\
\text { Performance }\end{array}$ \\
\hline $\begin{array}{l}\text { Current Performance } \\
\text { on the Measure \# 1 }\end{array}$ & & \\
\hline
\end{tabular}

If the above table format is used, the pre-work team should fill out only the first two columns in the Performance Measure Prioritization Matrix, and only the first column in the Internal Assessment table. 
Tool 6 - Review of Current Strategic Plan, Higher HQ Plan and other requirements

Current Strategic Plan: Include a copy of the organization's current strategic plan and supporting action plans, if available. Don't forget to review the Installation Priority List (IPL) recommendations of the Installation Planning Board (IPB).

Plans from higher headquarters systems: Collect mission and vision statements, goals, objectives and performance measures used by higher headquarters systems such as IMCOM, Army or other higher headquarters. It is very important to have this information available during the planning process to ensure the organization is aligned with its parent and supported organizations.

Note: It is helpful to group all higher headquarters mission statements, vision statements, etc., on the same page so that they can be looked at simultaneously for alignment.

Interview results: Include the results of the interviews conducted during the assessment of readiness phase of the planning process.

Strategic planning project plan: Include the strategic planning project plan, probably in the form of a Gantt chart so that the planning team members can reference as needed.

Organization schedule of events: If it exists, include a schedule of events for the upcoming year. The schedule should include such things as upcoming inspections, planned deployments, major personnel changes, holidays, senior leader leaves, etc. This is a very valuable reference tool during

the planning event.

Other data: The organization may have other data that they would like gathered for inclusion. If so, have the strategic planning team assign appropriate POCs and ensure the data is collected and included in the Senior Leader Strategic Planning Information Binder.

Note: Remember to take into consideration the time to reproduce copies of the Senior Leader Strategic Planning Information Binder for each member of the planning team and the strategic planner.

Set Suspense Dates: This is your last check as to who will be doing what and by when. Make sure everyone knows their assigned responsibilities in terms of pre-work, and when it is to be completed. Make sure that the information is collected and in the hands of the person assembling the Senior Leader Strategic Planning Information binders (if you chose to use one) at least two weeks before the strategic planning session 1.

The assessment of readiness and project planning session should be ended with closing comments from the GC. After the session, distribute a handout to include a list of the interview questions from the readiness phase, the analysis of the interview data 
with a complete list of orphans, and what conclusions the group drew from the data. Minutes from this meeting should also be distributed.

\section{B.3 Working Session 1 - Critical Issues and Challenges Development Session}

This session is designed to validate input from installation experts compiled in the previous steps. In the week preceding the working session, there are many details to address to ensure a smooth session (Figure 11). Appendix $C$ provides a sample letter of invitation for stakeholders internal to the installation. A sample workshop sign-in sheet is provided in Appendix M. A sample floor plan for the workshop room layout is provided in Appendix $\mathrm{N}$, and Appendix $\mathrm{P}$ provides a participant evaluation form. The following list provides additional items to consider in preparation of the working session.

- Provide the draft of the baseline as assembled and request that each stakeholder make comments and if applicable identify data to collect to fill in gaps

- Prepare table tents for participants names

- Work with facility manager to ensure the room is set up as desired (six round tables seating 6 each works best)

- Prepare sign in sheets (Name, organization, e-mail, phone)

- Print any worksheets, posters or table references (worksheets and definitions are commonly provided in the ISSP Guidebook Companion slides)

- Gather supply kits for each team (table), including markers for flip charts

- Flip charts

Working Session 1 - Significant Issues and

Duration: 4-6 hours

$$
\text { Challenges }
$$

Format: Lectures and facilitated group work

Host: Planning Lead (PAIO)

Participants:

- Garrison Commander

- Deputy Garrison Commander

- Major tenant representatives

- Garrison Directorate Chiefs

- Key Garrison program managers

Products:

- Lists of significant issues, by core business area, that threaten the sustainability of the installation

- One challenge statement per core business area that summarizes the strategic issue.

Figure 11. Working Session 1

- Easels (one per table)

- Painter's tape for posting materials on the walls

- Post it notes (4x6" works well)

- Projectors, if needed

- CDs for transferring files

- Ensure the facilitator has ready access to a printer.

- Coordinate to assure that the equipment in the room will be able to save data on a $\mathrm{CD}$, transfer the data to other groups, and access the local printer, all off-network if necessary

The session begins with background of the ISSP process, long-term goal setting and its relationship to sustainability. After initially summarizing the findings presented in the baseline session, teams are formed (one per table) based upon the core business areas 
as defined through the previous efforts. Teams will perform strengths, weaknesses, opportunities, threats (SWOT) analysis for each major activity within their core business area. Using the SWOT, teams are directed to identify critical issues that may threaten the long-term sustainability of the installation. The teams will refine their critical issues and develop a list of additional data (and decide who will provide it to PAIO) that will be needed to finalize the baseline. The teams will also work to develop challenge statements that encompass the most critical issues. These Challenge Statements constitute the scope for the Installation Strategic Planning Goal Setting session (Phase 2, step C).

Now that the scope of each goal (based upon the challenges) is clearer, the teams will be asked to identify additional stakeholders for each challenge. Stakeholders will also identify the proponent organization that should lead each goal teams and support PAIO in ensuring strong participation during the Goal Setting Session. Teams will be asked to provide a briefing to the other teams (and Command Group) to ensure all stakeholders understand the entire scope and assigned responsibilities for the planning activity.

\section{B.4 Finalize Baseline}

After this first working session, it's time to finalize the baseline. The baseline should reflect all of the work completed to date and will serve as a summary of the data available when determining measures needed to determine goal accomplishment (during Phase 3 - Action Planning). The final baseline should contain the results of the COPIS analysis, data collection and additions gathered from Working Session 1. The baseline will be used for Working Session 2 - Goal Development as described in the next section of this Guidebook. Each of these business areas targeted through the external and internal scans and related critical issues will be the focus of a goal team during Working Session 2 - Goal Setting. As such, the baseline will present relevant information, system descriptions (COPIS output), and data/trends that quantify the critical issues which threaten the sustainability of the installation. 


\section{Chapter 4: Where We Want To Be - Clear Mission, Vision, and Goals}

\section{Step C - Clear Vision}

Phase 1 , steps $A$ and $B$ is intended to prepare the installation staff for strategic planning within the context of the installation operating environment, including the community that surrounds it. The preceding steps are intended to provide the installation with an idea of the long-term challenges that it faces. In this step, installation and community stakeholders are asked to envision the optimal installation that supports the mission without consuming resources (social, natural, economic) at rates that compromise future missions. Stakeholders will be challenged to define goals and objectives that will result in achievement of the shared vision. When completed, the installation and surrounding community should have a clear vision of a sustainable installation within a thriving community.

This stage requires a great deal of creativity and encourages stakeholders to be bold in envisioning the future. Without a vision that encourages participants to stretch expectations, an installation may become mired in accomplishing the mission in inefficient, unsustainable ways. The steps within this strategic planning process are all about establishing a vision of an installation that will support current and future missions. It is about describing this vision through goals that will challenge stakeholders to embrace change to create an optimal installation. In this phase of the planning process we ask stakeholders to establish a strategic plan based on innovation and forward-thinking. This phase relies upon the following steps to establish a clear vision and strategic goals that belong to the people who support the installation operations:

\section{C.1 Establish the Installation Vision, Mission and Community Values Statements \\ C.2 Conduct Working Session 2: Goal Setting \\ C.3 Develop Strategic Plan Framework}

The Goal Setting workshop as a working session is a community event that will require significant time to prepare. The session, described below, will ask installation leaders to work with external stakeholders to define strategic goals. The results of this session will not only help leaders define the strategic vision for the installation but also build shared ownership of that vision. 


\section{C.1 Establish the Installation Vision, Mission and Community Values Statements}

Most installations have an established Garrison Mission and Vision Statement. The difference between a mission statement and a vision statement is that a mission statement focuses on an organization's present state while a vision statement focuses on an organization's future. The Values Statement provides a description of shared approach to how you accomplish your Mission and Vision. All three are closely related. Mission, Vision and Values Statement may change with new Commanders or may remain over the course of several Commanders. As part of the strategic planning process, the planning team should revisit the Installation Mission, Vision and Values Statements. These should be validated or revised prior to conducting Working Session 2: Goal-setting. Additional information and tools for developing new or revised Installation Vision, Mission and Values Statements are provided in the ISSP companion slides to this Guidebook located at http://www.us.army.mil/suite/page/608884 and in Appendix J.

\section{Vision Statement}

An installation vision statement describes the desired, long-term future state of the organization (Figure 12). The vision is what makes the strategic plan strategic. When the Apollo 7 astronauts left the Earth in their spaceship on their voyage to the moon, they didn't aim the rocket at the moon. They aimed it at the place where the moon was going to be to allow for the time needed to get there. Their example shows how crucial it is that you act in advance of the important changes which are going on outside your organization if you are to continue to succeed.

There are key elements which visioning should address. First, the organization's vision should focus everyone's attention on the future needs and desires and utilize the sufficient information documented in the baseline session. How will the installation function in the future to address the challenges identified previously? The purpose of installation strategic planning is to define change that will insure current and future mission accomplishment. It is no longer practical or advantageous to just continue to meet current mission requirements; that won't be sufficient 5, 10 or 25 years in the future. The vision element of strategic planning helps the organization to create its future.
Elements of a Useful Vision Statement

1. Effective visions are inspiring.

2. Effective visions are clear and challengingand about excellence.

3. Effective visions make sense, and by stressing flexibility and execution, stands the test of time in a turbulent world.

4. Effective visions must be constantly challenged-and changed at the margin.

5. Effective visions are beacons and controls when all else is up for grabs.

6. Effective visions are aimed at empowering our people first, customers second.

7. Effective visions prepare for the future, but honor the past.

8. Effective visions are lived in details, not broad strokes.

- Thriving On Chaos by Thomas Peters

Figure 12. Elements of a Vision Statement 
An installation vision statement should not change on an annual basis. However, leaders use a vision statement to inform their team about the direction to be taken. As such, in military organizations, where leadership rotates every two or three years, each new leader is likely to bring a new vision with them. The vision statement should be the senior leader's vision and while they should solicit input from everyone, they should approve a proposed shared vision or craft the actual statement themselves. The Vision statement is a starting point for the development of goals (see Working Session 2: GoalSetting below). As such, the Commander's vision for the installation is the initial direction, when combined with an analysis of the baseline issues that will be used to form the goals.

\section{Mission Statement}

A Mission Statement is a concise statement of the objectives of the organization (describes an organization's reason for existence). This statement crystallizes the vision and serves as a guidepost for present and future decisions about structure, power and resources. Mission Statements have two purposes. First it identifies what the overall purpose of the organization is to the members of the team. Secondly, it provides the framework for specific "action related" goals, objectives and performance plans developed later. If an activity does not directly link to the "mission" then it shouldn't be a part of the strategic plan.

For strategic planning purposes, the Mission Statement is much more concise than what may be in the organization's Regulation for Mission and Functions, though the two should be consistent.

The criteria for a Mission Statement are simple. First, organizations need to consider the makeup of their organization (Who are we). Second, in general terms, organizations need to identify the reason for their existence (What do we do?). Next, who is/are the significant customer(s) of the organization's mission output? (Who do we do it for?) Finally, how does your installation want people inside and outside the organization to view you and your mission? (How do you want to be perceived or how do you do the Mission)? You can pull all of this information from your COPIS analysis.

The Mission Statement should be concise and easily recognizable as a description of the purpose of the organization or installation. The IMCOM Mission Statement describes the purpose of the organization (Figure 13). It is recognizable as the purpose of the organization as well as all the installations within the Command. It is important that installations craft their Mission Statement in support of the Army and IMCOM Mission Statements. However, the IMCOM Mission

IMCOM Mission Statement

Mission: To provide Soldiers, Civilians and their Families with a quality of life commensurate with the quality of their service. 
Statement may not be sufficient to address the entire mission of an installation which will include the Garrison (IMCOM) function as well as Commands and tenants located at the installation.

Most organizations already have a Mission Statement and just need to ensure it is still in line with what they are doing. While a Vision Statement might change dramatically with each leadership change, a Mission Statement is much more likely to stay the same. Mission Statements may change with:

- A significant change in the mission of the installation

- An expansion or augmentation of the mission of the installation

- A change in the technical focus of the installation

In the event that the Mission Statement needs to be revised, start with the COPIS analysis results to identify a systems level perspective to assist the SC and GC as they draft a Mission Statement. This statement will be reviewed and refined during the Goal-setting session.

\section{Value Statement}

An organization's values provide an anchor in a turbulent and constantly changing environment. While values have always driven the decisions of the organization, making them explicit allows managers to be directly guided by them. Everyone in an organization needs to recognize the values that are important to the organization. They should also apply those values in their decision-making process.

Just as explorers align themselves with true north prior to embarking upon a voyage; leaders align their values

How do you know a value if you see one?

It permeates everything you do. It is the basis for decision making - consciously or unconsciously. It is the last thing you will give up.

$$
\begin{gathered}
\text { The Army values: } \\
\text { Loyalty } \\
\text { Duty } \\
\text { Respect } \\
\text { Selfless Service } \\
\text { Honor } \\
\text { Integrity } \\
\text { Personal Courage }
\end{gathered}
$$
before embarking on their installation strategic planning process. Values should be the foundation for the leader's decision-making processes. This means that a visible value system is essential. Values-based behavioral norms in the work environment will lead directly to improved productivity.

During this step you do not look at the list in Figure 14

Figure 14. Army Values and consider things like getting rid of loyalty and replacing it with something else. Look at how your organization is doing in these areas, determine if there are other important values the organization could work on improving and finally, agree on exactly what behaviors everyone will demonstrate to live up to these values. Much of the work for this step can (and should) be completed before starting the planning process. At a minimum, the Values Statement (as well as the Mission and Vision Statements) must be established before holding Working Session 2: Goal-setting. 
"The ultimate measure of a man is not where he stands in moments of comfort and convenience, but where he stands at times of challenge and controversy."

- Martin Luther King, Jr.

\section{Determine Critical Issues and Strategic Initiatives}

Once the group has listed all the major performance gaps, have them create an affinity diagram of the performance gaps to group all like items. Apply meaningful and grammatically consistent names to all data-related groups and orphan responses.

Multi-vote these groups and orphan responses from above using the following criterion, "Vote for the items which you identify as the greatest potential to move the organization toward the vision." Have the group reduce the list to the $4-5$ most critical gap groups or orphan responses. These are the critical planning issues.

Once the critical issues are identified, explain to the strategic planning team that the identified items are candidates for use in developing the organization's strategic initiatives; the basic elements of the organization's strategy for moving from the current state to the vision. Allow the group to modify the list until each member agrees that the items on the list are the things the organization absolutely must address to get where it wants to go.

Have the team, for each of the selected critical issues, draft a statement describing in broad terms what the organization must do in response to the critical issue to move from current to desired future state. Each of these statements makes up one of the organization's strategic initiatives. The summation of the strategic initiatives defines the organization's grand strategy.

\section{C.2 Conduct Working Session 2: Goal-Setting}

At this point, your installation has set the framework for its installation strategic plan. The baseline describes the challenges that the installation faces over the long-term. The Vision and Mission Statements describe the importance of the installation to the Army. The Value Statement articulates the common ground upon which all stakeholders stand - how they will operate. Together, these ISSP products provide the big picture. Now, the process turns towards documenting the goals, objectives, and actions the installation community will pursue to create change to insure the long-term ability of the installation to meet current and future needs.

Working Session 2: Goal-setting, is the next step in the ISSP process (Figure 15). Goal-setting is intended to develop long-range goals that are

Working Session 2 - Goal Setting

Duration: 20 hours over three days

Format: Lectures and facilitated group work

Host: Planning Lead (PAIO)

Participants:

- Garrison Commander

- Deputy Garrison Commander

- Major tenant representatives

- Garrison Directorate Chiefs

- Key Garrison program managers

- Community stakeholders

Products:

- Long-term Strategic Goals

- Initial supporting objectives

- Draft strategic plan

Figure 15. Working Session 2 
designed to address the critical issues facing the installation. The Goal Setting session is an opportunity to expand the number of stakeholders who will support development of and eventually own the resulting sustainability goals, objectives and action plans. The product goals of this effort should reflect the changes needed to develop a sustainable, enduring installation that can meet current and future Army missions in the context of the surrounding (and often growing) community.

This session builds upon the information developed in Phase 1, steps A and B. During the Goal-setting session, the issues and challenges identified through the SWOT analyses are explored further by a much larger group of stakeholders. Stakeholder teams (one per challenge statement) review the outcome of Working Session 1: Critical Issues and Challenges to draft initial goal statements for review by the Command staff. The Commander provides direction to the teams, who are then charged with developing final, long-term goal statements. Throughout the session, the fundamental concepts of sustainability and strategic planning are taught and integrated into the session products. See Appendix K for a SWOT analysis matrix.

\section{Preparing for Working Session 2}

In general, the Goal Setting session requires 2.5 days of time, continuing to draw on Garrison leadership at the Command and Directorate level. Allow three to four weeks between Working Sessions 1 and 2. Too soon and you won't have sufficient time to prepare. Too long and you risk losing momentum. Critical parameters in setting the session dates include:

- Garrison command staff availability for

- Day 1 Executive Session (full morning)

- Day 2 Outbrief and Wall Walk (mid-to-late afternoon)

- Day 3 Outbrief (late morning)

- Director, tenant representatives and team leader availability (all sessions)

- Suitable meeting space availability (see following discussion)

\section{Space}

Finding the right meeting space (Figure 16) has a significant impact on the efficiency of the workshop - comfortable stakeholders do better work than stakeholders who can't find their session, are too far away to see or hear the presentations, don't have sufficient elbow room or work surfaces; facilitators are more efficient when they are not struggling with insufficient walls for posting work, etc.

The actual space requirements are driven by the expected number of total attendees and the number of working teams. There must be one large room that can accommodate all of the attendees comfortably for the plenary sessions. A common layout for this room is a u-shaped rank of tables and chairs for the Command staff, directors, and honored guests (mayors, keynote speakers, etc.,) surrounded by rows of chairs for the remaining stakeholders. The large room must have sufficient $A / V$ 
capability so that all attendees can see projected PowerPoint presentations and hear the speakers. For large spaces, multiple projection screens and wireless microphones are extremely useful.

Once a suitable and available location has been identified, the ISSP POC will need to negotiate any contracts necessary to lock in the facility and the Garrison's requirements. You will need to provide the facility manager with room layouts, A/V requirements, food and beverage requirements (see discussion on Refreshments, below). You will also need to obtain maps showing the general facility location, as well as more detailed maps showing the location of the plenary session and break out rooms. Participants to the workshop include the Garrison commander, his staff, support offices, units, tenant commands and organizations that support the Garrison,

local and regional stakeholders who have vested interests in the success of the

\section{Goal Setting Requires Specialized Space}

- Sufficient space for all team members to work comfortably at a table. A u-shaped table layout allows the facilitator to work well with the team and ensures that everyone can see each other

- Projection screen

- Projector friendly layout, either with a built-in projector, or table space for the facilitator's projector

- Smooth walls that allow the team to tape or post work to the walls

- Quiet environs so team members can hear each other and not be distracted by outside noise

- Access to bathrooms, snacks, beverages

- Note the plenary room can often be used as a break out room

Figure 16. Goal Workshop Space installation.

\section{Keynote Speaker}

The purpose of the keynote speech is to provide a broader perspective on the importance and benefits of incorporating sustainability thinking into strategic planning and day-to-day operations. Past keynote speakers have included Garrison Commanders, Directors of Public Works (DPW) and ISSP POCs who have led other Garrisons through the ISSP process. Some installations have also engaged local university sustainability experts, community sustainable development advocates, private sector sustainability leaders, national and international sustainability speakers and published authors on sustainability. Participation by an external expert, especially one from the Army community, can be very helpful in providing participants with a strategic mindset as well as specific installation successes and potential pitfalls associated with goals and objectives.

\section{Team Organization}

Following the Working Session 1, the Garrison Commander should confirm availability of the team leaders from his/her staff to lead each goal team (core business activity). These teams are tasked to address one core business area and the challenges related to selected goals. The Team Lead should finalize the draft list of invitees developed during the previous session, providing the ISSP POC with a complete and final list. 


\section{Invitations}

This session should reach a wide audience, including not only those who participated in the previous workshop, but also additional subject matter expert staff for the core activities, e.g., Region and higher headquarters staff, tenants, community stakeholders and experts in sustainability. Attendance can be as many as 80 to 90 participants depending on the size and mission of the installation. Appendix $L$ offers an extensive list of participants for this working session.

The Goal Setting session invitation list is drawn primarily from recommendations developed at the conclusion of Working Session 1: Critical Issues and Challenge Statements. Table 12 provides examples of organizations that may be invited to participate.

Table 12. Working Session 2 - Participants

\begin{tabular}{|l|l|}
\hline \multicolumn{2}{|c|}{ Goal Setting Workshop Target Participants } \\
\hline Host & Garrison Commander \\
\hline Coordination & PAIO \\
\hline $\begin{array}{l}\text { Garrison Directors and } \\
\text { Special Staff Chiefs }\end{array}$ & $\begin{array}{l}\text { Public Works, Human Resources, FMWR, Logistics, DPTMS, } \\
\text { Emergency Services, Resource Management, Religious } \\
\text { Support, PAO, EEO, Safety, Internal Review, Legal Office }\end{array}$ \\
\hline Garrison Division Chiefs & $\begin{array}{l}\text { Environmental, Master Planning, Energy/Utilities Manager, } \\
\text { Engineering, Food Services, Transportation, Ranges, Army } \\
\text { Community Services, Fire Prevention and Protection, Army } \\
\text { Substance Abuse Program, etc. }\end{array}$ \\
\hline Centralized Support Offices & $\begin{array}{l}\text { IT Support, Civilian Personnel Assistance Center, Contracting, } \\
\text { etc. }\end{array}$ \\
\hline Unit and Tenant Commands & $\begin{array}{l}\text { Senior Commander representatives, military units, MEDDAC, } \\
\text { AAFES, Commissary, DoD agencies, etc. }\end{array}$ \\
\hline $\begin{array}{l}\text { Regional/National } \\
\text { Organizations that support } \\
\text { the Garrison }\end{array}$ & $\begin{array}{l}\text { IMCOM Region (Plans), USACE Districts, IMCOM AEC, USFS, } \\
\text { USFWS, DOE, BLM, etc. }\end{array}$ \\
\hline Community Stakeholders & $\begin{array}{l}\text { Community and state elected officials, Chamber of Commerce, } \\
\text { Regional Transportation Planning District, City planners, local } \\
\text { universities, regulators, and others identified during working } \\
\text { session 1 }\end{array}$ \\
\hline
\end{tabular}

Participants should be placed in teams by the PAIO to insure that all teams are crossfunctional. As such, there may be some competing demands for stakeholders from certain organizations. For example, many teams will have issues relating to infrastructure (e.g., building size and location, the quality of space and its impact on workforce productivity, energy costs). As such, DPW may need to send multiple representatives to participate in several teams. Other organizations may need to provide sufficient depth to cover multiple teams as needed. 
Most invitations to the installation community are sent by the GC. The SC may also extend invitations to Army leadership and elected officials (state and community). The invitations should be distributed three to four weeks before the workshop. Keep careful track of RSVPS, noting any teams that appear under-represented. The PAIO should plan to make personal appeals, via the phone or in person, to negative responses and non-respondents. Team Leaders should be aware of the RSVP status of their teams so that they also can make personal appeals to non-respondents. The quality of the teams' products will only be as good as the depth and breadth of the participants.

\section{Session Agenda}

The Goal Setting session requires 20 hours of working time (2.5 days). The session includes an executive briefing in the morning of the first day and two additional working days. The GC should host the executive session on the first day. The draft agenda should be distributed to the invitees with their initial invitation, or in final form as part of the reminder email the week prior to the session (see Pre-workshop Materials, below).

The nature of this session presents an opportunity for the GC to engage with their community counterparts. As such, many GCs want to provide additional information and experiences to stakeholders. Optional activities that might be included in the Goalsetting Agenda include:

- Garrison tours, highlighting existing sustainability success stories

- Community partnership tours, highlighting potential and existing projects

- Executive lunch (Day 1) including keynote speakers

- Evening reception (Day 1, furthering team building)

Such activities may result in the session taking longer than 2.5 days. It is important to protect the time allotted to the working sessions. The amount of time identified for each session has been validated over the past 10 years at 40 ISSP goal-setting sessions.

\section{Pre-workshop Materials}

One to two weeks prior to the workshop, the following materials should be distributed to the attendees as part of a "reminder" email:

- Agenda

- Directions to workshop

- Map showing breakout room locations

- Protocol for on-post access for visitors without CAC cards

- Lodging suggestions

- Pre-planning outbrief

- Baseline document, if prepared

- Pre-planning presentations slides, if desired 


\section{Visitor Access}

If the workshop occurs on post, the lead planning organization coordinates with the Installation security and gate personnel to facilitate the arrival of invited guests. Tracking down the details of this task early is important to minimizing Day 1 administrative problems, ensuring that any required data (passport or driver's license numbers, etc.) have been collected and transmitted to the proper parties, resulting in a complete access roster for all invited guests and facilitators without CAC cards.

\section{Facilitators}

Each team requires a facilitator to guide them through the ISSP work flow. The intense work environment is best supported by experienced facilitators who understand both the concepts of sustainability and strategic planning, as well as the ISSP process.

The Garrison Commander, Deputy and CSM play a critical leadership role throughout the Goal Setting workshop. By sending the invitations to the targeted stakeholders under his/her signature, the GC provides a powerful message about the value of the ISSP process to the installation's future, as well as an expression of his/her prioritization of this work. This leadership continues at the outset of the Goal Setting workshop, where the Command team leads the executive session, providing opening remarks, welcoming honored guests, giving direction, and setting expectations.

While the teams are working through the afternoon of Day 1 and during Day 2, the Command team may float among the teams, providing input and encouragement, and taking the pulse of the teams. Knowing that the Command team will be on site provides additional motivation to keep stakeholders on task and on site, and to fight the temptation to slip back to the office for other work. The Command staff is needed to receive an out brief on the initial goals mid-afternoon on the second day. The stakeholders, with the exception of the Team Leaders, are asked to vote and then are excused for the day after the out brief. The Command staff, Team Leaders, and facilitation team then conduct a Wall Walk (described in more detail below, see "Day 2") to provide direction on how to organize the many initial goals developed by the teams and finalize a stream-lined and prioritized set of long-term goals.

On the third day the Teams receive the GC's directions regarding his/her vision for the final goals. Late in the morning, the teams present their cut at the final goals in a briefing to the Garrison Command team. The Team Leaders and planning lead take note of the GC's feedback on the draft final goals so the teams can make any final adjustments to the goal statements prior to the subsequent workshop. The GC then provides his/her closing remarks and dismisses the workshop.

\section{Refreshments}

Refreshments are generally provided during the Goal Setting workshop. The stakeholders are working hard over the 2.5 days, and easy access to beverages, 
snacks, and lunches helps to keep folks on site and on task. When funds have not been available, many installations have collected money from participants for snacks and beverages. In several cases, Garrisons have also arranged for lunch orders (placed and paid for by participants) to be delivered (with orders taken in the morning during registration).

\section{Conducting the Goal-Setting Session}

In the week running up to the Goal Setting workshop, there are many details to track down to ensure a smooth work week.

- Prepare name tags that identify participant teams

- Obtain table tents for participant use (first name only)

- Work with facility manager to ensure rooms are set up (U-shape table, projector, screen or blank wall to project on to)

- Prepare sign in sheets that identify team assignments

- Print any posters, table references or session templates needed for each team

- Ensure the facilitators will have ready access to a printer

- Gather supply kits for each team, including:

o Markers for flip charts

o Flip charts

o Easels (2 per room)

o Painter's tape for posting materials on the walls

o Post It notes (4x6" works well)

o Projectors, if needed

o CDs for transferring files

\section{Day 1}

\section{Registration, coffee}

Staff a registration table to greet and sign in each stakeholder and guest as they arrive.

\section{Workshop Opening}

The PAIO opens the workshop with administrative remarks regarding the purpose and flow of the meetings. The GC then generally provides welcoming remarks, and takes some time to describe his/her expectations for the workshop's output. Then the lead facilitator describes in more detail how the sessions will run and what the stakeholders should expect to accomplish over the workshop. The ISSP Guidebook companion provides a slide set for the lead facilitator to use as a framework for Day 1, as well as the closing discussion on Day 3. Plan for breaks every hour or so. Upon reconvening, the planning lead then introduces the keynote speaker. After the keynote, the lead facilitator makes a presentation providing more details about how sustainability works in the Army. To the greatest extent possible, this presentation should provide Armyspecific examples that apply to the core business areas that are the scope of each goal 
team. The ISSP Guidebook companion also provides the Army Sustainability presentation. As part of this presentation, the lead facilitator also provides direction to the stakeholders regarding lunch and reconvening in the team breakout rooms.

\section{Goal Setting Team Sessions}

Following the facilitators' ISSP Guidebook Companion Slides (Companion Slide template located at https://www.us.army.mil/suite/page/608884), the facilitators take their teams through the first team session. Critical tasks include:

- Introductions, ice breaker, rules and roles

- Definitions, purpose, agenda review

- Review of Working Session 1 session outcomes - identification of key activities, critical issues, resultant challenge statements

- Discussion, expansion, analysis of critical issues

\section{Day 2}

Registration, coffee

Staff a registration table to greet and sign in each stakeholder and guest as they arrive.

\section{Goal Setting Team Sessions}

Continuing to follow their ISSP Guidebook companion slides, the facilitators take their teams through the Day 2 sessions. Critical tasks include:

- Re-statement of critical issues as "desired end states" (template available)

- Draft and polish initial strategic goals

- Identify proponents for the initial goals

- Prepare and practice briefing. Use prepared briefing template. Only the highlights should be briefed, keeping each team's presentation to about 8 minutes

- Print sufficient copies for Command team and presenter (if desired)

- Transfer slide file to presenter computer in plenary room

- Print and post initial goals on the wall and prepare for Wall Walk

\section{Presentation of Initial Goals to GC and Plenary}

The teams return to the plenary room for the initial goal briefing. The Team Leaders present the initial goals to the command team and assembled stakeholders. The ISSP Guidebook companion slides provide the Initial Goal Briefing template.

\section{Wall Walk}

The lead facilitator and the Garrison planner organize the initial goals on the Wall by general topic. It is quite common to find that different teams develop overlapping initial goals. This sorting process is best conducted by two, perhaps three people. After the briefings (and a break if needed) the stakeholders proceed to the wall where all of the initial goals have been posted and organized by general topic. Using the strip of dots 
provided by the facilitators, the stakeholders tag the initial goals that they believe are particularly valuable to the Garrison. A stakeholder may place as many of their dots on any particular goal statement(s) as they wish. Dots, however, cannot be split in half or given to other stakeholders. After voting, the stakeholders are adjourned for the day.

After "voting" is completed, the Command team, Planning Lead, Team Leads, facilitators and if desired, honored guests, conduct the Wall Walk. The POC or Lead Facilitator will explain the logic used to form the general groupings. The Team Leads must be available to answer any questions raised in the ensuing discussions. The GC then provides direction as to the ultimate shape of the final goals and determines which Team will continue development of each final goal. Typically, this process winnows the many dozens of initial goals down to a set of 5-8 broader goals. Generally, existing teams will be asked to work on one, and possibly two goals. Occasionally, the GC will determine that an additional team is needed to address a particular goal. The POC and Lead Facilitator then need to work after the wall walk to re-organize the Teams, stakeholders, and facilitation staff to accommodate an additional team. The Team Leaders and facilitators are responsible for tracking any questions and directions provided by the leadership and for reporting this feedback to their teams.

\section{Day 3}

\section{Registration, coffee}

Staff a registration table to greet and sign in each stakeholder and guest as they arrive.

\section{Goal Setting Team Sessions}

Continuing to follow their companion slides, the facilitators take their teams through the Day 3 sessions. Critical tasks include:

- Team Leader reports on GC direction received from Wall Walk

- The team works together to finalize their goal statement(s), generally working directly onto the final briefing slide set. If the team has several goals, they will need to work quickly to complete both in the time allotted

- Identify stakeholders for the goal who will work in the subsequent objectives development and action planning sessions

- If time allows, identify initial objectives (intermediate end-states to be accomplished while moving toward the final goal) using the template provided in the companion slides.

- Prepare, practice and polish the final presentation. Use prepared briefing template provided in the ISSP Guide Book Companion slides. Presenters should provide the final goal and any discussion highlights in less than 8 minutes

- Print sufficient copies of slide presentations for the Command team and presenter (if desired)

- Transfer slide file to presenter computer in plenary room 


\section{Presentation of Final Goals to GC and Plenary}

The teams return to the plenary room for the final goal briefing. The Team Leaders present the final goals to the command team and assembled stakeholders. Facilitators and PAIO take careful notes of any Command feedback. The GC generally offers concluding remarks in response to the briefing and progress made over the course of the workshop. The PAIO or lead facilitator then describes the "next steps" in the ISSP process (including follow-on workshop dates) where the objectives and actions supporting the final goals will be developed fully. The conference is then adjourned.

\section{Deliverables}

Shortly after the workshop conclusion, the facilitators should develop an After Action Report that summarizes results of the Goal Setting session. The products of the Goal Setting session include:

- A set of installation long-term goals that define the desired end-states for a sustainable installation

- A revised stakeholder list for each goal team who will participate in the Objective Development and Action Planning sessions (Chapter 5: How We Get There Down to Action). The stakeholder list will include a proponent organization, full members and adjunct members

- Initial objectives identified by those teams that had sufficient time to begin work on identifying the intermediate results (objectives) that the installation might accomplish on its way to meeting the long-term goal

\section{C.3 Develop Strategic Plan Framework}

Once the goal setting session is complete, it will be time to develop a framework for the installation strategic plan. This framework should include:

- An outline

- A list of the data and information to be presented for each goal

- A template for the Action Plans that will be developed during Phase 3, How We Get There of the A-G process. This template should identify the types of information that should be developed for each action identified to support objectives and goals

The planning team should also begin the process of defining how it will manage the information contained in the strategic plan. IMCOM has provided the Strategic Management System (SMS) as a tool for tracking measures and collected data. However, installations may want additional tools (databases or spreadsheets) to track and maintain action plans and supporting information. 
D Action

\section{Chapter 5: How We Get There - Down to Action}

\section{Step D - Action Planning}

After goal setting, the planning team has long-term goals, initial objectives, and a list of many actions that were identified during the development of goals. During Step D, goal teams will reconvene to refine goals, objectives, initiatives, and action plans. The teams will also establish measures and targets that will be used to accomplish and monitor the impact of action plans. The specific activities conducted during this phase include:

D1 - Finalize Objectives

D2 - Organize Objectives into a Strategy Map

D3 - Developing Performance Measures for Objectives

D4 - Set Targets for Measurements

D5 - Identify Initiatives to Execute Strategy

D6 - Create Action Plans to Support Initiatives

D7 - Implement Action Plans

D8 - Link Resources to Initiatives and Action Plans

It is essential to have and use common definitions for terms identified above when developing strategic plans. Figure 17 offers commonly used terms and definitions for strategic planning.
Goal: Installation-specific outcomes to sustain the outcomes over the long-term

Objective: Tangible, specific, measurable, attainable, results oriented and timely; end-states that contribute to the strategic goal

End - State: The set of required conditions that defines achievement of the commander's objectives.

Measure: Indicators used to gage performance.

Metric: A direct numerical measure that represents a piece of data, usually explicitly or implicitly expressing both the measure and the target together.

Target: How much or what part of the measure or metric should be accomplished within a specific time period (i.e. weekly, quarterly, yearly).

Initiative: A program consisting of many actions intended to accomplish an objective

Action Plan: a work breakdown of tasks and subtasks to accomplish an objective

Strategy Map: A visual representation of the strategic plan that depicts the relationships goals, objectives, initiatives, and action plans

Figure 17. Strategic Planning Term Definitions

\section{D.1 Finalize Objectives}

During working session 2 (Goal Setting), stakeholders will draft initial goals that are then grouped into overarching, cross-functional strategic goals that, if accomplished, will result in a more sustainable installation. During the process of creating those goals, shorter-term draft goals will be rolled up under the overarching goals. These shorterterm goals will represent initial objectives. 
To finalize objectives, the strategic planner will convene a one-day meeting with each goal team. During this meeting the goal teams will:

- Develop a full set of well-crafted mid-range objectives to achieve the strategic goals

- Develop initial lists of Actions needed to reach each objective

- Identify how the installation will progress in meeting an objective (measures)

- Develop a schedule for completing actions

- Identify the organizations and individuals responsible for completing actions

The amount of time needed to complete objectives will depend upon the amount of time spent on developing objectives during the prior Goal Setting workshop. As teams develop objectives, they will also identify initiatives that would support implementation of objectives. The person facilitating each goal-team meeting will strive to complete objectives during this initial meeting and plan to describe initiatives and action plans in subsequent sessions. This work is a departure from the big picture thinking required in the Goal Setting working session. In this remaining work, the teams are focused on breaking the long range goals into logical and more manageable pieces of work. They are asked first to identify each of the major steps (i.e., objectives) needed to accomplish the goals, and then to repeat that process for the objectives by laying out the specific initiatives needed to accomplish each of the objectives.

The teams continue to work intensely together during the objectives development workshop and subsequent action planning sessions, building the camaraderie and relationships that are needed to drive the teams through the implementation of the ISP. The facilitated workshop is designed to teach the skills needed to write the details of a useful strategic plan - what needs to be accomplished, in what time frame, with what staff, inter-directorate coordination and funding? Once the workshop is concluded, the teams will continue to meet, completing the details of their action plans and fine tuning their ideas.

\section{Scheduling}

Ideally, the objectives development session occurs four to six weeks after the Goal Setting workshop. Scheduling should take into account Command staff availability for a brief workshop kickoff (all teams), and, if desired, an out brief at the conclusion of the workshop. The amount of time needed for objectives development is dependent on:

- Number of Goal Teams

- Number of facilitators

- Amount of time spent with each team (generally 16 hours/team for Objectives and Action Planning)

- Number of key staff assigned to more than one Goal Team 
Most Garrisons find that a series of sessions can be completed in one week, particularly with two facilitators working with teams in parallel. Scheduling of the teams within this week should take into consideration any Team Leader and key staff scheduling constraints. Generally, teams are able to develop a full list of objectives and a partially developed set of initiatives in the first session (one day per goal distributed over a week).

\section{Space}

Space requirements for the Objectives Development session include:

- Plenary room for workshop kickoff (see Goal Setting space setup)

- Conference rooms for team meetings

- Number of rooms needed depending upon the number of facilitators and need for concurrent team meetings

- Each room needs to be large enough for the teams to work comfortably, and for the facilitator to project materials on a screen or wall

- Plenary room for workshop out-brief, if desired

\section{Participants and Invitations}

The targeted participants will have been identified at the conclusion of the Goal Setting workshop. The POC will work with the Team Leaders to target individuals with specific expertise and responsibility for any general entries in the invitation list. For example, during the Goal Setting workshop, a team may identify a need for expertise from a local community college without being able to identify a specific person. The POC and that team's Team Leader would work together to identify and reach out to an appropriate contact at the community college. Because the output of the Objectives and Action Planning workshop is geared toward developing short-range actions, the identification and inclusion of key expertise is particularly important, allowing the teams to function with a high level of efficiency.

The invitations for the session should be sent by the Garrison Commander to Directors, Offices and centralized support offices four weeks prior to the session. The Garrison Commander will also invite participation from tenant and non-Garrison organizations.

\section{Agenda}

The Objectives Development session requires 8-16 hours of facilitated support per goal team. The session or sessions typically direct the participants to:

- Review the goal

- Develop objectives - intermediate end states accomplished in support of the goal

- Develop targets - the incremental accomplishment of an objective (how much per year);

- Identify measures 
- Cross-walk applicable Campaign Plan directives to strategic goals

- Timeline objectives over the period covered by the goal

Teams should be scheduled to conduct the work during the same period of time to maintain momentum and insure completion in a reasonable timeframe.

\section{Pre-workshop Materials}

One to two weeks prior to the workshop, the following materials should be distributed to the attendees as part of a "reminder" email:

- Agenda

- After Action Reports (AAR) from the Goal Setting workshop

- Any other review materials from the Goal Setting workshop

- Directions to workshop

\section{Facilitators}

The Objectives Development session is designed to be run by one or two experienced facilitators. Two facilitators allow two teams to work in parallel, which generally means that the teams have more time with a facilitator and thus can complete more of the details of their action plans. Facilitators should have laptops for use during the workshops, both to run the workshop slide sets, and to capture the teams' work. Most facilitators capture the ideas generated by the teams "live", projecting the ideas and collaboratively refining the objectives and action plans.

Prior to the session, the facilitators, if not familiar with the Installation Strategic Plan, should coordinate with the installation strategic planners to determine the format and level of detail for the products of this session. The products must be compatible with the Strategic Plan to be fully integrated. In addition, the facilitators should coordinate with the installation to determine how many years the first detailed planning period will be. Most installations use either 5 years or a POM planning cycle ( 7 years - current year plus 6 years).

\section{Garrison Commander Participation}

The GC is needed to kick-off the session on Day 1 and, if desired, receive an out brief after all teams have met. Alternatively, the final out brief can be provided later as a Strategic Planning In-process Review (IPR). The Command staff can support the teams by dropping by the team sessions to observe and provide encouragement.

\section{Refreshments}

Beverage service for the kickoff session is generally provided, especially if the plenary is longer than one hour in duration. Providing beverage service for the team sessions is a helpful way to keep the teams focused and on site. If it is possible to use conference 
space near food service, easy access to lunch and snack food is helpful as well. Limited snacks in the conference rooms can also help the work day pass more quickly.

As with the prior workshops, in the week running up to the Objectives and Action Planning workshop, there are many details to address to ensure a smooth session.

- Prepare table tents for participants' names

- Work with facility manager to ensure the rooms are set up as desired

- Prepare sign in sheets (Name, organization, e-mail, phone)

- Print any worksheets, posters or table references (worksheets and definitions are commonly provided)

- Gather supply kits for each team, including markers for flip charts

- Flip charts

- Easels (one per table)

- Painter's tape for posting materials on the walls

- Post it notes (4x6" works well)

- Projectors, if needed

- CDs for transferring files

- Ensure the facilitator has ready access to a printer

\section{Day 1 Plenary Session}

The first day can include a plenary opening session, during which the GC welcomes the participants and charges them with their work challenges for the week. The facilitator provides a review of the key sustainability and strategic planning concepts covered in prior workshops, as well as an overview of the goals developed in the Goal Setting workshop. The extent of the facilitator's remarks is variable, taking into account how much time has passed since the Goal Setting workshop and the number of participants who are new to the ISSP workshops. If there is a strong community involvement component to the Garrison's goals, this plenary is a natural time to bring in outside speakers to cover any relevant community activities (e.g., economic development, green initiatives, zoning opportunities/challenges, education partnerships).

The team sessions can begin on Day 1 or Day 2, depending on how much time is allocated for each team. If there is a team with a particularly heavy work load, that team could begin work on Day 1 and continue on Day 2. The flexibility of the Objectives and Action Planning workshops allows for some variability in how the week is structured.

The facilitator will walk the teams through the following process steps:

Step 1 Tasking: Identify what major steps need to occur - what activities must be accomplished to make the Goal vision a reality

Step 2 Structure: Referring to list of definitions, organize and structure the identified activities into Objectives and Actions

Step 3 Sequence: Determine the order in which the Objectives and Actions must be accomplished to achieve the Goal 
Step 4 Measures and Targets: Define measures and yearly targets for each Objective selected for the current (5-yr) planning cycle

Step 5 Cross-walk requirements from Campaign Plans and Executive Orders to Objectives

Step 6 Timeline: Estimate how long it will take to complete an Objective and when effort will begin

These steps will results in refined objectives and some initial actions that will be further developed later in this phase.

\section{D.2 Organize Objectives into a Strategy Map}

Upon completion of the Objectives Development session, the strategic planner can compile the goals and objectives into a Strategy Map. The map should:

- Articulate how the organization creates value for its stakeholders.

- Display key priorities and relationships between outcomes (the "what") and performance drivers (the "how").

- Provide a clear view of "how I fit in" for all levels of the organization.

- Clearly map functions to the organization and can be cascaded throughout an organization, ensuring alignment.

- Mapping each of the objectives across and showing the cause-effect relationship.

- Aligning the strategy map with higher level strategy maps within the organization.

\section{D.3 Developing Performance Measures for Objectives - Getting Organized}

When the goal teams meet to finalize objectives, they will also identify measures that the strategic planning team will use to track progress in accomplishing the objective. Measuring performance means assessing results to determine how effective strategies and operations are in accomplishing the objective. By establishing measures from the beginning, the team will have information needed to determine if changes are to needed to address shortfalls and other problems. Before you start this task, you need to "get yourself organized." This section will show you how.

\section{Establish the Performance Measurement Team}

The first step in getting organized is to establish the performance measurement team. The team should be made up of:

1. People who actually do the work to be measured

2. People who are very familiar with the work to be measured.

It is important that each person understands the task before them and their role in its accomplishment. 


\section{Accountability for Measures}

Successful deployment of an integrated performance measurement system is related strongly to developing a successful system of accountability, that is, managers and members alike "buy in" to performance measurement by assuming responsibility for some part of the performance measurement process. When establishing accountabilities for the integrated performance measurement system, here are some things to remember:

- Each performance measure needs to have an owner who is responsible for that measure. Champions also may be identified for groups of measures.

- Members need to know how the measurement(s) for which they are being held accountable relates to the overall success/failure of the organization. In other words, they need to know how their performance affects the bottom line.

- Members must be given adequate resources to perform the work for which they are being held accountable.

- Members are most likely to meet or exceed performance goals when they are empowered with the authority to make decisions and solve problems related to the results for which they are accountable.

- The purpose of establishing accountability is not to play "gotcha." Rather, accountability is an expectation of the empowerment process.

- Good performance needs to be rewarded and, conversely, poor performance needs to be penalized.

\section{Integrating Performance Measures Vertically and Horizontally Vertical Integration of Performance Measures}

Vertical integration of performance measures motivates and improves operating performance by focusing all members' efforts on the organization's strategic objectives. It is initiated once the organization's strategic plan and measures are solidified. As each succeeding level of the organization reviews and makes performance measurement commitments, the developed measures must fit into the overall performance measurement framework established by the strategic agenda. Figure 18 provides a simplistic sample of how this deployment is accomplished. An actual deployment can have much more than the three levels depicted here. Full deployment of the performance measures occurs throughout the organization, all the way down to the individual staff member via the established member appraisal process. Staff members at each level should be able to identify the performance measures that provide a "lineof-sight" flow back up to the strategic measures. 


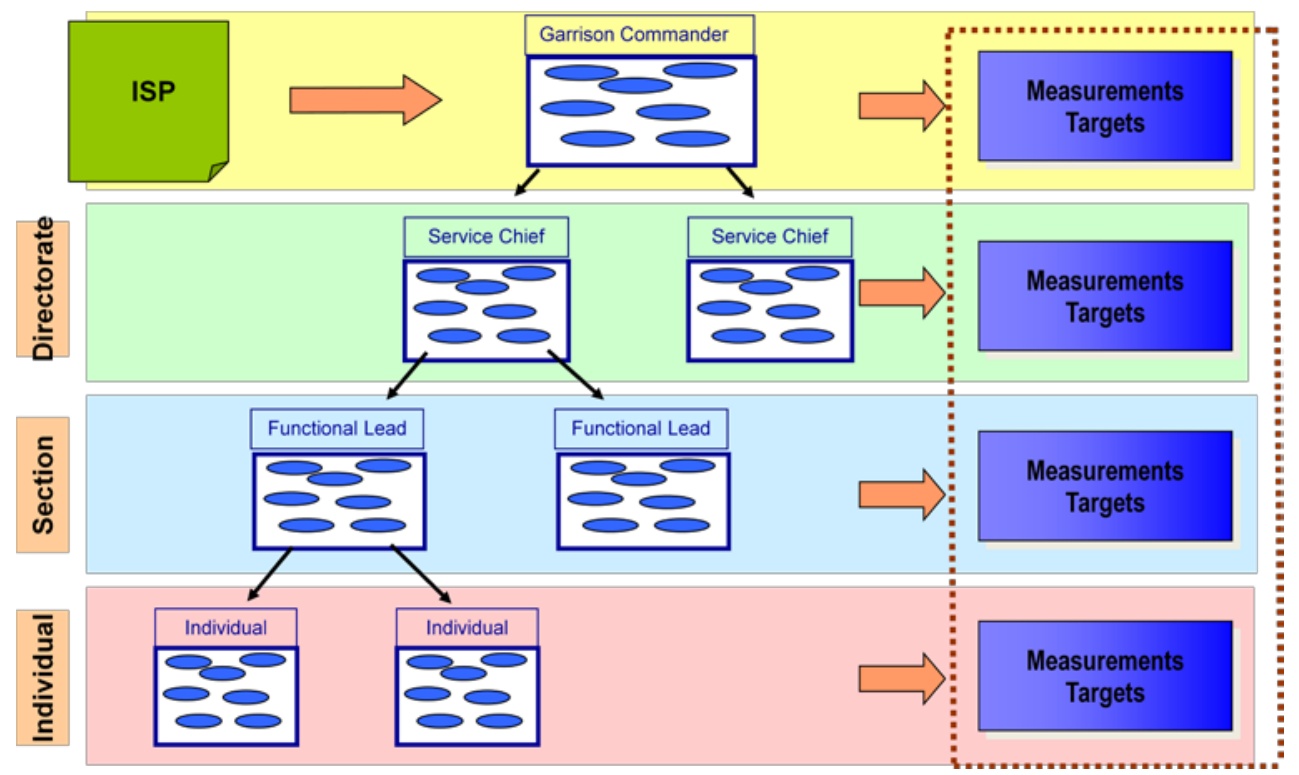

Figure 18. Example of How Different Levels of Performance Measures are Deployed at Different Level within the Organization

Characteristics of vertically integrated performance measures from the operational level on down through the organization include:

- The accomplishment time horizon is limited to the current year or current year plus one

- It should be mandatory that they align to strategic measure and goals. If a clear alignment is not possible, a cause-effect relationship can be identified by stating the objective the measure is intended to accomplish

- All measures must contain performance targets

- The use of process measures is increased, and they are integrated with results measures

- Ownership for each measure is assigned at the appropriate level of the organization.

\section{Horizontal Integration of Performance Measures}

Horizontal alignment of performance measures assures the optimization of work flow across all process and organizational boundaries. These performance measures are customer-focused and assess the system-level capability of a process to provide value from the customer's perspective. Customers do not "see" the process boundaries through which their services or products flow, but they care about the attributes of the service or product delivered to them.

An excellent example of this concept of horizontal alignment of performance measures is the procurement cycle. The procurement organization may measure cycle times to improve customer satisfaction with the procurement process. However, the procurement requester may see the cycle time for procurements as much more than the procurement organization's portion of the cycle. From the procurement requester's viewpoint, all of 
the processes, beginning with the identification of the need for a service or product to the actual delivery of the service or product, represent the complete procurement cycle. To capture the entire cycle, many units, computer services, mail room, procurement, receiving, property management and transportation, might all need to be involved.

\section{Guidelines for Teams}

When meeting as a team, consider these Guidelines for Teams:

1. Products including the performance objectives, criteria and measures, agreements, gradients and any site-specific issues must be reviewed and understood by the full team.

2. Focus on effectiveness of systems and the appropriate level of internal controls.

3. Maintain a balance between outcome (objective) and process (subjective) measures.

4. Develop measures that crosscut functional areas to better represent overall organizational performance.

5. Incorporate "Best Practices" and reflect leadership's judgment as to the key elements for overall successful operation, including cost/risk/benefit effectiveness, be certain that measures add value and improve effectiveness in support of the organizational mission.

6. Consider value-added criteria, including evaluating the cost of measuring and administering the measure, and the number of measures that can be effectively managed.

7. Performance objectives include criteria and measures that are objectively measurable and allow for meaningful trend and rate-of-change analysis where possible. Include targets or goals, upper and lower control limits, benchmark levels, or other delineators on all graphics to make them more useful to managers.

8. Each Performance measure must be measurable during the annual performance period.

9. Functional teams assign rating weights at the measure, criteria and performance objective level.

10. Functional teams should discuss the integration of operational awareness and selfassessment activities, and reporting as a part of the process.

\section{Gain an Understanding of the Jargon}

Performance measurement jargon can be very confusing, but needs to be understood and agreed to by the performance measurement team.

\section{Types of Performance Measures}

Generally, performance measures are divided into five types. These five types are:

- Input Measures - Used to understand the human and capital resources used to produce the outputs and outcomes. 
- Process Measures - Used to understand the intermediate steps in producing a service or product. In the area of training for example, a process measure could be the number of training courses completed as scheduled.

- Output Measures - Used to measure the service or product provided by the system or organization and delivered to customers. An example of a training output would the number of people trained.

- Outcome Measures - Evaluate the expected, desired, or actual result(s) to which the outputs of the activities of a service or organization have an intended effect. For example, the outcome of safety training might be improved safety performance as reflected in a reduced number of injuries and illnesses in the workforce. In some instances, such as the training example above, establishing a direct cause and effect relationship between the output of the activity and its intended outcome, can be difficult.

- Lagging Measures - Measure performance after the fact. Injury and illness measures such the Lost Workday Rate and the Total Recordable Rate are examples of lagging measures commonly used to measure environment, safety and health performance. Project cost performance is an example of a lagging indicator used to measure program performance.

- Leading Measures - Are more predictive of future performance and include measures such as near misses, procedural violations, or estimated cost based on highly correlated factors.

\section{Classifications of Performance Measures}

We have identified five classifications of performance measures. These five are listed below and described in Table 13:

- Efficiency

- Effectiveness

- Quality

- Timeliness

- Productivity

Table 13. Classification of Performance Metrics

\begin{tabular}{|l|l|l|}
\hline A Measure of . . & Measures ... & And Is Expressed as a Ratio of ... \\
\hline Efficiency & $\begin{array}{l}\text { The ability of an organization to } \\
\text { perform a task }\end{array}$ & $\begin{array}{l}\text { Actual input/planned input } \\
\text { perform a task }\end{array}$ \\
\hline $\begin{array}{l}\text { Effectiveness } \\
\text { plan }\end{array}$ & $\begin{array}{l}\text { The ability of an organization to } \\
\text { plan for output from its processes }\end{array}$ & $\begin{array}{l}\text { Actual output/planned output for } \\
\text { output from its processes }\end{array}$ \\
\hline Quality & $\begin{array}{l}\text { Whether a unit of work was done } \\
\text { Number of units produced } \\
\text { correctly/correctly }\end{array}$ & $\begin{array}{l}\text { Criteria to define total number of } \\
\text { units produced "correctness" are } \\
\text { established by the customer(s) }\end{array}$ \\
\hline
\end{tabular}




\begin{tabular}{|l|l|l|}
\hline Timeliness & $\begin{array}{l}\text { Whether a unit of work was done } \\
\text { on Number of units produced on } \\
\text { time/time }\end{array}$ & $\begin{array}{l}\text { Criteria to define "on time" are total } \\
\text { number of units produced } \\
\text { established by the customer(s) }\end{array}$ \\
\hline Productivity & $\begin{array}{l}\text { The amount of a resource used to } \\
\text { produce a unit of work }\end{array}$ & Outputs/inputs \\
\hline
\end{tabular}

\section{Consider the Considerations}

Here are some things for the measurement team to consider when developing performance measures:

- Keep the number of performance measures at each management level to a minimum. For any program, there are a large number of potential performance measures. It is important to identify a limited number, i.e., critical few, performance measures because acquiring and using information is costly. Measure what you want to have managed. Identification of critical performance measures is recommended. The more critical the individual result is to objective accomplishment, the more likely that development of a specific performance measure to evaluate the result may be appropriate. In a similar manner, if the result is not critical to accomplishing the objective, development of a separate performance measure may not be necessary.

- Develop clear and understandable objectives and performance measures. Performance measures should clarify the objective and be understandable. Experience has shown that performance measurement systems frequently fail because the respective parties do not have a common understanding regarding the purpose and concepts of the performance measurement system.

- Assure that the measure is comprehensive. Comprehensive measurement is desired, both the positive and negative effects should be measured. In developing performance measures, consider measuring positive performance as well as minimizing possible negative side-effects of the program. For example, a possible (negative) side-effect of a productivity program would be to increase the number of fatalities and injuries as safety practices are eliminated in the pursuit of greater productivity.

- Consider performing a risk evaluation. Organizations developing performance measurement systems should consider performing a risk evaluation of the organization to determine which specific processes are most critical to organizational success or which processes pose the greatest risk to successful mission accomplishments. The organization should place greater emphasis on measuring high-risk process and lesser emphasis on measuring medium to low-risk processes.

- Develop consistent performance measures that promote teamwork. Performance measures should be designed to maximize teamwork between different organizational elements. The performance measures for different levels of an organization should be generally consistent with each other from the top to the bottom and across the hierarchy. The risks of sub-optimization (pursuing a specific objective to such an extent that you sacrifice a second objective) should be determined when setting performance measures. Two examples of sub-optimization are: (1) a technical group, in its haste to complete a project, prepares an incomplete, error-filled specification which prevents the contractor from completing the project on time and results in 
increased costs and (2) a procurement group awarding a contract to an unqualified low bidder who delivers a defective product which results in both schedule delays and increased costs.

\section{Know How to Check/Test Your Performance Measures}

After you have developed your performance measures, you will need to check/test them for soundness (i.e., completeness, applicability, usefulness, etc.). Knowing how to perform these checks/tests and, thus, knowing what to look for in a performance measure, will help your team develop sound performance measures from the start. Here are several checks/tests from which to choose.

\section{The SMART Test}

The SMART test, Figure 19, is used to provide a quick reference for determining the quality of a particular performance measure:

$\mathbf{S}=$ Specific Is the measure clear and focused to avoid misinterpretation? It should include measurement assumptions and definitions, and should be easily interpreted.

$\mathbf{M}=$ Measurable Can the measure be quantified and compared to other data? It should allow for meaningful statistical analysis. Avoid "yes/no" measures except in limited cases, such as start-up or systems-in-place situations.

$A=$ Attainable Is the measure achievable, reasonable, and credible under conditions expected?

$\mathbf{R}=$ Realistic Does the measure fit into the organization's constraints? Is it cost-effective?

$\mathbf{T}=$ Timely Is measurement doable within the time frame given?

\section{The Quality Check}

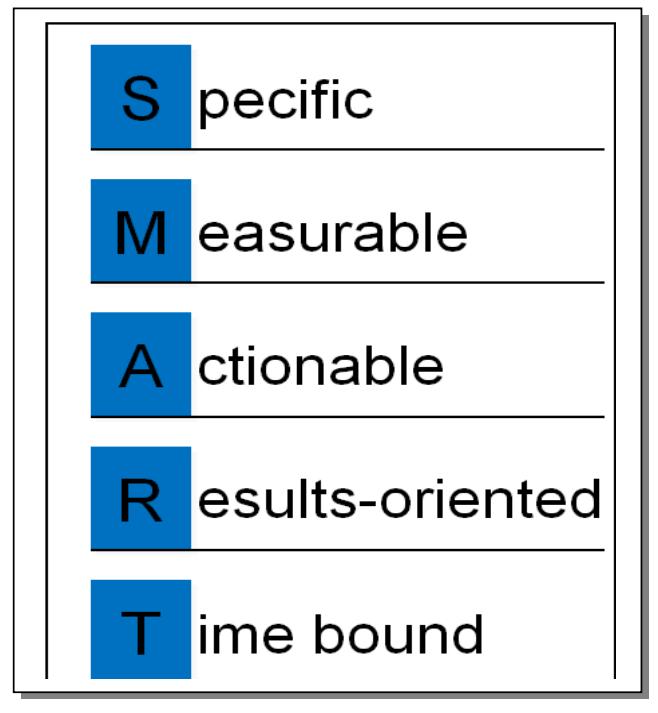

Figure 19. SMART Test

The following questions serve as a checklist to determine the quality of the performance measures that have been defined:

- Is the measurement objectively measurable?

- Does the measurement include a clear statement of the end results expected?

- Does the measure support customer requirements, including compliance issues where appropriate? (Keep in mind that in some areas compliance is performance.)

- Does the measure focus on the effectiveness and/or efficiency of the system being measured?

- Does the measure include milestones and or indicators to express qualitative criteria?

- Does the measure allow for meaningful trend or statistical analysis? 
- Have appropriate industry or other external standards been applied i.e. benchmark the measure?

- Are the measures challenging, but, at the same time, attainable?

- Are assumptions and definitions specified for what constitutes satisfactory performance?

- Have those who are responsible for the performance being measured been fully involved in the development of this measure?

- Has the measure been mutually agreed upon by you and your customers?

\section{The Three Criteria Test}

Another test to which performance measures should be subjected to include the satisfaction of three broad criteria:

1. Strategic Criteria - Do the measures enable strategic planning and then drive the deployment of the actions required to achieve objectives and strategies? Do the measures align behavior and initiatives with strategy, and focus the organization on its priorities?

2. Quantitative Criteria - Do the measures provide a clear understanding of progress toward objectives and strategy as well as the current status, rate of improvement, and probability of achievement? Do the measures identify gaps between current status and future performance; highlighting improvement opportunities?

3. Qualitative Criteria - Are the measures perceived as valuable by the organization and the people involved with the metrics?

\section{Take a Look at How Other Organizations Measure Performance}

Now that your team is organized and ready to develop its performance measures, take one last important step: look at what other organizations similar to yours have done and are doing with regard to their performance measurement system. If it's an organization within IMCOM, an informal meeting or survey may suffice to gain the information for which you are looking. If it's an external organization (e.g., private sector and/or like organization), a more formalized structure for contacting them may be necessary. The point here is to eliminate your team's "reinventing the wheel" and save you valuable time and resources (and spare you many headaches!). The odds run high that you will be able to find another organization to share useful information that your team and organization can adapt to its particular circumstances.

\section{D.4 Set Targets for Measurements}

Once measures have been finalized, work with teams to define targets for those goals and objectives where a target level of performance makes sense. For example, a net zero energy goal might include an objective to increase the purchase of renewable power by $50 \%$ over the next 10 years (See Appendix $V$ for more information on the Army Net Zero initiative. Renewable energy targets constrained by availability, future 


\section{Installation Strategic Planning Guidebook}

generation capacity and cost might suggest target increases in renewable energy purchase by $5 \% / y e a r$ for 10 years.

Establishing targets will require expertise concerning the topic. Target setting is generally an iterative, negotiated process with the leadership team. There are a number of ways to approach target setting, including:

- Deriving targets from existing regulatory and executive mandates and then expanding these to best suit local installation conditions

- Benchmarking objectives and measures against installations with similar missions and installation size

- Establishing incremental improvement based on historical performance

- Establishing a baseline of past behavior and using the positive trend to define future targets

Once established, targets must be validated with the goal team stakeholders to allow modification and adoption by the team.

\section{D.5 Identify Initiatives to Execute Strategy}

As teams develop the objectives, they will also identify initial projects and initiatives that will be needed to accomplish the objective in support of the strategic goal. At this point, teams will convene to define their path forward for the next $2-5$ years. In doing so, the teams will need to identify what activities will be needed to start and carry out the change defined by the strategic goal and component objective. The teams will be asked to develop a list of initiatives needed to accomplish objectives and targets over the next 5 years.

\section{D.6 Create Action Plans to Support Initiatives}

Each goal team will be asked to describe the efforts intended to execute each initiative in support of an objective. Each team should have a complete set of actions for all the goals. The teams should expect to continue to meet without facilitated support in the weeks following the Objective Development session. To develop action plans, teams will be asked to:

- List all actions required to accomplish the initiative

- Identify resource requirements (dollars, man-hours, source) for each initiative

- Identify (and justify) the Owner/Champion and those with appropriate supporting roles

- Develop a timeline for execution with milestones

The team should check their action plan against current requirements, schedules, and funding. It is critical to develop realistic plans that document need and expected benefit. 
For each goal, all objectives, measures, targets, initiatives and supporting action plans will become the content of the installation strategic plan. Once compiled, the plan should be staffed through the SC and GC for approval.

\section{D.7 Implement Action Plans}

The purpose of a strategic plan is to support Commanders in making decisions about the how the installation will position itself to best support current and future Army missions. The plan is the first step in developing a sustainable installation. To implement the plan, the strategic planner will need to work with the goal team leaders to support their efforts to integrate the goals and objectives of the strategic plan into their installation plans and operational plans/budgets. For example, goals and objectives related to installation infrastructure should be integrated into the installation master plan and installation design guide. If the contents of the strategic plan are not integrated into existing plans, the strategic plan will fail to promote the desired change. In addition to plan integration, the strategic planner can sponsor a variety of efforts to ensure that the strategic plan is moving forward.

The ISSP process provides goals, objectives, and actions that Garrison staff and stakeholders own and use. The approach is intended to:

- Foster improved partnerships \& improved communication between all functional areas within the command and between government and community partners

- Provide a vision and course for all installation activities to insure the long-term sustainability of the installation for current and future missions

- Identify requirements and provide a schedule for all stakeholders who have a role in timely implementation and realized results

- Provide a strong installation-level emphasis and support of individual projects and overall program objectives

- Support command emphases by highlighting and strengthening general awareness of program objectives

- Provide required oversight to ensure program requirements are completed and standards are met

- Provide an active lessons learned forum to provide feedback and guidance to program participants

- Allow program flexibility for aggressive and innovative ISSP implementation

- Develop and implement innovative and simplified administration and procedures

While the process encourages engagement as a means for building ownership of the outcome, it is imperative to distribute responsibility for accomplishment of goals and objectives to the correct proponent (i.e., infrastructure goals should be the responsibility of the DPW and subordinate components.) Further, oversight and tracking of goals should be integrated into Garrison-wide decision-making processes. Garrisons have, in some cases, developed goal oversight teams to accomplish integration. Other Garrisons have integrated the goals and objectives into existing committees and boards 
that support program implementation. Throughout the implementation process, the strategic planning team may directly support teams by:

- Supporting integration of strategic goals and objectives into existing plans

- Providing information and training on emerging technologies and approaches that have been successful at other installations

- Identifying and participating in demonstration efforts that will raise visibility in the efforts within the installation community

- Developing partnerships (with local stakeholders) that will support specific efforts

- Supporting PAO in developing outreach and describing successes

- Monitoring progress and identifying mid-course corrections

- Providing visibility of the strategic plan and successes to the Command Group

- Using the strategic plan to support transition as new Commanders arrive at the installation

Ultimately, the PAIO is the keeper of the plan for the Garrison Commander in support of the Senior Commander. The PAIO will support and monitor plan progress once the plan is established.

\section{D.8 Link Resources to Initiatives and Action Plans}

Many strategic plans do not drive the desired change because the resulting goals and objectives are not programmed into current and future budgets. The purpose of the strategic plan is to document the changes needed to ensure peak performance for current and future missions and long-term sustainability of the installation. These changes will ultimately be accomplished if, and only if, the required resources (staff and funds) are integrated into annual budgets and staffing plans. The GC, in conjunction with the SC and IMCOM, will determine priorities for staff and funding. Those activities not funded in any given year will be pushed into future years. The goal of the strategic plan is to document what is needed. Mission and resources will define the pace at which the prescribed change can be accomplished. 


\section{Step E - Evaluation}

In step D of the ISSP process, performance measures and targets were identified. In step $E$ these performance measures and targets are used to track and evaluate progress in accomplishing key initiatives and objectives and to ensure the installation is making progress toward its overall strategic goals and vision.

There are many activities performed within an installation. Performance measurement methods can be developed and used to monitor performance for any or all of these activities. Because performance information can be extensive, it is necessary to effectively and efficiently manage, analyze and present large amounts of performance information.

The Strategic Management System (SMS) is the Army's tool for managing strategic performance. SMS serves as the foundation for ensuring Army-wide strategy execution, strategy management, organizational alignment (vertical and horizontal) and data synchronization.

HQ IMCOM uses SMS to track IMCP performance and requires Garrisons to enter IMCP performance data into SMS. Each Garrison PAIO has an individual assigned the role of SMS local administrator. Local administrators assign updater, reviewer and owner roles to local users and can build SMS models to support the Installation's ISP. (Note: HQ IMCOM SMS administrators have created an Organization Node for the Garrison.)

The SMS web-based tool generates a performance rating comprised of red-amber-green color indicators for individual performance measures and metrics and for combinations of metrics at higher levels (e.g. goals, objectives, tasks) (Figure 20). All SMS users (senior leaders, directors, or action officers) have the ability to quickly view performance indicators at the goal, objective and task levels or to "drill down" to the performance metrics to see individual measures (e.g. data elements).

SMS is an excellent tool to track ISP progress, and is a best practice. Appendix R: Using the Army's Strategic Management System (SMS) to Evaluate ISP Performance contains more detailed information on building an SMS performance management model to support your ISP. Additional guidance

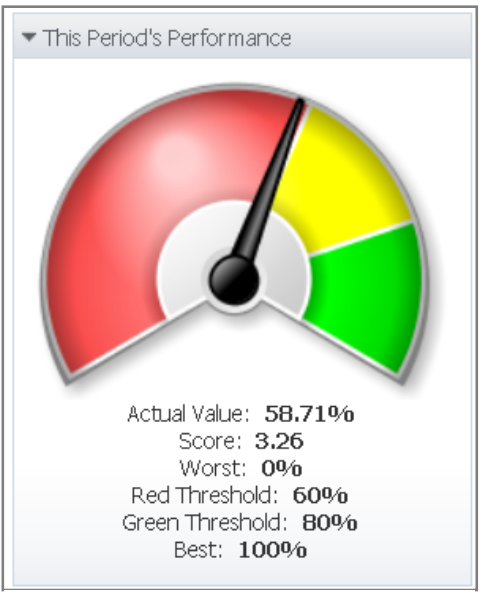

Figure 20. SMS Performance Metric for the US Army SMS is posted on Army Knowledge Online, https://www.milsuite.mil/book/community/spaces/orion/sms. 


\section{Chapter 7: How We Are Doing - Feedback and Continual Improvement}

\section{Step F - Feedback and Continual Improvement}

It is important, in the rigors of day to day work, that there is constant and immediate feedback on progress. This feedback keeps all members engaged each and every day. In addition to performance management reviews, selected performance information and data should be publicly displayed at the appropriate levels. Unit performance information may be posted where the unit conducts its work. Organizational measures should be posted more widely to ensure that all of the organization's members understand the overall progress and see a clear linkage between what they are doing and how the organization as a whole is performing.

In step $E$ of the ISSP process, data is collected and evaluated to determine the organization's progress toward achieving its goals, objectives and overall vision. In step F, this performance information is provided to process owners and operators, Directors, Garrison Leadership, Installation boards and councils, and key stakeholders and partners to enable them to adjust their processes and operations to better meet ISP targets.

The planning team, in coordination with Garrison and Installation leadership, must determine how often to review progress, and the level of detail and types of adjustments to allow at each review. The purpose of the review is to measure progress, identify performance gaps, anticipate and fix problems, reallocate time and resources, and focus the workforce.

As you enter into the Feedback Session you need to ensure that you evaluate your strategy to ensure objectives, actions, and initiatives reflect sustainability principles. Assess and adjust your ISP action plans to close the gaps with respect to supported commander mission capability gaps; add action items as necessary to the ISP; identify and add metrics as needed to track interim progress or results at the installation level. Prepare a documented gap analysis. Document a corrective action plan. Take corrective actions. Communicate gap analysis and corrective actions plan. Track progress toward achievement of the ISP actions and report as appropriate to the IPB. How you complete this cycle is a combination of the Feedback and Get Better sessions. Sections F1, F2, F3 and F4 below provide additional tools for you to consider during this process.

\section{F.1 Performance Management Review}

Performance Management Reviews (PMRs) have traditionally been the forum of choice for this type of review. Typically held monthly, quarterly or semi-annually, PMRs are usually a formal briefing by the proponents for each specific goal.

Leadership should review performance information routinely. The frequency of the reviews should be determined by the nature of the objectives being measured, the level of review, and many other factors. There may be construction projects with tight milestones and tight 
funding. There may be urgent environmental efforts underway, or, there may be other politically sensitive issues requiring frequent management reviews of progress.

Each organization must determine the frequency of its PMRs of performance information, but, generally speaking, performance data should not be allowed to deteriorate for too long before leadership responds. Prompt responses are much less expensive and may avoid crises; late remedial reactions are more expensive and usually do not avoid crises.

\section{Using Performance Information to Drive Improvement}

This section provides insights and examples for leadership and management's use of performance data to drive organizational performance improvement. It addresses the use of performance information for presentation, analysis, planning, decision-making, and motivating members.

\section{Reaction to Data}

The tone for how an organization performs will be set by how leadership reacts to performance information. When shortfalls are evident, leadership must demonstrate a commitment to the actions necessary to execute a recovery. Leadership's attention and interest in the recovery plan and in monitoring the progress towards recovery are of utmost importance.

\section{Sharing Results with Customers and Stakeholders}

End-to-end process and improvements will often cross organizational boundaries. It is incumbent on the various partners to define and monitor the metrics necessary to perform (and improve) effectively and efficiently.

\section{Using Performance Information to Identify Opportunities}

As performance information is gathered and analyzed, opportunities for improved allocation of resources will become clear. Benchmarking performance is extremely valuable for targeting initial improvement priorities. Determination of the largest gaps in performance between the organization's current level and the "best practitioner" identified makes selection of opportunities much more effective. This information is critical for selecting initial improvement targets. Once the larger gaps are closed or narrowed, continuous improvement is made possible by maintaining, refining, and using performance metrics. Other types of improvements such as continuous improvement or process improvement, benchmarking and reengineering can provide the key elements to achieving performance for driving improved results and reduced costs of operation.

\section{F.2 Army Communities of Excellence (ACOE)}

We utilize the sustainable principles into Army Communities of Excellence practices in support of ARFORGEN which enables the installations to excel in their current and future missions through the application of sustainability principles across all key enterprise business processes and reduce the enterprise's global footprint. 


\section{F.3 Installation Status Report (ISR)}

The Installation Status Report (ISR) rates installation assets and functions against Armywide standards developed by HQDA functional proponents IAW Army regulations, policy and guidance. The ISR is a decision support tool that allows leadership at all levels to assess the condition and mission capability of installation assets and evaluates the cost and quality of providing installation support services to the Army.

The ISR is comprised of two components:

Component 1: ISR Infrastructure (ISR-I) evaluates installation facility condition and adequacy and identifies improvement costs used to quantify Army backlog costs (renovate facilities to Army standard). The ISR-I provides four sets of ratings - Quality, Quantity, Mission Support Functional Capability and Commander's Readiness - which assist in estimating macro level resourcing requirements as well as prioritizing programs and projects. Infrastructure was implemented first in 1996 and is also the most mature. This maturity contributes to the reports usefulness to Army Leadership at all levels, from the installations up to the Secretary of the Army. The ISR-I supports Army level funding for all Army Installation Facilities.

Component 2: ISR Services (ISR-S) determines the quality and reports the cost of installation support functions. Performance and cost data from ISR-S are the basis upon which the Army develops Base Operations Support (BOS) funding requirements during the Program Objective Memorandum (POM) process using the BOS Requirements Model (BRM). The ISR-S directly affects the accuracy of BRM; quality input is essential to achieving accurate BRM requirements. Each component of the ISR contributes to the common understanding of an Army (Active, Reserve and Army National Guard) installation's capability to support readiness and to accomplish assigned missions. That common understanding is essential to developing, recommending and implementing policy pertaining to planning, programming, budgeting, executing, and operating Army Installations worldwide. Access to the online ISR system can be found at: http://isr.hqda.pentagon.mil/.

\section{F.4 Interactive Customer Evaluation (ICE)}

Provide installations a standardized program for capturing customer feedback and using it to continuously improve services and institutionalize Garrison Customer Management Support processes and procedures that identify performance and importance of services from leader and customer perspectives to track, understand and gauge the provision of installation services. Standardize and synchronize Garrison Interactive Customer Evaluation (ICE) organizational structure to align to Common Levels of Service CLS). 


\section{Step G - Get Better - Monitoring and Evaluating Your Strategy}

Strategic plans often fail because installations are busy with current issues and stop paying attention to the goals that they have established. Once initial changes are considered a success, an installation may see this as the time to move on to other activities. Successful implementation of a strategic plan requires constant vigilance. Over time, new mission requirements, emerging technologies and new processes and procedures may present new opportunities. To take advantage of these opportunities, the installation must pay attention and be willing to change technical direction, modifying action plans, objectives and even goals. This chapter presents an approach to monitoring and evaluation that will support long term efforts to improve the installation strategic plan. There are four steps which should be followed to accomplish the monitoring and evaluation processes.

1.) Maintenance Check \#1: ISP System Components

2.) Maintenance Check \#2: The Performance Measurement Team

3.) Maintenance Check \#3: New Legal Requirements/ Issues

4.) Maintenance Check \#4: New Developments/Technology

\section{G.1 Maintenance Check \#1: ISP System Components}

There are seven key components listed below that are integrated into your Feedback and Improvement system. These components should be checked (reevaluated) annually to look for any changes within the component that would impact the ISP. Additional items you should consider for successful development and maintenance of your ISP are contained in Appendix S.

\section{The Installation Strategic Plan}

An organization's strategic plan is its foundation, and it is the foundation for an effective performance measurement system. Here are some maintenance checks for this component:

- If the strategic plan has been revised, check the current measurement system for alignment to the revised plan and revise the system as necessary

- If the strategic plan has not been revised, check the measurement system to ensure that it remains in proper alignment with the plan

- Check linkages of division/unit/program objectives to strategic objectives

- Check the mapping of measures to the plan. Reconcile any gaps that still exist 


\section{Key Processes}

The secret to a successful integrated performance system is to clearly identify the organization's "key" processes, that is, those having the most impact on the success or failure of the organization's goals. Maintenance checks for this component are:

- Review all identified key processes to ensure that they are, in fact, "key business processes"

- Check to see whether any key business processes have been added, altered, or dropped from the organizational function. Revise the measurement system to reflect these changes

- Check the number of key processes being measured to ensure that it is at a manageable yet useful level. Make adjustments as necessary

\section{Stakeholder Needs}

Stakeholders' points of view and expectations are considered in developing strategic goals and objectives. If they have a stake in the output of the process, they should have a stake in the input to the process. Here are some maintenance checks for this component: Reevaluate stakeholder points of view and expectations for significant changes. For example, the emergence of a new program within your organization may impact your stakeholders' points of view or expectations of your organization. Or a significant change in organizational mission (e.g., from non-hazardous waste storage to hazardous waste storage) may significantly impact stakeholder point of view and expectations. Assess your stakeholder base for new individuals/groups that originally weren't included but should be included. Gain an understanding of their point of view and expectations.

\section{Senior Leadership Involvement}

Leadership commitment to the development and use of performance of the organization is a critical element in the success of the performance measurement system. When performing a maintenance check" of this component, here are things to consider:

- Reevaluate senior leadership involvement in and commitment to the system. Recommunicate this commitment throughout the organization.

- If new leadership is in place, ensure their involvement in and commitment to the system.

- Communicate their commitment throughout the organization.

- Check to see that leadership is seeking feedback on the system and using this feedback to improve the system and the organization.

\section{Team Member Involvement}

Team member involvement is one of the best ways to create a positive culture that thrives on performance measurement. Maintenance checks for this component include:

- Check to see that members are, in fact, involved in the system. 


\section{Installation Strategic Planning Guidebook}

- Reevaluate member experience and gaps in knowledge to see if additional training is needed.

- Evaluate the member base to see if its diversity has changed or its numbers have changed due to turn-over. Address these changes accordingly.

\section{Accountability for Measures}

Organizations must develop a successful system of accountability, that is, managers and members alike "buy in" to organization's performance by assuming responsibility for some part of the performance measurement process. Here are some maintenance checks for this component:

- Check to see that each measure has an owner." Reassign ownership" as necessary

- Check to see that the accountability system is communicated to and understood by all relevant parties. If it is not, take steps to ensure that it is

- Check to ensure that the accountability system is not being used to play "gotcha" Take immediate corrective actions if your check reveals incidences of "gotcha"

- Assess the use and impact of rewards and incentives

\section{Communication}

Communication is essential for establishing and maintaining the organization's performance system. It should be multidirectional, running top-down, bottom-up, and horizontally within and across the organization. Refer to section A.8, Develop and Execute a Strategic Communication Plan for assistance. When performing a "maintenance check" of this component, here are things to consider:

- Assess your organization's communication methods to ensure that they are sufficient in number and reaching the intended audience.

- Evaluate the existence and use of new methods/styles of communication.

Here is a list of questions to help you evaluate the effectiveness of the communication tasks and their results.

\begin{tabular}{|l|l|l|l|}
\hline $\begin{array}{l}\text { Questions for Evaluating the ISSP } \\
\text { Communication Plan }\end{array}$ & Yes & No & $\begin{array}{l}\text { Follow-Up Actions I } \\
\text { Responsible Person }\end{array}$ \\
\hline $\begin{array}{l}\text { 1. Are / were the leadership roles and } \\
\text { accountabilities defined for communicating } \\
\text { the ISP, and did the people assigned follow } \\
\text { through? How do you know? }\end{array}$ & & & \\
\hline $\begin{array}{l}\text { 2. Was communication about the strategic } \\
\text { planning efforts consistent and ongoing? }\end{array}$ & & & \\
\hline
\end{tabular}




\begin{tabular}{|l|l|l|l|}
$\begin{array}{l}\text { 3. Where the target audiences segmented } \\
\text { based on a particular message? }\end{array}$ & & & \\
\hline $\begin{array}{l}\text { 4. Are there different messages (one to } \\
\text { management, customers, employees, } \\
\text { stakeholders etc.)? }\end{array}$ & & & \\
\hline $\begin{array}{l}\text { 5. Were the communication methods } \\
\text { effective? Did they capture the intended } \\
\text { audience's attention? How do you know? }\end{array}$ & & & \\
\hline $\begin{array}{l}\text { 6. Did the media used meet the audiences' } \\
\text { needs? How do you know? }\end{array}$ & & & \\
\hline
\end{tabular}

\section{G.2 Maintenance Check \#2: The Performance Measurement Team}

The performance measurement team is made up of the people who actually do the work being measured and those who are very familiar with the work being measured. It is important to periodically check the following things about your team:

- Changes to the make-up of the team due to turn-over, reassignment, etc.

- "Burn-out" of team members due to stagnant, repetitive roles/responsibilities. Perhaps a rotation of assignments is in order.

- Understanding of roles/responsibilities and task by team members. All should understand them and agree to them.

\section{G.3 Maintenance Check \#3: New Legal Requirements/ Issues}

The issuance of new laws, regulations, and orders can have significant impact on an organization and its mission. For the most part, adherence to these laws, regulations, and orders is a requirement, not an option. Therefore, it is imperative that an organization "stay on top" of legal developments and incorporate their requirements into the performance management system. It also is "a must" that these requirements be communicated thoroughly to team members and stakeholders.

\section{G.4 Maintenance Check \#4: New Developments/Technology}

It will be necessary to keep abreast of and review any new developments (theories, practices, etc.) and/or technology that have emerged since the time that your ISP was instituted. When assessing these new developments / technology, consider:

- The impact (both positive and negative) the incorporation of these new developments and/or technology into your system would have on the organization and the system.

- The value-added of these new developments and/or technology.

- The cost of these new developments and/or technology. 
Installation Strategic Planning Guidebook 


\section{Chapter 9: Installation Planning Board (IPB)}

Installation Management, as you are well aware, involves many players. The ISSP process takes us to a level of Installation management where you need to be; collaborative, integrated and long-range. When crucial Garrison/installation stakeholders are not involved in the process or in the implementation of the plan and the governance of the plan - the chain of responsibility is broken.

Figure 21 provides a representation of the various boards and councils that advise or participate in the IPB to ensure all legal requirements, contributing factors or impacts are taken into account in planning objectives. This is essential to ensure all planning is done with a common understanding and in an integrated and coordinated manner. The feedback loop is to ensure the process is continually informed by results being achieved and lessons learned.

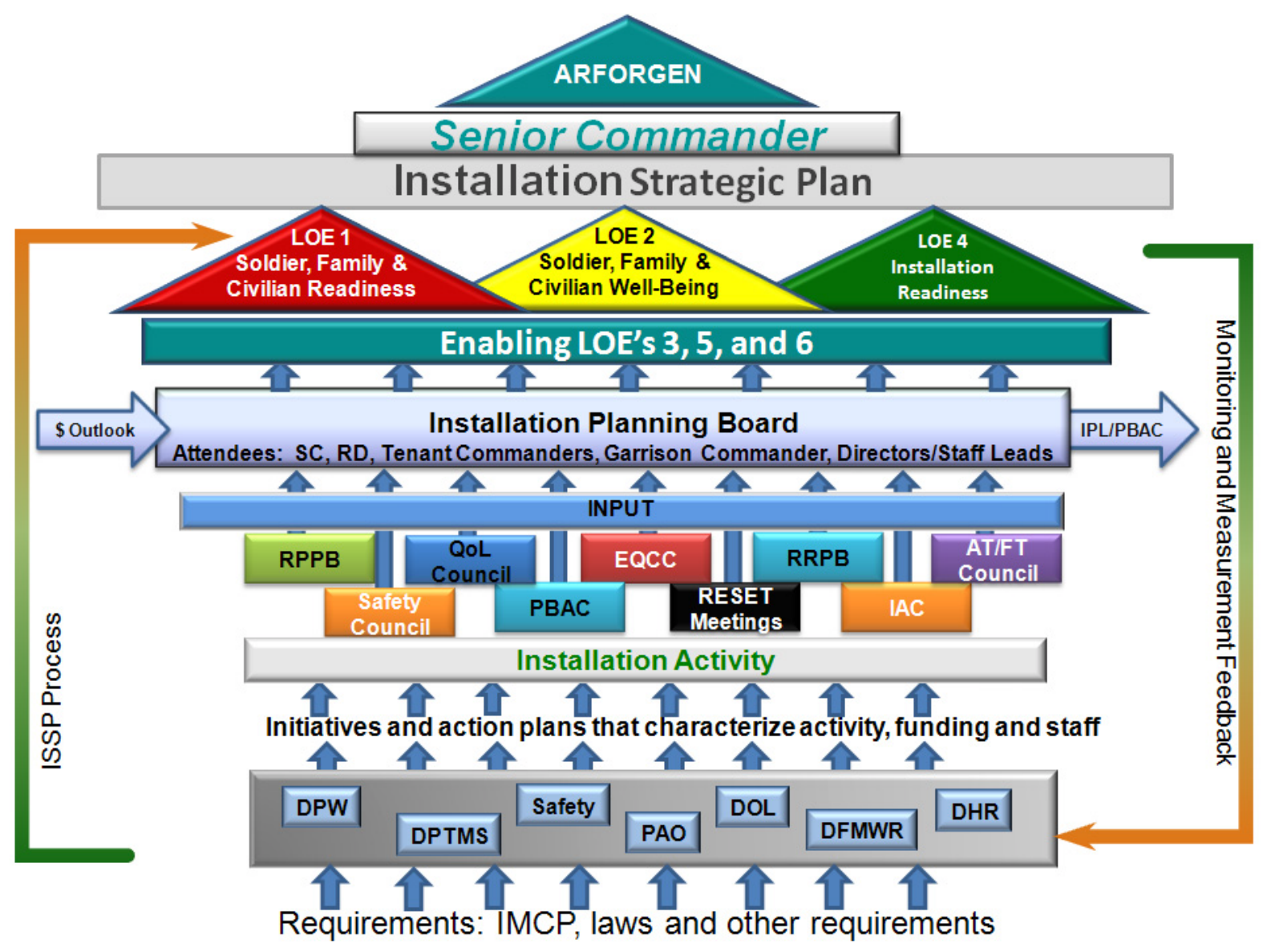

Figure 21. IPB Boards and Processes 


\section{Installation Strategic Planning Guidebook}

The various boards that feed information to the IPB process can include:

- PBAC - Program Budget Advisory Committee

- ATFP - Anti-terrorism Force Protection Council

- RPPB - Real Property Planning Board

- $\mathrm{IPL}$ - Integrated Priority List

- QOL - Quality of Life

- EQCC - Environmental Quality Control Committee

- IAC - Installation Action Council

- HPWBC - Health Promotion and Well Being Council

- RM - Resource Management

- ES - Emergency Services

\section{How to Strategically Build Sustainable IMCOM Capacity?}

The illustration, Figure 22, below links the three elements of ISSP, ISP and IPB into your planning efforts and it will not only achieve the intent Army Sustainability Campaign Plan (ASCP) Task 10-22, but will drive activity and actions geared towards creating a Sustainable Army Community of Excellence.

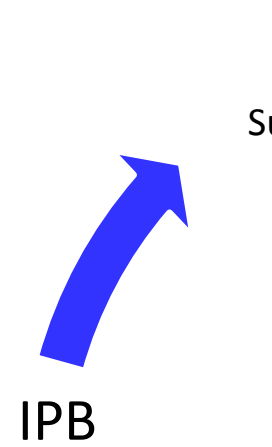

Installation Planning Board (IPB)

(Continual Improvement/ Governance)

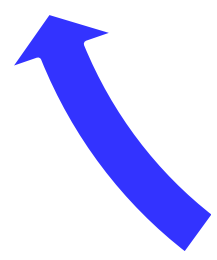

Operationalization

Integrated Strategic \&

Sustainability Planning (ISSP)

(Process)

Action Plan Implementation/Execution

(Action)

Figure 22. Linking ISSP, ISP, and IPB Together 


\section{Installation Strategic Planning Guidebook}

As you have seen in the elements of the ISSP process your organization will intentionally weave the complexities of IMCOM's principles of sustainability into the development of an ISP. During this systems thinking process, elements were brought together from the Senior Commander's Staff; Garrison Staff; Tenants; and the community (within and outside the fence line) in order to identify long-term, integrated installation-wide goals and action plans that are networked with SC priorities; the IMCP; and Installation / community specific issues and challenges. Goals identified in this process are truly strategic as they look 25 years out and are intended to transcend Command.

The ISP has become a living strategic implementation document managed by the Garrison Plans, Analysis, and Integration Office. This document guides and directs Installation-wide collaborative actions and priorities. See Appendix O: Examples of Installation Plans for a list of supporting plans to the ISP. These plans are the means by which the funded actions are implemented. As you can see from Figure 23 below, updates are to be made semi-annually in coordination with higher level planning document reviews (e.g. IMCP) and will serve as their mechanism to adjust their Installation Prioritization List in order to execute / resource requirements based on SC priorities, the IMCP, and ISP actions plans.

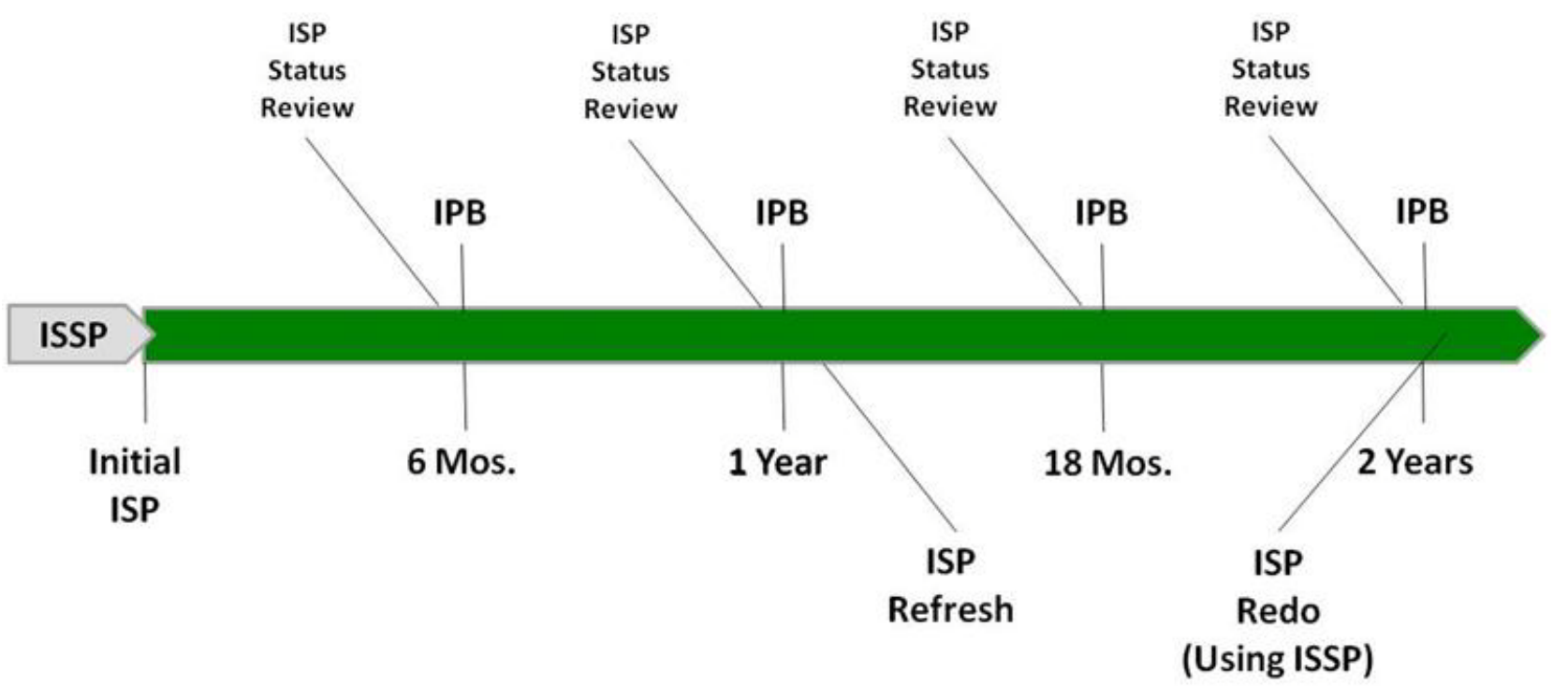

Figure 23. Strategic Planning Timeline

At this point the Installation should have integrated sustainability principles within a strategic planning document with 25 year goals. The installation should have a mature governance process and utilizes the Installation Planning Board as their mechanism to adjust their Installation Prioritization List in order to execute / resource requirements. So, what is the IPB and how does it work in the ISSP process?

Installation Planning Board (IPB) 


\section{What is it?}

Garrisons facilitate a variety of boards and planning activities which integrate regulatory, planning, and constituent informational requirements. The board and planning activities conducted at an installation create a battle rhythm which facilitates a pattern of communications and control to coordinate individual planning efforts and prioritize conflicting goals. Examples of these boards and planning activities are the Real Property Planning Board (RPPB), Antiterrorism and Force Protection Master Plan, Cultural Resources Master Plan, Energy Management Plan, Environmental Quality Control Committee, Environmental Management System, Executive Quality Council, Human Resources Master Plan, Information Technology Master Plan, Non Appropriated Fund (NAF) Capital Purchase and Minor Construction Master Plan, Range and Training Land Master Plan, and Installation Safety Council. Each of these boards and activities should produce a product that is presented to the SC and/or GC in an appropriate forum and provide feeder information to the IPB.

The semi-annual IPB, co-chaired by the SC and the RD (or equivalent), serves as the platform for identifying and providing a common operating picture of installation capabilities and tenant requirements. The IPB enhances communications and decision making, prioritizes local requirements, enhances readiness, promotes stewardship of resources and highlights issues for elevation to Army senior leaders. The IPB produces an Integrated Priority List (IPL), cosigned by the SC and RD (or equivalent), which sets or resets installation priorities and requirements. Requirements that cannot be met in the near-term are candidates to be incorporated into the Installation Strategic Plan. For Garrisons directly reporting to HQ IMCOM, the IPB will be co-chaired by the SC and the designated HQ IMCOM Deputy Commanding General (DCG) or their representative.

\section{Why is this important to the Army?}

Instituting IPBs at each Garrison integrates a wide range of Garrison programs and provides the Senior Commander and Tenant Commanders at the Region and Garrison levels with a common operating picture of installation resources and management. Garrison commanders also receive feedback regarding these programs. By informing and gaining buy-in from our stakeholders, the IPB enables a better way to manage and minimize installation resource impacts, and will make certain required un-programmed requirements or shifts in funding priorities in the year of execution are planned for and executed effectively. Roll-up of actions at the Garrison IPBs through the regions and the headquarters of IMCOM will inform the operational and strategic level of the enterprise performance architecture. The IPB is an IMCOM-lead function and, as such, will be organized, prepared and facilitated by the GC/GM or his/her Deputy and will meet semiannually.

\section{How the IPB is conducted?}


For Garrisons directly reporting to $\mathrm{HQ}$ IMCOM, the IPB will be co-chaired by the SC and the designated HQ IMCOM DCG or their representative. SC and DCG or their representative participation can be in person, via VTC, or teleconference. For Garrisons directly reporting to $\mathrm{HQ} I \mathrm{IMCOM}$, the IPL will be updated annually and codified in a memorandum signed by the SC, HQ IMCOM DCG, Tenant Commanders and the GC/GM, demonstrating their commitment towards achieving the desired results. IMCOM Deputy Commanding General (DCG) for Operations (DCG-O) and IMCOM DCG for Support (DCG-S) as the IPB co-chairs for the Direct Report Garrisons (DRGs) they oversee. 11 Garrisons from the two CONUS Regions have been designated as DRGs to IMCOM HQ effective 11 Aug 11, with one additional Garrison designated as DRG effective 1 Oct 11. These 12 Garrisons will no longer report to an RD and instead will report to the IMCOM DCG-O or DCG-S. FRAGO 02 will add the IMCOM DCG-O and DCG-S as the IPB cochairs for the DRGs they oversee. Operations Order 11-359, Installation Planning Board (IPB), 14 Jun 11 provided in Annex $X$ includes a template for memorandum will be modified to reflect the IMCOM DCG signature for Garrisons reporting directly to HQ IMCOM.

Figure 24 illustrates a macro perspective of how the frame work is used to execute the IPB. The Lines of Effort (LOE's) used in the IPB mirror the Installation Management Campaign Plan (IMCP) LOE's. The LOE's determine local planning focus from IMCOM your installation and other Higher Headquarters plans while capturing inputs to generate a 1-N list of initiatives to support the Keys to Success in the IMCP. The 1-N list is the endstate for the IPB, and includes projects ranging from energy projects to Suicide Prevention programs. The 1-N list allows the Senior Commander to make informed decisions when prioritizing the use of limited resources.

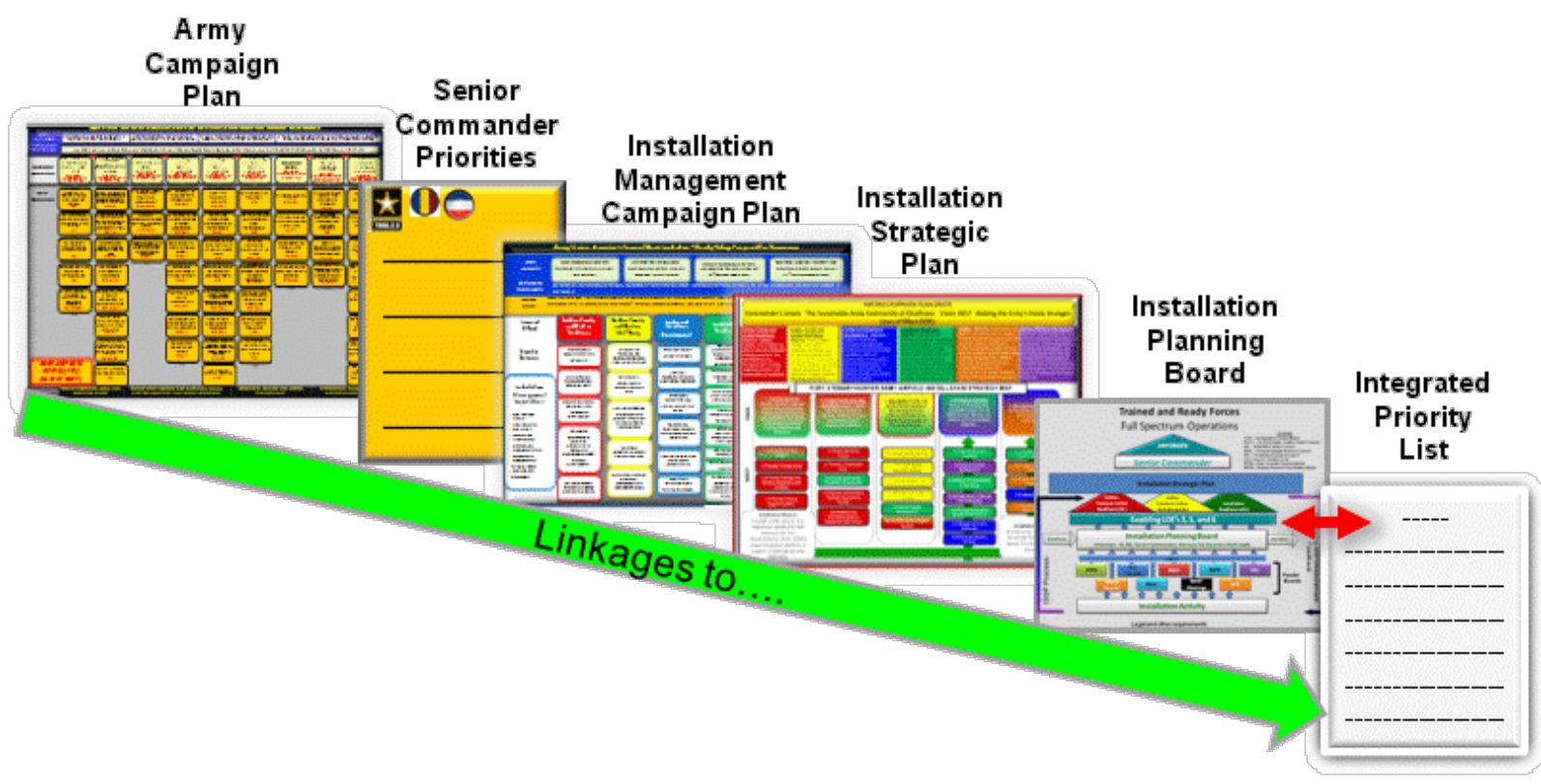

Figure 24. Installation Planning and Governance Process

The OUTPUT of the IPB is an Integrated Priority List, which informs current and future year budget requirements. The OUTCOME of IPB is to enhance Soldier, Family and 
Civilian Readiness and Well Being and Installation Readiness so that the Senior Commander can perform his/her mission and role in ARFORGEN. 


\title{
Appendix A: Sample Commander's Letter of Intent to Begin Integrated Strategic Planning
}

\author{
MEMORANDUM FOR SEE DISTRIBUTION
}

SUBJECT: Integrated Strategic and Sustainability Planning (ISSP) at Fort Courage - Working Session \#1

1. The Fort Courage ISSP process is being initiated via a four part working session series. ISSP Working Session \#1 is scheduled for [date] and will meet each day beginning at 0800 and ending at [time] at the [location]. Registration will take place and a continental breakfast will be provided in the [location] from [time] prior to each daily session.

2. The objectives of ISSP Working Session \#1 are to introduce the attendees to the concepts of the ISSP process and to identify the issues and challenges Fort Courage faces in the future. Subsequent working sessions will set collaboratively developed goals, objectives, and action plans that will guide the direction of installation decision making over the next 25 years. The team-based process of creating the baseline together is intended to build consensus among the core team members on the critical issues facing the installation. I will take the working session \#1 out-brief on [date].

3. It is important that attendees participate during the entire working session as each day builds upon the previous day, and each working session in the series builds upon the previous working session. As a key player on Fort Courage, you are required to attend and participate in the entire working session series. If you are unable to attend, designate an alternate.

4. ISP Workshop \#1 was held [date], at which attendees were introduced to the concepts of sustainability and the strategic planning process. [Example sentence given here] Five core teams and proponents were identified that are focusing on specific installation activities and their associated significant impacts on the training mission, surrounding community and supporting environment. These teams include: 1) Mission; 2) Transportation; 3) Procurement; 4) Infrastructure and 5) Regional Development.

5. Please RSVP NLT [date] to assist with planning efforts and tracking of attendance. To RSVP and for additional information, contact [POC name, email and phone number]

6. Subsequent ISSP Working Sessions are anticipated in the [month and year] timeframe.

Encl

Fort Courage ISSP Working Session \#1 Agenda

DISTRIBUTION:
COL [name]

GARRISON COMMANDER 


\title{
Appendix B: Invite Letter to Stakeholders
}

\author{
DEPARTMENT OF THE ARMY \\ Fort Courage \\ [address]
}

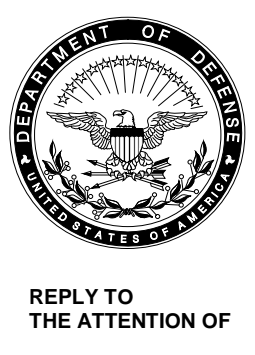

Office of the Commanding General

Dear

Camp Courage will host an Integrated Strategic and Sustainability Planning (ISSP) Working Session \#1 [date], at the [location]. The working session will bring together stakeholders from the Army, environmental regulatory agencies, the community, and other agencies with shared interests to form a consensus on the Camp Courage 25-year strategic goals. In a facilitated setting, the outcome of this working session is to introduce the attendees to the concepts of the ISSP process and to identify the issues and challenges Fort George G. Meade faces in the future. Subsequent working sessions will set collaboratively developed goals, objectives, and action plans that will guide the direction of installation decision making over the next 25 years. The long-range goals will form the basis for the Camp Courage Strategic Plan.

I invite you to attend the executive session on [date]. If appropriate, please provide a representative for the issues and challenges sessions that will occur during the remaining three days (more than one representative may be appropriate for some agencies). Where pertinent, we have provided for your consideration as possible attendees the names of the persons from your agency who are the Camp Courage key points of contact (see enclosure).

We consider the working session essential to preparing an Installation Strategic Plan that effectively addresses sustainability issues which transcend our installation boundaries and which have regional or national interest. The Camp Courage long range goals that address these issues must be established with input from our stakeholders.

The enclosed agenda provides further details about the ISSP Working Session \#1. If you intend to participate or have questions about the event, please call or email [name] at [number], (email) by [date]. Directions to the workshop room and other information will be provided to attendees prior to the workshop date. I hope to see you there.

Sincerely,

[name]

Major General, US Army

Commanding 


\title{
Appendix C: Invite Letter Internal to Installation
}

\author{
DEPARTMENT OF THE ARMY \\ Fort Courage \\ [address]
}

Office of the Garrison Commander

Dear

You are invited to attend the Executive Session of the Fort Courage Integrated Strategic and Sustainability (ISSP) Working Session \#1. The purpose of this working session is to bring together stakeholders from Fort Courage, the Army, and other agencies, and the community to introduce the attendees to the concepts of the ISSP process and to identify the issues and challenges Fort Courage faces in the future. Subsequent working sessions will set collaboratively developed goals, objectives, and action plans that will guide the direction of installation decision making over the next 25 years. The long-range goals will form the basis for the Fort Courage Strategic Plan to form a consensus on Fort Courage's 25-year strategic sustainability goals.

It is imperative that the installation's long-term sustainability goals are consistent with shared responsibilities between installations and surrounding communities. You are invited to join Fort Courage in this endeavor.

The working session will be held at the [place]. The Executive Session will be held [date], from 8:30 a.m. until approximately 11:45 a.m. The Stakeholders Session will begin at [time] p.m., [date] and continue until [time] p.m., [date]. You are also welcome to attend the stakeholders session if you wish to do so. A draft agenda is enclosed

The Fort Courage community hopes you will be able to attend this important event. Please let us know if you can attend by electronic mail or telephone response to [name], [phone number], [email], no later than [date]. My workshop staff will provide confirmed attendees with visitor access instructions for Fort Courage, directions, and other information.

Sincerely,

[name]

Colonel, U. S. Army

Commanding 


\title{
Appendix D: Sample Strategic Planning Training Course Agenda
}

\author{
Integrated Strategic Planning Basic course
}

Description:

Strategic Planning course provides an introduction to the principles and practices of strategic planning. Conducted interactively, it leads participants in the step-by-step creation of a strategic plan. Designed to provide a framework for planning, the course is valuable to both those involved in developing strategy and those called upon to deploy strategy in action. The principles presented are applicable at a variety of levels in the organization.

Course Length: 2 days

Learning Outcomes:

Affective Objectives

Participants will value the importance of strategy in the workplace as reflecting environment, service requirements, and effective alignment

Participants will value the contributions of strategic planning in structuring their own work.

Participants will feel greater confidence in responding to strategic initiatives.

Cognitive Objectives

Participants will understand principles of effective strategic thinking and planning.

Participants will understand strategic lifecycles in organizations.

Participants will understand the steps in building, communicating and evaluating results of a strategic plan.

Participants will understand the relationships of strategic and action planning to their own workplace.

Behavioral Objectives:

Participants will be able to participate in strategic and action planning processes, employing recognized tools and techniques.

Course Content

1. What is Strategy?

2. Defining Mission and Vision for Strategy.

3. Understanding Customer and Stakeholder Requirements

4. Understanding the Environment and Technology

5. Assessing Strategic Capabilities (SWOT analysis)

6. Assessing Strategic Risks

7. Developing Strategic Measures (Balanced Scorecards and Other Strategic Measures)

8. Planning and Empowering Strategic Action (Linking Strategy and Action Planning)

9. Communicating, Supporting and Measuring Strategic Action (Includes integrating Planning with action initiatives such as Six Sigma)

10. Cycles of Planning and Tracking Long Term Results 


\section{Appendix E: Recommended Strategic Planning Professional Reading List}

The list identifies several books on strategic planning for professional reading. Some are textbooks used in graduate and undergraduate level courses; others are books available in book stores and on-line. Many of these books are also available in your local library. The list is not in priority or ranked order, but is only a composite list of good sources of information related to strategy and strategic planning. Please let us know if you have a strategic planning/management book that you would like to add to the Professional Reading List.

1. Plan or Die!: 10 Keys to Organizational Success by Timothy N. Nolan, Leonard D. Goodstein, William Pfeiffer

2. The Strategy-Focused Organization by Robert S. Kaplan and David P. Norton, Harvard Business School Publishing, 2001

3. Team-Based Strategic Planning - A Complete Guide to Structuring, Facilitating, and Implementing the Process by C. Davis Fogg, AMACOM American Management Association Books, 1994

4. Competitive Strategies: Techniques for Analyzing Industries and Competitors by Michael E. Porter, New York: Free Press, 1980

5. Strategy Pure \& Simple: How Winning CEOs Outthink Their Competition by Michel Robert, McGraw-Hill, 1993

6. Real Time Strategic Change by Robert W. Jacobs, Berrett-Koehler Publishing, 1994

7. Strategy Safari - A Guided Tour Through the Wilds of Strategic Management by Henry Mintzberg, Bruce Ahlstrand, and Joseph Lampel, Free Press 2005.

8. U. S. Department of Energy, Guidelines for Performance Measurement (DOE G 120.1-5), 1996. Available at: http://www.orau.gov/pbm/documents/documents.html.

9. U. S. Department of Energy, Office of Environmental Management (DOE/EM), Office of Environmental Management Critical Few Performance MeasuresDefinitions and Methodology, 1996. Available at: http://www2.em.doe.gov/crosscut.

10. U. S. Department of Energy, Office of Procurement and Assistance Management (DOE/PR), Balanced Scorecard Homepage. Available at:

http://www1.pr.doe.gov/bsc001.htm

11. Essential Challenges of Strategic Management by Dr. William B. Rouse, John Wiley \& Sons, Inc, Wiley-Interscience Publications, 2001 


\section{Installation Strategic Planning Guidebook}

12. Strategic Management and Business Policy by Thomas L. Wheelen and J. David Hunger, Eighth Edition, Prentice Hall, 2002

13. Levers of Control: How Managers Use Innovation Control Systems to Drive Strategic Renewal by Robert Simons, 1995

14. The Strategy Process by H. Mintzberg, J.B.Quinn, and R.M. James, Prentice-Hall, 1988

15. The Way of Strategy by William A. Levinson, ASQC Quality Press, 1994

16. Strategies for Change: Logical Incrementalism by J. B. Quinn, Homewood-Irwin, 1980

17. American Productivity and Quality Center (APQC), Corporate Performance Measures, International Benchmarking Clearinghouse Performance Measures Study, 1996.

18. Linking Performance Measurement to Strategy, Journal of Strategic Performance Measurement by, Atkinson, Anthony, 1997.

19. Baldridge Award Winning Quality: How to Interpret the Malcolm Baldridge Award Criteria. Ninth Edition, Brown, Mark Graham, ASQ Quality Press, 2011.

20. Keeping Score-Using the Right Metrics for World Class Performance, Brown, Mark Graham, Quality Resources, 1996.

21. The Balanced Scorecard, Kaplan, Robert and David Norton, Harvard Business School Press, 1996.

22. National Partnership for Reinventing Government, Balancing Measures: Best Practices in Performance Management, 1999. Available at: http://www.orau.gov/pbm/documents/documents.html.

23. Office of the Auditor General of Canada and the Commissioner of the Environment and Sustainable Development, Developing Performance Measures for Sustainable Development Strategies, 2010. Available at: http://www.oagbvg.gc.ca/domino/cesd_cedd.nsf/html/pmwork_e.html.

24. The Complete Guide to Systems Thinking and Learning, Stephen G. Haines, HRD Press 2000

25. Redesigning the Future: A Systems Approach to Societal Problems. Ackoff, R. (1974). NY: John Wiley \& Sons, Inc

26. The Learning Alliance: Systems Thinking in Human Resource Development. Brinkerhoff, R. O. \& Gill, S. J. (1994). San Francisco: Jossey-Bass Publishers 27. The 7 Habits of Highly Effective People Covey, S. (1989). NY: Simon \& Schuster 


\section{Installation Strategic Planning Guidebook}

28. Systems Theory for Organization Development. Cummings, T. G. (1980). NY: John Wiley \& Sons

29. Horizontal Management Beyond Total Customer Satisfaction. Denton, D. K. (1991). NY: Lexington Books

30. Goldratt's Theory of Constraints. Dettmer, H. W. (1996). Milwaukee, WI: ASQC Quality Press

31. How Organizations Learn. Dibella, A. J. (1998). San Francisco: Jossey-Bass Publishers

32. Managing in a Time of Great Change. Drucker, P. (1995). NY: Dutton

33. Organizing for the Future: The New Logic for Managing Complex Organizations. Galbraith, J. R. (1993). San Francisco: Jossey-Bass Publishers

34. Seeing Systems: Unlocking the Mysteries of Organizational Life. Oshry, B. (1995). San Francisco: Berrett-Koehler Publishers

35. Thriving on Chaos. Peters, T. (1987). NY: Knopf

36. Shaping Strategic Planning: Frogs, Dragons, Bees and Turkey Tails. Pfeiffer, J. W., Goodstein, L. D. \& Nolan, T. M. (1989). San Diego, CA: Pfeiffer \& Company

37. Order Out of Chaos. Prigogine, I. \& Stengers, I. (1984). NY: Bantam Books

38. Quinn, D. (1992). Ishmael. NY: A Bantan and Turner Book

39. Intelligent Enterprise: A Knowledge and Service Based Paradigm for Industry. Quinn, J. B. (1992). NY: The Free Press

40. The Dynamics of Organizational Levels: A Change Framework for Managers and Consultants. Rashford, N. S. \& Coghlan, D. (1994). Menlo Park, CA: AddisonWesley Publishing Company

41. The Fifth Discipline: The Art and Practice of the Learning Organization. Senge, $P$. (1990). NY: Doubleday/Currency 


\section{Appendix F: Sample ISSP Leadership Interview Questions}

Sample Questions for Senior Leader Data Gathering Interviews

1. What key challenges does the organization face in the future?

2. The ISP process requires the development of long-term (25-year) strategic sustainability goals and subordinate mid- and short-term objectives to ensure the Installation is available and capable of providing for future missions. What obstacles, if any, do you see arising for the planning team(s)

3. What global issues will affect the organization's future?

4. What is your major concern about the organization's future and its ability to overcome that concern?

5. What do you think are the key competencies today?

6. How do those competencies need to change for the future of our organization?

7. What do you think the mission statement should reflect?

8. Do you think the current mission statement paints the right picture?

9. What major business strategies will require technological support?

10. What constraints do you see in getting the organization from where it is to where it needs to be in the future?

11. What risks does our organization face in the future?

12. What metrics do you think are important to measure the strategy's success in preparation for the future?

13. Are there other organizations from which we should gather information; if so, what types of information would be beneficial in building our strategy?

14. What do you think is important for the organization to consider regarding the development of the strategy?

15. Who are this installation's important customers today? Review ACOE, Org Profile for information. Are we missing anyone?

16. What are installation's key products and services? Review/update ACOE, Org Profile for information. Are we missing anything? 


\section{Appendix G: ISSP Leadership Interview Data Analysis Process}

Interview Data Feedback/Project Planning Meeting Agenda

1. Objectives: To determine organizational readiness for Installation Strategic and Sustainability planning (ISSP), highlight similarities and differences between team member perceptions, determine the planning horizon, and create the project plan for the ISSP process.

2. Personnel Present:

3. Agenda Items:

A. Introduction

1. Background of the ISSP project

2. Purpose of this session

3. About the data

- Aggregated and analyzed, but not interpreted

- Number following each response is the number of times each item was mentioned

- Number in the lower right corner is the number of single responses

- No discussion during presentation of results

4. Establish group norms or rules of engagement (ROEs)

B. Data feedback

- Current state

- Future state

- Change factors

C. Facilitate discussion

- Capture group conclusions

5. Decide if installation is ready to plan

E. Determine planning horizon

- Facilitate the group through consensus on the planning horizon using interview data as the basis

F. Create the strategic planning project plan

- Create the Gantt chart

- Resource the pre-work

- Recap

- Follow-up actions 


\title{
Appendix H: Environmental Scanning Matrix/Worksheets
}

\author{
Installation Internal and External Factors Worksheet \\ IDENTIFYING EXTERNAL AND INTERNAL FACTORS
}

The installation is greatly influenced by external and internal factors. Identify major external and internal factors that impact on the installation, specifically. Internal refers to anything that is within the installation. External influences include all things outside the installation:

\section{MAJOR EXTERNAL INFLUENCES}

1.

2.

3.

4.

5.

6.

7.

8.

\section{MAJOR INTERNAL INFLUENCES}

1.

2.

3.

4.

5.

6.

7.

8. 


\title{
Installation Strategic Planning Guidebook
}

\section{Appendix H: Environmental Scanning Matrix/Worksheets}

\author{
Environmental Scanning Matrix \\ Installation External environmental Analysis
}

Planning begins by assessing the external environment and forecasting (making an educated guess) the impact of major driving forces and emerging trends on the installation as it moves to a point in time. These forecasts are evaluated to identify opportunities and threats created primarily by forces outside the control of (Installation's Name) and the Installation's Name/IMCOM organization.

Listed below and continuing on the following pages are tables that allow you to forecast major driving forces and emerging trends from the external environment.

Much has happened in the Army over the past few years. Analysis of the external environment will allow you to identify current and projected installation program opportunities and threats. Identification of driving forces and emerging trends will allow the development of potential courses of action that may be included into your plan.

\section{Group Instructions:}

1. Identify driving forces and emerging trends.

2. For external analysis Indicate impact in terms of an opportunity or threat.

3. For internal analysis indicate impacts in terms of a strength or weakness.

4. Do not complete the last column of the table (courses of action) at this point.

NOTE: Use sufficient words in the table that the entries will stand alone. 


\title{
Appendix H: Environmental Scanning Matrix/Worksheets
}

\author{
Installation External Environmental Analysis
}

Category 1 - Policy, Regulation, Laws, New Missions:

When completing this table, consider policies/regulations at all levels (DoD, DA, MACOM), U.S. laws or rules, state and local regulatory issues, and other agreements that impact the ability to perform.

1. Policies: Within the Installation, IMCOM, or DA/DOD, are there any current policies that either help or hinder your ability to perform your duties? Are there any new policies that should be considered? Are there policies that are outdated or expired that need to be considered for renewal or permanent cancellation?

2. Regulations: Within the Installation/Region//IMCOM, or DA/DOD, are there any current regulations that either help or hinder your ability to perform your duties? Examples:

Service Regulation, ISO, Quality Standards, Safety and Environmental. Are there any new policies that should be considered? Are there policies that are outdated or expired that need to be considered for renewal or permanent cancellation?

3. Laws: Are there any current or new (laws, local, state, or federal) that impact on how the installation operates?

4. Missions: Has the installation taken on any new missions without additional resources? Are the missions currently being performed that should be discontinued? How does the installation control overall costs of operation? How does the installation prevent errors, and rework and minimize costs and productivity losses, as appropriate? How does the installations disaster and emergency preparedness system consider prevention management, continuity of operations and recovery?

Policies, Regulations, Laws, and Missions:

\begin{tabular}{|c|c|c|c|}
\hline$\#$ & $\begin{array}{c}\text { Driving Force or Emerging } \\
\text { Trend }\end{array}$ & $\begin{array}{c}\text { Opportunity } \\
\text { I Threat }\end{array}$ & $\begin{array}{c}\text { Potential Course(s) of Action } \\
\text { (Use Bullets) }\end{array}$ \\
\hline & & & \\
\hline & & & \\
\hline & & & \\
\hline & & & \\
\hline
\end{tabular}




\title{
Appendix H: Environmental Scanning Matrix/Worksheets
}

\author{
Installation External Environmental Analysis
}

Category 2 - Community/Region Profile:

1. Demographics/Resources: Discuss and identify information about the population on-post and off. Demographic mix, age distribution, social patterns, trends, etc. that may have an impact on the installations operations.

2. Land/Facility Use, Development and Key Physical Attribute: Identify any patterns of land/facility development in the area, both military and civilian. Does it impact the installation? Do the physical attributes such as location, natural resources, net zero (Appendix V), climate change (Appendix Q) and environmental factors influence availability, accessibility, and feasibility of operations? How do regional development patterns impact the mission? Could growth trends impact future missions? When was the installation Joint Land Use Study (JLUS) last updated? The JLUS is a critical source of information regarding community land use plans.

3. Economic, Social, and Cultural Attributes: This set of factors considers major economic, social values and attitudes toward the military and the installation program. Factors considered here are current and projected economic conditions, wage rate, prices, size of the economy compared to the civilian community, and community desire and capability to support the installation. What is the installation annual impact on the local, regional and state economies? How does the surrounding community view the installation with respect to employment? What job market exists around the installation for military family members? Discuss each of these and identify any impacts or trends. What resources are scarce? Who are the greatest users of these resources?

Community and Region Profile:

\begin{tabular}{|l|c|l|l|}
\hline$\#$ & $\begin{array}{c}\text { Driving Force or Emerging } \\
\text { Trend }\end{array}$ & $\begin{array}{c}\text { Opportunity } \\
\text { I Threat }\end{array}$ & $\begin{array}{c}\text { Potential Course(s) of Action } \\
\text { (use Bullets) }\end{array}$ \\
\hline & & & \\
\hline & & & \\
\hline & & & \\
\hline & & & \\
\hline & & & \\
\hline & & & \\
\hline
\end{tabular}




\title{
Installation Strategic Planning Guidebook
}

\section{Appendix H: Environmental Scanning Matrix/Worksheets}

\author{
Installation External Environmental Analysis
}

Category 3 - Business and Industry Standards and Trends:

1. Technology Assessment: The technology industry is constantly updating and adding new technologies to streamline operations, improve service and reduce costs. Are they being used in the Installation? Are there new technologies we should be implementing to improve the effectiveness of the installation, or old technologies we should abandon? Assess the overall quality of Installation's technologies, e.g. computer, phone, copiers, fax, etc.

2. Business Practices: Are there business practices in other Army, military, government, or private sector businesses that we should/can implement within the installation? Does the installation have mechanisms in place to adapt upon receipt of changes from the external environment?

3. Delivery Systems: Are our program and service delivery systems integrated and streamlined to improve customer service? Are we keeping up with trends in the industries? Are there redundancies or duplications that could be merged or eliminated?

Business and Industry Standards and Trends:

\begin{tabular}{|l|l|l|l|}
\hline$\#$ & $\begin{array}{c}\text { Driving Force or Emerging } \\
\text { Trend }\end{array}$ & $\begin{array}{c}\text { Opportunity } \\
\text { I Threat }\end{array}$ & $\begin{array}{c}\text { Potential Course(s) of Action } \\
\text { (Use Bullets) }\end{array}$ \\
\hline & & & \\
\hline & & & \\
\hline & & & \\
\hline & & & \\
\hline & & & \\
\hline & & & \\
\hline & & & \\
\hline & & & \\
\hline
\end{tabular}

\section{Appendix H: Environmental Scanning Matrix/Worksheets}




\section{Installation Strategic Planning Guidebook}

\section{Installation External Environmental Analysis}

Category 4 - Business and Industry Standards and Trends:

1. Professional Organizations: Identify professional organizations within the installation disciplines develop and provide demand projections, standards and customer trends. Are we actively engaged with these professional associations? Are we using data they provide? Is participation in professional organizations and use of their data meaningful in our environment?

2. Business Operating Performance Measures and Standards: Output based standards are available for many key performance areas. They include professional standards, historical trends, and time standards. Are we using them? Are they meaningful in our environment? Are there any organizations or agencies that have existing measures and standards we can use or compare to? Is Six Sigma, Lean Organizations, ISO 9000/14000 in use and/or applicable within the installation?

\begin{tabular}{|l|l|l|l|}
\hline$\#$ & $\begin{array}{c}\text { Driving Force or Emerging } \\
\text { Trend }\end{array}$ & $\begin{array}{c}\text { Opportunity } \\
\text { I Threat }\end{array}$ & $\begin{array}{c}\text { Potential Course(s) of Action } \\
\text { (Use Bullets) }\end{array}$ \\
\hline & & & \\
\hline & & & \\
\hline & & & \\
\hline & & & \\
\hline & & & \\
\hline & & & \\
\hline & & & \\
\hline & & & \\
\hline & & & \\
\hline & & & \\
\hline & & & \\
\hline & & & \\
\hline & & & \\
\hline & & & \\
\hline & & & \\
\hline & & & \\
\hline & & & \\
\hline & & & \\
\hline & & & \\
\hline & & & \\
\hline & & & \\
\hline
\end{tabular}

\section{Appendix H: Environmental Scanning Matrix/Worksheets}

Installation Internal Environmental Analysis 


\title{
Installation Strategic Planning Guidebook
}

Another step in the planning update is assessing the installation's internal environment in terms of operating performance. In this analysis, we look at operating performance in terms of driving forces and emerging trends. These forecasts are evaluated to identify strengths and weaknesses and used to develop potential courses of action that may be included in your planning.

Category 5 - Leadership and Management:

1. Command Climate: Discuss the command climate and identify any key issues that relate to the current command climate. How would you rate the overall command climate? Is morale high, low, or somewhere in the middle? What are key impacts on command climate? How can we make it better? How is mission success measured and how well does the installation achieve success?

2. Policies and Decision Making: Are current policies and new policies being effectively implemented and are we fully in compliance? Evaluate our overall policy environment and the effectiveness of decision-making. Are there any recent regulatory changes that impact the installation?

3. Information Flow: Does information flow freely and effectively throughout the organization? Why or why not? How can we make it better?

\begin{tabular}{|c|c|c|c|}
\hline$\#$ & $\begin{array}{c}\text { Driving Force or Emerging } \\
\text { Trend }\end{array}$ & $\begin{array}{c}\text { Strength } \\
\text { Weakness }\end{array}$ & $\begin{array}{c}\text { Potential Course(s) of Action } \\
\text { (Use Bullets) }\end{array}$ \\
\hline & & & \\
\hline & & & \\
\hline & & & \\
\hline & & & \\
\hline & & & \\
\hline & & & \\
\hline & & & \\
\hline & & & \\
\hline
\end{tabular}

\section{Appendix H: Environmental Scanning Matrix/Worksheets}

\author{
Installation Internal Environmental Analysis
}




\section{Installation Strategic Planning Guidebook}

Category 6 - Leadership and Management:

1. Strategic Planning: Are strategic plans within the installation being used? If so, are they effective? If not, why are they not being used? How can we improve the strategic planning process? Is additional training in strategic planning/management needed?

2. Management of Change and Process Improvement: Does the installation manage change effectively? To satisfy our stakeholders, what internal processes do we need to execute on and excel at? How does the installation managing major issues such as Net Zero, or Climate Change Adaptations? Does the installation have mechanisms in place to improve and streamline internal business processes? Are there process improvements that need to be implemented or at least considered for revision? Have there been any changes in leadership that impacted operating philosophy?

3. Performance Managements Review (PMR) and Productivity Improvement Review (PIR): Does HRD participate in the PMR and PIR process? Is there any value in participating? What are the weaknesses? How can we make it better?

\begin{tabular}{|c|c|c|c|}
\hline$\#$ & $\begin{array}{c}\text { Driving Force or Emerging } \\
\text { Trend }\end{array}$ & $\begin{array}{c}\text { Opportunity } \\
\text { I Threat }\end{array}$ & $\begin{array}{c}\text { Potential Course(s) of Action } \\
\text { (Use Bullets) }\end{array}$ \\
\hline & & & \\
\hline & & & \\
\hline & & & \\
\hline & & & \\
\hline & & & \\
\hline & & & \\
\hline & & & \\
\hline & & & \\
\hline & & & \\
\hline & & & \\
\hline
\end{tabular}

\section{Appendix H: Environmental Scanning Matrix/Worksheets}

Installation Internal Environmental Analysis 


\section{Installation Strategic Planning Guidebook}

Category 7 - Operating Environment:

The systems thinking approach lets you search each of the sub-systems to identify driving forces or emerging trends. The sub-systems include:

1. People: Workforce elements. Do we have a balanced workforce in terms of age, skill, and division of duties? How does your CPAC/DHR assess the workforces' capability and capacity needs, including skills, competencies, and staffing levels? How does the installation recruit, hire, place, and retain new members of your workforce? How does the installation organize and manage your workforce to:

- Accomplish the work of your installation,

- Capitalize on the installation's core competencies,

- Reinforce customer and business focus, exceed performance expectations, address your strategic challenges and action plans.

How does the installation manage the workforce, its needs, to ensure continuity, prevent workforce reductions, and minimize the impact of workforce reductions, if they do become necessary?

2. Management/Leadership: Discuss command and control elements of the installation. Is the leadership at all levels being held accountable? Does leadership manage effectively according to a plan? Is leadership consistent in managing the installations affairs?

3. Structure: Discuss the formal installation in which work is accomplished in the installation. Does the current installation structure work? Should it be re-designed or restructured?

4. Tasks: Are you doing the right things at the right time. Are you prioritizing effectively? Are tasks being assigned to the right person or office? The nature of "what needs to be accomplished." Is the tasking system current, up to date, and accurate?

\begin{tabular}{|l|l|l|l|}
\hline$\#$ & $\begin{array}{c}\text { Driving Force or Emerging } \\
\text { Trend }\end{array}$ & $\begin{array}{c}\text { Opportunity } \\
\text { I Threat }\end{array}$ & $\begin{array}{c}\text { Potential Course(s) of Action } \\
\text { (Use Bullets) }\end{array}$ \\
\hline & & & \\
\hline & & & \\
\hline & & & \\
\hline & & & \\
\hline & & & \\
\hline
\end{tabular}

\section{Appendix H: Environmental Scanning Matrix/Worksheets}

Installation Internal Environmental Analysis 


\title{
Installation Strategic Planning Guidebook
}

Category 8 - Operating Environment:

1. Technology: Do you have the right technology tools to accomplish work? What improvements should we make in our technology investments?

Do we have an increased need for the use of microcomputers, robotics, and electronic information transfer?

2. Operational Environment: Discuss the formal workplace environment. Is the work environment free of fear? Do employees feel involved and are they given opportunities to participate in the decision making process? If not, how can we make it better?

3. Installation Culture: What are the key attributes that make up our installation's culture? Do we have sub-cultures within the installation? If so, identify and discuss.

- Customer Relationships; requirements, satisfaction, loyalty and expectations.

- Organizational Structure; business units, functions, boards and management layers.

- Partner Relationships; alliances, long-term, suppliers and customer partnerships.

4. Community Collaboration: What are the collaboration activities between the installation and the community? Is the installation engaged with community leaders? Is the community better as a result of collaboration? How do we meet the needs and requirements of all of our stakeholders / customers?

5. Training: Evaluate the training that is being provided within the Region, IMCOM, and the Army. Identify Training that is needed. Are we training the right things at the right time? Do we adequately invest in training?

\begin{tabular}{|c|c|c|c|}
\hline$\#$ & $\begin{array}{c}\text { Driving Force or Emerging } \\
\text { Trend }\end{array}$ & $\begin{array}{c}\text { Strength/ } \\
\text { Weakness }\end{array}$ & $\begin{array}{c}\text { Potential Course(s) of Action } \\
\text { (Use Bullets) }\end{array}$ \\
\hline & & & \\
\hline & & & \\
\hline & & & \\
\hline & & & \\
\hline & & & \\
\hline & & & \\
\hline
\end{tabular}

\section{Appendix H: Environmental Scanning Matrix/Worksheets}

\author{
Installation Internal Environmental Analysis
}




\section{Installation Strategic Planning Guidebook}

Category 9 - Program and Market Analysis:

1. Customer and Market Analysis: This area includes all types of customer feedback including: Use, Facilities Rating, Service Rating, Equipment Rating, Perception of Quality, and Competitive Advantage. Use available Market Research. What partnerships with the community support the installation? How many established partnerships does the installation have with the local community? What are the greatest social issues for the community (education system, transportation, crime, employment)?

2. Program Analysis: Discuss installation programs and services. This area includes customer program feedback and management analysis of operations. Some areas to consider include staffing, equipment, accessibility, fees and charges, operating hours, and customer use, etc. Are we doing the right things at the right time for the right reasons?

3. Facilities Analysis: Is the installation effectively utilizing available facilities and spaces? Are facilities safe, clean, and comfortable for customers and employees? If not, what can we do to make it better? Identify any major safety deficiencies or problems.

4. Economic Analysis: What are the installations funding situation in the out years? Is the installation required to be more fiscally conservative than before?

\begin{tabular}{|l|l|l|l|}
\hline$\#$ & $\begin{array}{c}\text { Driving Force or Emerging } \\
\text { Trend }\end{array}$ & $\begin{array}{c}\text { Opportunity } \\
\text { I Threat }\end{array}$ & $\begin{array}{c}\text { Potential Course(s) of Action } \\
\text { (Use Bullets) }\end{array}$ \\
\hline & & & \\
\hline & & & \\
\hline & & & \\
\hline & & & \\
\hline & & & \\
\hline & & & \\
\hline & & & \\
\hline & & & \\
\hline
\end{tabular}




\title{
Installation Strategic Planning Guidebook
}

\section{Appendix H: Environmental Scanning Matrix/Worksheets}

\author{
Installation Internal Environmental Analysis
}

Category 10 - Program and Market Analysis:

1. Competitive Analysis: This area includes competition identification and competitor strength and weakness. It considers both on- and off-post competition and competition with other Services. Identify any competitive forces that may be affecting the installation.

2. Program Costs: Are program costs increasing, decreasing, or remaining the same. Are costs reasonable? Are there cost containment and cost reduction initiatives we can implement?

3. Resource Analysis: This area includes resource availability and use, revenue generation, budget performance, net income results and cash flow required for future operations. It targets requirements for the future and prioritizes resource allocations. What infrastructure, funding, people, and other resources do we need for sustaining and securing the future?

\begin{tabular}{|c|c|c|c|}
\hline$\#$ & $\begin{array}{c}\text { Driving Force or Emerging } \\
\text { Trend }\end{array}$ & $\begin{array}{c}\text { Opportunity } \\
\text { I Threat }\end{array}$ & $\begin{array}{c}\text { Potential Course(s) of Action } \\
\text { (Use Bullets) }\end{array}$ \\
\hline & & & \\
\hline & & & \\
\hline & & & \\
\hline & & & \\
\hline & & & \\
\hline & & & \\
\hline & & & \\
\hline & & & \\
\hline & & & \\
\hline
\end{tabular}




\section{Appendix I: Probability I Impact Matrix - Issues Priorities}

ISSUES PRIORITY MATRIX

\section{PROBABLE IMPACT ON THE ORGANIZATION}

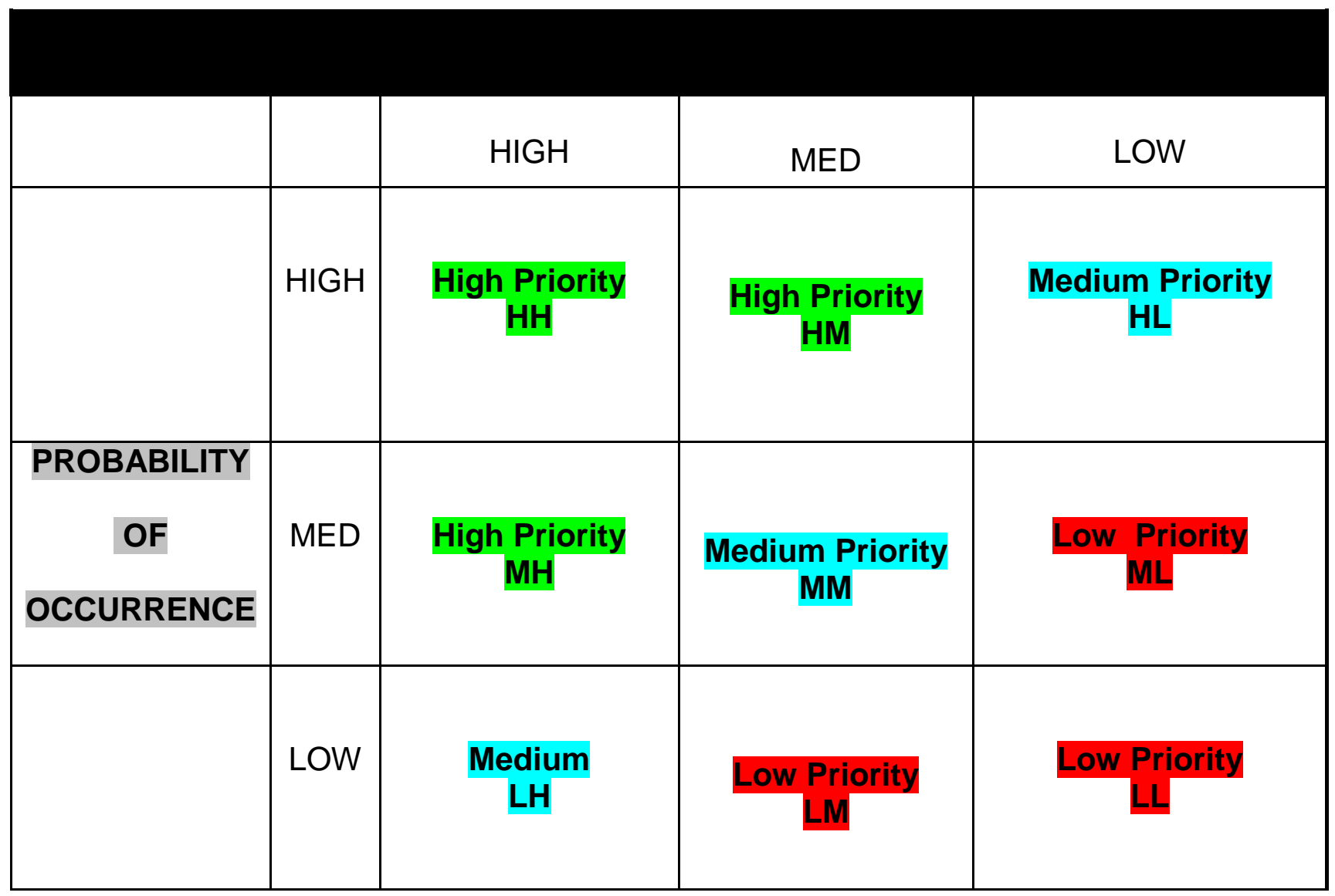




\section{Appendix J: Vision, Mission and Values}

\section{Vision}

A vision or vision statement declares for the membership what the desired, long-term future state of the organization should be. The vision is what makes the strategic plan strategic. When the Apollo 7 astronauts left the Earth in their spaceship on their voyage to the moon, they didn't aim the rocket at the moon. They aimed it at the place where the moon was going to be to allow for the time needed to get there. It is crucial that we act in advance of the important changes which are going on outside our organization if we are to continue to succeed.

There are key elements which visioning should address. First, the organization's vision should focus everyone's attention on future needs and desires and utilize the sufficient information from the Awareness $[A]$ and Baseline $[B]$ sections to construct a vision statement. Certainly IMCOM's vision builds upon our heritage but it also lets us know what IMCOM's broad future goal is, as well as how every IMCOM members contributes to it. Senior leaders must keep future mission requirements in mind when envisioning their organizational future. Just continuing to meet mission requirements won't be enough 5, 10 or 25 years into the future. The vision element of strategic planning helps the organization to create its future. This is where Senior Leaders get to be proactive and influence the future of the organization creating what could be and not settling for just what is needed.

\section{What a Good Vision Looks Like}

IMCOMs Vision is a good example:

Army installations are the Department of Defense standard for infrastructure quality and are the provider of consistent, quality services that are a force multiplier in supported organizations' mission accomplishment, and materially enhance Soldier and Family well-being and readiness.

\section{Examples from America's best-run companies}

\begin{tabular}{|l|l|}
\hline Company & Vision \\
\hline $\begin{array}{l}\text { Outback Steakhouse, } \\
\text { Inc. }\end{array}$ & $\begin{array}{l}\text { Our key goal is to create a world-class casual dining company that } \\
\text { endures }\end{array}$ \\
\hline Harley-Davidson & $\begin{array}{l}\text { Our key goal is to fulfill dreams through the experiences of } \\
\text { motorcycling }\end{array}$ \\
\hline
\end{tabular}

How do you get through this step?

First of all, keep in mind that a vision statement is not something that should change on a yearly basis. Visions are very leadership dependent though, which means that in military organizations where leadership rotates every year or so, each new leader is likely to bring a new vision with them. This is the spot for each leader to point what direction they want their organization to go in. Actually, the vision statement should be the senior leader's vision and while they should get inputs from everyone, they should craft the actual 
statement themselves. One of the reasons these statements are crafted in group sessions is because it can be less threatening. Unfortunately, these statements may end up being so watered-down and only fill the "vision statement" square. Your senior leader needs to communicate the vision in order to encourage everyone to reach it; it should be something that he / she understand well enough that they could have written it themselves.

As a facilitator, start with a group meeting where all participants have reviewed the data that was gathered during Phase 1 - (Where We Are). The External Scanning factors (Threats and especially Opportunities) which were identified in Phase 1 and sorted through during the scan analysis should be a big consideration when the senior leaders get together to contemplate their organizational vision. Using the tried and true, post-it note brainstorming process, have everyone write what they would like to see their organization doing 20 years from today, and how they would like to see the organization perceived by others in the future. Place no limits on the number of ideas they can generate. During this session encourage the feeding off of ideas as the information is posted on a predetermined location in the meeting room. Once the group completes the idea generation, have them group similar ideas together. Let the participants review the ideas as they are grouped together and ask them to vote on their favorites.

The facilitator should collect the inputs and ask the group to place them in priority order. Either move the post-it notes around from most selected to least selected or type them up in that order. Now it is time for the senior leaders to take the inputs and craft a statement that expresses the vision of the organization in 5, 10, 20 years. Start by asking the senior leader to remove, through consensus everything they do not feel comfortable with or just plain don't like. Next, ask them to circle their favorite words and phrases. After the senior leaders have crafted the vision for the organization, the next step is to tell the organization what it is. And tell them again and again and again to get everyone moving towards it.

\section{Mission}

"Of the four wars in my lifetime none came about because the United States was too strong." Ronald Reagan

The difference between a mission statement and a vision statement is that a mission statement focuses on the organizations present state while a vision statement focuses on the organizations future. However, some organizations tend to blend these statements. A mission statement is a brief clear statement of the objectives of the organization (describes an organization's reason for existence). This statement crystallizes the vision and serves as a guidepost for present and future decisions about structure, power and resources. A critical key to the organization effectiveness is its clarity of its vision and articulation of its mission (Birnbaum, 1990).

\section{What a Mission Statement Does}

Mission statements have two purposes. First a mission statement identifies what the overall purpose of the organization is to the members of the team. Secondly, the mission statement

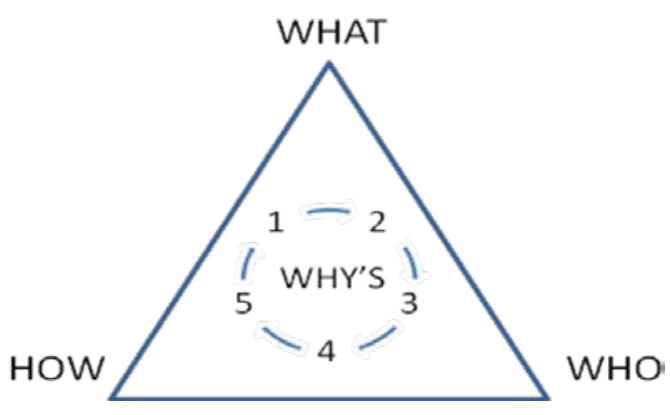


provides the framework for specific "action related" goals, objectives and performance plans developed later. If an activity does not directly link to the "mission" then it shouldn't be a part of the strategic plan.

\section{What a Mission Statement Looks Like}

The criteria for a mission statement are simple. First, organizations need to consider the makeup of their organization (Who are we). Second, in general terms, organizations need to identify the reason for their existence (What do we do?). Next, who is/are the significant customer(s) of the organization's mission output? (Who do we do it for?) Finally, how do we want people inside and outside the organization to view us and our mission? (How do we want to be perceived?).

Another criterion for a good mission statement also includes making sure that it is written in the native language of the majority of the organization.

A good example is the IMCOM Mission Statement.

Mission: to provide Soldiers, Civilians and their Families with a quality of life commensurate with the quality of their service.

The IMCOM Mission is also a good place for installation to start as they should cascade their unique mission statements from it. (This is important as installations should make sure that their mission statement supports the Army Vision, and IMCOM Mission statements.) The IMCOM Mission Statement identifies every IMCOM member and what his or her contribution is to the mission and who he or she is doing it for.

Mission statements like the Vision Statement and they should be something close to the leader's heart so that they feel comfortable speaking to others about it. Don't worry if your mission statement is not a sentence on a brown poster, for a lot of people a picture can say a whole lot more.

\section{How do you get through this step?}

Most organizations already have a mission statement and just need to make sure it is still in line with their current mission. While a vision statement might change dramatically with each leadership change, a mission statement is much more likely to stay the same. The only time a mission statement needs to be changed would include:

- A significant change in the mission of the organization

- An expansion or augmentation of the mission of the organization

- A change in the technical focus of the organization, or

- Assignment to a new ACOM

In the event that the mission statement does need revision, have everyone on the planning team answer these questions in five minutes or less. (Ask them to answer quickly so that they respond with their gut feeling -- this should not require too much contemplation.)

1. Who are we?

2. What do we do? 
3. Who do we do it for?

4. How do we want to be perceived? / How do we do our mission?

Have them write their answers on post-it notes. Designate one piece of butcher paper for each question and place their answers to the questions on the appropriate piece of paper. Next, complete an affinity diagram for each question, looking for words and topics appear the most? Once the responses are grouped together, ask the participants to multivote (say, three votes for each piece of butcher paper) on which responses they think most closely represent the mission of the organization. If you are revising a mission statement, you simply can check the words on your affinity diagram to make sure that they still match your mission statement. If there is something dramatically different from what is currently on your mission statement, and it received a lot of votes - you may consider incorporating it into a revised mission statement. If you are crafting a mission statement for the first time, you now have the information needed to start the process and you can wordsmith later. Be careful though, it is very easy to spend way too much time wordsmith your statements and not enough time implementing your plan! Finally, like the vision statement, the mission statement can also be crafted and wordsmith by the senior leader and then presented to the rest of the organization.

Values

"What you do speaks so loud that I cannot hear what you say." Ralph Waldo Emerson

An organization's values give you the anchor you need in our turbulent and constantly changing environment. While our values have always driven the decisions of the organization, making them explicit allows managers to be directly guided by them as well as to question the values they see in action. Not only does everyone need to know what values are important to the organization, they also need to feel like they can make decisions which make those values real. Otherwise they will feel the values do not represent them or the organization.

\section{How do you know a value if you see one?}

It permeates everything you do.

It is the basis for decision making - consciously or unconsciously.

It is the last thing you will give up.

\section{Why look at values?}

Steven Covey pointed out that just as explorers and navigators would align themselves with true north prior to starting their journey, leaders must also align their values before embarking on their strategic planning journey. Values should be the foundation for leaderships' decision-making process. This means that a visible value system is essential. Behavioral norms within any work environment will lead directly to improved productivity. We already have many values in place such as the organizational value of "patriotism" which binds service members together. 

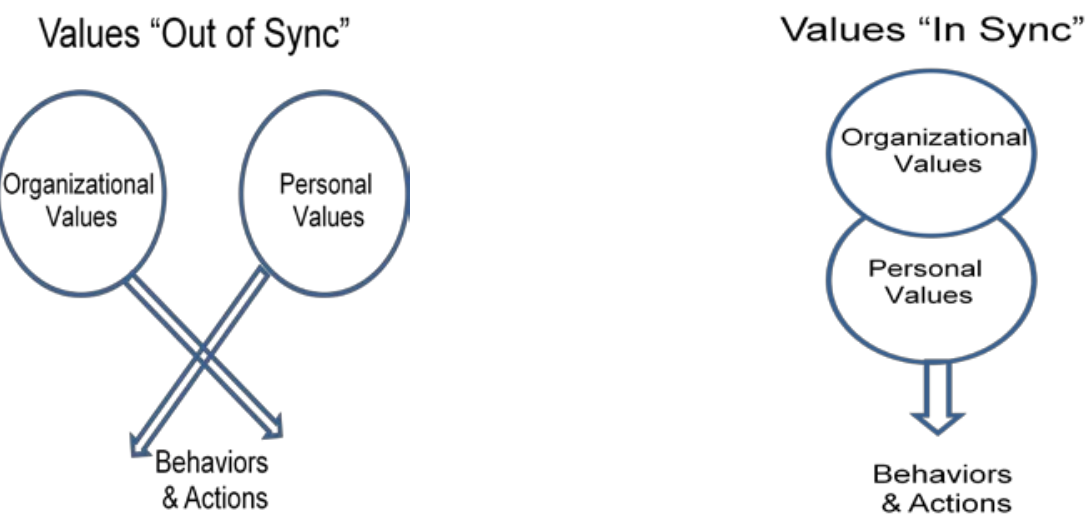

At this point it is not only important to determine what you would like the values to be, but you also need to take a look at where they are currently. Some of the information gathered during the internal scan should be looked at here such as: Security Forces blotter trends, Family Advocacy, Chaplain, mental health, test scores, safety incidents, etc. are all information that will come into play here. The idea is to look at where the organization "is", and decide where you want it to be. Now bringing you to "where you want the values to be" means that personal values are being considered here. Some people may say that personal values are separate from work values and should not even be considered. That isn't so! Values are something that runs so deep it permeates everything you do. They don't work like a light switch where you can turn one set on when you step in the door at work and turn them off the moment you walk out at the end of the day!

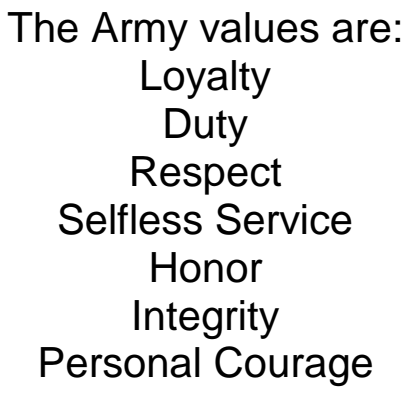

During this step you do not look at the above list and consider things like getting rid of that loyalty one and replacing it with something else. Look at how your organization is doing in these areas, determine if there are other important values the organization could work on improving and finally, agree on exactly what behaviors everyone will demonstrate to live up to these values.
Values Scan

$X=$ Where the Organization is at $\underline{O}=$ Where the Organization should be

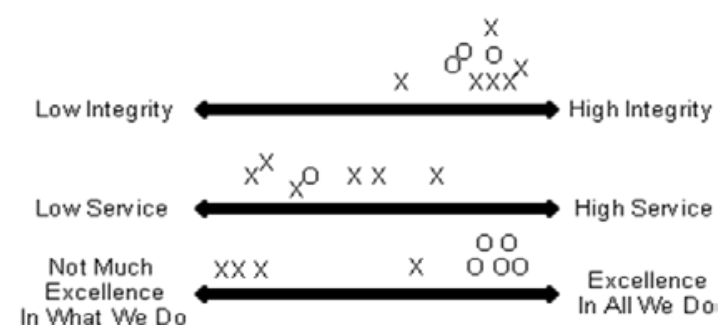

\section{How to get through this step.}

Much of the work for this step can (and should) be completed during the internal scan step of pre-work. A values assessment tool such as this one can be used to scan the organizational values and identify which ones have the biggest gap in comparison to the personal values of leadership. Start by brainstorming all the values that are important to the organization and use any previous value statements (be sure to use the Army values) 


\section{Installation Strategic Planning Guidebook}

as a starting point. Plot each value and its opposite on arrows like the chart above. (If you prefer the scientific method you can apply arrows with a scale and actually determine a score for the entire step. You can also use a simple word table with a Likert-type scale off to one side.)

Give these scales to the planning team well before any planning session so that they can give their anonymous inputs back to you and you can have them charted in time. If you follow this specific process, each member of the planning team places an "O" on each line to indicate where his or her own value lies, or where he or she would like the organization to operate. Team members then place an " $X$ " on each line to indicate where they believe the organization actually operates. Each line will then have both an " $X$ " and an "O" on it.

These forms should definitely be completed anonymously. The facilitator can then put all of the X's and O's onto one sheet to ensure the results ready for the actual planning session. This process allows you see if there are any large and glaring gaps between the X's and O's for any value. Anything with a huge gap would be something to address when deciding what values are important to the organization. For example, the second value on the sample, "service," has a large gap between where the organization is and where they want to be. This could be an area to consider when creating goals. For example, you can have an electronic brainstorming session to list all of the values you believe are important and total the list. Put them on a form like the one below and give to everyone to fill out with the X's and O's thing. (Lesson learned - use Excel not Microsoft Word for this process!) After the scores are totaled you should be able to identify any gaps. (Note: It would be interesting to compare the value scan results as you merge two organizations together. In this process some value differences are made clear up front and by completing this process the differences could be dealt with right away.)

Now you should have a list of values you brainstormed during Strategic Planning Session \#1 as being important to the organization. Put an " $X$ " in the square that represents where we are at currently and an "O" where you think we should be.

\begin{tabular}{|l|l|l|l|l|l|}
\hline Army Values & low & & med & & high \\
\hline 1. Loyalty & & & & & \\
\hline 2. Duty & & & & & \\
\hline 3. Respect & & & & & \\
\hline 4. Selfless Service & & & & & \\
\hline 5. Honor & & & & & \\
\hline 6. Integrity & & & & & \\
\hline 7. Personal Courage & & & & & \\
\hline
\end{tabular}

Another thing you can do during this step that does not require pre-work is to use a force field activity to demonstrate behaviors attached to each Army value and any other values your organization thinks are important. Display the values you will be using and break the group up with one value or so per group. Have each group develop a force field analysis showing what behaviors they have seen in the organization which support that value and what behaviors they have seen that constrain or hold back that value. Have each group debrief their force fields to the rest of the group. These force fields can then be used to find gaps and help guide goals / objectives later on. 
Using either of these methods or tools (and there are probably many, many more out there) will help to focus and guide the discussion of values. More than any other subject you will tackle during the entire strategic planning process; this one is the easiest to get off track and lost in discussions that will get you nowhere. This is not an easy topic to discuss so be sure to acknowledge that to everyone up front. You can help to make this step more relevant by doing the following:

- Keep the discussion as focused as possible

- Bring in data and facts and show how this subject can impact the mission

- Get personal inputs anonymously before the discussion ever takes place

While this is not an easy step to tackle it is important. As we move into a future where the only thing certain is change, there are some things we need to take with us and our values are one of them! While our environment may change, our mission may change and how we do our work may change--things like values need to stay the same! This means that we must do this step so we can be sure that we aren't losing something we want to hold on to. We need to find out early on where any potential problems are and tackle them before they get out of control. In order for the organization to buy into a set of values, leadership must model those values for everyone around them. 


\section{Appendix K: SWOT Analysis Matrix}

The purpose of the SWOT analysis is to develop courses of action that capitalize on the installations strengths and external opportunities or overcome program weaknesses and external threats. The courses of action resulting from the analysis should move the organization to its vision. The analysis will suggest the strategies needed to close the gap between today and the vision.

Using the tables previously completed in the external and internal analyses prioritize and develop potential courses of action for each driving force or emerging trend. As you develop courses of action ensure that those actions will help the organization reach the modified vision just developed. The chart below illustrates the process.

Challenge

\begin{tabular}{|l|l|l|l|l|}
\hline \multicolumn{1}{|c|}{ \# } & Strength & Weakness & Opportunity & Threat \\
\hline Eission & & & & \\
& & & & \\
\hline $\begin{array}{l}\text { Community } \\
\text { Partnerships }\end{array}$ & & & & \\
\hline $\begin{array}{l}\text { Environmental } \\
\text { Stewardship }\end{array}$ & & & & \\
& & & & \\
& & & & \\
\hline Economic & & & & \\
\hline Benefit & & & & \\
& & & & \\
\end{tabular}




\section{Appendix L: Sample List of Prospective Strategic Planning Workshop Participants}

POTENTIAL ATTENDEES

Organization

Senior Mission Commander

Garrison Commander

Deputy Garrison Commander

Garrison PAIO, Sustainability (Strategic) Planner

Garrison PAIO, Management Analyst

$D P W$, Director

DPW, Deputy Director

DPW, MPD, Master Planner

DPW, MP, Space Management

DPW, MP, Real Property Management

DPW, ENRD, Division Chief

DPW, TS, Division Chief

DPW, HS, Division Chief

DPW, IMO, Division Chief

DPW, ENS, Division Chief

DPW, ENRD, EMO, Team Leader

DPW, ENRD, EMO

DPW, ENRD, EMO, Air Quality/UST

DPW, ENRD, EMO, Restoration

DPW, ENRD, EMO, Water Quality

DPW, ENRD, FO, Team Leader

DPW, ENRD, FO, Asst. Forester

DPW, ENRD, WO, Team Leader

DPW, ENRD, WO, Wildlife Biologist

DPW, ENRD, WO, Wildlife Biologist

DPW, ENRD, WO, Soil Conservationist

DPW, ENRD, WO, Cultural Resources

DPW, ENRD, WO, Archaeologist

DPW, ENS, Energy

DPW, ENS, Work Order Coordinator

DPW, ENS, Mechanical Engineering

DPW, Maintenance

Base Housing (RCl/Maintenance) Contractor

Recycling Center Business Manager
MAX \# of attendees

\#

1

1

1

1

1 
DOL, LS, Project Manager 1

DOL, LS, Food Services 1

DOL, TS, MT Branch Chief (Fleet Manager) 1

DOL, TS, MT (Rental Coordinator-Fleet manager) 1

DOL, TS, MT (Bus Fleet Manager-Route Coordinator) 1

DOIM, Director 1

DOIM 1

DOIM $\quad 1$

DPTMS, Director 1

DPTMS, Range Control Manager 1

DPTMS/DPW Geographer (GIS Mapping) 1

ITAM, Coordinator 1

ITAM, Research Coordinator 1

Safety Office 1

Security 1

SJA, Environmental Law Specialist 1

SJA, Contract law 1

SJA, Ethics/General Law 1

MWR, Director 1

MWR, Community Covenant 1

MWR, Youth Services 1

MWR 1

DOC, Director 1

DOC, Contract Specialist 1

DOC, Purchasing Agent 1

DHR, Director 1

CPAC, Human Resources Specialist 1

CPAC, Personnel Management Specialist 1

DRM, Garrison RMO 1

DRM, Garrison Budget Analyst 1

DRM, Mission Director 1

DRMO 1

DES, Director 1

LEA 1

MP 1

Fire Department 1

EMS 1

DoD Schools 1

Hospital Director, Medical Activity 1

PAO, Public Affairs Officer 1

PAO, Deputy Public Affairs Officer 1 
PAO, Community Relations 1

Soldier Support Institute $\quad 1$

Army Chaplain Center 1

AAFES 1

Military Tenant 1

Military Tenant 1

Tenant 1

$\begin{array}{ll}\text { Tenant } & 1\end{array}$

Off Post Military-Civilian (VIP)

Regional Military Base Representative $\quad 1$

State Pollution Prevention Assistance 1

US Fish \& Wildlife Service, Region Representative 1

State/Regional/Local Historic Preservation Office 1

Resident Engineer, US Army Corps of Engineers 1

District Representative, US Army Corps of Engineers 1

US Army Corps of Engineers, Construction Engineering

Research Laboratory 1

Regional National Laboratory 1

Dept. of (Health \& Environmental Control), State, Air, Water

and Waste Quality

Dept. of (Natural Resources), State, Ecosystem

Representative

Dept. of (Natural Resources), State, Division 1

Dept. of (Commerce), State, Recycling/Marketing Division 1

Chamber of Commerce 1

Director, University, Sustainability Program 1

University Military Economic Values Studies 1

The Nature Conservancy 1

Director, State Wildlife Federation 1

Director, State Audubon Society 1

Director, Regional Land Trust 1

President, Regional Recycling Association 1

Historic City Foundation $\quad 1$

NGO Partner 1

Regional Economic Development $\quad 1$

Regional Economic Development 1 


\section{Appendix M: Workshop Sign-In Roster/Sheet}

\section{Sign In Roster}

Session: $\quad$ Strategic Planning Workshop

Date(s):
Location:

Facilitator:

\begin{tabular}{|c|c|c|c|c|}
\hline & Name (please print clearly) & Organization & Phone/E-mail & Signature \\
\hline 1. & & & & \\
\hline 2. & & & & \\
\hline 3. & & & & \\
\hline 4. & & & & \\
\hline 5. & & & & \\
\hline 6. & & & & \\
\hline 7. & & & & \\
\hline 8. & & & & \\
\hline 9. & & & & \\
\hline 10. & & & & \\
\hline 11. & & & & \\
\hline 12. & & & & \\
\hline 13. & & & & \\
\hline
\end{tabular}




\section{Appendix N: Sample Workshop Floor Plan}

Sample Floor Layout for Large Group Sessions

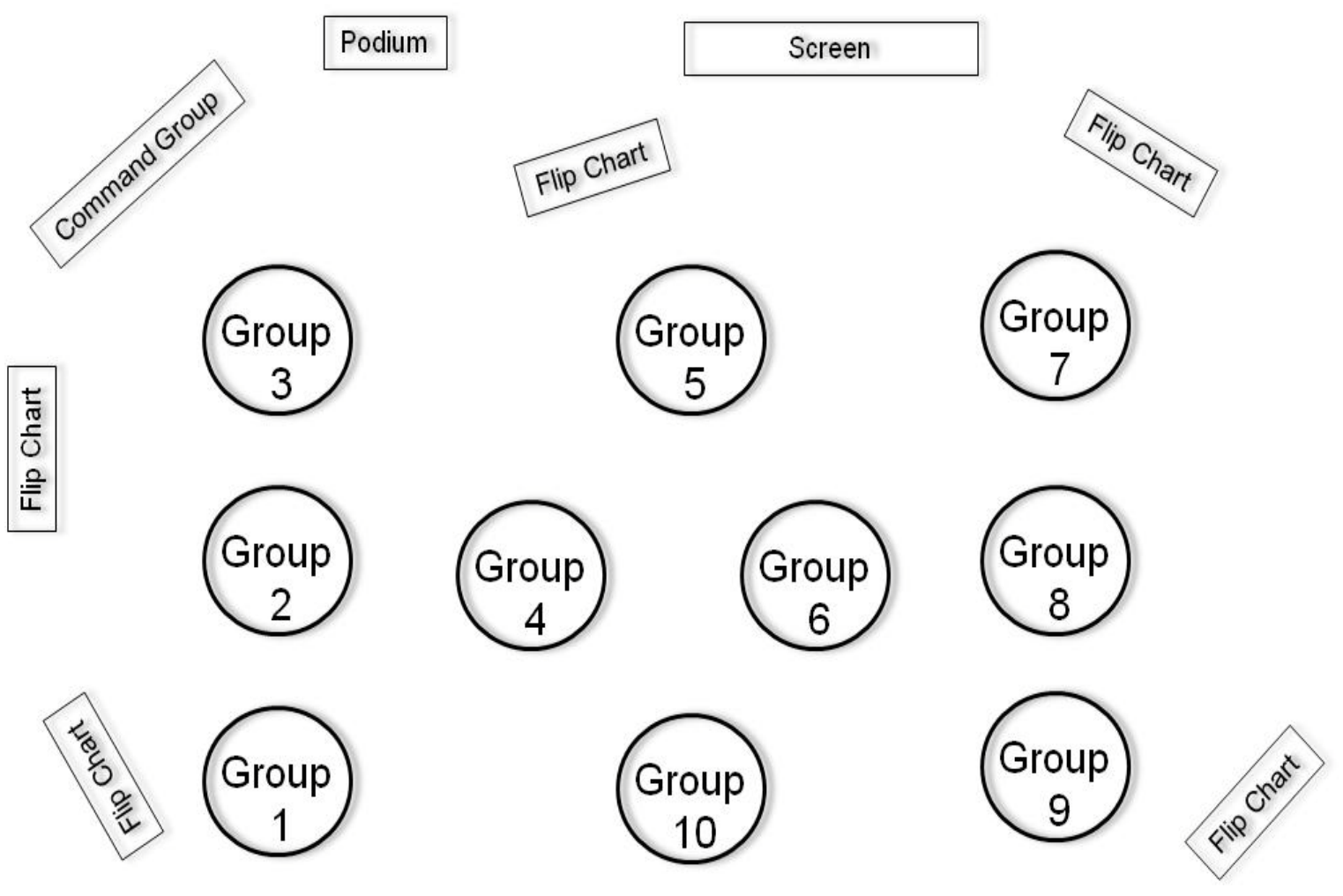


Installation Strategic Planning Guidebook

\section{Appendix O: Examples of Installation Plans Matrix}

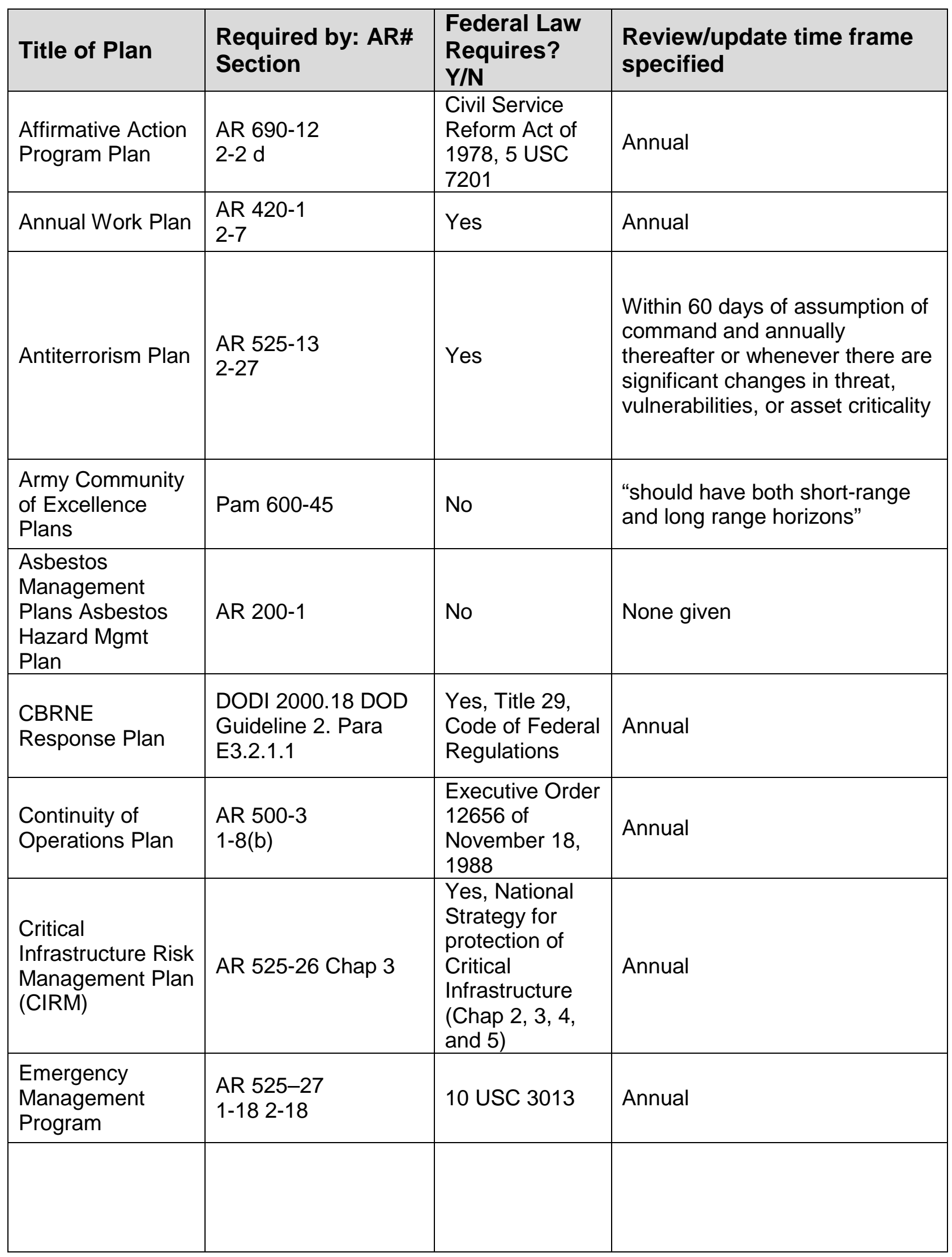


Installation Strategic Planning Guidebook

\begin{tabular}{|c|c|c|c|}
\hline Title of Plan & $\begin{array}{l}\text { Required by: AR\# } \\
\text { Section }\end{array}$ & $\begin{array}{l}\text { Federal Law } \\
\text { Requires? } \\
\text { YIN }\end{array}$ & $\begin{array}{l}\text { Review/update time frame } \\
\text { specified }\end{array}$ \\
\hline $\begin{array}{l}\text { Endangered } \\
\text { Species } \\
\text { Management } \\
\text { Plans (ESMP) }\end{array}$ & $\begin{array}{l}\text { AR 200-1 } \\
4-3\end{array}$ & $\begin{array}{l}\text { No - however } \\
\text { Endangered } \\
\text { Species Act } \\
\text { requires "all } \\
\text { methods and } \\
\text { procedures } \\
\text { necessary .... }\end{array}$ & $\begin{array}{l}\text { Annual review and report on } \\
\text { status progress; update themes } \\
\text { as required to meet conservation } \\
\text { goals. (ESMP is required one } \\
\text { year from discovery of new } \\
\text { species." }\end{array}$ \\
\hline $\begin{array}{l}\text { Emergency } \\
\text { Planning } \\
\text { OPORD 09-001 } \\
\text { FRAGO 5 } \\
\text { OPORD 10-094 } \\
\text { FRAGO 1 } \\
\text { Note: Command } \\
\text { Direction to } \\
\text { combine } \\
\text { emergency } \\
\text { planning } \\
\text { requirements } \\
\text { (COOP, AT, EM, } \\
\text { CIRM and } \\
\text { CBRNE) into a } \\
\text { protection plan) }\end{array}$ & $\begin{array}{l}\text { AR 500-3 1-8(b) } \\
\text { AR 525-13 2-27 } \\
\text { AR 525-26 Chap } 3 \\
\text { AR 525-27 1-18 }\end{array}$ & $\begin{array}{l}\text { SECARMY } \\
\text { Directive (2011- } \\
\text { 04) }\end{array}$ & $\begin{array}{l}\text { Within } 60 \text { days of assumption of } \\
\text { command and annually } \\
\text { thereafter or whenever there are } \\
\text { significant changes in threat, } \\
\text { vulnerabilities, or asset critically }\end{array}$ \\
\hline $\begin{array}{l}\text { Environmental } \\
\text { Noise } \\
\text { Management Plan }\end{array}$ & $\begin{array}{l}\text { AR 200-1 } \\
14-1\end{array}$ & No & $\begin{array}{l}\text { As required by RCRA, EPCRA, } \\
\text { CWA, National Contingency } \\
\text { Plan, CAA, etc. }\end{array}$ \\
\hline $\begin{array}{l}\text { Forest } \\
\text { Management Plan }\end{array}$ & AR 200-15-2(b) & No & $\begin{array}{l}\text { "prerequisite for timber harvest } \\
\text { availability ..." }\end{array}$ \\
\hline $\begin{array}{l}\text { Hazardous Waste } \\
\text { Management Plan } \\
\text { (HWMP) }\end{array}$ & $\begin{array}{l}\text { AR 200-1 } \\
10-1\end{array}$ & $\begin{array}{l}\text { Laws applying } \\
\text { to HAZMAT and } \\
\text { POL use and } \\
\text { storage }\end{array}$ & \\
\hline $\begin{array}{l}\text { Information } \\
\text { Technology } \\
\text { Capital Asset } \\
\text { Planning }\end{array}$ & $\begin{array}{l}\text { AR 25-1 } \\
3-3(3)\end{array}$ & $\begin{array}{l}\text { Title } 40 \text { USC } \\
\text { Subtitle III } \\
\text { (Clinger-Cohen } \\
\text { Act (CCA)) }\end{array}$ & Annual \\
\hline $\begin{array}{l}\text { Installation } \\
\text { Biological } \\
\text { Preparedness } \\
\text { Plan (IBPP) } \\
\end{array}$ & $\begin{array}{l}\text { HQDA Directive } \\
\text { 002/2009 } \\
\text { USNORTHCOM } \\
\text { CONPLAN 3551-08 } \\
\end{array}$ & $\begin{array}{l}\text { Yes, Homeland } \\
\text { Security } \\
\text { Presidential } \\
\text { Directive } 7\end{array}$ & Annual \\
\hline $\begin{array}{l}\text { Installation Pest } \\
\text { Management Plan } \\
\text { (IPMP) }\end{array}$ & $\begin{array}{l}\text { AR 200-5 } \\
2-6(\mathrm{a}) \\
\text { AR 200-3 }\end{array}$ & No & $\begin{array}{l}\text { "updated as necessary and will } \\
\text { be reviewed at least annually ... } \\
\text { " }\end{array}$ \\
\hline
\end{tabular}


Installation Strategic Planning Guidebook

\begin{tabular}{|c|c|c|c|}
\hline Title of Plan & $\begin{array}{l}\text { Required by: AR\# } \\
\text { Section }\end{array}$ & $\begin{array}{l}\text { Federal Law } \\
\text { Requires? Y/N }\end{array}$ & $\begin{array}{l}\text { Review/update time frame } \\
\text { specified }\end{array}$ \\
\hline $\begin{array}{l}\text { Installation } \\
\text { Utilities } \\
\text { Management Plan } \\
\text { (IUMP) }\end{array}$ & $\begin{array}{l}\text { AR } 420-1 \\
23-4\end{array}$ & No & Not specified \\
\hline $\begin{array}{l}\text { Integrated } \\
\text { Cultural } \\
\text { Resources } \\
\text { Management } \\
\text { Plans (ICRMP) } \\
\end{array}$ & $\begin{array}{l}\text { AR 200-1 } \\
4-3\end{array}$ & No & "a 5-year plan..." \\
\hline $\begin{array}{l}\text { Integrated Natural } \\
\text { Resources } \\
\text { Management Plan } \\
\text { (INRMP) }\end{array}$ & $\begin{array}{l}\text { AR 200-1 } \\
4-3\end{array}$ & $\begin{array}{l}\text { Yes - Sikes Act } \\
\text { and SAIA }\end{array}$ & $\begin{array}{l}\text { Major revision of all parts will be } \\
\text { accomplished at least every } 5 \\
\text { years. }\end{array}$ \\
\hline $\begin{array}{l}\text { Integrated Solid } \\
\text { Waste } \\
\text { Management Plan }\end{array}$ & $\begin{array}{l}\text { AR 200-1 } \\
10-2\end{array}$ & No & "as required" \\
\hline $\begin{array}{l}\text { Installation Range } \\
\text { Modernization } \\
\text { Planning }\end{array}$ & $\begin{array}{l}\text { AR 350-19 } \\
3-3\end{array}$ & No & Annual \\
\hline $\begin{array}{l}\text { Internal Control } \\
\text { Evaluation Plan } \\
\text { (ICEP) }\end{array}$ & $\begin{array}{l}\text { AR 11-2 } \\
1-14(3)\end{array}$ & $\begin{array}{l}\text { Federal } \\
\text { Managers } \\
\text { Financial } \\
\text { Integrity Act } \\
\text { (FMFIA) of } \\
1982\end{array}$ & Annual \\
\hline $\begin{array}{l}\text { Morale, Welfare } \\
\text { and Recreation } \\
\text { (MWR) 5-year } \\
\text { plan }\end{array}$ & $\begin{array}{l}\text { AR 215-1 } \\
2-4(d)\end{array}$ & No & Annual review \\
\hline Title of Plan & $\begin{array}{l}\text { Required by: AR\# } \\
\text { Section }\end{array}$ & $\begin{array}{l}\text { Federal Law } \\
\text { Requires? Y/N }\end{array}$ & $\begin{array}{l}\text { Review/update time frame } \\
\text { specified }\end{array}$ \\
\hline $\begin{array}{l}\text { Pollution } \\
\text { Prevention Plan }\end{array}$ & $\begin{array}{l}\text { AR 200-1 } \\
7-4\end{array}$ & No & $\begin{array}{l}\text { "All P2 plans should be updated } \\
\text { whenever a change in function } \\
\text { or process occurs" }\end{array}$ \\
\hline $\begin{array}{l}\text { Range and } \\
\text { Training Land } \\
\text { Program (RTLP) } \\
\text { Development } \\
\text { Plan }\end{array}$ & $\begin{array}{l}\text { AR 350-19 } \\
1-25\end{array}$ & No & $\begin{array}{l}\text { "RTLP reviews generally span a } \\
\text { seven-year period ... " "Process } \\
\text { begins when installations } \\
\text { develop and submit their annual } \\
\text { RTLP Development Plan ... " }\end{array}$ \\
\hline
\end{tabular}


Installation Strategic Planning Guidebook

\begin{tabular}{|c|c|c|c|}
\hline Title of Plan & $\begin{array}{l}\text { Required by: AR\# } \\
\text { Section }\end{array}$ & $\begin{array}{l}\text { Federal Law } \\
\text { Requires? Y/N }\end{array}$ & $\begin{array}{l}\text { Review/update time frame } \\
\text { specified }\end{array}$ \\
\hline $\begin{array}{l}\text { RCRA Hazardous } \\
\text { Waste } \\
\text { Contingency Plan; } \\
\text { Facility Response } \\
\text { Plan }\end{array}$ & $\begin{array}{l}\text { AR 200-1 } \\
11-4\end{array}$ & $\begin{array}{l}\text { Yes, for } \\
\text { use/storage of } \\
\text { hazardous } \\
\text { materials, } \\
\text { generation of } \\
\text { hazardous } \\
\text { waste }\end{array}$ & $\begin{array}{l}\text { As required by RCRA, EPCRA, } \\
\text { CWA, National Contingency } \\
\text { Plan, CAA, etc. }\end{array}$ \\
\hline $\begin{array}{l}\text { Real Property } \\
\text { Master Plan } \\
\text { (RPMP) }\end{array}$ & $\begin{array}{l}\text { AR } 210-20 \\
1-1 \mathrm{c}\end{array}$ & No & $\begin{array}{l}\text { Revision to LRC: "when overall } \\
\text { installation assigned strength } \\
\text { changes significantly, changes } \\
\text { in mission trigger need for } \\
\text { different land use, operational } \\
\text { safety requirements affect land } \\
\text { use, or directed by HQDA but at } \\
\text { least every } 10 \text { years" }\end{array}$ \\
\hline $\begin{array}{l}\text { Resource } \\
\text { Management Plan } \\
\text { (RMP) }\end{array}$ & $\begin{array}{l}\text { AR 420-1 } \\
6-11\end{array}$ & No & Semi-Annual \\
\hline $\begin{array}{l}\text { Safety Strategic } \\
\text { Plan }\end{array}$ & $\begin{array}{l}\text { AR 385-10 } \\
2-1\end{array}$ & $\begin{array}{l}\text { Occupational } \\
\text { Safety and } \\
\text { Health Act of } \\
1970\end{array}$ & Annual \\
\hline $\begin{array}{l}\text { Spill Prevention } \\
\text { Control and } \\
\text { Countermeasure } \\
\text { Plan (SPCCP) }\end{array}$ & $\begin{array}{l}\text { AR 200-1 } \\
11-4\end{array}$ & $\begin{array}{l}\text { Yes, for certain } \\
\text { POL storage } \\
\text { facilities }\end{array}$ & Annual \\
\hline Strategic Plan & $\begin{array}{l}\text { AR } 5-1 \\
3-2\end{array}$ & No & Annual \\
\hline $\begin{array}{l}\text { Water Resources } \\
\text { Management Plan } \\
\text { (WRMP) }\end{array}$ & $\begin{array}{l}\text { AR 200-1 } \\
4-2\end{array}$ & No & Annual \\
\hline
\end{tabular}




\section{Appendix P: Strategic Planning Workshop Evaluation Form}

Integrated Strategic and Sustainability Planning Workshop Evaluation

(Date)

(Name of Organization)

ISSP Workshop

Your comments will help improve future workshops.

1. Workshop Topics

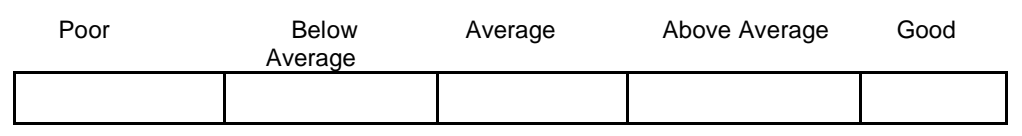

2. Workshop location

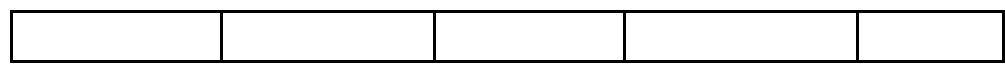

3. Workshop length

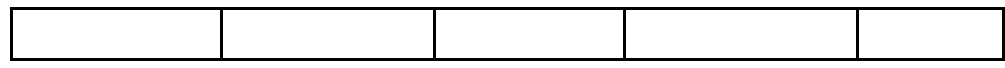

4. Accommodations

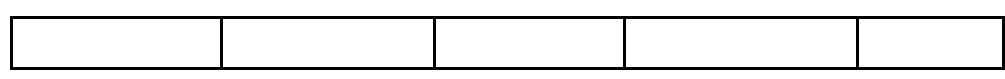

5. Written material

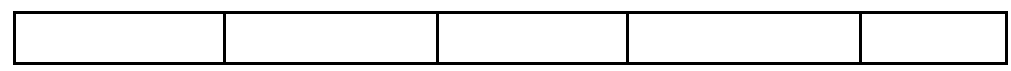

Workshop topics that should be added:

Other Comments:

Conference frequency:

Location next workshop:

\section{Strategic Planning Workshop Evaluation Form (Part 2)}




\section{ISSP Evaluation Matrix}

Installation/Garrison:

Date of the Evaluation:

Evaluation Completed by:

\section{Executive Summary:}

(In this space provide an overall assessment summary of the plan that outlines the details contained below in the matrix below) 


\section{Appendix Q: Climate Change Effects Adaptation Framework and Methodology}
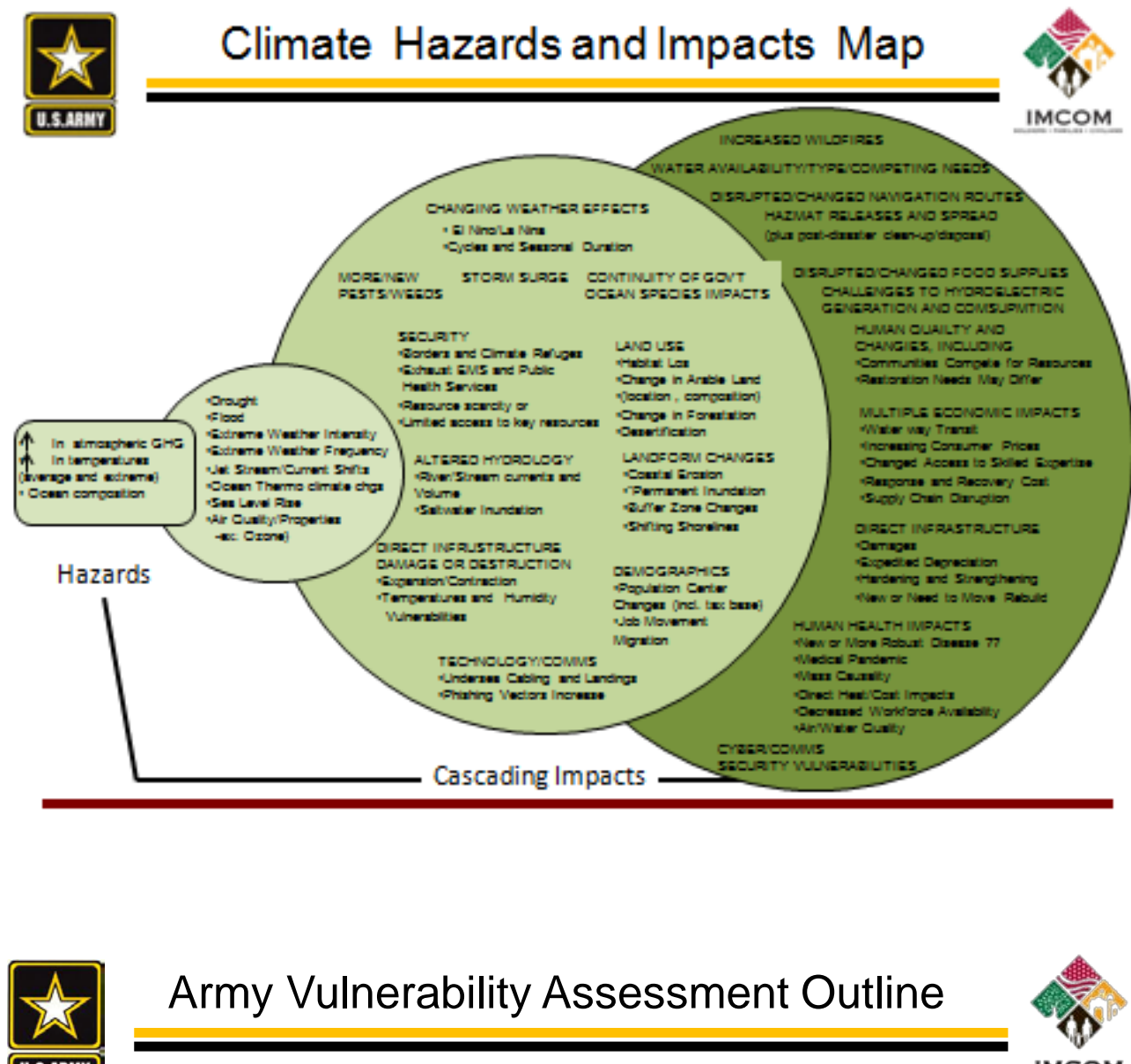

\section{Army Vulnerability Assessment Outline}

I. Executive Summary

II. Summary of $3^{\text {rd }}$ NCA climate projections by region, scenario \& time period A. Table/Figures of installations by region and MACOM

III. Summary of installations and functions by region

IV. Assessments by Region and Mission Function (Sectors)

A. Southeast Region x Mission Functions

B. Southwest Regions $x$ Mission Functions

C - H. Other Regions x Mission Functions

(Narratives for each section would highlight the most predominant mission impacts associated with that particular region. For example, impacts on testing mission may be more important in the southwest region versus the southeast region. This is also where selected installation examples may be useful.)

V. Implications of anticipated timing of impacts for different command levels and decision process such as Stationing 2020

VI. Reference to adaptation planning framework

VII. Recommendations for more detailed assessment requirements and supporting capabilities going forward 


\section{Assessment Matrix}

\begin{tabular}{|c|c|c|c|c|c|c|}
\hline \multicolumn{7}{|c|}{ Groupling Varlables } \\
\hline $\begin{array}{l}\text { Miseilon } \\
\text { Function } \\
\text { Sector }^{*}\end{array}$ & NCA Reglon 8 & $\begin{array}{l}\text { NCA Cllmate } \\
\text { Projection } \\
\text { Time Perlode }\end{array}$ & $\begin{array}{c}\text { NCA } \\
\text { Scenarlos }\end{array}$ & NCA Sectors & $\begin{array}{l}\text { Command } \\
\text { Hlerarchy }\end{array}$ & $\begin{array}{l}\text { Planning } \\
\text { Procasвe8 }\end{array}$ \\
\hline Tralining & Northesst & 2035 & $\bar{A} 2$ (Hligh) & $\begin{array}{l}\text { Bult } \\
\text { Environment }\end{array}$ & $\begin{array}{l}\text { Insta Gion sub- } \\
\text { commands }\end{array}$ & \begin{tabular}{|l|} 
Critical \\
Intrastructure
\end{tabular} \\
\hline $\begin{array}{l}\text { Force } \\
\text { Projection }\end{array}$ & $\begin{array}{l}\text { Southeast } \\
\text { and } \\
\text { Carlbbean }\end{array}$ & 2055 & B1 (LOW) & Energy & Insta ations & $\begin{array}{l}\text { Range } \\
\text { Complex } \\
\text { Masiar Plans }\end{array}$ \\
\hline Testing & Midwest & 2085 & & Human Heath & MACOMs & $\begin{array}{l}\text { Insta ation } \\
\text { Strategli } \\
\text { Plans or } \\
\text { (RPMP) }\end{array}$ \\
\hline $\begin{array}{l}\text { ReservalNGB } \\
\text { Support }\end{array}$ & Great Plain & & & $\begin{array}{l}\text { Natural } \\
\text { Ecosystems }\end{array}$ & Army HQ & $\begin{array}{l}\text { Insta ation } \\
\text { Mastar Plans }\end{array}$ \\
\hline AMC Activities & Southwest & & & Agriculture & & INRMPs \\
\hline \multirow[t]{3}{*}{ Other?? } & Northwest & & & $\begin{array}{l}\text { Flsherles \& } \\
\text { Aquaculture }\end{array}$ & & \\
\hline & $\begin{array}{l}\text { Alasika \& } \\
\text { Arctic }\end{array}$ & & & Forests & & \\
\hline & $\begin{array}{l}\text { Hawall \& } \\
\text { Pacific } \\
\text { Island } 8\end{array}$ & & & $\begin{array}{l}\text { Adaptation \& } \\
\text { Mitigation }\end{array}$ & & \\
\hline
\end{tabular}

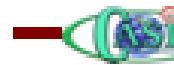

Alaska permafrost thaw

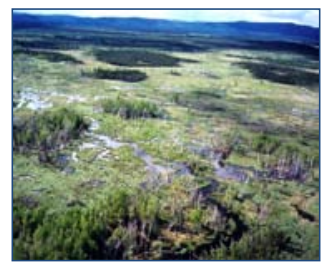

Current
Increased frequency

of extreme events

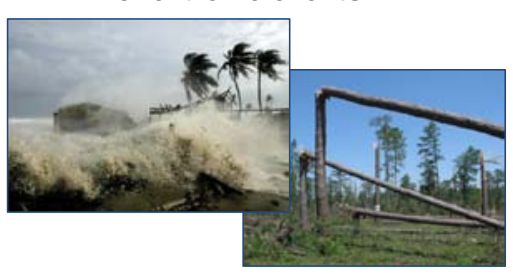

Mid-term

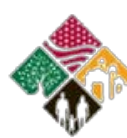

IMCOM

Ecological Transitions

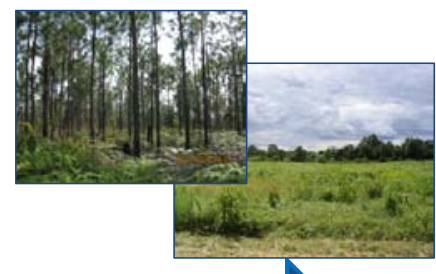

Long-term

\section{Current and Potential Impacts}

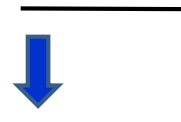

Days and land area available for off-road military vehicle maneuvers on Alaska military ranges are currently reduced because of permafrost melt

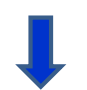

Reduced land access for training because of decreased land carrying capacity, vegetation and soil loss, infrastructure damage, and environmental regulatory constraints

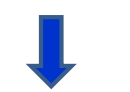

Installation mission support capabilities irreversibly altered because of fundamental shifts in the physical and biological properties of the installation environment 


\section{Appendix R: Using the Army's Strategic Management System (SMS) to Evaluate ISP Performance}

The Strategic Management System (SMS) is the Army's tool for managing strategic performance. SMS serves as the foundation for ensuring Army-wide strategy execution, strategy management, organizational alignment (vertical and horizontal), and data synchronization. SMS is the performance management platform for the Army Campaign Plan (ACP) and the Installation Management Campaign Plan (IMCP). This appendix provides guidance on building an ISP performance management model in SMS.

\section{Performance Measurement System Architecture}

For each strategic goal there will be multiple objectives and tasks that need to be accomplished. Developing installation-wide performance measurement and presentation architecture is a key step in monitoring performance and achieving strategic alignment from top to bottom and across the installation. This alignment should result in each organization, division, unit and individual knowing and understanding their roles in achieving the Installation's overall strategic goals and objectives.

SMS provides a flexible performance measurement architecture that can be easily adapted to fit any Installation. SMS is built on two hierarchical structures, Organization Nodes represented by the $\mathrm{O}$ icon, and Scorecard Trees represented by the Organization Nodes create hierarchical, parent-child relationships between different Scorecard Trees. Scorecard Trees create hierarchical, parent-child relationships between scorecard elements. There can only be one Scorecard Tree per Organization Node, but additional Organization Nodes can be added to accommodate additional Scorecard Trees.

Keep in mind that an Organization Node represents a Scorecard Tree. You will probably need just one organization node for your ISP. If you use SMS to track other plans, processes, operations, or services, you will need additional organization nodes. While you may be inclined to create an organization node structure that resembles your Garrison's organization chart- Garrison-Directorates-Divisions-Branches, etc, it may be more practical to create one Organization Node for the Garrison and create the organization chart structure within the Scorecard Tree using the Scorecard elements.

SMS Scorecard Tree elements include Overarching Strategy, Initiative, Task, and Metric levels. Table 14 illustrates SMS Scorecard Tree elements and how they can be used to represent a Garrison organization or service structure and Table 15 illustrates SMS Scorecard Tree elements and how they relate to the Army Campaign Plan (ACP), IMCP, and traditional strategic planning terminology. The terminology used in the ISP should be consistent with the terminology used or preferred by the Senior Commander. 
Table 14. SMS Scorecard Tree: Organization/Service Structure

\begin{tabular}{|l|l|l|}
\hline SMS Hierarchy & Garrison Org. & Service \\
\hline \hline Averarching Strategy & $\begin{array}{l}\text { Directorate/Special Staff } \\
\text { Office }\end{array}$ & Major Service Area \\
\hline Initiative & Division & Service \\
\hline Task & Mranch & SSP \\
\hline $\mathbf{0}$ Metric & $\begin{array}{l}\text { Metric or Data } \\
\text { Element/Data Measure }\end{array}$ & $\begin{array}{l}\text { Metric or Data } \\
\text { Element/Data Measure }\end{array}$ \\
\hline
\end{tabular}

Table 15. SMS Scorecard Tree: ACP-IMCP-ISP

\begin{tabular}{|l|l|l|l|}
\hline \multicolumn{1}{|c|}{ SMS Heierarchy } & \multicolumn{1}{|c|}{ ACP } & \multicolumn{1}{c|}{ IMCP } \\
\hline A Overarching Strategy & Army Imperative & Line of Effort & Goal \\
\hline is Initiative & Campaign Objective & Key to Success & Objective \\
\hline Task & Major Objective & Metric & Task \\
\hline Metric & $\begin{array}{l}\text { Metric or Data } \\
\text { Element/Data Measure }\end{array}$ & $\begin{array}{l}\text { Metric or Data } \\
\text { Element/Data Measure }\end{array}$ & $\begin{array}{l}\text { Metric or Data } \\
\text { Element/Data Measure }\end{array}$ \\
\hline
\end{tabular}

SMS Overarching Strategy, Initiative, and Task elements can be placed in any order. For example, Overarching Strategies can be placed under other Overarching Strategies or under Initiatives or Tasks. Subordinate relationships are created when one hierarchy element is placed beneath another hierarchy element. Care should be taken to ensure there is a logical flow from one level to another and that elements are used consistently throughout the Scorecard Tree.

The Metric level is the lowest level in the hierarchy and is the only level that can contain manually entered, uploaded, or calculated data. Metrics can be placed at any level in the hierarchy and can be nested under other Metrics, but no other Scorecard Tree elements can be placed under the Metric element. Metrics can be scored or unscored. Unscored metrics are normally used as data elements in calculated metrics. For example, the performance measure "percentage of reports completed on time", calculated by dividing the number of reports completed on time by the total number of reports completed, requires three SMS metrics, one for the numerator data, one for the denominator data, and one for the calculation. In this case the numerator and denominator metrics would be unscored and the calculation metric would be scored. There may be some instances when a single data point would be scored.

Defining naming and numbering conventions is a critical step in designing your performance measurement system architecture. Consistent naming conventions enable easy identification of the various hierarchical levels and will make reports and queries easier to read. Naming conventions should be established prior to building your SMS 
model, but will probably require some modifications as your model grows in scope and complexity. Clear and complete definitions upfront will reduce confusion and re-work down the road.

Figure 25 illustrates Organization Node and Scorecard Tree structures in SMS. Note that in addition to typical "organizational" Organization Nodes, such as DPW, DPTMS, and DFMWR, there are Organization Nodes for the IMCP and Installation Strategic Plan. Since there can only be one Scorecard Tree per Organization Node, you must create an Organization Node for each Scorecard Tree you need. Data values and scores entered or calculated in one Scorecard Tree can be used in any other Scorecard Tree.

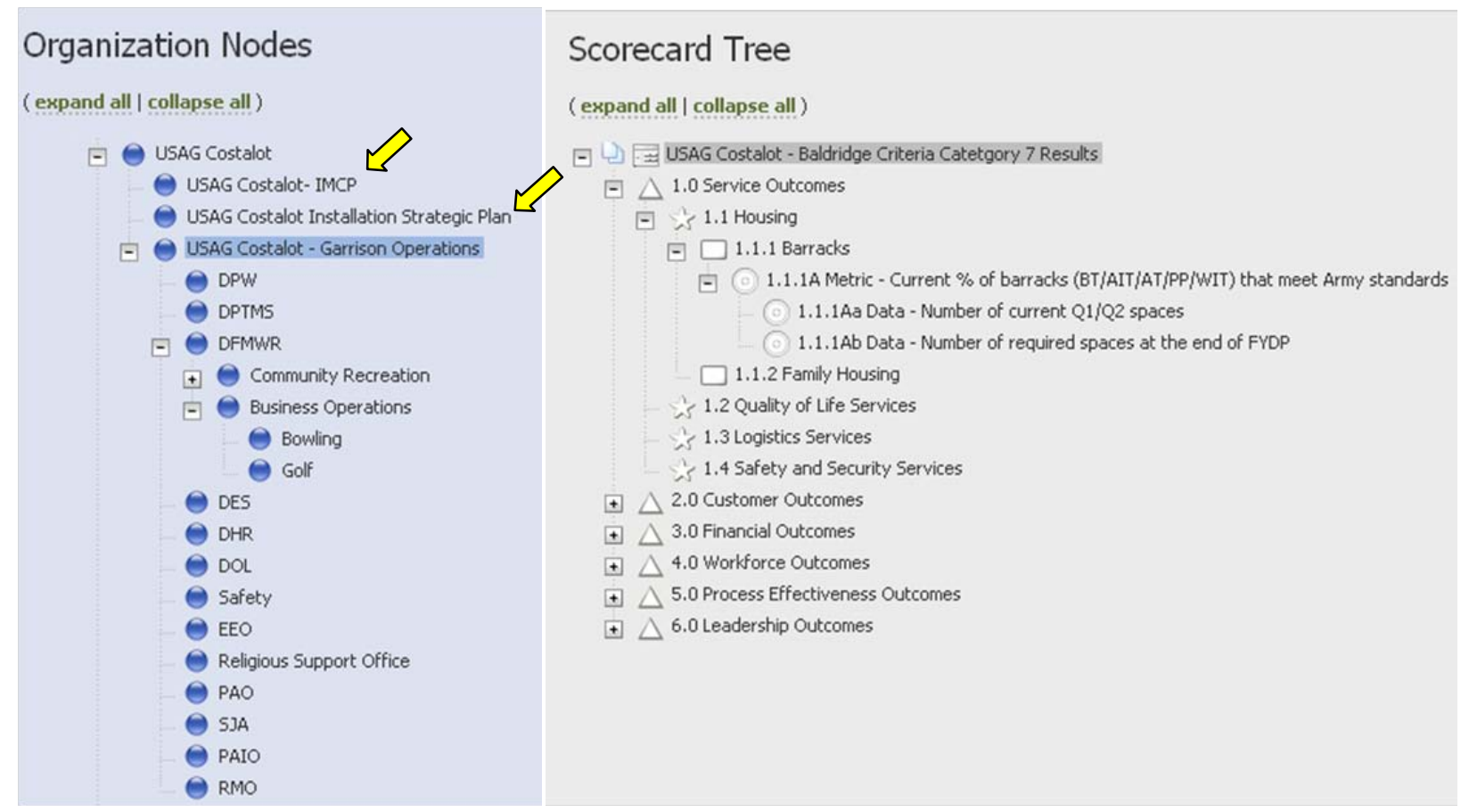

Figure 25. SMS Organizational Node and Scorecard Tree

In the example above, the USAG Costalot- Garrison Operations node Scorecard Tree is structured according to the six areas defined in the Baldridge Criteria, Category 7: Results. Other Organization node Scorecard Trees in this hierarchy can follow this structure or can have completely different structures depending upon the needs of the organization.

Figure 26 depicts the DPW Organization Node and Bowling Organization Node Scorecard Trees. Each is structured on a different format. The DPW Scorecard Tree was copied and pasted from the Scorecard Tree example in Figure 25 above. Changes were made to customize the elements to DPW. The Bowling Scorecard Tree is structured in a balanced scorecard format to capture key business information useful to MWR operating managers including Operations, Workforce, Customer Focus, and Financial Results data. Information contained in the Bowling and DPW Scorecard Trees can be linked to and used by the Garrison Operations Scorecard Tree, which in turn can be linked to the ISP Scorecard Tree. 


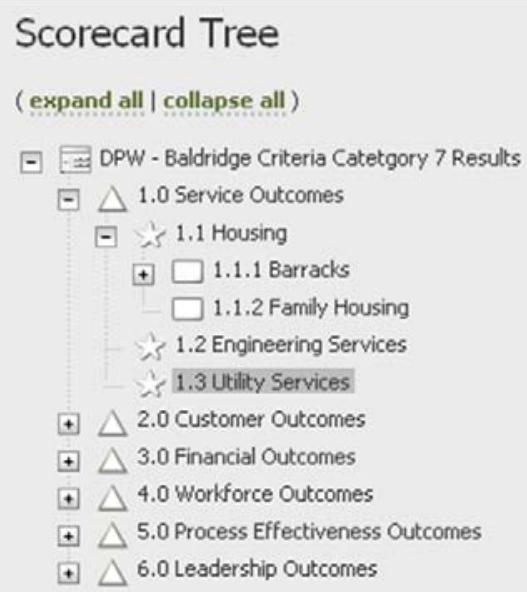

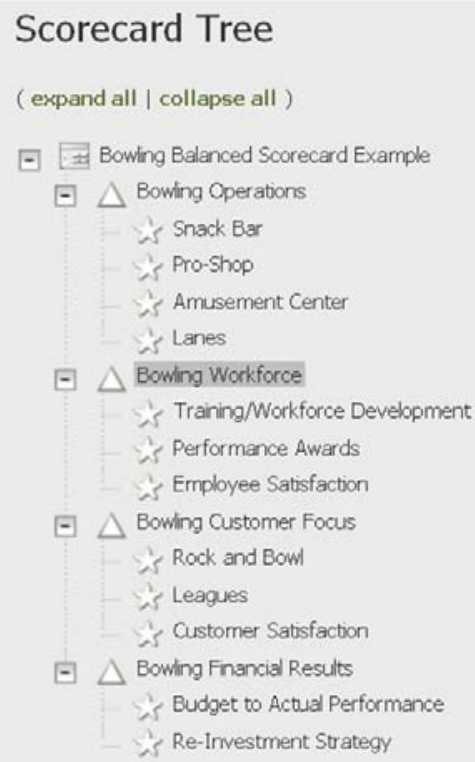

Figure 26. DPW Organizational Node and Bowling Scorecard Tree

The examples provided here illustrate the flexibility of SMS in adapting to Garrison needs. Organization models can be created to capture operational business information for operational managers. This information can then feed other models to provide mid and senior level managers with the tactical and strategic level information they need to manage operations, monitor strategic performance and feed enterprise level models.

\section{Building Metrics in SMS}

In Step D of the A to G model measures and targets were identified. Those measures and targets must be incorporated into the SMS Scorecard Tree. The terms measure and metric are often used interchangeably. Generally speaking, measure refers to a numerical value representing a unit of measure, such as dollars, square miles, cubic feet, or gallons, while metric represents a calculated value, such as a percentage $(a / b)$. When compared to a target value, both measures and metrics can be used as performance indicators to monitor and track progress or improvement.

The term "data element" refers to numerical values used in a metric. By themselves, data elements have little value; combined with targets, however, they may serve as useful performance measures. For example, knowing that 90 troops were trained last month doesn't really tell us much. If you assign a target of training 100 troops each month, you now have a useful performance measure.

In SMS, the Metric Scorecard Tree element can be used as an un-scored data element, or as a scored metric/measure. Scored metrics/measures are those with assigned threshold (target) values and weights. Thresholds are typically assigned for green and red performance levels. In our example above, you might assign a green threshold of 90 and a red threshold of 79 as illustrated in Table 16. 
Table 16. SMS Metric Scorecard Tree Thresholds

\begin{tabular}{|c|l|c|}
\hline \multicolumn{1}{|c|}{ Red } & \multicolumn{1}{|c|}{ Amber } & \multicolumn{1}{c|}{ Green } \\
\hline 79 or fewer Soldiers Trained & $\begin{array}{l}\text { Between } 80 \text { and 89 Soldiers } \\
\text { Trained }\end{array}$ & 90 or more Soldiers Trained \\
\hline
\end{tabular}

As discussed earlier, establishing naming conventions is critical when constructing the SMS Scorecard Tree. Metrics should follow a consistent numbering scheme and should be clearly labeled as a "metric" so that they can be easily distinguished from data elements and other Scorecard Tree elements. Likewise, data elements should also be clearly labeled so that they can be easily distinguished from metrics. Figure 27 provides an example of the naming conventions used in the IMCP.

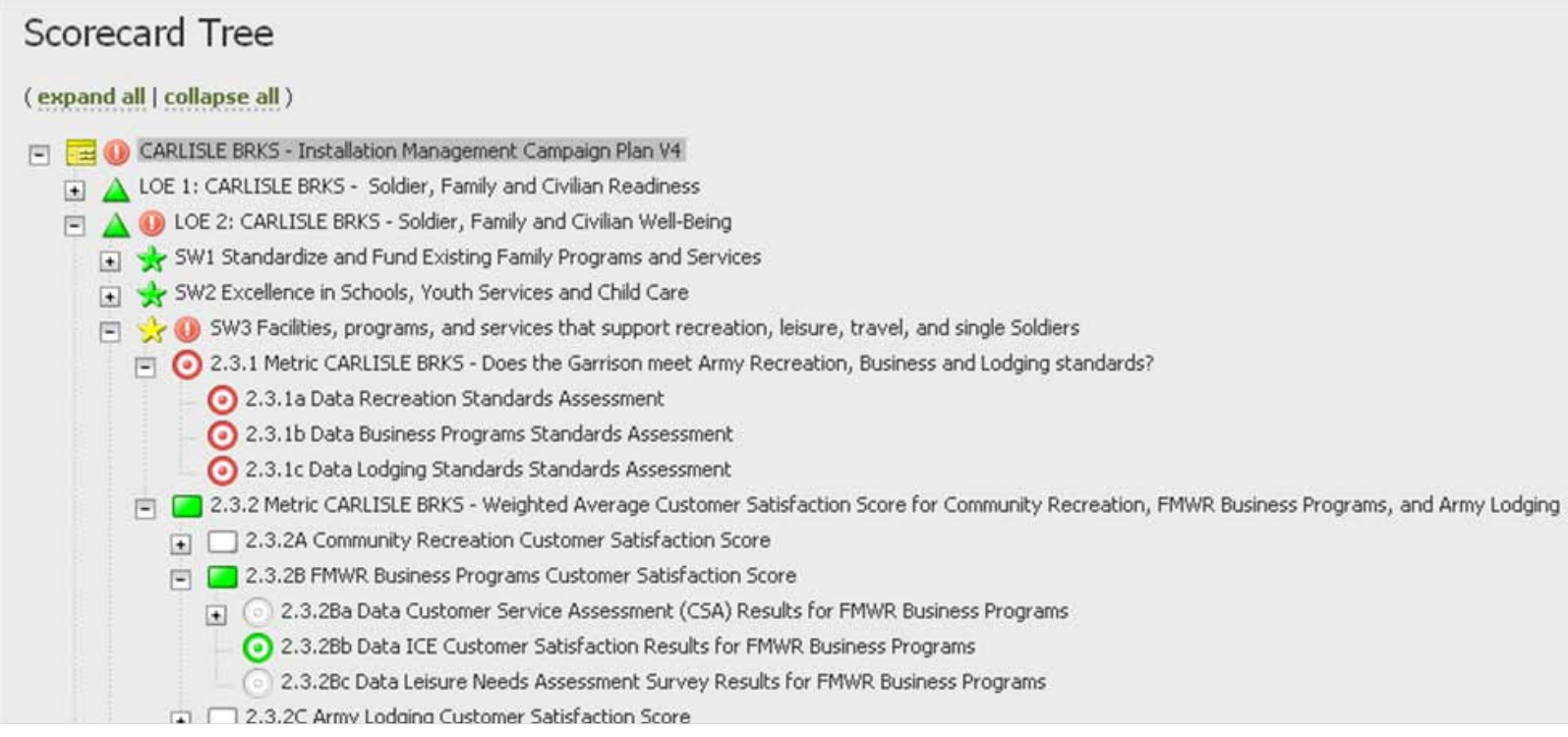

Figure 27. SMS Scorecard Tree Naming Convention Example

The SMS metric number corresponds to the metric number identified in Annex D of the IMCP. Looking at Metric 2.3.1 you can see that the three data elements used in the metric calculation are labeled 2.3.1a, 2.3.1b and 2.3.1c respectively. You can also see that an SMS Scorecard Tree Task element was used to represent IMCP metric 2.3.2.

As previously mentioned, SMS metrics can be either scored or unscored. Scored metrics can be represented in five different formats; Yes/No, Goal Only, Standard, 3 Color, and 3 Color Stabilize as depicted in Figure 28. 


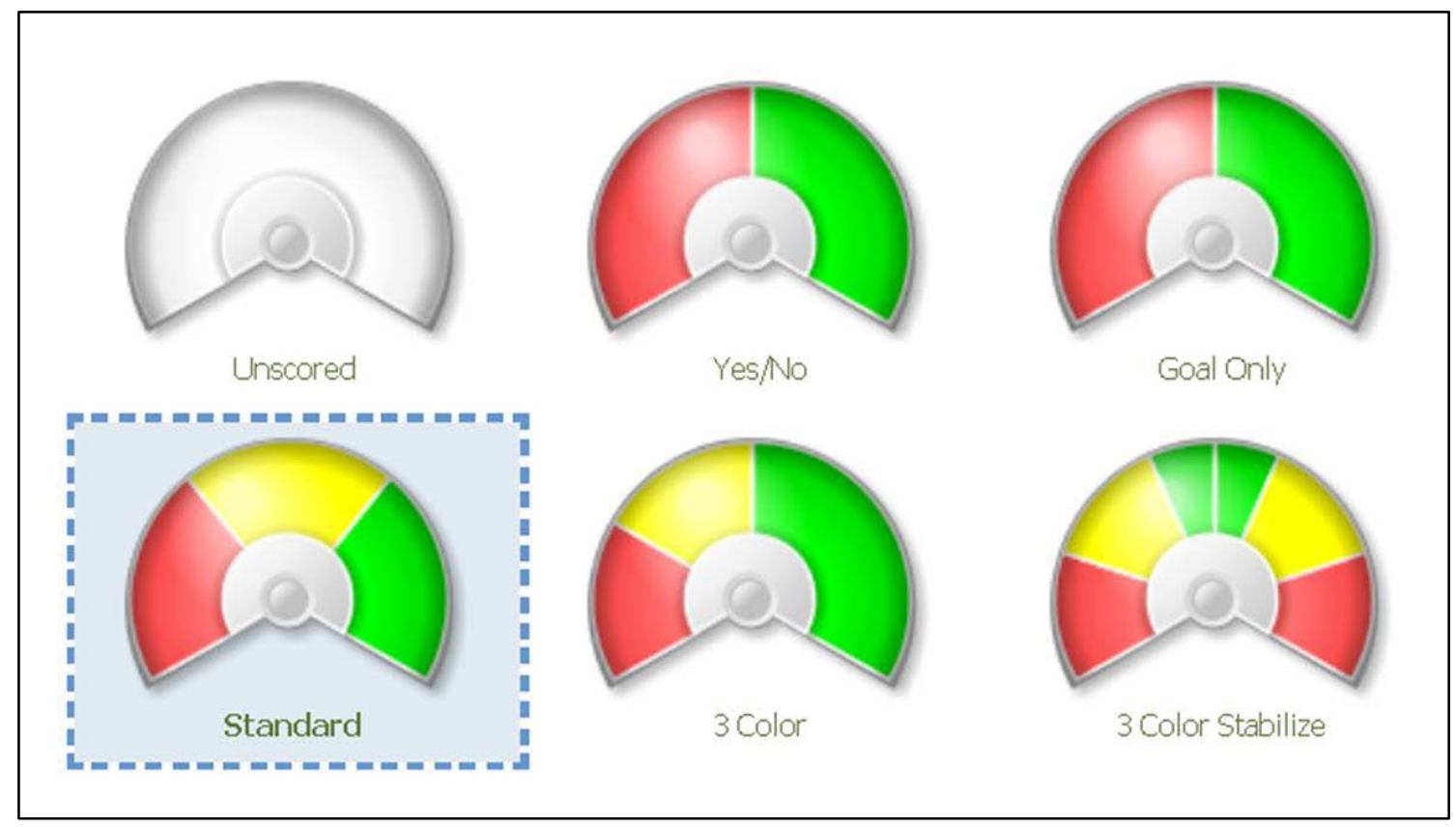

Figure 28. SMS Metric Types

Yes/No metrics, as the name implies, require a yes or no answer and result in a score of either 10, green or 0 , red. Yes/No metrics are most often used to measure compliance. They are an all or nothing proposition and do little to illustrate how well you are performing. Accordingly, use of Yes/No metrics should be minimized.

Goal Only metrics are similar to Yes/No metrics in that they are an all or nothing proposition, either the goal is met $(10$, green) or it is not met $(0$, red). The only difference is that a numeric value is substituted for the yes or no answer. If the target value is met, or exceeded the score is 10, fully green. If the target value is not met, by any amount, the score is 0 , fully red. Like Yes/No metrics, Goal only metrics should be used sparingly.

Standard is the SMS default metric type and scores a range of performance based on a zero to ten normalized scale where red ranges from 0 to 3.33, amber between 3.33 and 6.67 , and green from 6.67 to 10 . The system computes the metric score by adding the range between the green and red targets to the green target and subtracting it from the red target. That scale is then compared against the normalized zero to ten scale. In the Standard metric the range is fixed and the upper and lower limit values are adjusted. Figure 29 illustrates how Standard metric red-amber-green limits are calculated. In this example, a perfect score of 10 could only be achieved with an actual value of 110 . If the metric measures the percentage of employees who completed required training, a score of 10 could only be achieved if $110 \%$ of employees completed the required training. In this case, the rating scale would not accurately reflect actual performance. 


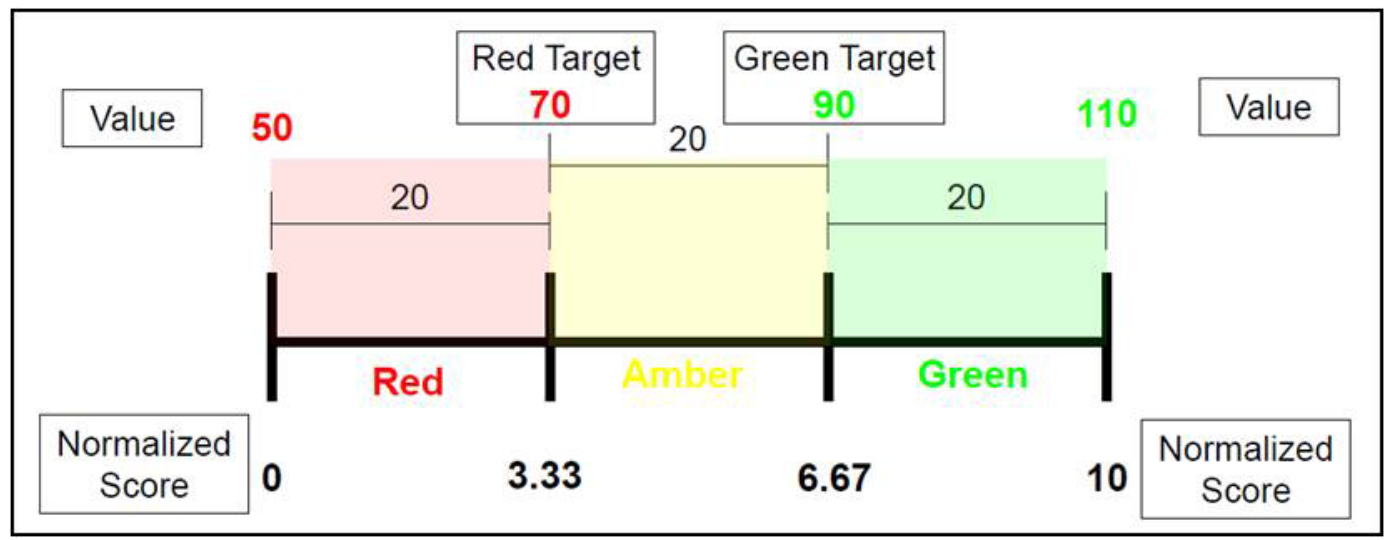

Figure 29. SMS Standard Metric Threshold Ranges

3 Color metrics are similar to Standard metrics in that they use red-amber-green scoring ranges. However, 3 Color metrics allow you to specify the upper and lower range limits. In this case the limits are fixed and the range is adjusted. Unlike the Standard metric, redamber-green ranges will vary. This type of metric works well when one of the ranges is much larger or smaller than the others, or when upper and lower limits are fixed, as in the example above. Figure 30 illustrates how 3 Color metric red-amber-green ranges are calculated.

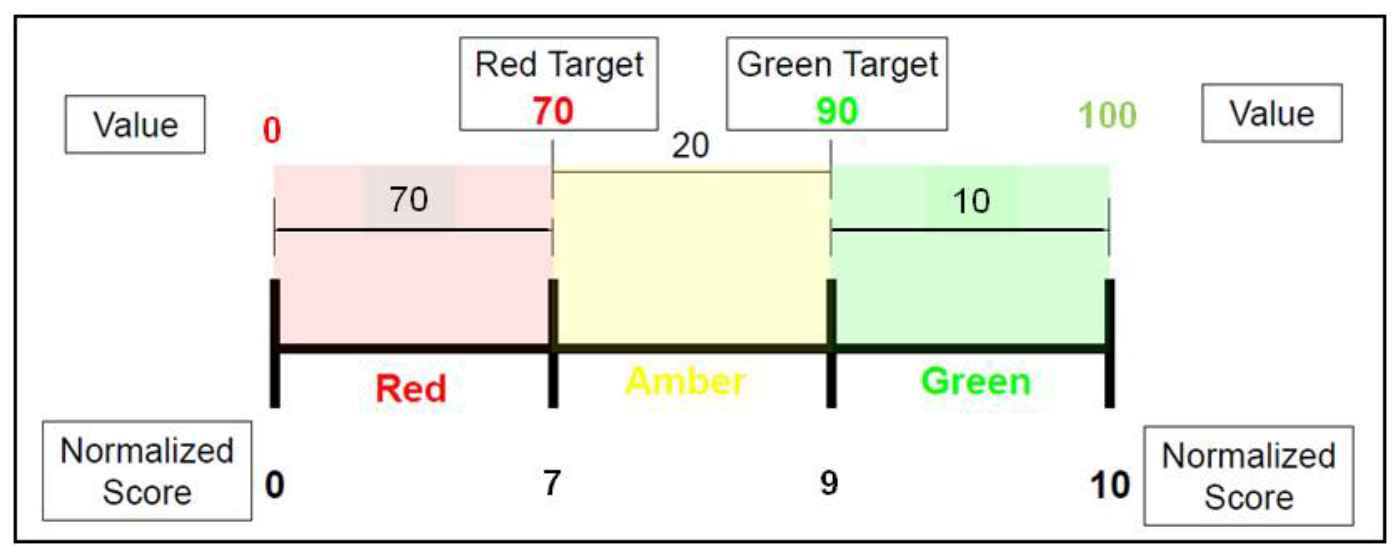

Figure 30. SMS 3 Color Metric Threshold Ranges

The final SMS metric type, 3 Color Stabilize, allows high and low red and amber ranges. High and low targets set the green range while high worst and low worst set the upper and lower limits. High and low red flags determine the high and low red and amber ranges. The best value identifies the value that equates to the normalized 10 score. This metric type is best used when values above or below an optimum value are undesirable. For example, up to a point a high barracks occupancy rate is good. Beyond that point there is the risk of running out of space or of over occupying the barracks. Figure 31 illustrates how 3 Color Stabilize metric red-amber-green-amber-red ranges are calculated. 
Installation Strategic Planning Guidebook

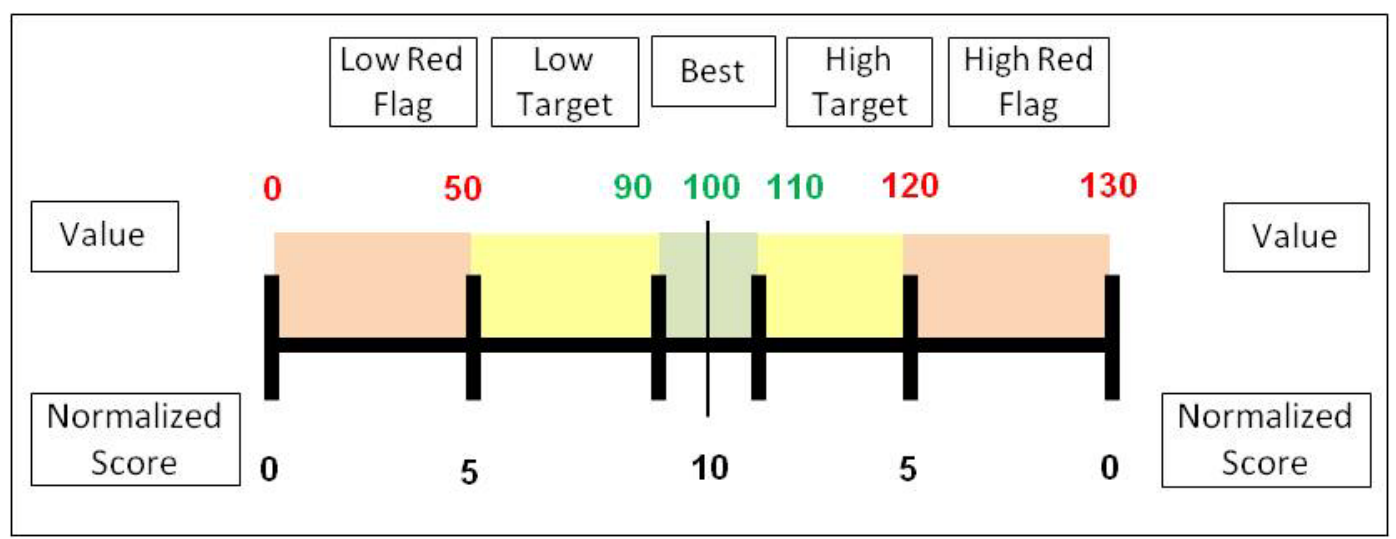

Figure 31. SMS 3 Color Metric Stabilize Threshold Ranges

Other factors to be aware of when creating SMS metrics include the frequency of data collection and the method used to aggregate data from different time periods. SMS allows for weekly, biweekly, monthly, quarterly, semi-annual FY, semi-annual, FY, annual, and biennial data collection. The period chosen will depend upon the availability of the data and the effort required to collect and enter it into SMS. SMS automatically aggregates data at higher time intervals according to the aggregation rules applied. Data can be aggregated by summing, averaging, or by using the most recent data. Care should be taken to consider which aggregation rule best suits the type of data the metric is measuring.

\section{Performance Measurement Presentation: Presenting Data in SMS}

ISP performance measures provide senior leaders, managers, and process owners and operators with a snapshot of current performance. Combined with historical data they can indicate progress or improvement. Sometimes historical data can be used to predict future trends. Performance measure information identifies where the installation (or specific unit) stands relative to its goals and objectives. It is incumbent upon the planning team, in conjunction with installation leadership to establish an appropriate method for presenting key performance information in a way that promotes and encourages the behaviors necessary to attain the organization's strategic vision, goals and objectives.

What used to take hours to create pivot tables, charts, trend lines and reports can be generated in SMS by Local Administrators, in far less time. With a little practice, the end user can create electronic, SMS-based, Briefing Books complete with Charts including trend lines, Reports, and Dashboards/Strategy Maps/Performance Management Review.

Briefing Books are compilations of relevant, past or current data in various formats that suit the user's needs. The Briefing Book is stored in SMS and is available for viewing to those that have access to that specific hierarchy node (e.g. HQ IMCOM) (Figure 32). Those that desire access must request it via the Local Administrator in the Plans Analysis and Integration Office (PAIO) at the Garrison or Installation. The illustration below, taken from SMS, shows that the Briefing Book titled "Garrison Leader Course FEB 2012" is located at the IMCOM Campaign Plan V4 node (on the left of the page). The briefing materials; Dashboards, Strategy Maps, Report and PMR in the form of a Quad Chart (Commander's Update Brief) are also housed in SMS (on the right side) and available 
electronically. This feature allows the presenter to drill down in any object within the Briefing Book. In short, copious backup slides are no longer as necessary as they once were.

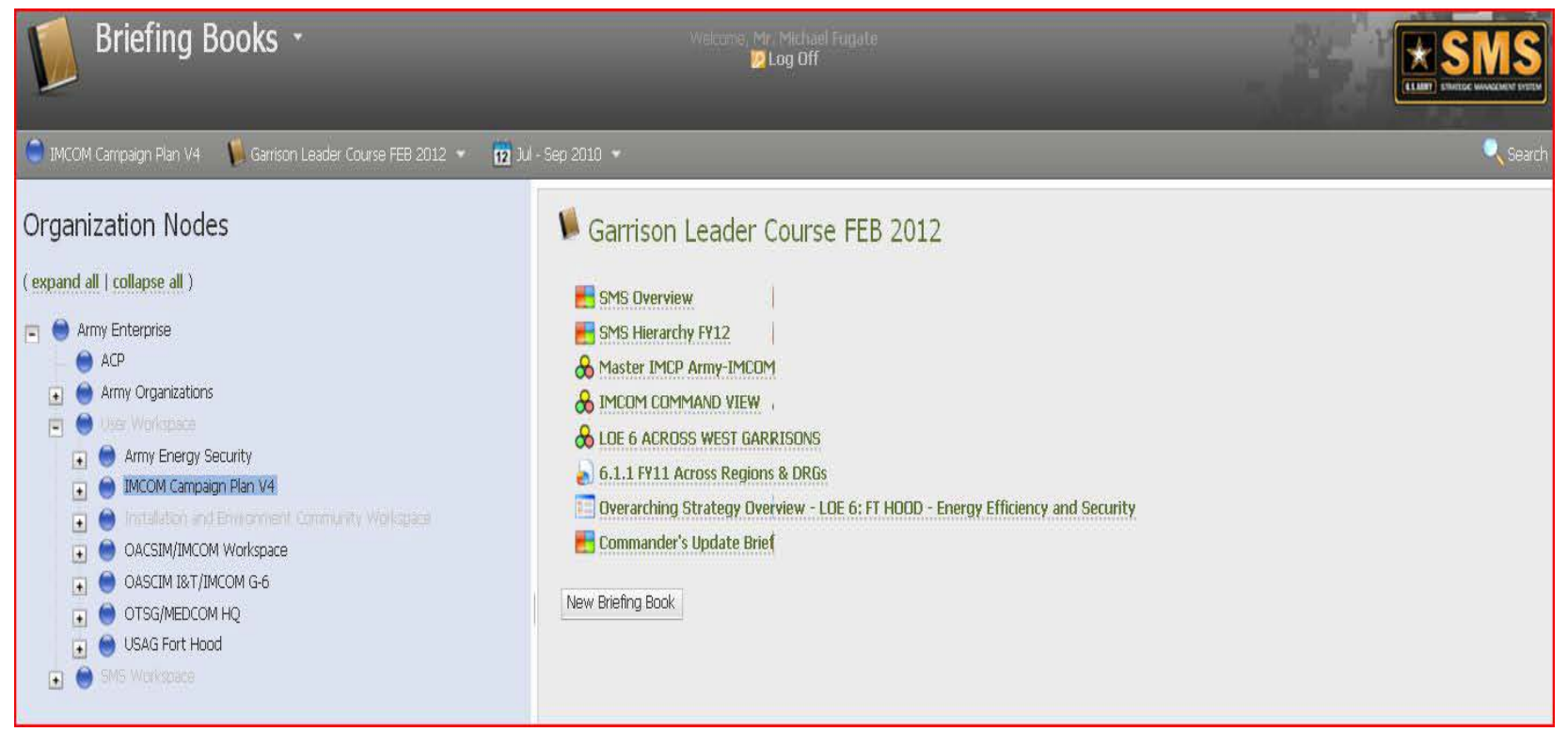

Figure 32. SMS Briefing Book Example

Charts are easily created in SMS. In the Briefing Book above, "6.1.1 FY11 Across Regions \& DRGs" is a chart created by the Chart Writer utility in SMS. Figure 33 is an example of what data, on a 1-10 scale, looks like over time, including the trend line.

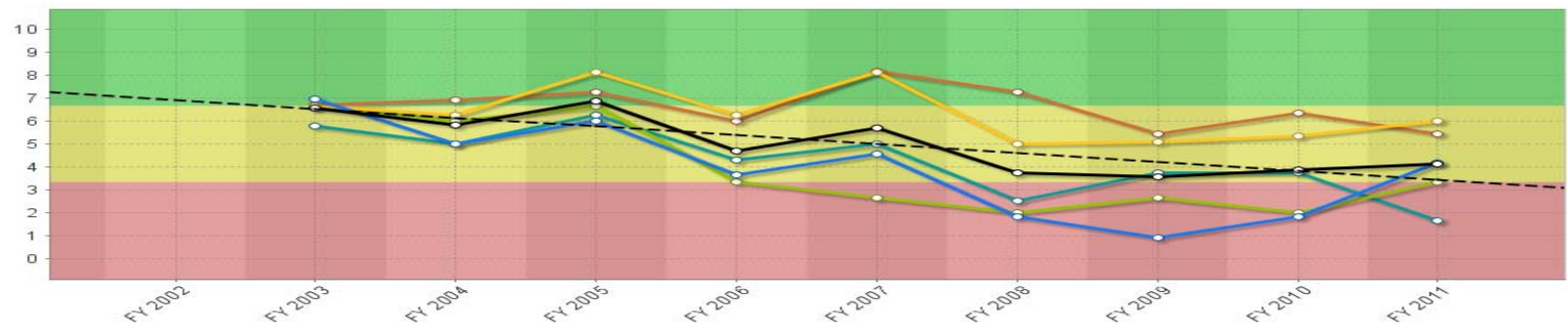

Figure 33. SMS Charts Example

Reports are just as easily created. Reports can be created independently. The report in Figure 34, below, was generated by the Reports Utility in conjunction with the chart in Figure 33, above. 
Installation Strategic Planning Guidebook

\begin{tabular}{|c|c|c|c|c|c|c|c|c|c|c|c|c|c|}
\hline $\begin{array}{l}\text { Series } \\
\text { Color }\end{array}$ & Hierarchy Node & $\begin{array}{c}\text { Organization } \\
\text { Node }\end{array}$ & Series & FY 2002 & FY 2003 & $\begin{array}{c}\text { FY } \\
2004\end{array}$ & FY 2005 & $\begin{array}{c}F Y \\
2006\end{array}$ & FY 2007 & $\begin{array}{c}\text { FY } \\
2008\end{array}$ & FY 2009 & $\begin{array}{c}F Y \\
2010\end{array}$ & FY 2011 \\
\hline & $\begin{array}{l}\text { 6.1.1 Metric - } \\
\text { Reduced Energy } \\
\text { Consumption }\end{array}$ & $\begin{array}{c}\text { IMCOM } \\
\text { Campaign Plan } \\
\text { V3 }\end{array}$ & Score & & 6.55 & 5.83 & 6.86 & 4.7 & 5.7 & 3.72 & 3.58 & 3.85 & 4.12 \\
\hline & $\begin{array}{l}\text { 6.1.1 HQ DIRECT } \\
\text { REPORTING - } \\
\text { Reduce energy } \\
\text { consumption }\end{array}$ & $\begin{array}{l}\text { HQ DIRECT } \\
\text { REPORTING }\end{array}$ & Score & & 6.95 & 5 & 6 & 3.64 & 4.55 & 1.82 & 0.91 & 1.82 & 4.17 \\
\hline & $\begin{array}{l}\text { 6.1.1 Metric } \\
\text { ATLANTIC - } \\
\text { Reduced energy } \\
\text { consumption }\end{array}$ & ATLANTIC & Score & & 6.66 & 6.25 & 8.12 & 6.25 & 8.12 & 5 & 5.11 & 5.33 & 6 \\
\hline & $\begin{array}{l}\text { 6.1.1 Metric } \\
\text { CENTRAL - } \\
\text { Reduced energy } \\
\text { consumption }\end{array}$ & CENTRAL & Score & & 6.65 & 6 & 6.67 & 3.33 & 2.67 & 2 & 2.67 & 2 & 3.33 \\
\hline & $\begin{array}{c}\text { 6.1.1 Metric - } \\
\text { Reduced energy } \\
\text { consumption - } \\
\text { EUROPE }\end{array}$ & EUROPE & Score & & 6.72 & 6.92 & 7.27 & 5.99 & 8.18 & 7.27 & 5.45 & 6.36 & 5.45 \\
\hline & $\begin{array}{c}\text { 6.1.1 PACIFIC } \\
\text { REGION - Reduce } \\
\text { energy } \\
\text { consumption }\end{array}$ & PACIFIC & Score & & 5.79 & 5 & 6.25 & 4.29 & 5 & 2.5 & 3.75 & 3.75 & 1.67 \\
\hline
\end{tabular}

Figure 34. SMS Reports Example

Dashboards, Strategy Maps, and Performance Management Reviews can mean the same thing, or different things. SMS doesn't draw a distinction between them. It simply presents the data in a format designed by the user. Think of them as an Overview. Figure 35 illustrates several examples with data (as displayed as Red/Amber/Green):
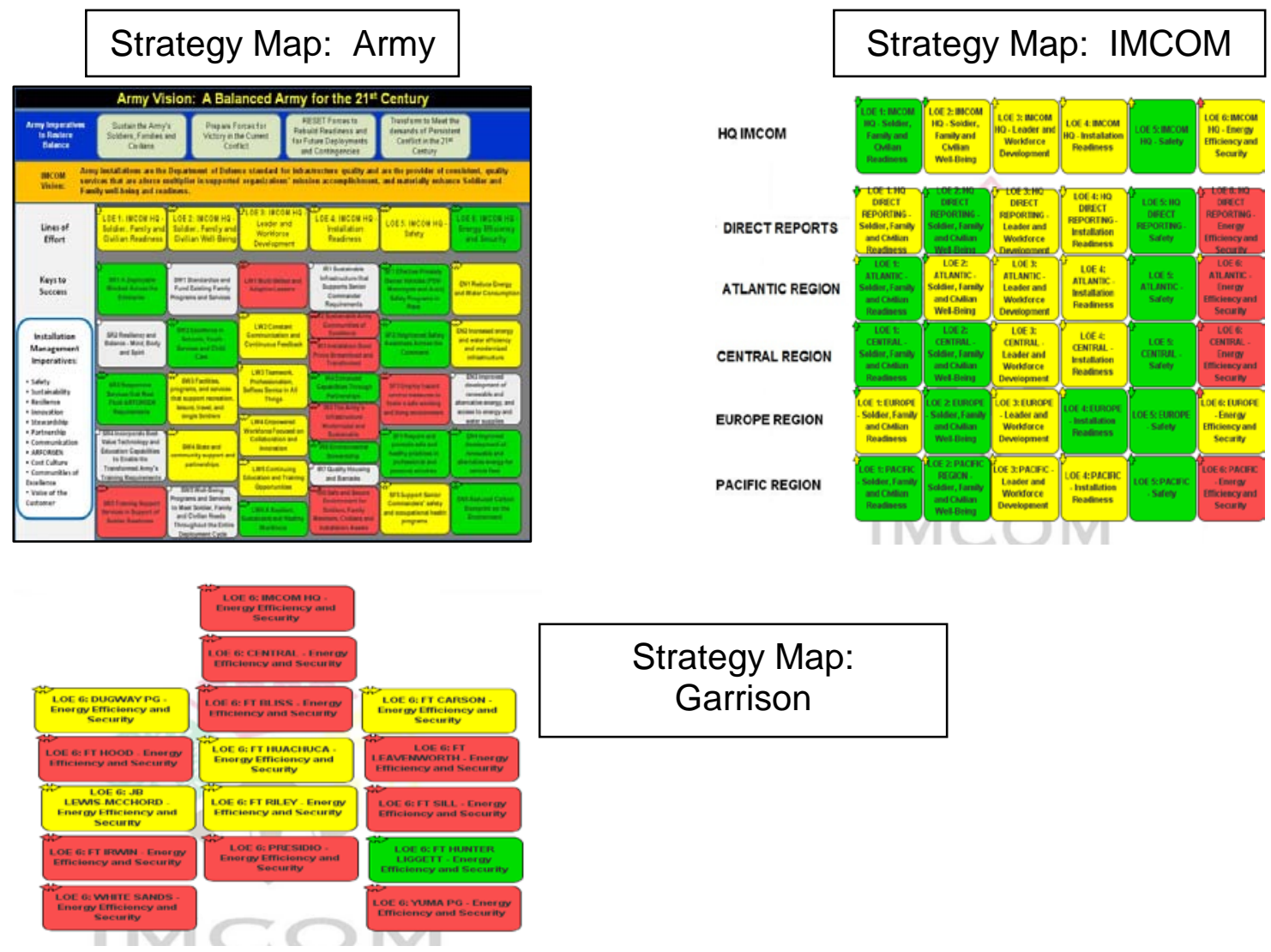

Figure 35. SMS Strategy Maps for Army, IMCOM and Garrison Levels

Finally, Figure 36 illustrates a Dashboard, created within SMS. 


\begin{tabular}{|c|c|c|}
\hline Key To Success & Perform & Metrics \\
\hline $\begin{array}{l}\text { EN 1: Reduce Energy and Water Consumption } \\
\text { EN 2: Increased energy and water efficiency } \\
\text { and modernized infrastructure } \\
\text { EN 3: Improved development of renewable } \\
\text { and alternative energy, and access to energy } \\
\text { and water supplies } \\
\text { EN4: Improved development of renewable and } \\
\text { alternative energy for vehicle fleet } \\
\text { EN 5: Reduced Carbon Bootprint on the } \\
\text { Environment }\end{array}$ & $\begin{array}{l}\text { 6.1.1 Score: } 10 \\
\text { Red: } 82.1 \% \text { / Green: } 82 \%\end{array}$ & $\begin{array}{c}\begin{array}{c}\text { Energy Reduction } \\
\text { Reduce Energy Consumption } \\
\text { per Sq Ft. }\end{array} \\
\text { FY11: HQ IMCOM }\end{array}$ \\
\hline SR1 Metrics: & \multicolumn{2}{|c|}{ Proposed Way Ahead } \\
\hline FT HOOD - 6.1.1 Quarterly Data & \multicolumn{2}{|c|}{$\begin{array}{l}\text { 6.1.1: } \\
\text { 1. Continue reducing energy consumption through } \\
\text { all possible, reasonable, means to establish a } \\
\text { baseline. } \\
\text { 2. Invest in energy-reducing infrastructure } \\
\text { 3. Build alternative/renewable energy } \\
\text { infrastructure }\end{array}$} \\
\hline
\end{tabular}

Figure 36. SMS Dashboard Example 


\section{Appendix S: Strategic Planning Checklist}

\begin{tabular}{|c|c|c|c|c|}
\hline$\#$ & Strategic Plan Evaluation Criteria & Yes/No & Finding & Recommendation \\
\hline 1. & $\begin{array}{l}\text { Does the plan have an attractive cover } \\
\text { identifying the organization, logo, and } \\
\text { planning years? }\end{array}$ & & & \\
\hline 2. & Is the plan in color? & & & \\
\hline 3. & $\begin{array}{l}\text { Are pictures used and well-placed } \\
\text { throughout the plan? }\end{array}$ & & & \\
\hline 4. & Does the plan have an Appendix? & & & \\
\hline 5. & $\begin{array}{l}\text { Does the plan contain charts and } \\
\text { tables that easily and clearly present } \\
\text { information? }\end{array}$ & & & \\
\hline 6. & $\begin{array}{l}\text { Is it evident the planning team used } \\
\text { the IMCOM A-to-G Strategic Planning } \\
\text { Model? }\end{array}$ & & & \\
\hline 7. & $\begin{array}{l}\text { Are the planning years clearly and } \\
\text { consistently identified throughout the } \\
\text { document, both in the content and in } \\
\text { the header or footers of the document? }\end{array}$ & & & \\
\hline 8. & $\begin{array}{l}\text { Is the mailing address, phone numbers } \\
\text { and proponent office/point of contact } \\
\text { contained in the document? }\end{array}$ & & & \\
\hline 9. & $\begin{array}{l}\text { Does the document have a Table of } \\
\text { Contents? }\end{array}$ & & & \\
\hline 10. & $\begin{array}{l}\text { Are pages and titles in the Table of } \\
\text { Contents accurate and complete? }\end{array}$ & & & \\
\hline 11. & $\begin{array}{l}\text { Does the document start with a letter } \\
\text { of intent and/or summary of strategic } \\
\text { priorities and focus? }\end{array}$ & & & \\
\hline 12. & $\begin{array}{l}\text { Is the planning process and cycle used } \\
\text { for developing the plan outlined or } \\
\text { summarized in the document? }\end{array}$ & & & \\
\hline 13. & $\begin{array}{l}\text { Does the plan include a clear and well } \\
\text { organized Organizational Profile? }\end{array}$ & & & \\
\hline 14. & $\begin{array}{l}\text { Have planning assumptions been } \\
\text { documented in the plan? }\end{array}$ & & & \\
\hline 15. & $\begin{array}{l}\text { Does the plan have a Mission } \\
\text { Statement? }\end{array}$ & & & \\
\hline 16. & $\begin{array}{l}\text { Are Core Values and Guiding } \\
\text { Principles contained in the document? }\end{array}$ & & & \\
\hline 17. & $\begin{array}{l}\text { Does the Mission Statement clearly } \\
\text { identify the purpose of the organization } \\
\text { and what the key products and } \\
\text { services are and who the customers } \\
\text { are? }\end{array}$ & & & \\
\hline 18. & $\begin{array}{l}\text { Does the plan have a } \text { Vision } \\
\text { Statement? }\end{array}$ & & & \\
\hline
\end{tabular}




\begin{tabular}{|c|c|c|c|c|}
\hline 19. & $\begin{array}{l}\text { Does the Vision Statement describe a } \\
\text { clear end-state or desired conditions or } \\
\text { outcomes in the future? }\end{array}$ & & & \\
\hline 20 . & $\begin{array}{l}\text { Are Environmental Scanning and } \\
\text { SWOT analysis visible in the plan? } \\
\text { (SWOT: Strengths, Weaknesses, } \\
\text { Opportunities and Threats) }\end{array}$ & & & \\
\hline 21. & $\begin{array}{l}\text { Are the Goals clearly written and } \\
\text { identify the future desired outcomes? }\end{array}$ & & & \\
\hline 22. & $\begin{array}{l}\text { Are the Objectives consistently and } \\
\text { accurately aligned under the Goals? }\end{array}$ & & & \\
\hline 23. & $\begin{array}{l}\text { Is there a list of references used for the } \\
\text { development of the plan? }\end{array}$ & & & \\
\hline 24. & Is there a Glossary of Acronyms? & & & \\
\hline 25. & Is there a Glossary of Terms? & & & \\
\hline 26. & $\begin{array}{l}\text { Have Goal and Objective Champions } \\
\text { been identified? }\end{array}$ & & & \\
\hline 27. & $\begin{array}{l}\text { Has responsibility been assigned for } \\
\text { each of the initiatives and associated } \\
\text { actions contained in the plan? }\end{array}$ & & & \\
\hline 28. & $\begin{array}{l}\text { Do the initiatives and actions have } \\
\text { clear and reliable measures and } \\
\text { targets? }\end{array}$ & & & \\
\hline 29. & $\begin{array}{l}\text { Is the implementation plan clearly } \\
\text { identified and articulated in the plan? }\end{array}$ & & & \\
\hline 30. & $\begin{array}{l}\text { Does the plan contain a } \\
\text { communication strategy for ensuring } \\
\text { that all that need to know are aware of } \\
\text { the plan? }\end{array}$ & & & \\
\hline 31. & $\begin{array}{l}\text { Does the plan have a process for } \\
\text { adjusting actions and initiatives in } \\
\text { response to change? }\end{array}$ & & & \\
\hline 32. & $\begin{array}{l}\text { Is the plan easy to read and the } \\
\text { strategy clearly understood? }\end{array}$ & & & \\
\hline 33. & $\begin{array}{l}\text { Does the format of the plan flow } \\
\text { easily? }\end{array}$ & & & \\
\hline 34. & $\begin{array}{l}\text { Is the length of the plan conducive for } \\
\text { easily reading and understanding the } \\
\text { plan? }\end{array}$ & & & \\
\hline 35. & $\begin{array}{l}\text { Does the plan contain a schedule for } \\
\text { review and update? }\end{array}$ & & & \\
\hline 36 & $\begin{array}{l}\text { Does the plan include how the IPB will } \\
\text { be utilized? }\end{array}$ & & & \\
\hline
\end{tabular}




\section{Appendix T: References}

PUBLICATIONS. Publications applicable to this process are listed in Table 17 below. This is not an all inclusive list, as other publication may apply but are not identified below.

Table 17. Publications Related to the ISSP Process

\begin{tabular}{|c|c|}
\hline Title & Source Location \\
\hline Army Campaign Plan, 2011 & $\begin{array}{l}\text { http://www.army.mil/-news/2011/02/07/51471-army- } \\
\text { campaign-plan-2011/ }\end{array}$ \\
\hline $\begin{array}{l}2011 \text { Army Posture } \\
\text { Statement; Sustainability }\end{array}$ & $\begin{array}{l}\text { http://www.army.mil/standto/archive/issue.php?issue =2012 } \\
-02-17\end{array}$ \\
\hline $\begin{array}{l}\text { Army Sustainability } \\
\text { Campaign Plan, } 2010\end{array}$ & $\begin{array}{l}\text { http://aec.army.mil/usaec/sustainability/campaign- } \\
\text { plan 2010.pdf }\end{array}$ \\
\hline $\begin{array}{l}\text { Installation Management } \\
\text { Campaign Plan, v4, } 2012\end{array}$ & http://www.imcom.army.mil/hq/about/campaign plan/ \\
\hline Executive Orders 13423 & http://edocket.access.gpo.gov/2007/pdf/07-374.pdf \\
\hline Executive Orders 13514 & http://edocket.access.gpo.gov/2009/pdf/E9-24518.pdf \\
\hline Energy Policy Act of 2005 & http://doi.net/iepa/EnergyPolicyActof2005.pdf \\
\hline $\begin{array}{l}\text { Energy Independence and } \\
\text { Security Act of } 2007\end{array}$ & $\begin{array}{l}\text { http://www.gpo.gov/fdsys/pkg/PLAW- } \\
\text { 110publ140/pdf/PLAW-110publ140.pdf }\end{array}$ \\
\hline $\begin{array}{l}\text { Army Regulation (AR) } \\
5-1 \text {, Total Army Quality } \\
\text { Management }\end{array}$ & http://www.apd.army.mil/pdffiles/r5 1.pdf \\
\hline $\begin{array}{l}\text { AR 11-32, Army Long-Range } \\
\text { Planning System }\end{array}$ & $\begin{array}{l}\text { http://www.apd.army.mil/pdffiles/r11 32.pdf Reader must } \\
\text { extrapolate the intent of this dated regulation as may be } \\
\text { applied to installation management. }\end{array}$ \\
\hline $\begin{array}{l}\text { Army Environmental Policy } \\
\text { Institute }\end{array}$ & http://www.aepi.army.mil/ \\
\hline $\begin{array}{l}\text { AR 200-1, Environmental } \\
\text { Protection and Enhancement }\end{array}$ & http://www.apd.army.mil/pdffiles/r200 1.pdf \\
\hline $\begin{array}{l}\text { AR 210-20, Real Property } \\
\text { Master Planning for Army } \\
\text { Installations }\end{array}$ & http://www.apd.army.mil/pdffiles/r210 20.pdf \\
\hline $\begin{array}{l}\text { AR 350-1, Army Training and } \\
\text { Leader Development }\end{array}$ & http://www.apd.army.mil/pdffiles/r350 1.pdf \\
\hline $\begin{array}{l}\text { AR 420-1, Army Facilities } \\
\text { Management }\end{array}$ & http://www.apd.army.mil/pdffiles/r420 1.pdf \\
\hline $\begin{array}{l}\text { DA PAM 600-45, Army } \\
\text { Communities of Excellence }\end{array}$ & http://www.apd.army.mil/pdffiles/p600 45.pdf \\
\hline $\begin{array}{l}\text { Army Compatible Use Buffer } \\
\text { Program }\end{array}$ & http://aec.army.mil/usaec/acub/index.html \\
\hline $\begin{array}{l}\text { Army Sustainability Report } \\
2009\end{array}$ & $\begin{array}{l}\text { http://www.aepi.army.mil/docs/whatsnew/FINALArmySusta } \\
\text { inabilityReport2010.pdf } \\
\text { This is an annual Army report prepared by the Army } \\
\text { Environmental Policy Institute following GRI Standards, } \\
\text { released in May of the following year. }\end{array}$ \\
\hline Army Sustainable Range & https://srp.army.mil/ \\
\hline
\end{tabular}


Installation Strategic Planning Guidebook

\begin{tabular}{|c|c|}
\hline Title & Source Location \\
\hline \multicolumn{2}{|l|}{ Program } \\
\hline Army Sustainability & http://www.sustainability.army.mil/ \\
\hline Army Family Toolbox & http://www.imcom.army.mil/hq/armyftool/ \\
\hline $\begin{array}{l}\text { Army Sustainability 2001- } \\
2008\end{array}$ & $\begin{array}{l}\text { http://www.aepi.army.mil/docs/timeline brochure FINAL.p } \\
\underline{\text { df }}\end{array}$ \\
\hline $\begin{array}{l}\text { Army Strategy for the } \\
\text { Environment, } 2004\end{array}$ & $\begin{array}{l}\text { http://www.asaie.army.mil/Public/ESOH/doc/ArmyEnvStrat } \\
\text { egy.pdf }\end{array}$ \\
\hline $\begin{array}{l}\text { Worldwide Emerging } \\
\text { Environmental Issues } \\
\text { Affecting the US Military }\end{array}$ & http://www.aepi.army.mil/reports/ \\
\hline $\begin{array}{l}\text { Army Sustainability } \\
\text { Webpage }\end{array}$ & http://www.sustainability.army.mil/ \\
\hline $\begin{array}{l}\text { Army Energy and Water } \\
\text { Program }\end{array}$ & http://army-energy.hqda.pentagon.mil/ \\
\hline $\begin{array}{l}\text { Army Communities of } \\
\text { Excellence }\end{array}$ & http://www.hqda.army.mil/leadingchange/APIC/ \\
\hline $\begin{array}{l}\text { DoD Dictionary of Military } \\
\text { Terms }\end{array}$ & http://www.dtic.mil/doctrine/dod dictionary/ \\
\hline \multirow{2}{*}{$\begin{array}{l}\text { DoD's Environmental } \\
\text { Research Programs } \\
\end{array}$} & http://www.estcp.org/ \\
\hline & http://www.serdp.org/ \\
\hline $\begin{array}{l}\text { DoD Strategic Sustainability } \\
\text { Performance Plan }\end{array}$ & $\begin{array}{l}\text { http://www.acq.osd.mil/ie/download/green energy/dod su } \\
\text { stainability/DoD\%20SSPP-PUBLIC-26Aug10.pdf }\end{array}$ \\
\hline $\begin{array}{l}\text { Defense Advanced Research } \\
\text { Projects }\end{array}$ & http://www.darpa.mil/ \\
\hline $\begin{array}{l}\text { US Army Environmental } \\
\text { Command, Sustainability }\end{array}$ & http://aec.army.mil/usaec/sustainability/index.html \\
\hline Army Research Office & http://www.aro.army.mil/ \\
\hline $\begin{array}{l}\text { IMCOM Strategic Planning } \\
\text { Division }\end{array}$ & https://www.us.army.mil/suite/page/608972 \\
\hline $\begin{array}{l}\text { IMCOM Workforce } \\
\text { Development }\end{array}$ & https://www.us.army.mil/suite/page/616432 \\
\hline $\begin{array}{l}\text { IMCOM Talent Management } \\
\text { Division }\end{array}$ & $\begin{array}{l}\text { http://www.imcom.army.mil/hq/about/organization/directora } \\
\text { tes/hr/workforce/ }\end{array}$ \\
\hline $\begin{array}{l}\text { GSA Strategically } \\
\text { Sustainable }\end{array}$ & http://www.gsa.gov/portal/category/26433 \\
\hline $\begin{array}{l}\text { Engineering Knowledge On- } \\
\text { line, Sustainable Design and } \\
\text { Development }\end{array}$ & https://eko.usace.army.mil/fa/sdd/ \\
\hline
\end{tabular}




\section{Appendix U: Glossary of Terms}

\begin{tabular}{|c|c|c|}
\hline \multicolumn{3}{|c|}{ Integrated Strategic and Sustainability Planning Definitions } \\
\hline Term & Definition & $\begin{array}{l}\text { Sourcel } \\
\text { Reference }\end{array}$ \\
\hline $\begin{array}{l}\text { Army } \\
\text { Communities of } \\
\text { Excellence }\end{array}$ & $\begin{array}{l}\text { An Army program for the total Army which focuses on } \\
\text { improvements in the environment, in services and } \\
\text { facilities, and improving working and living conditions, } \\
\text { renewing pride and developing a sense of } \\
\text { accomplishment in every member of the community. The } \\
\text { by-product of the program is designed to increase } \\
\text { performance and productivity as the Army focuses its } \\
\text { resources toward the common goal of readiness. }\end{array}$ & $\begin{array}{l}\text { DA PAM 600- } \\
\text { 45, } 1 \text { Aug } 1991\end{array}$ \\
\hline Action Plans & $\begin{array}{l}\text { Documents that describe the specific method or process } \\
\text { to achieve the results called for by one or more } \\
\text { objectives of the strategic plan. Action plans document } \\
\text { the "who, what, when, where, and why" of the objective } \\
\text { to be achieved. Additionally, they document the } \\
\text { resources required to accomplish each objective. }\end{array}$ & $\begin{array}{l}\text { AR 5-1, Total } \\
\text { Army Quality } \\
\text { Management, } \\
15 \text { Mar } 2002\end{array}$ \\
\hline $\begin{array}{l}\text { Army Regulation } \\
\text { (AR) }\end{array}$ & $\begin{array}{l}\text { A rule issued by a government agency that provides } \\
\text { details on how legislation will be implemented and may } \\
\text { set specific minimum requirements for the public to meet } \\
\text { if they are to be considered in compliance with the } \\
\text { legislation and the regulations that implement it. }\end{array}$ & \\
\hline Campaign Plan & $\begin{array}{l}\text { A joint operation plan for a series of related major } \\
\text { operations aimed at achieving strategic or operational } \\
\text { objectives within a given time and space. See also } \\
\text { campaign; campaign planning. }\end{array}$ & $\begin{array}{l}\text { JP 1-02, DoD } \\
\text { Dictionary of } \\
\text { Military and } \\
\text { Associated } \\
\text { Terms }\end{array}$ \\
\hline $\begin{array}{l}\text { Challenge } \\
\text { Statement }\end{array}$ & $\begin{array}{l}\text { A brief statement that assimilates multiple issues of } \\
\text { concern for a given planning team or core business } \\
\text { area, and is intended to focus subsequent planning } \\
\text { steps on the key or most critical issues. }\end{array}$ & \\
\hline Climate Change & $\begin{array}{l}\text { Changes in long-term averages of daily weather over } \\
\text { time. }\end{array}$ & NASA \\
\hline $\begin{array}{l}\text { Continuity of } \\
\text { Operations Plan } \\
\text { (COOP) }\end{array}$ & $\begin{array}{l}\text { Army regulation that establishes responsibilities, policies } \\
\text { and policy guidance to ensure effective execution of } \\
\text { critical Army missions and functions. }\end{array}$ & AR500-3 \\
\hline $\begin{array}{l}\text { Contemporary } \\
\text { Operating } \\
\text { Environment }\end{array}$ & $\begin{array}{l}\text { The synergistic combination of all the critical variables } \\
\text { and actors that create the conditions, circumstances, } \\
\text { and influence that can affect military/base operations } \\
\text { today and in the near and mid-term. }\end{array}$ & \\
\hline $\begin{array}{l}\text { Cross-functional } \\
\text { (teams) }\end{array}$ & $\begin{array}{l}\text { Planning teams that include both stakeholders and } \\
\text { process owners, not solely structured along traditional } \\
\text { organizational lines. }\end{array}$ & \\
\hline $\begin{array}{l}\text { Department of } \\
\text { Defense (DoD) }\end{array}$ & $\begin{array}{l}\text { Federal agency responsible for maintaining and } \\
\text { organizing national security efforts and our country. }\end{array}$ & \\
\hline End-State & $\begin{array}{l}\text { The set of required conditions that defines achievement } \\
\text { of the commander's objectives. }\end{array}$ & \\
\hline
\end{tabular}




\begin{tabular}{|c|c|c|}
\hline \multicolumn{3}{|c|}{ Integrated Strategic and Sustainability Planning Definitions } \\
\hline Term & Definition & $\begin{array}{l}\text { Sourcel } \\
\text { Reference }\end{array}$ \\
\hline $\begin{array}{l}\text { Facilitator's } \\
\text { ISSP Guidebook } \\
\text { Companion } \\
\text { Slides }\end{array}$ & $\begin{array}{l}\text { An informal document prepared for and used by ISSP } \\
\text { process facilitators during each ISSP working sessions. } \\
\text { It outlines the step-by-step flow of actions that the } \\
\text { facilitator needs to complete during and provides a } \\
\text { general set of session slides for use during the specific } \\
\text { ISSP session being conducted. The facilitator } \\
\text { companion slides also documents the products that a } \\
\text { working session is intended to achieve and a } \\
\text { recommended approach for each facilitator to follow. }\end{array}$ & \\
\hline $\begin{array}{l}\text { Goals and } \\
\text { Objectives }\end{array}$ & $\begin{array}{l}\text { Goals and objectives describe what the program/project } \\
\text { is striving to accomplish. Goals depict general } \\
\text { programmatic outcomes, while objectives specify more } \\
\text { specific outcomes. It is common to have several } \\
\text { objectives for each program/project goal. For each goal, } \\
\text { develop objectives that will help ascertain if the goal is } \\
\text { being reached. Objectives are tangible and should follow } \\
\text { the SMART model: Specific, Measurable, Attainable, } \\
\text { Results-oriented and Time-bound. }\end{array}$ & $\begin{array}{l}\text { Office of } \\
\text { Institutional } \\
\text { Research and } \\
\text { Assessment, } \\
\text { Syracuse } \\
\text { University }\end{array}$ \\
\hline Governance & $\begin{array}{l}\text { The term "governance" refers to the system of } \\
\text { management and controls exercised in the stewardship } \\
\text { of your organization. }\end{array}$ & $\begin{array}{l}\text { Baldridge } \\
\text { National } \\
\text { Quality } \\
\text { Program } \\
2010-2011 \\
\text { Criteria for } \\
\text { Performance } \\
\text { Excellence }\end{array}$ \\
\hline Indicator & $\begin{array}{l}\text { An item of information which reflects the intention or } \\
\text { capability of the responsible and/or accountable POC to } \\
\text { adopt or reject a course of action. }\end{array}$ & JP 2-0 \\
\hline Installation & $\begin{array}{l}\text { An aggregation of contiguous or near contiguous real } \\
\text { property holdings commanded by a centrally-selected } \\
\text { commander. Installations represent management } \\
\text { organizations. An installation may be made of one or } \\
\text { more sites. For the purposes of this regulation, } \\
\text { installation will also include Army Reserve Regional } \\
\text { Readiness Commands. }\end{array}$ & $\begin{array}{l}\text { DA } \\
\text { Memorandum } \\
\text { DAIM-ZA, } 2 \\
\text { December } \\
2005 .\end{array}$ \\
\hline $\begin{array}{l}\text { Installation } \\
\text { Management } \\
\text { Campaign Plan } \\
\text { (IMCP) }\end{array}$ & $\begin{array}{l}\text { IMCP is the detailed strategy map that will guide } \\
\text { installations to more effectively and efficiently support } \\
\text { Army readiness, sustain the All-Volunteer Force, and } \\
\text { provide the necessary infrastructure for current and } \\
\text { future mission requirements. }\end{array}$ & $\begin{array}{l}\text { IMCP v.4 } \\
\text { https://www.us } \\
\text { army.mil/suite/ } \\
\text { doc/27694035 } \\
\end{array}$ \\
\hline $\begin{array}{l}\text { Installation } \\
\text { Planning Board }\end{array}$ & $\begin{array}{l}\text { Institutionalizes a mechanism for enhanced } \\
\text { communication and decision making at the installation, } \\
\text { as well as providing a template for prioritizing local } \\
\text { requirements, gauging impact on readiness, and } \\
\text { highlighting issues for elevation to Army senior leaders. }\end{array}$ & \\
\hline
\end{tabular}




\begin{tabular}{|c|c|c|}
\hline \multicolumn{3}{|c|}{ Integrated Strategic and Sustainability Planning Definitions } \\
\hline Term & Definition & \begin{tabular}{|l|} 
Sourcel \\
Reference
\end{tabular} \\
\hline ISSP & $\begin{array}{l}\text { A strategic planning process that allows installations to } \\
\text { bring together stakeholders from throughout the } \\
\text { installation community to think proactively about future } \\
\text { challenges with respect to sustainability. The result of } \\
\text { the planning process is a strategic plan that addresses } \\
\text { not only the physical and environmental components of } \\
\text { Army installations, such as buildings and natural } \\
\text { resources, but also management practices, human } \\
\text { capital and community involvement. An ISSP is unique } \\
\text { in that it looks at a 25-year period and reviews life-cycle } \\
\text { cost-effective investments to meet future missions and } \\
\text { community aspirations. }\end{array}$ & $\begin{array}{l}\text { Army } \\
\text { Sustainability } \\
\text { Report } \\
2009\end{array}$ \\
\hline $\begin{array}{l}\text { (The) ISSP } \\
\text { process }\end{array}$ & $\begin{array}{l}\text { The ISSP process is the integration of existing and } \\
\text { extension of Garrison planning into installation-wide } \\
\text { planning that incorporates the principles of sustainability. } \\
\text { When Garrison planning is mature, ISSP process serves } \\
\text { to enhance integration of the principles of sustainability } \\
\text { with other planning efforts and to encourage innovation } \\
\text { resulting in an ISP. When Garrison planning is less } \\
\text { mature, the ISSP process guides planners towards an } \\
\text { initial long-, mid- and short-range installation-wide plan } \\
\text { while providing training and tools necessary for } \\
\text { measurable progress and continual improvement. }\end{array}$ & $\begin{array}{l}\text { IMCOM } \\
\text { Operations } \\
\text { Order 11-052: } \\
\text { Region } \\
\text { Sustainability } \\
\text { Awareness } \\
\text { Training and } \\
\text { Strategic } \\
\text { Planning Site } \\
\text { Assistance } \\
\text { Visits; Nov } \\
2010 \\
\end{array}$ \\
\hline Issue & $\begin{array}{l}\text { The situation or challenge that needs to be resolved to } \\
\text { ensure installation, process, workforce, or infrastructure } \\
\text { sustainability. }\end{array}$ & \\
\hline Issue Statement & $\begin{array}{l}\text { A concise description of an issue to be resolved in terms } \\
\text { of its impacts on the mission, community and } \\
\text { environment. }\end{array}$ & \\
\hline Keys to Success & $\begin{array}{l}\text { The long-term unchanging vision towards which goals } \\
\text { and subsequent objectives, actions and initiatives are } \\
\text { aligned. }\end{array}$ & IMCP v.4 \\
\hline $\begin{array}{l}\text { Line of Effort } \\
\text { (LOE) }\end{array}$ & $\begin{array}{l}\text { The foundation of the Installation Management } \\
\text { Campaign Plan is the Commander's Intent. This intent } \\
\text { has been broken down into six Lines of Effort (LOEs) } \\
\text { that drive the overall strategy }\end{array}$ & IMCP v.4 \\
\hline $\begin{array}{l}\text { Measure of } \\
\text { effectiveness }\end{array}$ & $\begin{array}{l}\text { A criterion used to assess changes in system behavior, } \\
\text { capability, or operational environment that is tied to } \\
\text { measuring the attainment of an end state, achievement } \\
\text { of an objective, or creation of an effect. }\end{array}$ & JP 3-0 \\
\hline $\begin{array}{l}\text { Measure of } \\
\text { performance }\end{array}$ & $\begin{array}{l}\text { A criterion used to assess actions that are tied to } \\
\text { measuring task accomplishment. }\end{array}$ & JP 3-0 \\
\hline Metric & $\begin{array}{l}\text { A metric is an indicator of performance, usually explicitly } \\
\text { or implicitly expressing both the performance measure } \\
\text { and performance target together. It is a measurement, } \\
\text { taken over a period of time that communicates vital } \\
\text { information about a process or activity. A metric should }\end{array}$ & AR 5-1 \\
\hline
\end{tabular}




\begin{tabular}{|c|c|c|}
\hline \multicolumn{3}{|c|}{ Integrated Strategic and Sustainability Planning Definitions } \\
\hline Term & Definition & $\begin{array}{l}\text { Sourcel } \\
\text { Reference }\end{array}$ \\
\hline & $\begin{array}{l}\text { drive appropriate leadership or management action. } \\
\text { Physically, a metric package consists of an operational } \\
\text { definition, measurement over time and presentation. }\end{array}$ & \\
\hline Milestone & $\begin{array}{l}\text { Quantitative and/or qualitative indicators of activity to } \\
\text { chart progress toward an objective over time (aka } \\
\text { performance targets). }\end{array}$ & \\
\hline $\begin{array}{l}\text { Net Zero } \\
\text { Installation } \\
\text { Energy, Water, } \\
\text { Waste }\end{array}$ & $\begin{array}{l}\text { Net Zero Energy Installation - an installation that } \\
\text { produces as much energy on site as it uses, over the } \\
\text { course of a year. } \\
\text { Net Zero Waste Installation - an installation that } \\
\text { reduces, reuses, and recovers waste streams, } \\
\text { converting them to resource values with zero landfill over } \\
\text { the course of a year. } \\
\text { Net Zero Water Installation - an installation that limits the } \\
\text { consumption of freshwater resources and returns water } \\
\text { back to the same watershed so not to deplete the } \\
\text { groundwater and surface water resources of that region } \\
\text { in quantity and quality over the course of a year. }\end{array}$ & \\
\hline Objective & $\begin{array}{l}\text { Specific, measurable, achievable, relevant and time } \\
\text { sensitive intermediate end-state that accomplishes one } \\
\text { or more of the goals in part or in whole. }\end{array}$ & \\
\hline Objective & $\begin{array}{l}\text { The clearly defined, decisive, and attainable goal toward } \\
\text { which every operation is directed. }\end{array}$ & JP 5-0 \\
\hline $\begin{array}{l}\text { Organizational } \\
\text { Self Assessment } \\
\text { (OSA) }\end{array}$ & $\begin{array}{l}\text { Performance Indicator, diagnostic tool that provides } \\
\text { timely, comprehensive and objective feedback to } \\
\text { leadership }\end{array}$ & AR5-1 \\
\hline $\begin{array}{l}\text { Performance } \\
\text { Measures and } \\
\text { Targets }\end{array}$ & $\begin{array}{l}\text { Performance measures are the indicators or metrics that } \\
\text { are used to gauge program performance. Performance } \\
\text { measures can be either outcome or output related. } \\
\text { Performance targets are the quantifiable or otherwise } \\
\text { measurable characteristics that tell how well a program } \\
\text { must accomplish a performance measure2. Interim } \\
\text { performance targets should be used to track } \\
\text { performance or progress toward an objective over time. }\end{array}$ & \\
\hline $\begin{array}{l}\text { Principles of } \\
\text { Sustainability }\end{array}$ & $\begin{array}{l}\text { Mission Excellence, Community Collaboration, } \\
\text { Environmental Stewardship, Economic Impact, and } \\
\text { Systems Thinking. A set of principles to guide the } \\
\text { operationalizing of sustainability concepts into planning, } \\
\text { decision making and execution of IMCOM lines of effort. }\end{array}$ & CPM \\
\hline $\begin{array}{l}\text { Real Property } \\
\text { Master Plan } \\
\text { (RPMP) }\end{array}$ & $\begin{array}{l}\text { The Garrison commander's plan for the management } \\
\text { and development of the installation's real property } \\
\text { resources. It analyzes and integrates the plans prepared } \\
\text { by the DPW and other Garrison staff, mission } \\
\text { commanders and other tenant activities, higher } \\
\text { headquarters, and those of neighboring communities to } \\
\text { provide for orderly development, or in some cases, } \\
\text { realignment and closure, of real property resources. }\end{array}$ & AR210-20 \\
\hline
\end{tabular}




\begin{tabular}{|c|c|c|}
\hline \multicolumn{3}{|c|}{ Integrated Strategic and Sustainability Planning Definitions } \\
\hline Term & Definition & \begin{tabular}{|l|} 
Sourcel \\
Reference
\end{tabular} \\
\hline Stakeholders & $\begin{array}{l}\text { Organizations or individuals who will benefit from } \\
\text { achievement of the installation action plans. Includes all } \\
\text { groups that might be affected by an organization's } \\
\text { actions and success. Examples of key stakeholders } \\
\text { include leaders, customers, employees, partners, and } \\
\text { local or professional communities. }\end{array}$ & AR 5-1 \\
\hline $\begin{array}{l}\text { Strategic } \\
\text { Challenges }\end{array}$ & $\begin{array}{l}\text { A term that refers to those pressures that exert a } \\
\text { decisive influence on an organization's likelihood of } \\
\text { future success. }\end{array}$ & $\begin{array}{l}\text { Baldrige NQP } \\
2010-2011 \\
\text { Criteria for } \\
\text { Performance } \\
\text { Excellence }\end{array}$ \\
\hline Strategic Plan & $\begin{array}{l}\text { The document produced by the process during which an } \\
\text { organization envisions its future, develops management } \\
\text { strategies and action or implementation plans to achieve } \\
\text { that future. }\end{array}$ & AR 5-1 \\
\hline $\begin{array}{l}\text { Strategic } \\
\text { Planning }\end{array}$ & $\begin{array}{l}\text { The process by which managers at higher levels } \\
\text { envision their organization's future and develop the } \\
\text { necessary procedures and operations to achieve that } \\
\text { vision. It is a continual and systematic effort to determine } \\
\text { and meet the future needs of customers. }\end{array}$ & AR 5-1 \\
\hline $\begin{array}{l}\text { Sustainability - } \\
\text { (Army) }\end{array}$ & $\begin{array}{l}\text { Meeting current as well as future mission requirements } \\
\text { worldwide, while safeguarding human health, improving } \\
\text { quality of life, and enhancing our natural environment. }\end{array}$ & $\begin{array}{l}\text { Army } \\
\text { Sustainability } \\
\text { Campaign } \\
\text { Plan }\end{array}$ \\
\hline $\begin{array}{l}\text { Sustainability - } \\
\text { (IMCOM) }\end{array}$ & $\begin{array}{l}\text { Managing resources so we always have them when we } \\
\text { need them to accomplish the mission, resources include: } \\
\text { Human Capital (including knowledge), Natural } \\
\text { Resources, Infrastructure (vertical and horizontal, fixed } \\
\text { and mobile), Information Technology, Financial, and } \\
\text { Energy. }\end{array}$ & CPM \\
\hline $\begin{array}{l}\text { Sustainability } \\
\text { (Malcolm } \\
\text { Baldrige) }\end{array}$ & $\begin{array}{l}\text { An organization's ability to address current business } \\
\text { needs and to have the agility and strategic management } \\
\text { to prepare successfully for your future business, market, } \\
\text { and operating environment. }\end{array}$ & $\begin{array}{l}\text { Baldrige NQP } \\
\text { 2010-2011 } \\
\text { Criteria for } \\
\text { Performance } \\
\text { Excellence } \\
\end{array}$ \\
\hline $\begin{array}{l}\text { Sustainability } \\
\text { (Office of the } \\
\text { Federal } \\
\text { Environmental } \\
\text { Executive) }\end{array}$ & $\begin{array}{l}\text { To create and maintain conditions, under which humans } \\
\text { and nature can exist in productive harmony, that permit } \\
\text { fulfilling the social, economic, and other requirements of } \\
\text { present and future generations. }\end{array}$ & \begin{tabular}{|l} 
Executive \\
Order 13514
\end{tabular} \\
\hline Target & $\begin{array}{l}\text { How much or what part of the measure(s) should be } \\
\text { accomplished each year. A single-year intermediate } \\
\text { end-state to measure progress towards an objective. }\end{array}$ & $\begin{array}{l}\text { Dictionary of } \\
\text { Military and } \\
\text { Associated } \\
\text { Terms. US } \\
\text { Department of } \\
\text { Defense } 2005\end{array}$ \\
\hline
\end{tabular}




\begin{tabular}{|l|l|l|}
\hline \multicolumn{2}{|c|}{ Integrated Strategic and Sustainability Planning Definitions } \\
\hline Term & Definition & $\begin{array}{l}\text { Sourcel } \\
\text { Reference }\end{array}$ \\
\hline Timeframe & The span of time over which the goal is to be achieved. & $\begin{array}{l}\text { Dictionary of } \\
\text { Military and } \\
\text { Associated } \\
\text { Terms. US } \\
\text { Department of } \\
\text { Defense 2005 }\end{array}$ \\
\hline Unsustainable & $\begin{array}{l}\text { An anthropocentric action or decision that is or will lead } \\
\text { to the degradation of resources. The result of such an } \\
\text { action or decision will negatively impact IMCOM's ability } \\
\text { to proactively internalize the principles of sustainability. }\end{array}$ & \\
\hline Vision & $\begin{array}{l}\text { A statement of the organization's end state at a future } \\
\text { point in time. The "what" the leadership wants the } \\
\text { organization to be. }\end{array}$ & \\
\hline Weaknesses & $\begin{array}{l}\text { Voids or deficiencies within the organization that must be } \\
\text { improved. The focus is on root causes, not symptoms. }\end{array}$ \\
\hline
\end{tabular}




\section{Appendix V: Net Zero}

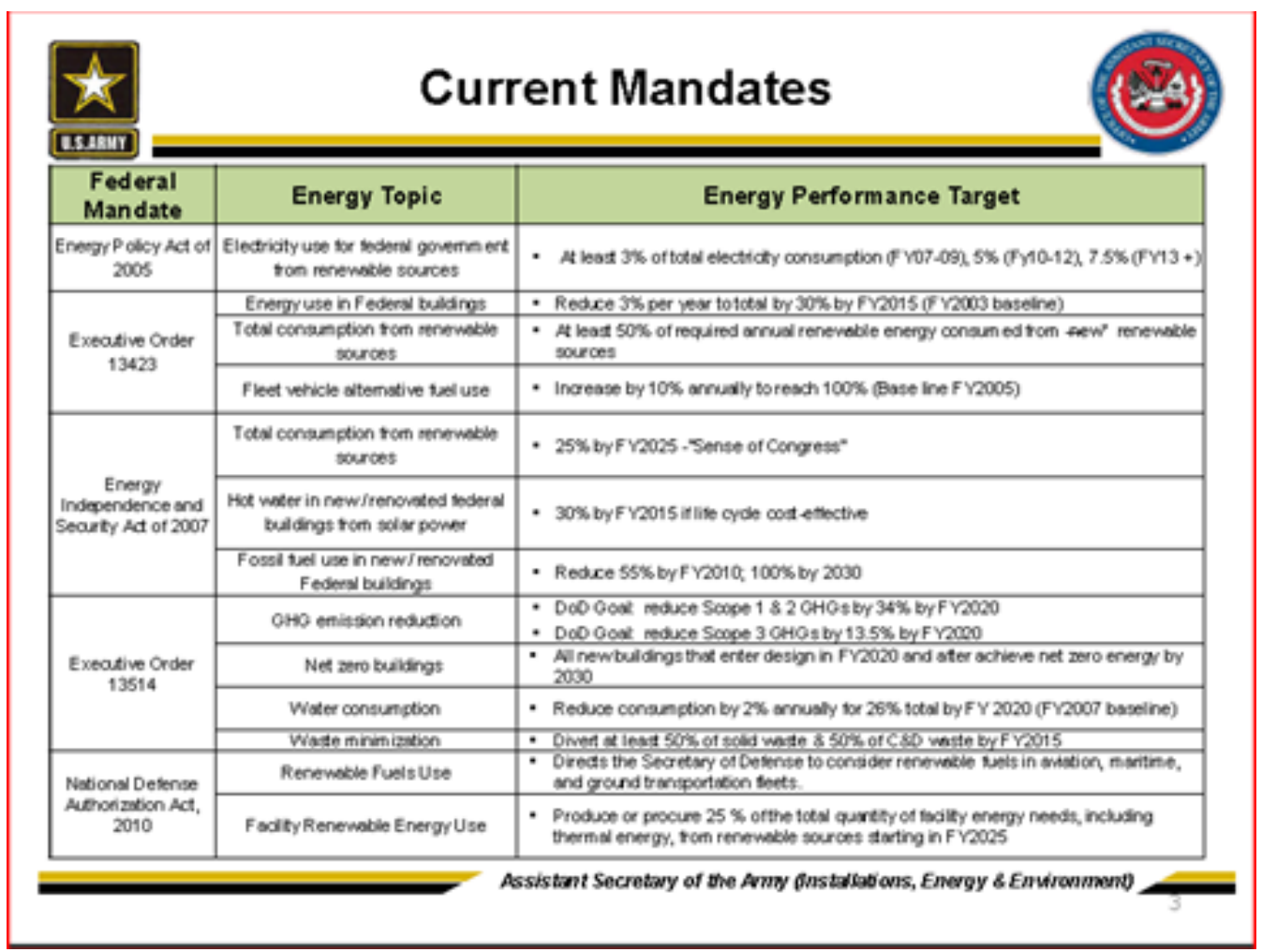

\section{Net Zero Hierarchy}

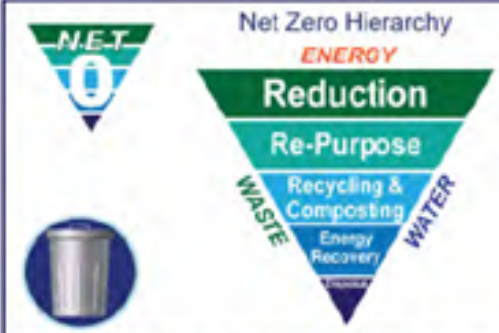

NET ZERO IS A FORCE MULTIPLIER

- Te primary goal is a focus toward net zero and when we talk about net zero, in's not only net zero energy, but it's net zero energy. water, and waste. When you look at the term "net zero" or a hierarchy of net zero you must start with reduction, then progress through repurposing. recycling, energy recovery, disposal being the last.-

- HON Katherine Hammack, DoD Bloggers Roundtable. 10 October 2010
> A Net Zero ENERGY Installation is an installation that produces as much energy on site as it uses, over the course of a year.

A Net Zero WATER Installation limits the consumption of freshiwater resources and returns water back to the same watershed so not to deplete the groundwater and surface water resources of that region in quantity or quality.

\section{$>$ A Net Zero WASTEInstallation is an} installation that reduces, reuses, and recovers waste streams, converting them to resource values with zero solid waste to landill.

> A Net ZERO INSTALLATION applies an integrated approach to management of energy, water, and waste to capture and corrmercialize the resource value and/or enhance the ecological productivity of land. water, and air. 
Installation Strategic Planning Guidebook 


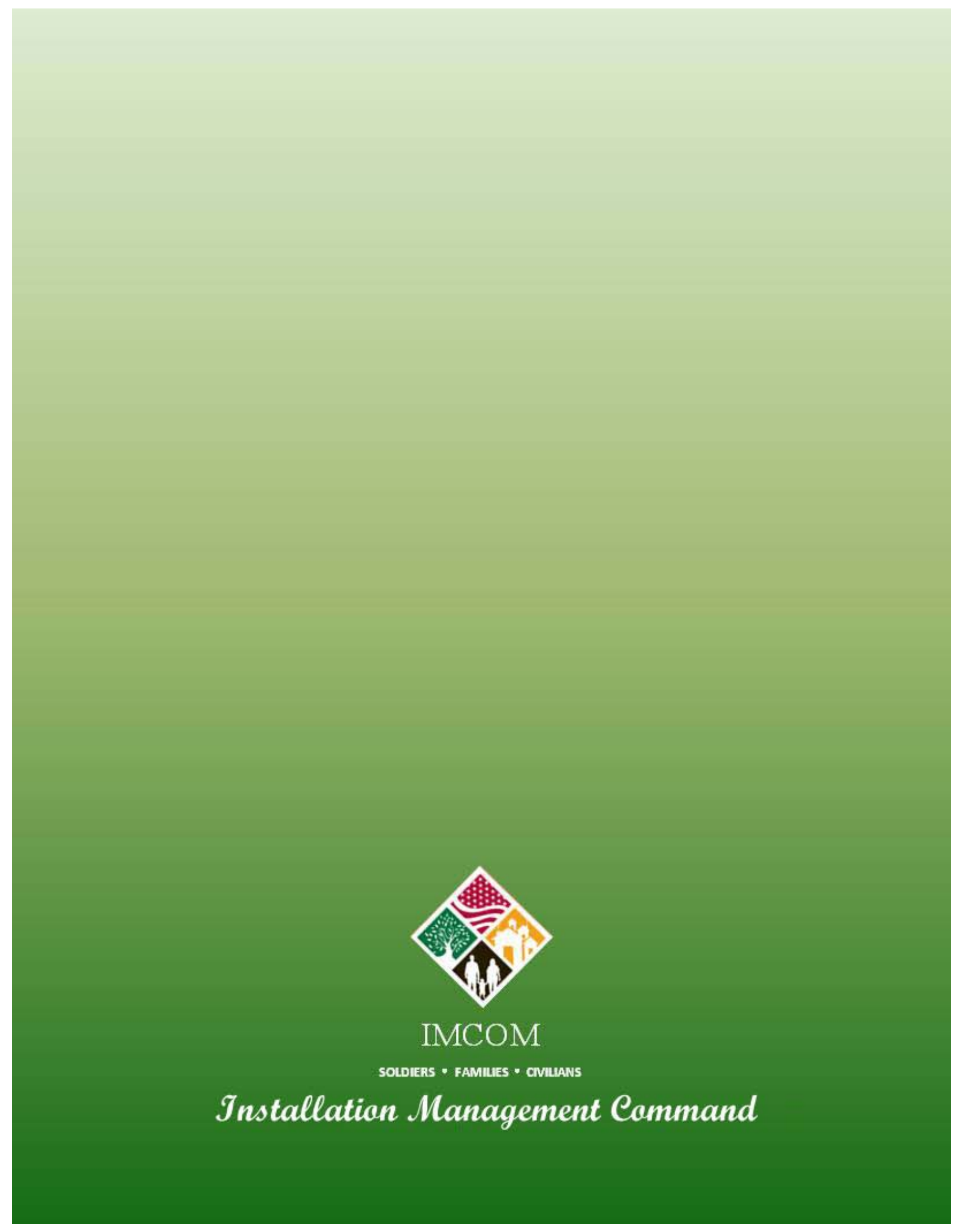




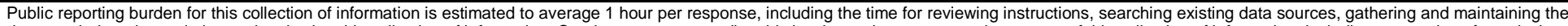

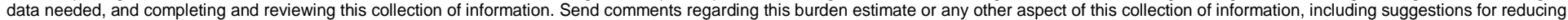

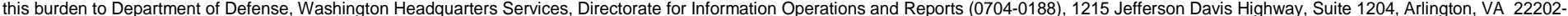

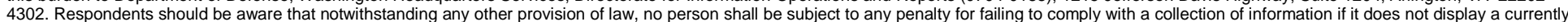
valid OMB control number. PLEASE DO NOT RETURN YOUR FORM TO THE ABOVE ADDRESS.

\begin{tabular}{|c|c|}
\hline $\begin{array}{c}\text { 1. REPORT DATE (DD-MM-YYYY) } \\
26-05-2012\end{array}$ & 2. REPORT TYPE \\
Final \\
\hline
\end{tabular}

\section{TITLE AND SUBTITLE}

Installation Strategic Planning Guidebook Final
6. AUTHOR(S)

Kathleen S. Vann, David R. Della-Rovere, Paul M. Loechl, and Harold E. Balbach
3. DATES COVERED (From - To)

5a. CONTRACT NUMBER

5b. GRANT NUMBER

5c. PROGRAM ELEMENT

5d. PROJECT NUMBER

5e. TASK NUMBER

5f. WORK UNIT NUMBER

8. PERFORMING ORGANIZATION REPORT NUMBER

ERDC/ CERL SR-12-4

Construction Engineering Research Laboratory (CERL)

PO Box 9005,

Champaign, IL 61826-9005

\section{SPONSORING / MONITORING AGENCY NAME(S) AND ADDRESS(ES)}

Headquarters, Installation Management Command (HQ IMCOM)

2405 Gun Shed Road

Fort Sam Houston, TX 78234-1223

\section{DISTRIBUTION / AVAILABILITY STATEMENT}

Approved for public release; distribution is unlimited.
10. SPONSOR/MONITOR'S ACRONYM(S)

IMPL-S

11. SPONSOR/MONITOR'S REPORT NUMBER(S)

\section{SUPPLEMENTARY NOTES}

\section{ABSTRACT}

The Installation Strategic Planning Guidebook is designed as a textbook for use in conjunction with the Installation Management Academy Plans, Analysis, and Integration Office (PAIO) Signature Course. The book is designed to leverage internet based multimedia content with embedded hyperlinks along with a capability for content to be searchable and copyable.

\section{SUBJECT TERMS}

IMCOM, guidebook, strategic planning, sustainability, ISSP, Integrated Strategic and Sustainability Planning,

ISP, Installation Strategic Plan

\section{SECURITY CLASSIFICATION OF:}

\section{a. REPORT}

Unclassified

\section{b. ABSTRACT}

Unclassified c. THIS PAGE

Unclassified

\section{LIMITATION} OF ABSTRACT

SAR
18. NUMBER OF PAGES

168 19a. NAME OF RESPONSIBLE PERSON

19b. TELEPHONE NUMBER

(include area code) 